\title{
AN INSTITUTIONAL ANALYSIS OF THE ECONOMICS OF IDENTITY
}

\author{
A thesis submitted \\ in fulfilment of the requirements for the degree of \\ Doctor of Philosophy
}

\author{
Alastair Lloyd Berg \\ BCom (University of Melbourne) \\ BA (Deakin) \\ MTeach(Sec) (University of Melbourne) \\ MEPI (University of Melbourne)
}

School of Economics, Finance and Marketing

College of Business and Law

RMIT University

August 2021 


\section{Declaration}

I certify that except where due acknowledgement has been made, the work is that of the author alone; the work has not been submitted previously, in whole or in part, to qualify for any other academic award; the content of the project is the result of work which has been carried out since the official commencement date of the approved research program; any editorial work, paid or unpaid, carried out by a third party is acknowledged; and, ethics procedures and guidelines have been followed. I acknowledge the support I have received for my research through the provision of an Australian Government Research Training Program Scholarship.

Alastair Lloyd Berg, 20 August 2021 


\section{Acknowledgements}

This thesis could not have been written without the help of others. The assistance and intellectual inspiration of those at RMIT have helped to develop many of the ideas in this thesis. Thanks to the help of my two supervisors Sinclair Davidson and Jason Potts. The ideas you have exposed me to, your thoughtful critiques, and your time have made this thesis what it is.

Others have influenced me. Chris Berg, Darcy Allen, Aaron Lane, Brendan Markey-Towler and Mikalya Novak have all provided much to think about. They have all been an invaluable source of knowledge and inspiration.

Thank you to the editors and anonymous reviewers of the journal articles published during my candidature, Economic Papers, Economics Bulletin, Constitutional Political Economy, Cosmos + Taxis, the Journal of Private Enterprise, and the Journal of the British Blockchain Association.

I also acknowledge the Australian taxpayer for their generous support.

To my family, thank you for always encouraging me.

To Lucy and Charles, this thesis is dedicated to you. 


\section{Publications}

Although not presented for examination, the following peer-reviewed publications are cited through this thesis:

- Berg, A 2020, 'The Identity, Fungibility, and Anonymity of Money', Economic Papers, vol. 39, no. 2, pp. 104-17.

- Berg, A and Berg, C 2020, 'Exit, Voice, and Forking', Cosmos + Taxis, vol. 8, no. 8+9, pp. 76-89.

- Berg, A, Markey-Towler, B and Novak, M 2020, 'Blockchains = Less Government, More Market', The Journal of Private Enterprise, vol. 35, no. 2, pp. 1-21.

- Allen, DWE, Berg, A Berg, C, Markey-Towler, B and Potts, J 2019, 'Some Economic Consequences of the GDPR', Economics Bulletin, vol. 39, no. 2, pp. 785-97.

- Allen, DWE, Berg, A and Markey-Towler, B 2019, 'Blockchain and Supply Chains: V-form Organisations, Value Redistributions, De-commoditisation and Quality Proxies', The Journal of the British Blockchain Association, vol. 2, no. 1, pp. 57-65.

Although not presented for examination, the following peer-reviewed publication was also published during my candidature:

- Berg, A, Berg, C and Novak, M 2020, 'Blockchains and Constitutional Catallaxy'. Constitutional Political Economy, vol. 31, no. 2, pp. 188-204. 


\section{Table of contents}

DECLARATION

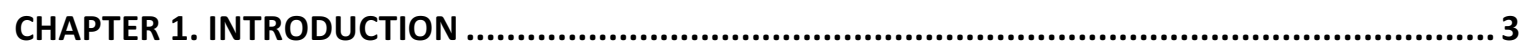

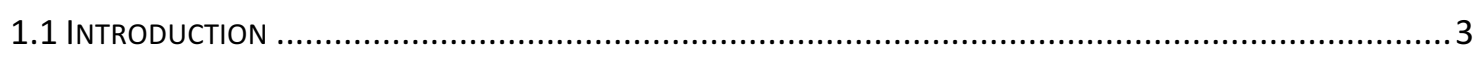

1.2 BACKGROUND TO THE PROBLEM OF UNCERTAINTY WITHIN A HETEROGENEOUS POPULATION..................... 3

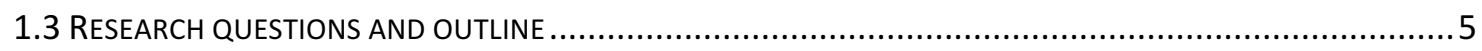

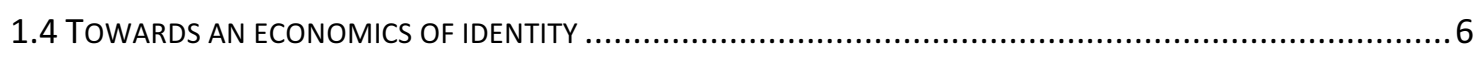

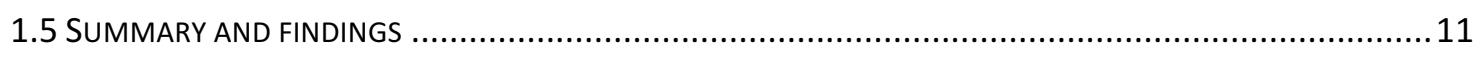

CHAPTER 2. INFORMATION ASYMMETRY AND IDENTITY IN ECONOMICS ................................ 15

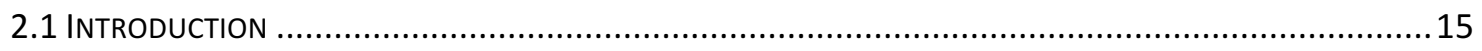

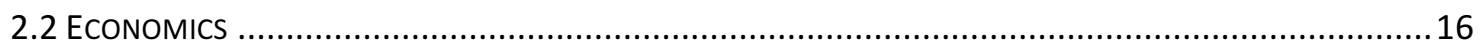

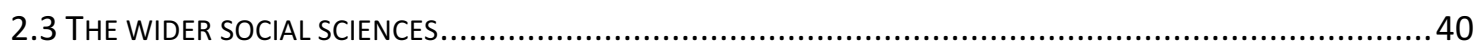

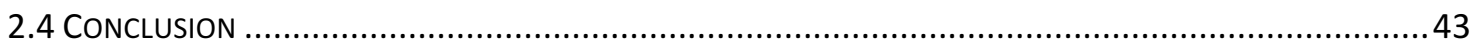

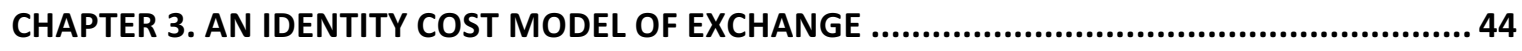

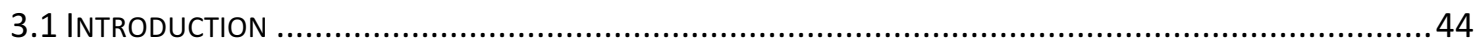

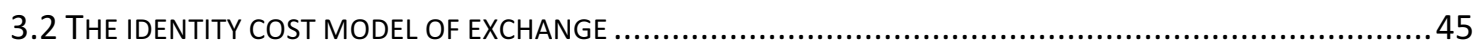

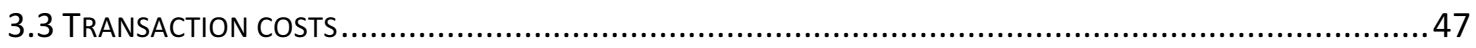

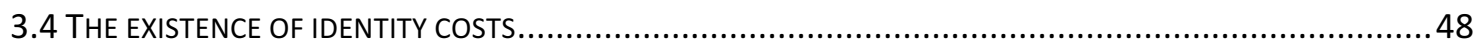

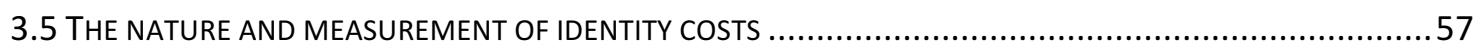

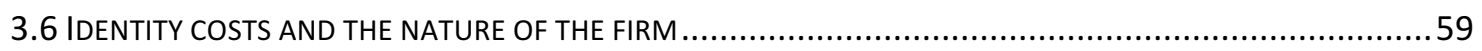

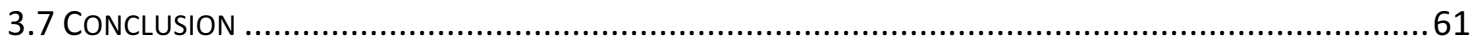

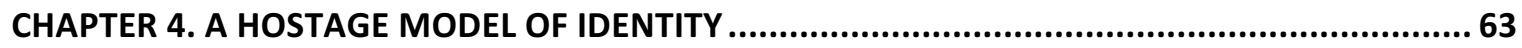

4.1 INTRODUCTION

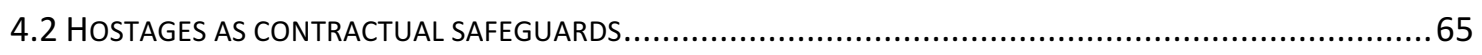

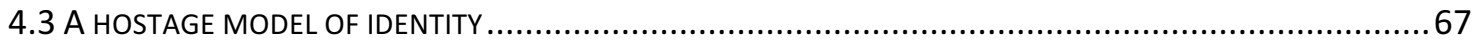


CHAPTER 5. AN ECONOMIC THEORY OF SURNAMES ................................................. 79

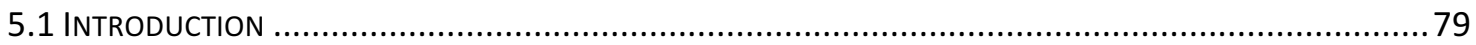

5.2 A MODEL OF INTERGENERATIONAL PROPERTY OWNERSHIP WITH SOVEREIGN RISK .........................81

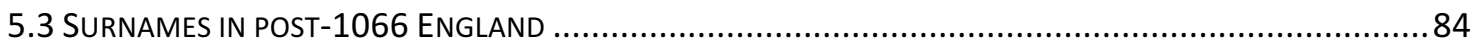

5.4 SOME FURTHER INSTITUTIONAL ECONOMICS OF NAMES ................................................... 100

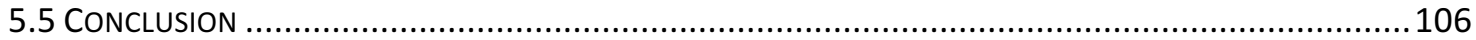

CHAPTER 6. THE STATIONARY BANDIT WITH STATIONARY CAPTIVES ............................... 108

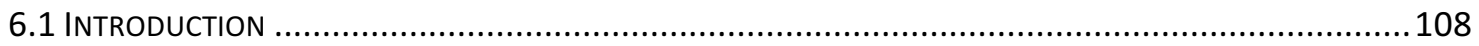

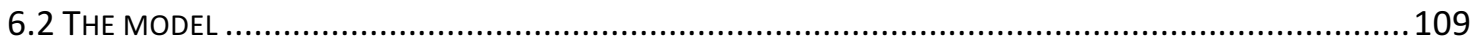

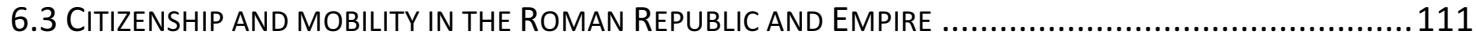

6.4 NE EXEAT REGNO AND SAUf CONDUIT: MEDIEVAL REGULATIONS ON MOVEMENT ..........................115

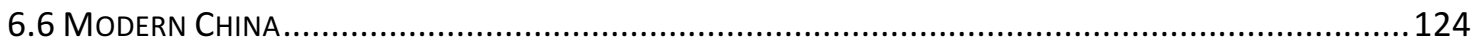

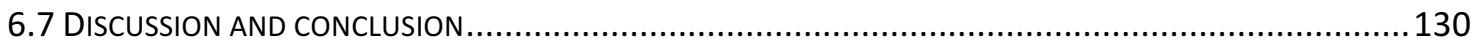

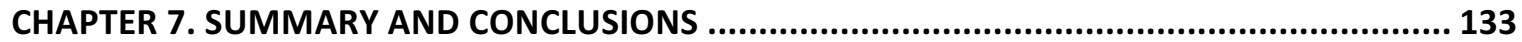

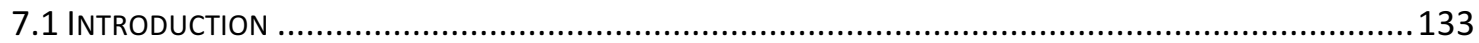

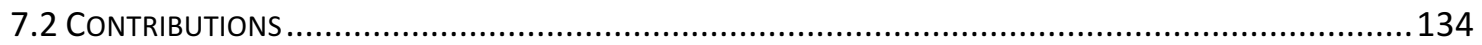

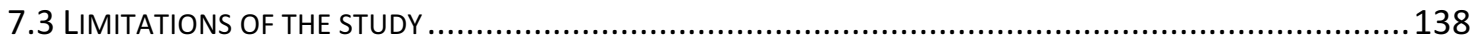

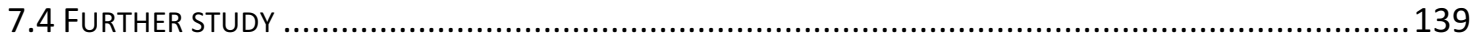

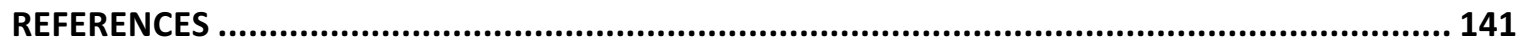




\section{Abstract}

This thesis develops a new institutional economics of identity. It develops a clear and consistent economic definition of identity, and demonstrates the ways identity overcomes information problems in economic and political exchange. The first contribution of this thesis is a clear and consistent economic definition of identity (Chapter 1). Here, identity is a vector of characteristics associated with a unique individual that allows other individuals to recognise them, or allow differentiation from other individuals. As goods are vectors of characteristics, this thesis introduces individuals as being vectors of characteristics. These identity characteristics are classified as being innate to, prescribed by, and prescribed to, the individual. This is in stark contrast to many previous conceptions of identity in economics and the broader social sciences, which have typically studied identity as a single characteristic (Chapter 2). This single characteristic is also often defined as a group characteristic, which ignores the individual and differentiating characteristics of economic and political agents.

The next contribution of this thesis is to clearly demonstrate the way identity can be characterised as overcoming uncertainty and mitigating instances of information asymmetry in economic exchange. In contrast to mainstream economics, this thesis treats the identity of the buyer and seller as an important part of economic exchange. That is, populations are heterogeneous, owing to the varied endowments, tastes and motivations of individuals. This leads to information problems, as due to this heterogeneity of economic and political actors, behavioural and contractual outcomes are difficult to predict. To overcome this information asymmetry, economic actors both demand and supply identity information. The demand of identity is a positive function of the need to recognise, and distinguish between, trading partners. Lenders will demand information related to an individual's ability to service a loan, for instance. Obtaining this identity information is costly and results in what I term 'identity costs', which I introduce as a distinct subset of transaction costs (Chapter 3 ). This model I develop uses the transaction cost framework of uncertainty, frequency of exchange, and asset specificity. The identity cost model of exchange demonstrates the mechanism by which economic actors produce predictability about the future state of the world. In addition, the supply of identity information can overcome this behavioural and contractual uncertainty. The supply of identity is a function of the need to differentiate oneself from potential competitors when seeking out trading partners. As I develop with a hostage model of identity (Chapter 4), constraints can be placed on human behaviour in the form of credible commitments. This model contributes an extension of the hostage model of exchange. I show how in the presence of information asymmetry economic actors can place an identity asset at risk - 'identity at risk' - as a prerequisite to entering some exchange. In this expanded hostage model of exchange, economic actors supply identity information because it is beneficial to do so. They supply this identity information via the posting of identity hostages which consist of information assets that are exploitable in the event of non-compliance with contractual terms.

The next contribution of this thesis is the demonstration of the transaction cost economising nature of identity. I have already mentioned the introduction of identity costs as my contribution to the transaction costs literature. I then extend this finding to determine that, as identity costs are a significant cost in some industries, the existence of certain hierarchical 
organisations can be attributed to identity cost economising (Chapter 3 ). For instance, banks exist as an aggregation of lenders who benefit from economies of scale in determining their borrowers' willingness and ability to repay loans.

The final contribution of this thesis is to demonstrate how identity can be characterised as being used by individuals and states to access economic rents and other privileges. Another way of stating this is that I examine identity as it is used to overcome uncertainty in political exchange. Here I contribute an understanding of the demand and supply of identity as it relates to the political sphere. I first examine uncertainty as it relates to sovereign risk, where sovereign risk results in the nationalisation of private property. I develop an intergenerational model of property ownership, which sees buyers manufacture certainty through the private supply of identity information in the form of heritable surnames (Chapter 5). Property owners suffer from an information problem related to a sovereigns' intention to expropriate land. In the context of Norman England post-1066, I examine heritable surnames as an identity institution used as a measure of protection against state action. In addition, I also use the property rights literature to characterise this process. I next contribute an expanded stationary bandit model of government to illustrate how a state can satisfy its own demand for identity (Chapter 6). Here, states have an asymmetry of information as to the nature of their citizens, owing to their heterogeneity, and their differing value in terms of extractable resources. They use identity technologies to increase their legibility over their populations, and to increase their extractive capacity. States also use identity technologies to discriminatorily supply public goods. The model developed in this chapter is then illustrated via case studies of Ancient Rome, early Medieval Europe, revolutionary France, and Communist China. 


\section{Chapter 1. Introduction}

\subsection{Introduction}

Adam Smith (1776a, b) recognised the economic relevance of imperfections in human behaviour. While Smith used different terminology, he understood, for instance, that moral hazard arises from a lack of vigilance when one is placed in charge of another's property. Similarly, Smith understood the differences intrinsic to a population. This heterogeneity is what Smith $(1776 a, 110)$ saw as the driving force behind the increase in the welfare of society; specialisation (and trade) results in "a proportionable increase of the productive powers of labour". In other words, society becomes wealthy when one does not have to prepare their own meat, bread, or beer. Rather, when these tasks are separately pursued by individuals endowed with different skill sets and motivations, society progresses. Yet much of the mainstream economic literature has studied the price system and ignored the way in which markets actually work (Demsetz 1988). Here Demsetz refers to the lack of literature examining the transaction costs inherent in market interactions, where these costs are derived from human imperfections including opportunism and bounded rationality. And while these "characteristics of the human decision makers" (Williamson 1975, 8) have long been understood, a clear explanation of the mechanism by which the relevant, and context dependent, characteristics of an individual are used and understood in economic and political life is largely missing from the literature.

In this thesis I will make three broad claims. The first of these is that coming to a level of assurance as to the identity of a counterparty is necessary for all but the most trivial spot market transactions. Using the new institutional economics literature (Williamson, 1975, North, 1994) I develop models of identity institutions whereby traders can understand relevant characteristics as to their trading partner, while the exchange of identity information can also act as a motivationally credible commitment device. The second claim is that these mechanisms can also be characterised as being transaction cost economising. The final claim is that, as uncertainty also exists in the political realm, identity institutions exist for the mitigation of this political uncertainty. Each of these claims is associated with one of the three research questions of this thesis.

This introductory chapter proceeds as follows. Section 1.2 provides background to the economic problem of dealing with heterogeneous actors amid a state of uncertainty. This will outline the two main literatures-the economics of information, and the new institutional economics - that motivate the thesis. Section 1.3 outlines the research questions along with the structure of the thesis, and what I will set out to achieve in the following chapters. Section 1.4 provides a working definition of the term identity, and introduces a new economics of identity. Section 1.5 summarises the thesis and outlines the main findings.

\subsection{Background to the problem of uncertainty within a heterogeneous population}

To provide context and background for the thesis, this section will outline the two main motivating literatures and perspectives that have given rise to it. These are, respectively, the 
economics of information and the new institutional economics. The economics of information can be traced to the work of the joint 2001 economics laureates. George Akerlof (see 1970), Michael Spence (see 1973), and Joseph Stiglitz (see 1975) shared the economics Nobel for their work on markets with asymmetric information. The new institutional economics literature similarly reflects the uncertainty endemic in social life, basing its analysis within the common behavioural assumptions of bounded rationality and opportunism (see Williamson 1985). This literature is also well pedigreed, with Nobel laureates including Ronald Coase in 1991, Douglass North in 1993, and Oliver Williamson in 2009.

The shared feature of the economics of information and the new institutional economics is the uncertainty endemic in social life. As the economics of information literature makes clear, less than perfect information can have economically negative effects on a market (Akerlof 1970). Without countervailing institutions, or "devices for eliminating uncertainties in quality" (Stigler 1961, 224), a market might cease to function. This uncertainty is itself not just a function of the qualities of the good itself. Behavioural realities come into play. The uncertainty surrounding the actions of a trading partner results in the widely-examined phenomenon of adverse selection (see Akerlof 1970) and moral hazard (see Spence and Zeckhauser 1971).

The new institutional economics is similarly based in uncertainty of behavioural outcomes. The core behavioural assumptions of bounded rationality (Simon 1957) and opportunism (Williamson 1985) make it clear that the precise future state of the world is unknowable. These "characteristics of the human decision makers" (Williamson 1975, 8) result in the existence of transaction costs, which are analogous to frictions in mechanical systems. These transaction costs broadly consist of those related to search, negotiation, drafting of agreements, monitoring, and dispute resolution. Overall, the economics of information and the new institutional economics take for granted that ex-post outcomes cannot be assumed to mirror the precise wording of ex-ante agreements. Similarly, both literatures study the institutions which exist to constrain those behavioural realities. That is, both literatures study the institutions that allow trade to occur in the presence of private information and uncertainty.

Within the economics of information literature, 'signalling' and 'screening' are the most commonly cited mechanisms by which uncertainty might be overcome. Signalling (Spence $1973,1974,2002$ ) overcomes adverse selection by communicating, for instance, a worker's productivity to the labour market. In contrast, screening is a mechanism by which an uninformed trader might discover economically useful information. They might do this by, for instance, offering a product at different prices to prompt a buyer to reveal private information (Rothschild and Stiglitz 1976, Salop and Salop 1976). The new institutional economics literature also examines the mechanisms which mitigate behaviourally derived uncertainty. This includes the examination of institutions which economise on transaction costs. Broadly, these can be delineated into institutions that limit the choice set of participants (Bates 2014, Crawford and Ostrom 1995), or those that allow for the application of sanctions in the event of a breach of ex-ante contractual arrangements (Akerlof 1980, Bernheim 1994, Dellarocas 2006). 
The uncertainty which crosses both literatures is a function of behavioural realities, including those traced back to the assumptions of bounded rationality and opportunism. Importantly, and more broadly, this uncertainty is derived from a rejection of the assumption that trading partners are homogenous. Homogeneity is an assumption common in mainstream economic thought and mainstream contract law. ${ }^{1}$ It results in economic models likened to 'perfect decentralisation' (Demsetz 1988), with participants (and traded commodities) being infinitely interchangeable (Telser and Higinbotham 1977, Salop and Salop 1976). That is, and according to mainstream economics, every individual who trades within a market is the same as every other individual. At the same time, choices are made purely based on price and technology. This is the basis for models of perfectly competitive marketplaces, which in turn treat any consideration of an individual as being different from another as irrelevant (Williamson 1985). That society is not comprised of homogenous trading partners is a motivating factor which led to this thesis.

That society is comprised of heterogeneous actors with varied endowments, tastes, and motivations, and that these variations have economic and political importance, is the overarching theme of this thesis. Mainstream economic models which treat exchange as taking place between 'anonymous partners' (Carr and Landa 1983) ignore the economically important characteristics which are specific to the individual. So important are these characteristics, that a lack of knowledge as to those characteristics would likely curtail much economic activity (Arrow 1972c, Ben-Porath 1980, Akerlof and Kranton 2000). That is, the relevant, and context dependent, characteristics of an individual must be understood by a trading partner precisely because of these varied endowments, tastes, and motivations. That this variation exists means that private information exists, while uncertainty in the economic and political realms is itself derived from this variation. I do not know for certain if you will fulfil your promise ex-post because I am different to you. Put another way, if you and I were in possession of the same endowments, tastes, and motivations, I would have complete knowledge as to your future actions; they are the same as I would do.

With this background in mind, the contributions I set out in this thesis are to develop a theoretical and practical understanding as to how identity facilitates trade, and political interactions, under conditions of uncertainty. That is, I will seek to understand the identity institutions that overcome uncertainty, and mitigate instances of information asymmetry as it arises in economic and political exchange. My focus is on the mechanisms by which the vector of characteristics of an individual are used and understood in economic and political life.

\subsection{Research questions and outline}

My research questions are as follows:

- Question 1: How can identity be characterised as overcoming uncertainty and mitigating instances of information asymmetry in economic exchange? (Chapter 3 , Chapter 4).

\footnotetext{
${ }^{1}$ Here, I use 'mainstream' to broadly refer to choice-theoretic economic analysis that views economic agents as honest and fully informed (Mitchell and Boettke 2017).
} 
- Question 2: How can the use of identity in economic exchange be characterised as transaction cost economising? (Chapter 3).

- Question 3: How can identity be characterised as being used by individuals and states to access economic rents and other privileges? (Chapter 5, Chapter 6).

I will first provide background as to the economic problem of trade amongst a heterogeneous population with uncertainty (Chapter 2).

Next, I will apply the transaction cost contractual schema to develop an identity cost model of exchange (Chapter 3). Following that, I will apply the institutional literature on credible commitments to develop a hostage model of identity (Chapter 4). These two chapters will demonstrate the use of identity in overcoming the uncertainty associated with dealing with heterogeneous trading partners, and the ways identity can overcome the effects of private information in economic exchange. Chapter 3 will also demonstrate the transaction cost economising nature of identity as it is used in economic exchange.

Finally, I will examine the ways identity has been used to grant access to rents and other privileges, and hence the way it has been used in political exchange under conditions of uncertainty. I will first examine the role of heritable surnames in the protection of private property under sovereign risk in post- $1066^{2}$ England (Chapter 5$)$. Then I will examine the ways that various state actors have used identity technologies to increase their extractive capacity over their populace, as well as discriminatorily supply public goods (Chapter 6). Together, these two chapters will examine identity from an institutional perspective, and use the historical record to show ways that identity has been used in the political realm. I will then present and summarise the findings of the thesis (Chapter 7 ).

\subsection{Towards an economics of identity}

As I will demonstrate in Chapter 2, the economics discipline lacks a clear and consistent economic definition of identity. One of the contributions of this thesis will be to rectify this shortcoming. Lancaster $(1966,1971)$ states that goods are vectors of attributes (see Allen, Berg and Markey-Towler 2019). In this thesis, I treat individuals in a similar way. Lancaster sees a dinner party as comprised of "nutritional, aesthetic, and perhaps intellectual characteristics" (Lancaster 1966, 133). My formulation of identity sees an individual as being comprised of a vector of economically and socially important characteristics. These characteristics, while practically innumerable and context dependent, can be broadly classified as being innate to, prescribed by, and prescribed to, the individual.

Inspired by this insight, I contribute a new definition of identity as a vector of characteristics associated with a unique individual that allows other individuals to recognise them, or allow differentiation from other individuals. At the outset, it should be stated that this conception of identity, and what I see as its economic and political importance, explicitly relaxes the assumption of homogeneity as typically applied in mainstream economics. That is, while participants in economic exchange are typically treated as homogenous in mainstream economic thought (Telser and Higinbotham 1977, Williamson 1985, Demsetz 1988), I consider

${ }^{2}$ All dates are CE unless indicated otherwise. 
this a naïve assumption. As I shall make clear, rather than individuals as perfect substitutes for every other individual, economic and political agents are heterogeneous; these agents have varied endowments, tastes, and preferences.

So, identity is a vector of characteristics associated with a unique individual that allows other individuals to recognise them, or allow differentiation from other individuals. At the same time, these characteristics are innate to, prescribed by, and prescribed to, the individual. Innate characteristics are those (somewhat) immutable characteristics which make one either tall or short, thin or fat, blue eyed or brown eyed, extraverted or introverted. To be sure, one might restrict their caloric intake and go from fat to thin. Yet these characteristics are 'sticky', especially in the short-run. Characteristics prescribed by the individual are those actions one takes which have the follow-on consequence of affixing a 'label' or a 'type'. One might study and obtain a university qualification to indirectly signal productivity to employers (Spence $1973,1974)$. One might buy an electric car to signal environmental credentials (Brooks and Wilson 2015, Brisman 2009). Or one might undertake some violent act to manufacture such a reputation (Silverman 2004). Finally, characteristics can be prescribed to an individual, both with and without the recipient's knowledge. A seller on an online marketplace has feedback given to them by their customers based on past performance (McDonald and Slawson 2002, Lee, Im, and Lee 2006), while the act of 'vouching' as to the employability of an acquaintance serves a similar function. To be sure, these characteristics are not always known to the bearer. A teacher who is unaware of teacher rating websites, or does not check their credit score, is none the wiser as to some aspect(s) of their identity as I have defined it. Finally, these classifications of characteristics as innate to, prescribed by, and prescribed to, tend to overlap in some respects.

So then, what gives this vector of characteristics associated with a unique individual-an identity-economic value? First consider the counterfactual, where the identity of an economic agent serves no economic or social purpose. Briefly resorting to the much-used trope of 'Robinson Crusoe' (see Robbktson 1933, Mathias 2007, Watson 2011), an individual who leads a solitary existence has no economic need for an identity. ${ }^{3}$ One who is selfsufficient-one who prepares their own meat, bread, and beer-has no need to recognise and distinguish one from amongst many, or to be themselves recognised. Only in social contexts does value attach itself to the ability to do so. Throughout the Crusoe story, and as his world takes on increasingly complex social dimensions, the importance of recognising one individual amongst a crowd takes on profound importance. Quite simply, his ability to recognise and distinguish Friday from amongst the cannibals is likely the difference between life and death. Likewise for Friday's ability to distinguish Crusoe from the cannibals. Similarly, when Crusoe returns to civilisation, his ability to identity himself as his father's son allows him to reclaim his inherited wealth. The Robinson Crusoe example also makes it clear that characteristics of the individual can be internalised or externalised to that individual. For while living alone Crusoe did not revert to referring to himself as 'man'. Even while alone, he had a sense of internalised identity, which only took on external meaning when he returned to a social setting. In sum, in isolation there is no value related to the characteristics associated with a unique individual that allows other individuals to recognise them, or allow

\footnotetext{
${ }^{3}$ This necessarily ignores the implications that follow from the existence of an omniscient god.
} 
differentiation from other individuals. It is only in social contexts that this vector of characteristics has economic and social value.

To be sure, economists have studied identity, and identity related concepts. Yet this has usually been from a very limited viewpoint, or broader social science perspective. ${ }^{4}$ As shown in Figure 1. below, the economic study of identity can be associated with one of two approaches. With a few exceptions noted below, these have typically associated identity with a single characteristic. In addition, and in contrast to my treatment, this single characteristic is typically derived from membership in a group, or a social categorisation. The choice theoretic branch can be delineated into group identity as prescribed by, and prescribed to. For instance Akerlof and Kranton (2000) consider identity as a person's 'sense of self'. Their construct of identity is a group one, and is related to prescriptive behaviours, and subsequent payoffs, associated with membership in some group. Along with individual preferences, they apply this sense of self into a standard utility function. The latter depends on; 1) social categorisation, for instance gender or race; 2 ) behavioural prescriptions applicable to that social categorisation; and 3) payoffs associated with conformity to these prescriptions. Akerlof and Kranton's (2000) conception of identity as sense of self can be thought of selfcategorisation, or to use my terminology, characteristics prescribed by the individual. In a similar manner, Sen (see for instance 1977) examines the role of a self-prescribed social identity as being a prime motivator of human behaviour.

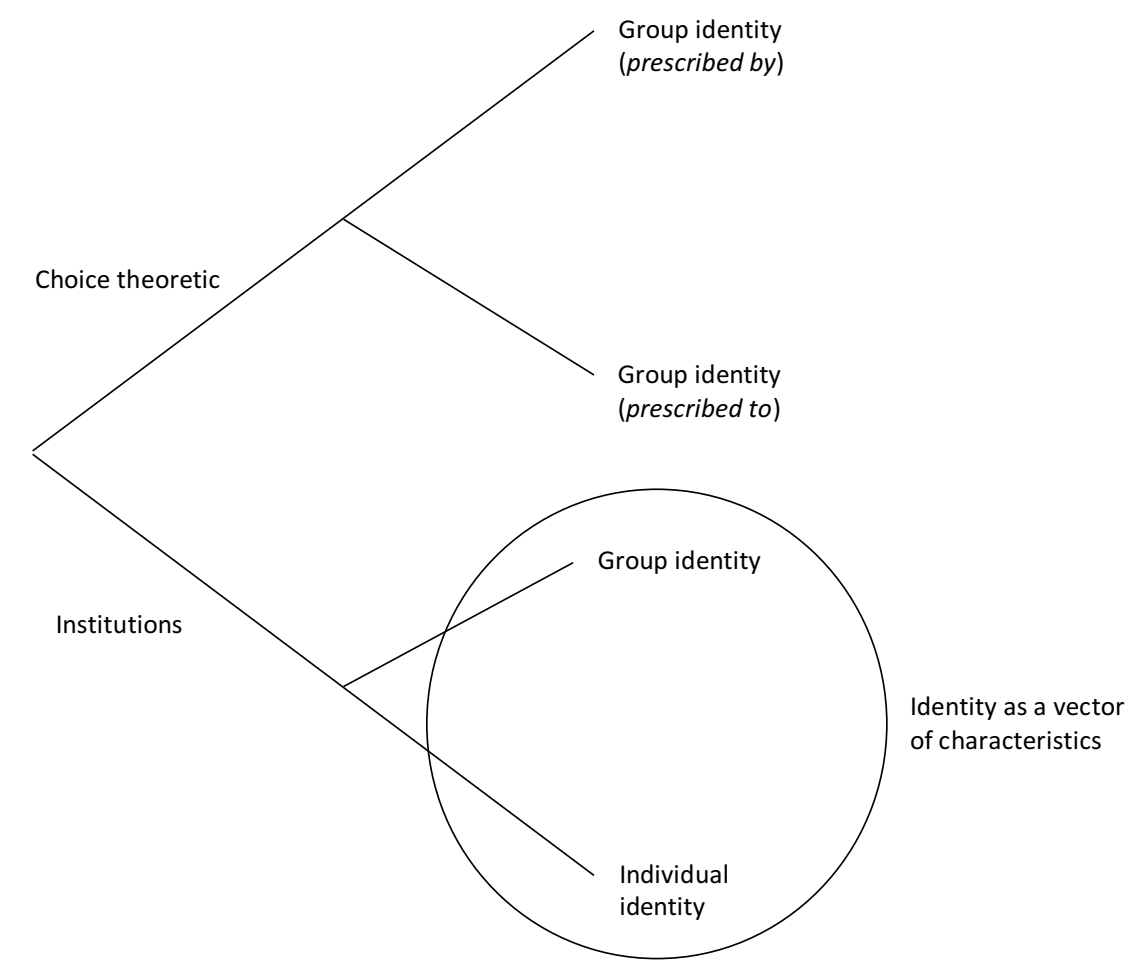

$\underline{\text { Figure 1. Cognitive map of identity in economics }}$

In examining the economics of discrimination, the existence of discrimination is explained by examining just a single characteristic. Again, this single characteristic relates to a social

\footnotetext{
${ }^{4}$ The literatures mentioned throughout this section are set out at length in Chapter 2 of this thesis.
} 
categorisation. However, unlike Akerlof and Kranton's (2000) or Sen's (1977) conceptions of identity, this literature is more akin to my categorisation of identity as related to characteristics prescribed to the individual. For instance, Becker's (see for instance 1957) taste-based discrimination sees economic agents as willing to pay a premium, or accept lower income, to avoid exchange with those of a certain social categorisation, such as ethnic minorities. In contrast, yet still employing a single (social) categorisation, the statistical discrimination of Arrow (see 1972a) and Phelps (see 1972a) sees those social categorisations, race or gender for instance, as proxies for some unobservable characteristic like labour productivity.

The institutions branch includes the study of transaction cost economising social identities. For instance, group membership is transaction cost economising as it provides for behavioural constraints (Carr and Landa 1983, Ostrom 1986), while it also provides for applicable sanctions in the event of a behavioural breach (Posner 1996, Eckel and Grossman 2005). Similarly, the literature on reputation sees this marker of past behaviour used to differentiate counterparties (Cabral 2005, Rogerson 1983, Shapiro 1983b) or constrain opportunism (Bolton, Katok, and Ockenfels 2005), where this characteristic is related to the individual identity of the individual.

What I set out to achieve in this thesis is a rectification of the shortcoming associated with these literatures on identity. For while these literatures examine identity as it relates to economic exchange and social interactions, their limiting factor is that they constrain analysis to just one characteristic of the individual. Sen $(2008,6)$ goes part of the way to close this gap when he allows for the same individual to be "a Norwegian citizen, of Asian origin, with Bangladeshi ancestry, a Muslim, a socialist". However, this does not go far enough to allow for a concise economic formulation of identity. For the Norwegian-Asian-Bangladeshi-Muslim Socialist's identity consists of far more than that they categorise themselves as. In addition, this individual probably has a credit score, a reputation in their community, academic qualifications, a driver licence, and so forth. They might have also been the subject of casual gossip, in doing so being labelled a certain way in the absence of their knowledge. That is, the vector of characteristics that comprise their identity are innate to, prescribed by, and prescribed to, themselves. As shown in Figure 1. above, this thesis takes the institutions branch, while allowing for individuals to be members of a group, while also taking on other and economically important characteristics. My approach of identity as a vector of characteristics acknowledges the social identities individuals adopt, while also considering the individual and differentiating characteristics of economic and political agents.

So, having introduced identity as the vector of characteristics associated with a unique individual that allows other individuals to recognise them, or allow differentiation from other individuals, it is worthwhile spending some time further considering where this identity derives its economic value. Here, I will introduce the basic economics of the demand and supply for the identity of the individual.

The demand for identity is a function of the need to recognise, and distinguish between, trading partners. Any sort of exchange in the presence of uncertainty results in profit seeking individuals seeking to mitigate the potential for future loss. Where the endowments, tastes, and motivations of heterogeneous actors are private information, understanding the 
distinctiveness of those you interact with increases the predictability of future states. As I make clear in Chapter 3, this demand for identity is commensurate with the value and the complexity of the exchange.

The demand for identity can be characterised as private or public. The private demand for identity sees commercial trading partners purchase increased certainty about the future state of the world by gathering private information related to who they trade with. For instance, a commercial lender will demand information related to a borrower's willingness and ability to repay a loan. The public demand for identity is not derived from commercial imperatives, but can be considered as a manifestation of the need for the state to have legibility over a population (Scott 1998), in order that they might be embraced (Torpey 2000). Returning to the example of a commercial loan, the regulatory requirements for lending institutions to conduct extensive background checks on their customers, as well as monitor them on an ongoing basis for the duration of the relationship, is an instance of the public demand for identity information. Anti-Money Laundering and Counter-Terrorism Financing (AML/CTF) requirements are a clear example of this. The manifestation of the private and the public demand for identity in economic exchange is examined at length in Chapter 3. Finally, the public demand for identity can be seen in the way states overcome the effects of private information between themselves and their citizens. As I show in Chapter 6, owing to the heterogeneity of endowments, tastes, and motivations possessed by individuals, states demand identity information for the purposes of resource extraction. It follows that as individuals have varying capacities to pay tribute, the state has an incentive to distinguish between those individuals.

The supply of identity is a function of the need to differentiate oneself from potential competitors when seeking out trading partners. Like the demand for identity, the supply of identity can be considered as both private and public. Supplying identity information prior to exchange can be a private ordering solution to uncertainty. This private supply of identity is what I deem as 'voluntary'. As I describe it in Chapter 4, producing and placing an 'identity hostage' at risk plays a similar role to that of a 'bond' or a 'deposit' (see, Milgrom, North, and Weingast 1990). That is, economic actors "should not expect to have their cake (low price) and eat it too (no hostage)" (Williamson 1983, 538). Identity in this sense has value because individuals expend resources obtaining it to subsequently use it. The private supply of identity is a function of financial, temporal, and other sacrifices such as educational attainment, the cultivation of a reputation, and so forth. Similarly, and as I describe it in Chapter 5 , the private supply of identity information might be used to overcome uncertainty as it relates to property ownership and sovereign risk. In this manner, heritable surnames have arisen in part to mitigate the threat of nationalisation in the context of post-1066 England.

In contrast, the public supply of identity can be characterised as the compulsory use of a defined identity technology as a prerequisite to some exchange or interaction. This public supply of identity is what I term 'involuntary'. As I describe in Chapter 6, rulers have an incentive to deploy identity technologies to distinguish between individuals. ${ }^{5}$ This has seen states declare the compulsory use of identity technologies such as sauf-conduit, passports,

\footnotetext{
${ }^{5}$ In this situation the ruler (government or state) supplies an identity to an individual because it demands the ability to identity unique individuals.
} 
and other administrative means. In the public supply of identity, it is easy to see supply following demand. States have an incentive to distinguish between individuals within their population-demand-therefore they require the use of, and administer, various identity technologies-supply.

The supply of identity can also be thought of as a property right over private information about the individual. As I describe in Chapter 5, the supply of identity has not emerged purely under economic conditions in the manner of Demsetz (1967). If this were so, this supply would emerge via the actions of market participants in the presence of scarcity, and through the internalisation of externalities. The emergence of this supply of identity-what I have analogised to property rights-might emerge from exogenous stimuli including new technologies, markets, and price shocks. Yet this is a naïve explanation. Quite simply, in some circumstances 'rule makers' (Riker and Sened 1991) give value to identity information when they recognise its legitimacy and enforce contracts struck using such identity information. That is, the-economically and socially useful-supply of identity is a consequence of both economic and political conditions. Property rights associated with the supply of identity have emerged in part owing to utility maximisation by political actors, and a monopoly on violence by those same political actors (Riker and Sened 1991, Sened 1997). In Chapter 5, I describe the initial private supply of identity information used to overcome uncertainty, which is subsequently co-opted by the state to obtain greater information over their populace.

Finally, the supply of identity is constrained by privacy considerations. It is true that much economic and social interaction is contingent on the supply of private (identity) information. However, and as described by Posner (1979), the manufacture of a positive reputation can also be a function of the 'concealment of personal facts'. That is, there is often an incentive to keep hidden previous actions and instances of exchange (Posner 1981, Acquisti, Taylor, and Wagman 2016). This means that the supply of identity information might be restrained at the individual level, depending on the tastes and preferences of the individual; privacy is 'subjectively desirable' (Berg 2018).

\subsection{Summary and findings}

\subsubsection{Chapter 2: Information asymmetry and identity in economics}

The purpose of Chapter 2 is to provide background to the economic problem of trading in an environment with heterogeneous actors amid uncertainty. A secondary purpose is to review the significant economic and other social science literatures on identity. The main section of this chapter (Section 2.2) will outline the way private information and identity have been examined in the economics literature. This will include reviews of the literatures on the economics of asymmetric information, 'identity economics', the economics of discrimination, the broader politics, philosophy and economics (PPE) discipline, and finally from an institutional perspective. I will then turn to the study of identity within non-economic social sciences (Section 2.3). My review will be broader than just the economic literature, as much of the economics literature takes inspiration from the sociology and psychology disciplines. I find that there is a litany of usages of the term identity across and within many disciplines. It can broadly be lumped into two categorisations, with the first of these related to group membership, and the second as an individual concept. This sees group membership as 
prescribing behavioural norms according to that membership, while also allowing for sanctions in the case those norms are breached. Studied as an individual concept, identity is analogous to a label, in that previous actions by that individual might follow that individual over time.

\subsubsection{Chapter 3: An identity cost model of exchange}

Chapter 3 will be the first of two to examine the role of identity in economic exchange. Here I will develop an identity cost model of economic exchange. This model will incorporate an individual's identity-the vector of characteristics associated with a unique individual that allows other individuals to recognise them, or allow differentiation from other individuals. This chapter will begin by developing a model of stylised credit contract to demonstrate the costs associated with identifying, and subsequently verifying, a counterparty to exchange (Section 3.2). Following this, the transaction costs contractual schema, along with its attendant behavioural assumptions will be outlined (Section 3.3). Using the transaction cost framework of uncertainty, frequency of exchange, and asset specificity (Williamson 1979, 1985), I will then validate this model (Section 3.4). Applying this framework to my simple model of a credit contract, I contribute the finding that 'identity costs' comprise a distinct and significant subset of transaction costs. Owing to the heterogeneous nature of participants in credit markets, participants have both a commercial and a regulatory imperative to understand the characteristics of those they do business with. I will then outline some ways in which the empirical transaction costs literature (see for instance Wallis and North 1986, Dollery and Leong 1998, Polski 2001) might be applied to the measurement of identity costs (Section 3.5). Finally, I will examine the nature of hierarchical organisations which exist to economise on identity costs (Section 3.6). Another contribution is the finding that credit contracts typically occur within hierarchical organisations, rather than in a decentralised marketplace, to economise on such costs. Overall, this chapter develops a model of economic exchange which sees identity used to obtain private information from counterparties to exchange. The next chapter will examine identity as an institution that constrains the actions of participants to exchange.

\subsubsection{Chapter 4: A hostage model of identity}

In Chapter 4 I will develop a hostage model of identity. This model is an expanded version of that originally developed by Williamson $(1983,1984)$. This chapter will be constructed around the premise that uncertainty is endemic in economic life, in part owing the combined behavioural assumptions of bounded rationality (Simon 1957) and opportunism (Williamson 1985). I will begin the chapter by outlining the way hostages are a form of contractual safeguard which mitigate the effects of uncertainty (Section 4.2). A contribution of this chapter is the development of a hostage model of identity, which sees participants to exchange post identity hostages subject to exploitation in the event of any divergence from ex-ante contractual expectations (Section 4.3). The identity hostages I will incorporate into the model are information assets from which one can derive information about past instances of exchange. I find that these identity hostages are exploitable by both execution and revelation, and that these predict as well as explain certain behavioural practices. For instance, certain restricted networks would lose the value of exclusivity absent such a mechanism. Overall, this chapter will demonstrate the mechanism by which identity-the 
vector of characteristics associated with a unique individual that allows other individuals to recognise them, or allow differentiation from other individuals-constrains the behaviour of individuals.

\subsubsection{Chapter 5: An economic theory of surnames}

Chapter 5 is the first of two which will examine the role of identity in political exchange. The focus of this chapter will be the origin of heritable surnames, and the role they have played in the protection of property rights. A contribution of this chapter is a model of intergenerational property ownership under sovereign risk (Section 5.2). As part of this model, I will use two literatures, the new institutional economics of history (NIEH) (see North 1971, North, Wallis, and Weingast 2006), as well as the property rights literature (see Demsetz 1964, 1967, Riker and Sened 1991). I will then apply this model to England in the period after the Norman invasion of 1066 (Section 5.3). I contribute the finding that heritable surnames were adopted almost immediately by the followers of William the Conqueror to constrain the actions of the sovereign. These followers acted as institutional entrepreneurs, using this newly introduced technology to maintain intergenerational ownership over land in the face of uncertainty as to the actions of the monarch. Part of this finding is that the institution of heritable surnames was only partially successful, owing to the need for future generations of landholders to apply further political pressure, including via the Magna Carta of 1215. I also find that the property rights literature of Riker and Sened (1991) has more explanatory power compared to that of Demsetz $(1964,1967)$ in relation to this process. This is owing to the role of political power in the granting of property rights. Finally, I will describe some further ways in which surnames as an identity technology might be further examined from an institutional perspective (Section 5.4). Overall, and in the case of post-1066 England, this chapter contributes the finding that heritable surnames have been used as a mechanism to constrain the actions of a ruler in the maintenance of private property under conditions of behavioural uncertainty.

\subsubsection{Chapter 6: The stationary bandit with stationary captives}

Chapter 6 is the second, and final, chapter which will look at the role of identity in political exchange. I first contribute a model of stationary bandit with stationary captives (Section 6.2). Consistent with the overarching theme of the thesis, participants in exchange will be assumed to be heterogeneous, with varied endowments, tastes, and motivations. The model developed in this chapter is an expanded version of Olson's $(1993,1995)$ stationary bandit model of government. I will incorporate the incentive of the stationary bandit to use identity technologies to increase their extractive capacity over a captive population. This model will be examined in the context of four historical case studies; Ancient Rome (Section 6.3), Mediaeval Europe (Section 6.4), Revolutionary France (Section 6.5), and Revolutionary China (Section 6.6). I contribute the finding that a range of identity technologies have been used to increase the extractive capacity of the state, and that their use is in part a function of the heterogeneity of a captive population. Their use in turn reduces uncertainty to the benefit of the ruler. In addition, their use can be related to the discriminatory provision of public goods. Overall, and in contrast to the previous chapter, Chapter 6 finds that as individual members of a population are varied in their capacity to provide tribute to a ruler, the ruler has an 
incentive to use identity technologies to distinguish between their population. Similarly, these same technologies can be used to provide public goods on a discriminatory basis.

\subsubsection{Chapter 7: Summary and conclusion}

Chapter 7 is the last of the thesis. In the conclusion, I will provide a summary of my contributions (Section 7.2). This will include the broad findings as to the role of identity in economic, and political, exchange. I will then raise some limitations of the thesis (Section 7.3). Finally, I will offer some broad avenues which might provide opportunity for future research (Section 7.4). 


\section{Chapter 2. Information asymmetry and identity in economics}

\subsection{Introduction}

The purpose of this chapter is threefold: to provide context for trade under uncertainty, to outline the literatures dealing with the concept of identity, and finally to demonstrate the need for a new economic definition of identity. The first of these sees this chapter provide context for the economic and political problem of trade in an environment where trading partners are heterogeneous, and where the endowments, tastes, and motivations of those endowments and tastes are private information. The second purpose of this chapter it to outline the significant literature which incorporates the concept of identity-however defined-into their analysis. Finally, this chapter demonstrates the need for a clear and concise economic definition of identity. This I have already done, with this thesis contributing a new economic definition of identity as a vector of characteristics associated with a unique individual that allows other individuals to recognise them, or allow differentiation from other individuals. Identity as a concept has a diversity of meanings and usages across many fields, and this chapter aims to provide an accounting of some of these. This task is made difficult, in no small part due to the ambiguity which comes with the use of the term. As early as the 1960 s the "terminological situation had gotten completely out of hand" (Gleason 1983, 915). The use of the word has been similarly described as 'indiscriminate' (Erikson 1968, 16), while Brubaker and Cooper $(2000,3)$ claim the overuse of the term has led to a "devaluation of meaning".

Much of the economics literature examining "identity" sees it as a group concept. That is, identity is characterised by group membership, commonly defined by racial, ethnic, religious, or gender types. This can be seen in the 'identity economics' literature (Akerlof and Kranton 2000, 2002, 2005), that related to the economics of discrimination (Becker 1957, Arrow 1972a, 1972b, 1973), the broader politics, philosophy and economics (PPE) discipline (Sen $1977,1985,2002,2005$ ), and finally as related to the economics of institutions (Carr and Landa 1983, Posner 1980). Within these economic sub-fields, identity as characterised by membership in a group can be used to explain behaviours which would appear to be nonsensical if purely monetary motivations were considered. That is, (group) identity can explain much human behaviour which might appear to be irrational if standard models of behaviour were applied. As I have described in section 1.4, this use of a single characteristic to comprise the individual's identity is limiting to analysis of decision making.

As shall become clear in section 2.3, much of the literature on group membership and identity takes stimulus from broader social science disciplines. Identity is also examined from an individual perspective, which is seen in the literature on reputation, as well as how it has been indirectly studied in the literature on information asymmetry. In this literature, reputation acts as a 'label' from which information about past instances of exchange can be derived, thereby overcoming instances of adverse selection and moral hazard. The review of the information asymmetry and reputation literatures also identifies a semantic issue when reviewing that related to identity. For instance, although usually not explicitly described as such, reputation is often seen as an aspect of the identity of an economic agent. Again, and 
in contrast to my use of the term, the use of a single characteristic to comprise the individual's identity is limiting to analysis of decision making.

Despite this ambiguity and variety in these literatures, I will outline the ways in which identity has been used in economics. In addition, I will provide an overview of some of the related literature. Following this, I shall outline some of the literature from which the identity concept in this field is derived. The reason for this should become plain in the remainder of this chapter; preceding this it should serve to emphasise that identity in the economics literature has been greatly influenced by other fields (see, for instance Akerlof and Kranton 2000, Barrett 2013a, Davis 2010). The inter-relatedness of the study of identity in competing fields is often blurred and at times difficult to disentangle. According to Folbre $(1994,16)$, "this is beginning to sound more like sociology than economics". Indeed, Folbre's statement could be readily repurposed, replacing sociology with ethnography, anthropology, or psychology.

The remainder of this chapter proceeds as follows. In the main part of this chapter-section 2.2-l look at the ways private information and identity have been examined in the economics literature, including via the economics of asymmetric information, 'identity economics', the economics of discrimination, the broader PPE discipline, and finally from an institutional perspective. In section 2.3 , I shall outline some of the literature from non-economic disciplines, in part to examine the source material from which the study of identity in the economics discipline has been inspired. Section 2.4 concludes the chapter.

\subsection{Economics}

\subsubsection{The problem of information asymmetry}

This section outlines the problem of information asymmetry. ${ }^{6}$ As I make clear throughout this thesis, identity solves an asymmetric information problem under conditions of uncertainty, and where counterparties to exchange can be considered as heterogeneous agents. Assuming heterogeneity of economic and political agents rejects a model in which those agents, as well as that which is traded, is perfectly homogenous (Telser and Higinbotham 1977, see, also Salop and Salop 1976, Williamson 1985). The contrast to this is a model of 'perfect decentralisation' where economic choices are made based on prices, tastes, and technologies (Demsetz 1988), and where the identity of buyer, seller, and commodity are treated as being irrelevant (Williamson 1985). As should become clear in this section, and throughout the thesis, a more realistic treatment is that there is inherent uncertainty about not only that which is traded, but also about the ex-ante characteristics, as well as the ex-post actions, of counterparties. As such, the vector of characteristics associated with a unique individualthe identity-are of paramount importance, as is how that identity is discovered and verified.

\footnotetext{
${ }^{6}$ The assumption of asymmetry of information is in direct contrast to Walrasian (2013) and Marshallian (2013) models of perfect information. Perfect, or 'complete' information sees every agent as possessing knowledge of "his own taste and endowments as well as the tastes and endowments of all other agents" (Mirman, 3). In this respect, de Vroey $(2003,468)$ critiques what he deems 'ambiguous accounts' of any assumption of perfect information throughout the economic literature.
} 
As examined in the economic literature, an asymmetry of information can be said to lead to situations including adverse selection and moral hazard. I examine both in this section. In addition, I outline some of the ways this problem is, and might be, overcome by counterparties to exchange. This problem of information asymmetry is most readily identifiable with George Akerlof in his Market for "Lemons" (1970), ${ }^{7}$ along with the subsequent work of Michael Spence (see for instance 1973, 1974, 2002) and Joseph Stiglitz (see for instance 1975, Rothschild and Stiglitz 1976, Grossman and Stiglitz 1980, Stiglitz and Weiss 1981). In addition, and at the end of this section, I introduce how the problem of information asymmetry might be examined from a political economy perspective (see for instance Abdukadirov 2010, Acchiardo 2013, Boix and Svolik 2013).

In The Market for "Lemons" (1970) Akerlof presents his model of a market with information asymmetry resulting in adverse selection. In this market buyers are unable to distinguish between good and bad quality products. This results in a sort of reversion to the mean, where "prices adjust to average quality rather than true quality" (Kumar and Park 2012, 129). The basic model is a two-period model in which an agent can either buy or sell a product. All traders act as von Neumann-Morgenstern utility maximisers (von Neumann and Morgenstern 1947, see also Baumol 1951, Friedman and Savage 1952), while sellers have private information and buyers only know the average quality of products in that market. Private information is a function of the 'experience' (Nelson 1970) of owning a product. Adverse selection occurs as the trader with private information might use that informational asymmetry to trade at circumstances favourable to themselves while unfavourable to the uninformed party.

In such a market buyers, rather than having perfect information over the product sold, only know the probability of that product being of good quality, and by extension the probability that the product is a 'lemon' (see also Pauly 1974, Cohen and Siegelman 2010). Understanding the probabilities of, rather than the definite future states of nature sees models of information asymmetry treated as lotteries as it is understood in decision theory (Spence 1973). In this respect, Arrow's (1970, see also 1963) contemporaneous discussion of the 'inequality' of the distribution of information complements Akerlof's model (1970).

This inequality is ultimately derived from the mismatch between the information available to buyers and sellers, with the seller having a better understanding of the quality of the product than the buyer. As described by Akerlof, a buyer might eventually come into possession of this information, but only after they have owned the product for a period of time (see also Spence 1973). Here, deriving information as to the quality of the product comes from the 'experience' of owning it (Nelson 1970, see also Shapiro 1983a, Riordan 1986, Laband 1991, Che 1996). Hence information asymmetry arises. A trader can only meaningfully evaluate the quality of a product once they have owned it (Riley 2001). By extension any potential and future buyer of that product knows less about its quality than the seller at the point of sale. It should be noted that the type of good traded in the Akerlof (1970) model is an 'experience' good. This is contrast to that of a 'credence' good, whose quality is difficult for non-experts

\footnotetext{
${ }^{7}$ This paper was initially rejected by The American Economic Review as the journal "did not publish such trivial stuff" (Gans and Sheperd 1994, 171).
} 
to evaluate, even after purchase (see Darby and Karni 1973, Dulleck and Kerschbamer 2006, Emons 1997). ${ }^{8}$

According to Akerlof (1970) the outcome of private information-in the absence of supporting institutions or "devices for eliminating uncertainties in quality" (Stigler 1961, 224 see also Metzger 1983, Hoffer and Pratt 1987, Nicks 1987, Wimmer and Chezum 2003)-is that good quality products might be 'driven' out of that market. This is a "modified reappearance" (Akerlof 1970, 489) of Gresham's Law (Fisher 1894). As buyers cannot tell the difference between a good quality product and a low-quality product, a seller of the former cannot be expected to put that product to market. Quite simply, any buyer faces the risk that the product they purchase will be a 'lemon' and hence will demand a discounted price. Sellers of good quality products are subsequently discouraged from participating in such a market. This negatively impacts any potential gains from trade in that market (Levin 2001). Without any form of counterbalancing institutional intervention, the "average quality of the goods and also the size of the market" is diminished (Akerlof 1970, 488 see also Riley 2001). ${ }^{9}$ In Chapters 3 and 4,1 contribute to the literature two models of economic exchange which can be considered as counterbalancing institutional interventions that overcome this information asymmetry; these are, respectively, the incurring of 'identity costs' and the posting of 'identity hostages'.

Adverse selection arises from 'hidden information' (Cohen and Siegelman 2010) which is available to only one side of contractual negotiations. Adverse selection therefore presents itself as an ex-ante contractual phenomena. Owing to the uncertainty-and expectations of this uncertainty-as to the precise nature of the ex-post state of the world (Allen, Berg and Markey-Towler 2019), markets produce outcomes materially different from those with Walrasian or Marshallian perfect information assumptions (see de Vroey 2003). This uncertainty should itself be considered alongside the common behavioural assumptions of bounded rationality (Simon 1957, 1961) and opportunism (Williamson 1975, 1985, 1991, 1996). These behavioural assumptions, typical of transaction cost economics, precedes this uncertainty as to the future state of the world. Information asymmetries between counterparties to exchange can be said to result in transaction costs (see North 1990), meaning that the literatures should be considered as linked (Moe 2005). The concepts of

\footnotetext{
${ }^{8}$ Credence goods were added to Nelson's (1970) taxonomy of 'search' (see also Stigler 1961) and 'experience' goods by Darby and Karni (1973).

${ }^{9}$ The Market for "Lemons" has itself triggered a large literature, with the effects of information asymmetry and adverse selection examined, for instance, (again) in the market for used cars (see for instance Wilson 1980, Bond 1982, Metzger 1983, Kim 1985, Hoffer and Pratt 1987, Genesove 1993, Offer 2007, Emons and Sheldon 2009, Sultan 2010), credit markets (see for instance Stiglitz and Weiss 1981, Bester 1985, Hellmann and Stiglitz 2000, Berndt and Gupta 2009), corporate mergers and joint ventures (see for instance Balakrishnan and Koza 1993, Hennart and Reddy 2000, Kumar and Park 2012), the market for thoroughbreds (see for instance Wimmer and Chezum 2003, 2006) the labour market (see for instance Spence 1973, 1974, Greenwald 1986, Levine 1991, Gibbons and Katz 1991, Doiron 1995, Montgomery 1999, Krashinsky 2002, Stantcheva 2014, Bastani, Blumkin and Micheletto 2015), and insurance markets (see for instance Pauly 1974, Rothschild and Stiglitz 1976, Puelz and Snow 1994, Bundorf, Levin and Mahoney 2012, Cardon and Hendel 2001, Cohen and Siegelman 2010, Einav, Finkelstein and Levin 2010, Handel 2013).
} 
uncertainty, bounded rationality, and opportunism are incorporated in the economic models developed in chapters 3 and 4.

The market for insurance was cited as being the 'prime example' of information asymmetry by Weibull in presenting the 2001 Nobel to Akerlof, Spence and Stiglitz. ${ }^{10}$ According to Cohen and Siegelman (2010), the term 'adverse selection' originated in the study of this market. In addition, the labour market is well-studied as it relates to adverse selection, with prize winners Spence (see for instance 1973, 1974) and Stiglitz (see for instance Shapiro and Stiglitz 1984) both examining this market in well cited research.

In addition, and aside from the ex-ante contractual effects derived from 'hidden information', ex-post 'hidden actions' - moral hazards - are a further implication of information asymmetry (Cohen and Siegelman 2010). These 'hidden actions' are the ex-post contractual implications of private information. In short, moral hazard arises when the purchase of a product results in some reduction in the incentive to avoid, or take actions to minimise, loss by the purchaser. ${ }^{11}$ In both circumstances purchasing a product, most commonly insurance, "alter(s) an individual's motive to prevent loss" (Shavell 1979, 541 cf. Ehrlich and Becker 1972, Pauly 1974). These phenomena are commonly associated with the market for insurance (Winter 2000), as well as the banking industry, as moral hazard sees a party as in some way disassociated with some of the consequences of their risky activities (Stiglitz 2000). Baker (1996) provides a useful overview of the study of moral hazard as it relates to the insurance market, while Dembe and Boden (2000) examine its ethical origins (see also Haynes 1894). This tendency to not avoid, or not minimise, loss in part emerges from a lack of observability of certain actions of one party by the other to a contract (Hölmstrom 1979, Rubinstein and Yaari 1983). This lack of observability owes much to the difficulty and cost associated with observation (see Alchian and Demsetz 1972). As moral hazard arises from behavioural outcomes-such as dishonesty (Haynes 1894) or carelessness (see for instance Spieler 1994) - the "study of man as he is" (Coase 1984, 231) is relevant to any discussion of information asymmetry and moral hazard. ${ }^{12}$

\footnotetext{
${ }^{10}$ https://www.nobelprize.org/prizes/economic-sciences/2001/ceremony-speech/
}

\begin{abstract}
${ }^{11}$ Somewhat adding complexity to this sketch, Winter (2000) describes both ex-ante and ex-post moral hazard (see also Einav, Finkelstein and Levin 2010, Spenkuch 2012, Einav and Finkelstein 2018). To illustrate with an example, the former refers to a reduction in the incentive to avoid an accident after purchasing insurance, while the latter refers to an insured individual having a reduction in incentive to mitigate damage once an accident has occurred. This taxonomy should not be confused with my use of the terms to distinguish between adverse selection and moral hazard as they relate to a contractual timeline. In my usage, adverse selection shows its effects ex-ante to any contractual agreement, while moral hazard emerges ex-post. As used by Winter (2000), both ex-ante and ex-post moral hazards occur contractually ex-post according to my usage.
\end{abstract}

\footnotetext{
${ }^{12}$ As it is for adverse selection, the literature related to information asymmetry and moral hazard is large. Expost, in contrast to ex-ante contractual, implications of private information have been examined in, for instance, the insurance market (see for instance Pauly 1968, Zeckhauser 1970, Spence and Zeckhauser 1971, Ehrlich and Becker 1972, Shavell 1979, Hölmstrom 1979, Rubinstein and Yaari 1983, Chambers 1989, Einav et al. 2013, Horowitz and Lichtenberg 1993, Smith and Goodwin 1996, Stone 1999, Alger and Ma 2003, Einav and Finkelstein 2018, Wu, Goodwin and Coble 2020, Zweifel 2020), the labour market (see for instance Moffitt 1985, Meyer 1990, Christofides and McKenna 1995, Laffont and Matoussi 1995, Krueger and Meyer 2002, Rocheteau 2001, 2002, Johannson and Palme 2005, Demougin and Helm 2006, Chetty 2008, Hall and Hartman
} 
Owing to their relatedness and similarity of intellectual origin, a good deal of the literature has also examined information asymmetry as it relates to both adverse selection and moral hazard. For instance, both are examined in credit markets (see for instance Berndt and Gupta 2009), insurance markets (see for instance Pauly 1974, Chiappori and Salanie 2000 Einav et al. 2013, Prescott and Townsend 1984, Spenkuch 2012), the labour market (see for instance Prescott and Townsend 1984), as well as leasing arrangements (see for instance Johnson and Waldman 2010).

Informational asymmetry is also a key assumption of agency theory, as it relates to the so called 'principal-agent problem'. Eisenhardt (1989) provides a useful overview. This problem sees a 'principal' contract with an 'agent', where the latter is granted decision making authority by the former (Jensen and Meckling 1976). This problem is well illustrated using the architecture of a firm, whose delineation of ownership and management can be used to describe aspects of both adverse selection and moral hazard. Hölmstrom (1982) shows how adverse selection arises in the context of a firm where the choices of an agent cannot be precisely determined as the 'correct' one owing to information asymmetry. Moral hazard also arises as outputs cannot be directly correlated with the 'actions' of an agent. This latter point owes to the impossibility of correlating the actions of any one individual with their marginal productivity (Alchian and Demsetz 1972). The behavioural assumptions mentioned earlier in this section-bounded rationality and opportunism-are applicable here, with this association made as far back as Adam Smith. For when people are placed in charge of other people's property, "it cannot well be expected, that they should watch over it with the same anxious vigilance" that they would watch over their own (Smith, 1776b, 330).

However, clearly information asymmetry does not eliminate all trade. Neither is a 'reversion to the mean' necessarily observable, owing to the preponderance of higher quality goods selling at a higher price than those of lower quality (see for instance Janssen and Roy 2010). There are institutions and mechanisms which serve to counteract the reversion to the mean as described in The Market for "Lemons". ${ }^{13}$ This point is raised by Akerlof (1970), who discusses counteracting mechanisms including guarantees, brand names, and licencing practices. For instance, brand names serve to uphold contractual performance (Klein and Leffler 1981). These devices transmit-signal-information about past instances of exchange or some other relevant characteristic (Erdem and Swait 1998, Cabral 2000, Bolton, Katok, and

2010, Eliason, Johansson and Nilsson 2019) banking (see for instance Diamond 1984, Calomiris and Kahn 1991, Akerlof et al. 1993, Blum 1999, 2002, Hellmann, Murdock and Stiglitz 2000, Matutes and Vives 2000, Chiesa 2001, Decamps, Rochet and Roger 2004, Nier and Baumann 2006, Kopecky and VanHoose 2006, Niinimäki 2009, Farhi and Tirole 2012, Bianchi 2016), leasing arrangements (see for instance Smith and Wakeman 1985, Wolfson 1985, Benjamin, de la Torre and Musumeci 1995, Chau, Firth and Srinidhi 2006, Schneider 2010, Jackson and Schneider 2011), franchising arrangements (see for instance Lafontaine 1992, Wimmer and Garen 1997, Nygaard and Myrtveit 2000, Cochet and Ehrmann 2007, Fan, Kühn and Lafontaine 2017), crowdfunding (see for instance Strausz 2017, Chemla and Tinn 2020), as well as team environments (see for instance Hölmstrom 1982, Rasmusen 1987, Jeon 1996, Battaglini 2006, Rayo 2007, Franco, Mitchell and Vereshchagina 2011, Song 2012).

\footnotetext{
13 'Institutions' can be considered as "rules of the game" which both shape and provide certainty over human interaction (North 1990, 3). In this respect they provide common behavioural guidelines used by members of a group (Ostrom 1986, Bates 2014, Crawford and Ostrom 1995), while they can also be delineated into both formal and informal varieties. Later in this chapter I examine the economic literature on institutions in some depth.
} 
Ockenfels 2005), while they also provide a means to punish ex-post opportunistic behaviour (Shapiro 1983b, Greif 1989, Milgrom, North, and Weingast 1990, MacLeod 2007). In Chapter 3 I introduce an identity cost model of exchange which illustrates the transmission of information about past instances of exchange or other relevant characteristics. In Chapter 4 I introduce a hostage model of identity which demonstrates a mechanism for the punishment of ex-post opportunistic behaviour. I also outline the economic literature on brand names, reputation and other identity devices later in this chapter.

The function of quality 'signalling' is addressed by Spence (1973, 1974 see also 2002) who examines the way in which educational qualifications are used to indirectly communicate productivity to employers, thereby counteracting adverse selection. In short, the model Spence employs shows how in conditions of uncertainty, signalling serves to communicate an individual's 'type'. Like Akerlof (1970), traders are unable to perceive exacts future states, rather they operate as if in a lottery, observing a "distribution of abilities" (Rasmusen 2006, 267) across a population. In this case, they observe that some proportion of the population are high productivity, while the remainder are low productivity. This information is private in the sense that productivity is a characteristic known only to the bearer. In this original model, an employer is unable to (ex-ante) determine the productivity of any individual potential hire. Key to this literature is that with no method of communicating quality, average wages, and hence the quality of the labour pool drops due to high quality individuals selecting out of the labour market (Spence 2002). Yet rather than the labour market operating as a Market for "Lemons", an employment decision is made based on the employer's "probabilistic assessments over productive capacity given various combinations of signals and indices [emphasis mine]" (Spence 1973, 357). Signals are costly decisions to undertake education while indices consist of those immutable characteristics including race, gender, and so forth. ${ }^{14}$ I incorporate the use of signalling to differentiate oneself in my hostage model of identity in Chapter 4.

In this model workers with a greater productive capacity distinguish themselves from those of lower productivity, owing to the negative correlation Spence (1973) assumes between the cost of education and productivity. That is, the more productive the worker, the less costly is educational attainment and vice versa (Salop and Salop 1976, Kübler, Müller and Normann 2008). This sees an individual commit to undertaking educational actions up until the point where the cost of signalling outweighs the increase in wages. This 'critical' assumption (Spence 1973) precludes a scenario in which all workers invest in a uniform level of educational attainment. This circumstance would drown out any 'signal' of productive capacity amongst the noise (Silver 2012 see also Matthews and Mirman 1983). Only when this assumption of differing costs of signalling holds, does signalling succeed in mitigating adverse selection. Of course, and according to Grossman and Stiglitz (1980), signals of this nature do not necessarily reveal all useful information to the uninformed.

\footnotetext{
${ }^{14}$ These immutable characteristics-which Spence (1973) terms indices-should also be considered in the context of the literature on taste-based (Becker 1957) and statistical (Phelps 1972a, 1972b, Arrow 1972a, 1972b, 1973) discrimination. I discuss this literature in in some detail later in this chapter.
} 
Signalling - Stiglitz and Weiss (1990) first distinguished 'signalling' from 'screening', ${ }^{15}$ about which I will have more to say later in this section, while Riley (2001) provides a good background to these literatures - is an example of the informed party acting prior to the uninformed (Mailath 1987, Posey and Yavas 2007). It is common in some of the signalling literature for the informed party to be termed the sender, and the uninformed party the receiver (Rasmusen 2006, Connelly et al. 2011). Here it also useful to recognise Nelson's (1970) taxonomy of 'search qualities' versus 'experience qualities' where the former occurs ex-ante, and the latter ex-post (see also Darby and Karni 1973). Implicit in this distinction is that at least some of the characteristics of a search good can be understood prior to purchase. This can be illustrated in the labour market, and relates to the premise by which information about a worker's productivity is disseminated to the world at large. ${ }^{16} \mathrm{~A}$ signalling model can be distinguished from a human capital theory of the labour market (Weiss 1995). Human capital theory allows for education which 'enhances productivity' (see for instance Becker 1962, Schultz 1963), while a pure instance of the signalling model sees educational attainment as merely 'reflective' of the productivity of those who bear it (Chevalier et al. 2004). ${ }^{17}$

Signalling is an instance of the informed acting prior to the uninformed (Mailath 1987, Stiglitz 2000, Posey and Yavas 2007). In contrast 'screening' sees the uninformed take the first step

\footnotetext{
${ }^{15}$ As Rasmusen (2006) notes, these terms are often, and according to him incorrectly, used interchangeably by economists. For instance Milde and Riley $(1988,103)$ discuss how, from a menu of loans of varying sizes, "applicants with higher quality projects can signal by accepting smaller loans" [emphasis mine]. As shall be shown later in this section, I assert that this is a case of 'screening' rather than 'signalling' as the uninformedlenders offering a menu of varying contracts-move prior to the informed-the borrower. Similarly, Stiglitz (1975) uses the term 'screening' as it relates to costly educational endowments where I maintain that 'signalling' would now be understood as the correct term (cf. Rosser 2003).
}

${ }^{16}$ Worth mentioning briefly is that the literature on matching theory implicitly includes an understanding of the importance of individual identity in forming relationships. There is inherent uncertainty when forming any type of partnership, and this uncertainty must be overcome to the satisfaction of both parties before these partnerships are formed (Burdett and Coles 1999). For instance, much of the matching theory literature discusses the 'friction' inherent in the labour market that must be overcome before a successful hire (Pissarides 2000). Key to this literature is that both parties are evaluating the characteristics of the other. That is, the identity of each party must match the requirements of the counterparty prior to relationship formation. This literature also includes examination of creditor and debtor relationships (den Haan et al. 2003), school choice (Abdulkadiroglu and Sonmez 2003, Abdulkadiroglu et al. 2005, Kapor et al. 2018), tenant-landlord relationships (Abdulkadiroglu and Sonmez 1999), as well as the matching of organ donors with recipients (Ashlagi and Roth 2021).

${ }^{17}$ The literature on signalling includes examining its appearance in, for instance, prices (see for instance Gerstner 1985, Milgrom and Roberts 1986, Stiglitz 1987, Tellis and Wernerfelt 1987, Boyer and Laffont 1989, Dodds, Monroe and Grewal 1991, Rao 2005, Erdem, Katz and Sun 2010, Janssen and Roy 2010, Panzone 2012, Chenavaz 2017 see also Scitovszky 1944), advertising (see for instance Nelson 1974, Kotowitz and Mathewson 1979, Kihlstrom and Riordan 1984, Horstmann and MacDonald 1994, Anand and Shachar 2009, Tsui 2012 see also Grossman and Shapiro 1984, Bagwell and Ramey 1994), dividend payments (see for instance Ross 1977, Bhattacharya 1980, Eades 1982, John and Williams 1985, Miller and Rock 1985, Bajaj and Vijh 1990, Frankfurter and Wood 2002), as it manifests in the labour market (see for instance Stiglitz 1975, Salop and Salop 1976, Waldman 1984, Groot and Oosterbeck 1994, Tyler, Murnane and Willett 2000, Chevalier et al. 2004, Heywood and Wei 2004, Caplan 2017), in international relations (see for instance Ramsey 2004, Stern and O'Brien 2012), as well as in studies of leadership (see for instance Grabo, Spisak and van Vugt 2017). 
in an environment with asymmetries of information. ${ }^{18}$ This is illustrated by Rothschild and Stiglitz $(1976,632)$, who examine how the uninformed, in this case an insurance company, might ascertain useful information from their customers. Here the customers are informed about their own "accident probabilities", while they are ex-ante ignorant. To arrive at conclusions as to these probabilities, an insurance company uses 'self-selection', consisting of "a pricing scheme that causes the applicant to reveal truthful information about himself by his market behaviour" (Salop and Salop 1976, 620). Another common example is in credit markets, where a 'menu' of loan types can be offered to potential borrowers. This mitigates the negative effects of private information-risk type-known only to the borrower. These loans might vary in, for instance, collateral requirements (see for instance Bester 1985, Manova, Mattesini 1990, Padilla and Pagano 2001), loan term (see for instance Flannery 1986, Hertzberg, Liberman and Paravisini 2018), as well as performance based covenants (see for instance Levine and Hughes 2005, Wang 2017).

To illustrate a simple model of screening, consider an insurance market in which buyers of insurance know their 'accident probability', while insurers do not. There are high risk and low risk individuals, and this information is ex-ante private, although insurers do know the distribution of these risks across the population. Aside from differences in accident probabilities, there are no other differences across a population (see also Stiglitz 1975, Netzer and Schueur 2010). It is also assumed that high risk individuals will demand more insurance, and low risk individuals less. Individuals can only purchase one insurance contract, buyers of insurance are risk-averse, while insurers are risk-neutral. As in the Akerlof (1970) model, traders are von Neumann-Morgenstern utility maximisers. With no mitigating mechanism, this would place insurers in the unenviable state of offering 'pooling contracts'-insurance contracts with the same premium and excess for all customers-which under the Rothschild and Stiglitz (1976) assumptions is an impossibility if insurers are profit seeking (see also Rasmusen 2006).

This impossibility is derived from the scenario in which the single 'pool' price is too high for low-risk individuals, owing to their high-risk counterparts exacting an externality on the former through adverse selection (cf. Newhouse 1996, Allard, Cresta and Rochet, 1997). Such a market will 'collapse' in cases where the proportion of high risk individuals crosses a maximum level (Riley 2001). However, Rothschild and Stiglitz $(1976,643)$ demonstrate that insurers might derive private information from customers by offering a "menu of policies". They show that by offering multiple insurance contracts, one high cost (and high coverage) and the other low cost (and low coverage), a 'screening equilibrium' is reached. In short, this sees the 'menu' of insurance products as appealing to an individual based on their selfunderstood risk profile. A higher level of coverage is sold at a higher price, while according to the model's assumptions only the low coverage is attractive to low risk individuals (Riley 2001). To be sure, the assumption that even individuals are conscious of their own accident

\footnotetext{
${ }^{18}$ Weiss $(1995,134)$ uses the term 'sorting' as a catch-all categorisation of signaling and screening. In this usage sorting serves to "sort workers according to their unobserved abilities."
} 
probabilities has been weakened in subsequent literature (see for instance Doherty and Thistle 1996). ${ }^{19}$

Aside from the broad mechanisms of signalling and screening as outlined above, several other mechanisms have been suggested as mitigating problems of information asymmetry. These include; exposing an insured individual to behavioural observations (Shavell 1979); repeated dealings between counterparties to exchange (Rubinstein and Yaari 1983); 'joint long-term care' insurance contracts which cover multiple members of the same family (Zweifel 2020); social connections which have the effect of reducing the preponderance for opportunism and other contractual malfeasance (Jackson and Schneider 2011, Gil and Hartmann 2011); buyout agreements (Demski and Sappington 1991); as well as the use of futures contracts to constrain moral hazard in a team environment (Song 2012).

In addition, and as described by Stiglitz $(2002,29)$, "the analysis of information asymmetries has shed new light on the relationship between those governing and those governed". As discussed above, several solutions are available which might act to reduce information asymmetries between two parties. These solutions might be considered as instances of entrepreneurial discovery in the market. However entrepreneurial activities should not be assumed to be limited to the economic sphere (see for instance Libecap 1978). It should also not be assumed that these activities will be entirely devoted to 'productive' activities (Baumol 1996 see also Sened 1997, Barzel 2002, 2003, North, Wallis, and Weingast 2009, Acemoglu and Robinson 2012). That is, considering the models of markets with information asymmetry as described above, the assumption of homogeneity of endowments, tastes and subjective preferences amongst individuals is as difficult to justify in the economic sphere (see for instance Telser and Higinbothom 1977, Demsetz 1988, Williamson 1985) as it is in the political (Wintrobe 2009, Acchiardo 2013, 2019). State actors are subject to the effects of private information. Owing to this they might subsequently seek to gain 'legibility' (Scott 1998 see also Torpey 2000) over their citizenry via various institutional means.

There is some literature on how rulers discover private information held by their citizenry, thereby mitigating the political problems of information asymmetry. For instance, legislatures are a democratic fig-leaf used by dictators as part of the 'logic of political survival' (de Mesquita et al. 2003). Dictators use institutions like legislatures to measure "conditions in his country and the effectiveness of particular policies" (Acchiardo 2013, 31 see also Congleton 2001, Boix and Svolik 2013). Similarly, non-democratic rulers can also use 'business and professional associations', protests (Acchiardo 2013, 2019), a free media (Egorov, Guriev and Sonin 2009), and even elections (see Abdukadirov 2010) to derive private information from their populace. In Chapter 6, I demonstrate the use of identity technologies by the state in the discovery of private information held by citizens.

This information asymmetry is not just limited to that between ruler and ruled. For instance, Boix and Svolink (2013) examine how institutions are used to reduce the effects of private

\footnotetext{
${ }^{19}$ The literature on screening includes that related to credit markets (see for instance Stiglitz and Weiss 1981, Bester 1985, Smith 1987, De Meza and Webb 1988, Manova, Mattesini 1990, Manove, Padilla and Pagano 2001, Levine and Hughes 2005, Bediou et al. 2013, Wang 2017, Crawford, Pavanini and Schivardi 2018, Hertzberg, Liberman and Paravisini 2018) and the labour market (see for instance Guasch and Weiss 1980, Gibbons and Katz 1991).
} 
information between a dictator and their 'selectorate' (de Mesquita et al. 2003, see also Svolik 2012). This should be considered in the context of the 'dictator's dilemma' (Wintrobe 1990, 1998). Take a dictator who might use repression and fear to control their ruling coalition or their general populace. This fear leads to a greater level of information asymmetry between the ruler and the ruled, as the latter are less likely to reveal their feelings to the former owing to a fear of reprisal. The subsequent increase in private information held by citizens and other members of a ruling coalition also leads to apprehension on behalf of the dictator as they are fearful of the existence and creation of plans for revolution, assassination and so forth (see also Friedrich and Brzezinski 1965). In Chapter 5, I demonstrate the use of heritable surnames-a form of identity technology - by the property owning elite to mitigate the threat of nationalisation by the English monarch after the Norman invasion.

Problems of information asymmetry in the market-adverse selection and moral hazardcan be similarly analogised to the public sphere. Keech, Munger and Simon (2012) recognise that markets as well as governments face problems of adverse selection and information. Adverse selection might be considered from a public choice perspective, where government is comprised of individuals pursuing their own disparate goals according to their own subjective preferences. For instance, government employees might engage in rent-seeking (see Tollison 2004), while employment in government departments might suffer from selfselection as they attract individuals "who share a deep desire to expand the size and scope of their agency's activities" (Keech, Munger and Simon 2012, 7). Similarly, individuals might selfselect into government work owing to their propensity for corruption (Rose-Ackerman 2004, Banerjee, Baul and Rosenblat 2015).

This problem of adverse selection might be further exacerbated by private information held by government employees. For instance, moral hazard might exist in this case as these public servants "have an incentive to use their private information to maximize their private reward rather than social return" (Courty and Marschke 1997, 386). Moral hazard similarly exists where rulers do not bear the full costs of their actions, leaving the ruled to bear some or all the costs of some action. For instance, Cox (2011) shows how rulers finance warfare through taxation and loans which are subsequently paid back in the event of victory. However, in the event of defeat, rulers default on these loans with little option for recourse by their creditors. In some circumstances rulers become so far removed from the consequences of their risk taking that they see only the positive consequences of victory, with the downside risk borne only by their citizenry, at least in Western Europe prior to the French Revolution. According to Hoffman (2012) this instance of political moral hazard created the institutional arrangements which led to the rise in the technological superiority of European weaponry and warfare, along with their conquest of vast overseas colonies.

Finally, and as alluded to earlier in this section, both formal and informal non-market institutions might be considered in the context of information asymmetry. As mentioned earlier, the transaction cost literature of Ronald Coase (1937), Oliver Williamson (1985), and Douglass North (1990) should not be considered as existing in isolation from the literature related to informational asymmetry (Moe 2005 see also North 1990). Mechanisms including signalling and screening provide for "collectively recognised...behavioural beliefs" (Meijerink 2011, 21) which counteract the effect of 'hidden information' and 'hidden action' (Cohen and Siegelman 2010). Other institutions can also be examined as being mitigative against 
information asymmetry and its attendant behavioural effects. For instance, social identitieskinship, ethnic groups, and so forth-provide a degree of certainty over human interaction (Ostrom 1986, North 1990). These institutions serve as transaction cost economising devices, providing behavioural prescriptions (Ostrom 1986) which limit the choice set of participants (Bates 2014, Crawford and Ostrom 1995). These institutions can also serve to provide sanctions if these behavioural prescriptions are breached (see, for instance Akerlof 1980, Bernheim 1994, Dellarocas 2006). These and other institutions are examined at length in section 2.2.5, while Chapter 3 provides an overview of transaction cost economics.

\subsubsection{Group membership and 'Identity Economics'}

The contributions of George Akerlof and Rachel Kranton have been described as significant, in that they are the first to explicitly model identity in a utility function (see, for instance Aguiar et al. 2010, Armey and Melese 2018, Davis 2007, 2010, Teschl and Derobert 2008). As developed in sections 2.2.3 and 2.2.5, I suggest that any such claims are overstated, in that they ignore many earlier contributions. The literature on asymmetric information should be considered a being pre-emptive, as this literature examines the uncertainty inherent in dealings with heterogeneous agents and commodities. Other early contributions include Becker (1957), Arrow (1972b, 1973), McCall (1972) and Spence (1973), and their work on the economics of discrimination. A similar point on the economics of discrimination is made by Davis (2010), although he does not cite these earlier contributions. In addition, Landa (1981), Carr and Landa (1983), and Cooter and Landa (1984) preceded Akerlof and Kranton with their work on identity, and how it relates to institutions and trust. This point is made by Gordon Tullock in his commentary on Trust, Ethnicity and Identity: Beyond the New Institutional Economics of Ethnic Trading Networks, Contract Law, and Gift-Exchange (Landa 1994 [dust jacket]).

According to Akerlof and Kranton (2000), their inclusion of identity-a person's sense of selfinto standard utility theory provides a more complete explanation for the choices made by individuals than that which can be determined only by their tastes for goods and services. In their words, "Identity can account for many phenomena that current economics cannot well explain" (Akerlof and Kranton 2000, 715). Here, 'current economics' refers to the "standard model of utility maximisation" (Akerlof and Kranton 2000, 727)-later described as a "classic economic model" (Akerlof and Kranton 2002, 1167), or a "standard neoclassical view" (Akerlof and Kranton 2005, 12).

Beginning with Economics and Identity (2000), the motivation Akerlof and Kranton give in providing an alternative to 'current economics', is that the resulting analysis using such models fails to explain behaviour which appears nonsensical based solely on pecuniary factors. For instance, what motivates an individual to engage in drug and gang activity, or become pregnant at an early age (Akerlof and Kranton 2000, 737)? What motivates a student to 'act out' in a school context (Akerlof and Kranton 2002)? What explains the commitment individuals have towards the military, even though the monetary rewards for service can be significantly lower than those in the civilian workforce (Akerlof and Kranton 2005)? According to Akerlof and Kranton these questions cannot be sufficiently addressed by standard utility theory. With a standard utility function, they explain, the utility derived from undertaking an activity is dependent purely on taste. Utility is greater when the activity undertaken matches 
an individual's preferences. However according to the identity economics literature, much observed decision making cannot be explained by standard utility theory.

Akerlof and Kranton contend that in addition to the satisfaction gained by an action, or the avoidance of an action, one's identity-their sense of self-should be incorporated into an expanded utility function to better account for decisions made. This expanded function consists of both an individual's preferences, along with prescriptive behaviours which are dependent on the social categorisation that individual occupies (Akerlof and Kranton 2000, 2002, 2005, 2010). It is this "idea of 'identifying with' others" that gives the perception of identity, in this sub-field of economics, its social properties (Davis 2007, 350). (That the same behaviour can be both 'good' or 'bad', depending on the context of the group, is incorporated into the hostage model of identity in Chapter 4.) In general, this social categorisation component of the expanded utility function depends on; 1 ) the association of an individual with a social category, for instance defined by gender, race, religion and so forth; 2 ) the behavioural prescriptions associated with that category; and 3) the payoff associated with conforming to those prescriptions. ${ }^{20}$ As I have already raised in Section 1.4 of this thesis, I suggest that this limited conception of identity-a single characteristic-is insufficient. According to my definition of identity, individuals are made up of more than just membership in social categorisations.

To illustrate their 'sense of self', Akerlof and Kranton (2000) introduce a scenario where two social categories exist, 'green' and 'red'. Individuals who identity as 'green' or 'red' are designated 'behavioural prescriptions' of the activity they should undertake according to their social categorisation. 'Green' ('red') individuals should choose activity one (two). If they choose the wrong activity, they suffer a loss of utility. Likewise, if a 'green' ('red') individual undertakes activity two (one), other 'green' ('red') individuals similarly suffer a loss of utility. This illustrates the existence of externalities (Akerlof and Kranton 2010). While identity can affect one's utility as derived from some action, the costs or benefits of that action are also socialised. Actions taken by a member of some social category, and its consonance or dissonance with whichever norms are characteristic, can also impact on the utility of the members of the wider group (Charness, Rigotti, and Rustichini 2007, Fine 2008, Gely 2007). A more concrete example is the loss of identity felt by other men when a man is seen wearing a dress; as a dress is "a symbol of femininity ... this may threaten the identity of other men" (Akerlof and Kranton 2000, 717).

Akerlof and Kranton (2002) also emphasise the importance of identity, one's sense of self as derived from group membership, in aligning individual incentives with organisational goals (see, also Akerlof and Kranton 2005). According to this extension of their theory into education policy, effective schooling occurs when the norms associated with a school are correlated with good learning practices. If the school community of students, parents and teachers identify with that institution and its behavioural norms, learning occurs. The (expanded) utility of a student therefore depends on a pecuniary incentive, along with identity derived gains or losses. The pecuniary benefit is a "function of income and effort",

\footnotetext{
${ }^{20}$ The utility function is $U_{j}=U_{j}\left(\boldsymbol{a}_{j}, \boldsymbol{a}_{-j}, l_{j}\right)$. Utility therefore depends on the actions of the individual, $\mathbf{a}_{\mathrm{j}}$ and others, $a_{-j}$, along with the sense of self of the individual, $I_{j} . l_{j}$ in turn depends on the payoffs associated with conforming to the behavioural prescriptions associated with the individual's social categorisation.
} 
including leisure time and employment income foregone while engaged in education (Akerlof and Kranton 2002, 1172). The identity derived benefit is a function of the behavioural prescriptions of the group that student associates with. For instance, the behavioural prescriptions of a 'burnout' are to avoid doing schoolwork, even as the economic returns associated with study might be high. This explains the lack of effort associated with 'burnouts'; the gain in pecuniary benefits associated with increased effort at school is offset by the anxiety associated with the loss in identity (see, also Akerlof and Kranton 2010).

Furthermore, while categorisation into social categories determines the norms an individual should abide by, the social categories one associates with are themselves not immutable (Naseer and Heine 2017). Akerlof and Kranton (2005) describe how hierarchical institutions, particularly the military, can impose management policies designed to create group identification to achieve overall organisational goals. 'Breaking them down' and building them up, through exercise and rituals, stamps this new identity onto new recruits in the armed forces. These rituals include the "short haircuts, boot camp ... [and] uniforms" of military recruitment and training (Akerlof and Kranton 2005, 17). This case is used to describe how identity economics explains the relatively low monetary compensation associated with the military (see, also Goette, Huffman, and Meier 2006). Identity with a wider group, like the military, acts as a substitute for pecuniary incentives. More broadly in an organisational context, membership in a group can be useful for the monitoring of free-riding (Olson 1965), and the deterrence of such behaviours (Eckel and Grossman 2005). In this respect, the utility function of an individual, taste held constant, is derived from their actions abiding by the norms determined by the individual's social categorisation. Acting in accordance with the norms of one's social categorisation increases one's utility, while acting out of step with those norms reduces it. ${ }^{21}$

\subsubsection{Group membership and 'The Economics of Discrimination'}

The paper on 'identity economics' by George Akerlof and Rachel Kranton (2000) has been credited by some with first explicitly incorporating the concept of identity into utility theory, and therefore formal economic modelling (see, for instance Teschl and Derobert 2008). Yet this was not the first-time identity as a concept was used in the economics literature. In The Economics of Discrimination, Gary Becker (1957) sets out the first systematic and economic examination of discrimination in the marketplace. ${ }^{22}$ And while Becker does not use the

\footnotetext{
${ }^{21}$ The concept of identity in economics, as examined first by Akerlof and Kranton, has been further expanded by other economists to offer explanations of an individual's behaviour being reflective of the interests of their perceived social categorisations (Davis 2014). Using this idea of group membership-social identity-as playing a role in making economic decisions, explanations as to the existence of externalities have been offered, such as altruism towards one's own racial group, and antagonism towards those outside that group (Darity, Mason, and Stewart 2006). Identity economics, and its associated utility function has been used for modelling and analysis in areas including; racial norms and investment behaviour (Benjamin, Choi, and Strickland 2010); public sector activity (Armey and Melese 2018, Naseer and Heine 2017); income distribution (Arestis, Charles, and Fontana 2014, Shayo 2009); norms and their enforcement in the military (Goette, Huffman, and Meier 2006); political agency (Mueller 2016); as well as female genital mutilation (Coyne and Coyne 2014). Davis (2007) and Fine (2008) provide complementary critiques to the general approach of 'identity economics'.

${ }^{22}$ Interestingly, and according to the introduction to the second edition (Becker 1971, 1), the publication of the first volume "met with strong opposition" as it was published in the book series 'Economic Research Studies'. Again from the introduction, Becker recounts how "readers asserted that economics is not relevant in analyzing
} 
terminology of identity, or 'social identity', he does address these concepts implicitly. The Economics of Discrimination develops a utility function including a 'taste for discrimination'. This causes an individual to "act as if he were willing to pay something, either directly or in the form of a reduced income, to be associated with some persons instead of others" (Becker 1957, 14 emphasis in original). This model of taste-based discrimination was used to explain why different groups have been traditionally discriminated against, including women and minority ethnic groups. Crucially, economic outcomes differ for groups who share some social identity, whether defined by race, gender, ethnicity, or some other collective characteristic. It is important to highlight that Becker (1957) explicitly cites the sociological concept of 'social distance' as stimulus for this work. Social distance in general refers to the propensity for different groups to interact, as well as their comfort in doing so (see Bogardus 1933, Park 1924, Akerlof 1997, Wark and Galliher 2007).

According to this theory, those who discriminate against minority groups based on 'social identity', or group membership, are willing to pay a premium, or accept lower income, to avoid commercial exchange with those who are from some socially defined group (Becker 1957, see, also Akerlof and Kranton 2010, Guryan and Charles 2013). In the form that the model was originally developed, discrimination can be derived from both 'prejudice' and 'ignorance'. Prejudice refers to a preference for, or against, a particular group (see, for instance Lang and Lehmann 2012), while ignorance involves a lack of awareness "of their true efficiency. His behaviour is discriminatory not be because he is prejudiced against them but because he is ignorant" (Becker 1957, 16). Becker himself advanced this model of taste-based discrimination to study gender based discrimination, workplace discrimination, as well as broader instances of discrimination against ethnic minorities (Becker 1957, 1996). ${ }^{23}$

In contrast to the-animus derived-taste-based discrimination as originally proposed by Becker (1957), other scholars have looked at discrimination against certain groups due to information problems and costs. ${ }^{24} \mathrm{~A}$ model of 'statistical discrimination' was developed

racial discrimination against minorities" $(1971,1)$. At the same time, reviews in major economics journals were few, while it did receive several favorable reviews in sociology and other social science journals. This is indicative of two (related) matters. First, the publication of the first edition (1957) was groundbreaking in that it explicitly studied non-pecuniary incentives within the economics literature. Second, it similarly highlights the significant overlap, and inspiration, which economists studying identity have derived from sociologists, anthropologists and other non-economists.

${ }^{23}$ This model has further been adapted and used to examine; prejudicial discrimination against 'minority' groups in credit markets (Berkovec et al. 1994, Canner, Gabriel, and Woolley 1991, Peterson 1981, Ross 2000); the housing market (Courant 1978, Cronin 1982, Dymski 2006, Lee and Warren 1976, Masson 1973); the labour market (Black 1995a, Bowlus and Eckstein 2002, Bryson and Chevalier 2015, Charles and Guryan 2008, Coate and Loury 1993a, Flabbi 2010, Kahn 1991); consumer discrimination against minority sellers (Borjas and Bronars 1989); as well as in the market for coconuts (Akerlof 1985). This model has been adapted and advanced in the intervening years since Becker (1957). This is discussed by Altonji and Blank (1999), Flinn (2015) Lang and Lehmann (2012), Persico (2009) as well as Darity and Mason (1998). McAdams (1995) provides a detailed critique of Becker's model.

${ }^{24}$ As mentioned earlier, Becker $(1957,16)$ does in fact incorporate 'ignorance' into his model of discrimination, where ignorance results in discriminatory behavior not because "he is prejudiced against them but because he is ignorant". If 'ignorance' is taken to be synonymous with imperfect information about a counterparty to exchange, then much of the later literature which starkly delineates between taste-based, and statistical, discrimination seems to have overlooked these earlier contributions by Becker. Indeed, most subsequent 
independently (see Phelps 1972b) by Kenneth Arrow (1972a, 1972b, 1973) and Edmund Phelps (1972a, 1972b). This alternative model was partly developed in critique of Becker's. Arrow (1972b) criticised the taste-based model, in that it predicted competitive pressure, in labour and other markets, that would reduce the propensity for prejudicial behaviours. Similarly, criticism for the taste-based model originated from the implicit assumption that preferences should be taken as given; this point was conceded by Becker himself who, along with George Stigler, surveyed several "phenomena widely believed to be inconsistent with the stability of tastes" (Stigler and Becker 1977, 89). Aside from the more widely acknowledged work of Arrow and Phelps, around the same time George Akerlof $(1970,494)$ discussed 'race' as serving as a proxy for 'job capability', Michael Spence $(1973,1974)$ discussed 'information based discrimination', while John McCall (1972) looked at uncertainty of employee ability as a source of discrimination.

In general, the statistical model of discrimination sees certain markets as operating imperfectly, due to a lack of available information, along with a cost to collect information. For instance, the labour market might operate imperfectly "due to scarcity of information about the characteristics of workers and jobs" (Phelps 1972b, 659). The existence of this private information should be considered in light of the literature on information asymmetry examined earlier in this chapter. This model of statistical discrimination supposes that individuals who discriminate against groups based on some shared characteristic do not do so out of distaste, or animus, towards those groups. Rather, they discriminate because they are using that gender, ethnic or religious categorisation-a social identity-as a proxy for some unobservable characteristic (Arrow 1998, see also Akerlof 1976). According to an example given by Arrow (1998, 659), a profit maximising employer "will discriminate against blacks or women if he believes them to be less qualified, reliable, long-term etc. on the average than whites and men". Where the costs of gathering relevant information about a job applicant are significant, social identity acts as a proxy for certain characteristics which influence the hiring decision. ${ }^{25} 26$

literature on the economics of discrimination classify Becker's model as being one of purely prejudice, or animus, while statistical discrimination is derived from imperfect information (see, for instance Akerlof and Kranton 2010, Guryan and Charles 2013).

${ }^{25}$ The statistical model of discrimination has been adapted and used to examine information derived discriminatory behaviours, most commonly in the labour market (Aigner and Cain 1977, Albanesi and Olivetti 2009, Altonji and Pierret 2001, Autor and Scarborough 2008, Coate and Loury 1993b, Cornell and Welch 1996, Gayle and Golan 2012, Fryer Jr 2007, Lundberg and Startz 1983, Milgrom and Oster 1987, Moro 2003, Moro and Norman 2004, see, also Loury 2002), in addition to the legal system (Knowles, Persico, and Todd 2001, Ayres and Waldfogel 1993). Altonji and Blank (1999), Bertrand and Mullainathan (2004), along with Milgrom and Oster (1987) each provide an overview of this model, and subsequent methodological advances in the statistical discrimination literature.

\footnotetext{
${ }^{26}$ Considering these competing models, some more recent studies have incorporated both taste-based, and statistical, models, to distinguish between sources of discrimination. These include in; the labour market (Bertrand and Mullainathan 2004, Baert and De Pauw 2014, Kaas and Manger 2012, Lang and Lehmann 2012, Neumark, Bank, and Van Nort 1996); the housing market (Dymski 2006); the credit market (Dymski 1995, 2006, Han 2004, Ferguson and Peters 1997, Martin and Hill 2000); the collectibles market (List 2004); car markets (Ayres 1995, Ayres and Siegelman 1995, Zussman 2013); online marketplaces (Doleac and Stein 2013); in gameshows (Levitt 2004); and in wider consumer markets (Yinger 1998). Finally, and while not explicitly
} 
The taste-based, and statistical, models have become the two most accepted economic formulations of discrimination (Akerlof and Kranton 2010, Guryan and Charles 2013). In general, they seek to advance an understanding of the sources of discrimination against individuals, based on their membership in a group. This term can be considered as synonymous with an individual's social identity. Again, the notion that the identity of an individual is made up of a single characteristic is what my new definition of identity seeks to overcome (Section 1.4). It is important also to note that in this literature the process of categorising individuals into a social identity is often external to the individual being categorised. For instance, while examining racial discrimination in the labour market, Bertrand and Mullainathan (2004) manipulated perceived social identities on resumes distributed to employers. This was done by listing either "African-American-or-Whitesounding names" (Bertrand and Mullainathan 2004, 991). This had the effect of the potential employer categorising individuals into an ethnic group without having any direct contact with those fictitious job applicants. Those with names like 'Lakisha Washington' and 'Jamal Jones' were assumed by employers as being African-American, while those with names like 'Emily Walsh' and 'Greg Baker' were assumed to be White. These assumptions may or may not have had some relation to the actual ethnicities of those (fictitious) applicants. It should also be noted that classifications of individuals into groups is, in the case of race, often defined broadly as simply 'black', 'Hispanic', or 'white' (see, for instance Ayres and Siegelman 1995, Guryan and Charles 2013, Yinger 1998). In instances when social identities are selfcategorisations (prescribed by), individuals might be asked to choose from a list of ethnicities that "best describes your race" (Johnson Jr, Bienenstock, and Stoloff 1995, 14). In this just given example, the choices given to participants were 'White', 'Black/African American', 'Asian American', 'American Indian', and 'Other'.

Indeed, any categorisation into a racial social identity, especially if externally assigned, will involve some level of arbitrariness. As Yinger $(1998,24)$ describes it, "human history involves so much migration and blending of people with different birthplaces that genetic distinction across groups of people disappear over time". It is thought that 90 per cent of Americans who have African ancestry also have European ancestry, while 25 per cent of those Americans who appear to be Caucasian, have African or Native American ancestry (Simpson and Yinger 1985). This raises obvious issues of subjectivity in categorising individuals into social identities as defined by race, gender, religion and so forth, as well as legal categorisations of indigeneity (Chesterman and Galligan 1997) and 'national' identities (Anderson 2006). Accordingly, instances of discrimination based on animus (Becker 1957), or imperfect information (Arrow 1972b, Phelps 1972b), will at least in part be based on a subjective judgement as to an individual's racial, gender or religious social identity.

acknowledging the taste based or statistical discrimination literature, Hupkau and Maniquet $(2018,14)$ relate the efficiency of welfare provision to both the preferences of service providers, and the ability for recipients to signal their "pre-dispositions, motivations or character traits". In this model, costs are incurred, which consist of frictions that prevent otherwise eligible recipients from receiving welfare, due to the tastes of service providers for 'types' of recipients, as well as the information costs associated with determining an individual's true 'type'. Charles and Guryan (2011) and Guryan and Charles (2013) provide a methodological critique of some of these efforts to distinguish between sources of discrimination. 


\subsubsection{Philosophy, politics and economics (PPE)}

Identity has been further studied as part of the broader, and inter-related, cross disciplinary area of philosophy, politics and economics (PPE) for the past four decades or so (Qizilbash 2009). In this field, Amartya Sen was one of the earliest responsible for introducing identity as an explanatory variable in understanding human action. A large and growing body of work from Sen has emphasised the role of 'social identity', in that membership in a group motivates human behaviour (see, for instance Sen 1977, 1985, 2002, 2005). These social identities are not necessarily singular to the individual to which they apply. As Sen (2008) describes it, individuals occupy membership in many groups concurrently. The same individual might be "a Norwegian citizen, of Asian origin, with Bangladeshi ancestry, a Muslim, a socialist", along with a myriad of other social identities (Sen 2008, 6). Crucially, and in contrast to social identity as used in the economics of discrimination literature previously discussed, membership in a group is often assigned by self-categorisation (prescribed by). In this way, the social identities of an individual are at least partly reliant on how "the person sees himself or herself" (Sen 1985, 348, see, also Teschl and Derobert 2008).

Due to the number of contributions which Amartya Sen has made to the literature on identity, it is worth highlighting some of the different ways in which he examines the concept. Appiah (2009) and Qizilbash $(2009,2014)$ provide useful overviews of Sen's work. Beginning with Rational Fools (1977), Sen set out to use the concepts of 'strategy' and 'commitment' to provide an alternative to mainstream models of self-interested behaviour. Here 'strategy' refers to the "concern for others [which] directly affects one's own welfare" (Sen 1977, 326), while 'commitment' refers to taking some action, "breaking the tight link between individual welfare...and the choice of action ... to help remove misery even though one personally does not suffer from it" (Sen 1997, 7-8). Sen (1977) gives the example of becoming aware of the torture of another. Sympathy will result in being uncomfortable in the knowledge of the suffering of the other individual. In contrast commitment relates to being prepared to do something about it. It is from this conceptualisation of commitment behaviours that Sen develops ideas of social identity, or identifying with others, in contrast to what he terms individualistic self-maximising actions (Sen 1977, 1985, 2005, see, also Davis 2006, Qizilbash 2009, cf. Hausman 2005, Pettit 2005).

In more recent works, Sen also distinguishes between what he terms the 'reductionist' concept of a singular (social) identity (Sen 2006, 2008), with the choices individuals make in their dynamic social affiliations. In the former lies the danger of the division of "humankind along a single axis...groups as friends of foes" (Parekh 2009, 276). These singular social identities can, according to Sen $(2006,2008)$, be encouraged and exploited to create violence and divisions; strictly delineated and oppositional groupings are the catalyst of the 'clash of civilizations' (Huntington 1993, 1996), such as those between the Hindu and Islamic worlds, and between the Western and Islamic worlds. The latter conception of social identity is dynamic, in that individuals make context dependent choices, accounting for "the problem at hand...influenced by her own values as well as social pressures" (Sen 2008, 7). In distinguishing between these two conceptions of social identity, Sen argues that inter-group violence can be tempered by the emphasis on choice by the individual to self-identify in a manner that considers the "immense richness of the multiple identities that human beings have, given their diversity of affiliations, attachments and affinities" (Sen 2008, 6, cf. Appiah 
2008). This multiplicity of characteristics is more closely aligned with my new definition of identity, where individuals are defined as a vector of characteristics, rather than just membership in some social group (Section 1.4). Sen also adds a third conception of identity to his work. These are the social identities which are assigned by others (prescribed to). To illustrate, he cites Jean-Paul Sartre's Portrait of the Anti-Semite: "whom other men look upon as a Jew...it is the anti-Semite who makes the Jew" (as cited in Sen 2006, 7).

Much of Sen's work concerning identity-as derived from 'commitment' (see Sen 1977) - has focused on attributing certain behaviours to group membership, as well as disassociating rationality and self-interest (cf. Hausman 2005, Pettit 2005). This and related scholarship emphasises the motivations behind actions taken, which to an observer might seem to be detrimental to the individual in question, or at least irrational. (Irrational actions or choices should in this context be considered as those which do not correspond with an expectation of self-interest maximization (see, for instance Sen 2005, cf. Hindmoor and Taylor 2015)). In this way, social identity can have the effect of enlarging individual choice sets and goals. Social identity therefore makes "members of a community accept certain rules of conduct as part of obligatory behaviour toward others in the community" through their group membership (Sen 2002, 216). A secondary literature has grown out of Sen's work. In general, it incorporates the assumption that individuals make choices not purely out of self-interest, but as individuals who have affiliations with others via some social identity (see, for instance Glover 2008, Kirman and Teschl 2006, Davis 2006).

Following the work of Sen, contributors to PPE have addressed the seemingly paradoxical way in which individuals choose to make decisions when their impacts might be detrimental to themselves; these paradoxes have, in this literature, been explained by these so-called 'social identities' which are analogous to group membership. Sen (1985) examined the way in which the pursuit of 'individual' ends might be thwarted in some way. This might be by the competing ends striven for by others who share the same group identity. That is, membership in a group, however defined, affects an individual's perception of their own utility, goals, and perceived 'behavioural obligations' (see also, Sen 1984). Crucially, this scholarship argues that human action cannot simply be determined by the motivations of a self-interested actor; membership in a group itself provides additional and often competing motivations. ${ }^{27}$

The PPE, and wider economics literature cited in this section all have a broader commonality in how they address the concept of social-identity. In general, this literature will define the term as membership in a group, and an "individual's identification with others" (Davis 2006, 372). Stated another way, these social identities might be derived from the way a person is

\footnotetext{
${ }^{27}$ Other contributors have taken a similar approach, in that a social identity can provide motivations which appear to be detrimental to a self-interested agent. Folbre (1994) examines 'gender identity' and collective action as a way in which inequality in domestic duties might be exacerbated. Also examined in a similar fashion include; the relationship between schooling outcomes and group-specific behavioural expectations (AustenSmith and Fryer Jr 2005, Fryer Jr and Torelli 2010, cf. Wildhagen 2011); 'racial preferences' and labour market impacts (Akerlof 1997, Battu, Mwale, and Zenou 2007, Selod and Zenou 2013); and self-selection amongst racial groups and segregation in the housing market (Ihlanfeldt and Scafidi 2002, King and Mieszkowski 1973, Pascal 1970, cf. Charles 2000, Yinger 1978). Similarly, the dynamic between social identity and the existence and persistence of poverty and violence has been the subject of recent scholarship on development and economic growth (see, for instance Alesina et al. 2003, Barrett 2013b, Easterly and Levine 1997, Esteban and Ray 1994, Sen 2006, 2008).
} 
"perceived by others... [and] the specific social affiliations or identifications a person has - as a member of a family, cult, political party, or other group" (Qizilbash 2014, 14). Much of this literature is concerned with how an individual views himself, and their own self-categorisation into some group. This has been used to explain puzzling phenomena, including for instance; the way in which costs are incurred by ethnic minorities who 'act white' (Austen-Smith and Fryer Jr 2005, Fryer Jr and Torelli 2010, cf. Wildhagen 2011); or the self-selection of minorities into segregated neighbourhoods (Ihlanfeldt and Scafidi 2002). This is in contrast with the economics of discrimination literature, which sees the categorisations of others as being an explanatory variable of discriminatory behaviour. This of course does not mean there is no conceptual overlap. It is difficult to argue that the violence which Sen $(2008,7)$ attributes to the "reductionist cultivation of singular identities" is too far removed from the prejudicial discrimination of Becker (1957). Violence, when limited to a defined social group, is surely a form of discrimination, albeit on a different scale compared to that in the labour, housing and credit markets cited earlier (see, for instance Bryson and Chevalier 2015, Dymski 2006, Ross 2000).

Up until this point in this chapter, I have reviewed the way 'social identity' has been addressed in the economics literature. As should have become clear in the previous sections, much identity work in economics characterises individuals as "embodiments of group prototypes rather than as independent individuals" (Davis 2007, 354, see, also Aguiar et al 2010). Yet as Aguiar et al. $(2010,264)$ states, "social identity is only a portion of the identity of a person; that portion the person shares with others". Indeed, such generalisations likely obscure the motivations which influence individual choices and behaviour (Aguiar and de Francisco 2009). It should be stated that, in comparison to the extensive work on social identity in the economics literature, that relating to personal identity is limited (Davis 2003). This is a limitation of the literature I hope to overcome with my contribution of a new economic definition of identity (Section 1.4).

One notable exception to this is Davis $(2003,2010)$, who presents 'identity criteria', upon which the existence of an individual should rest. These are 'individuation', and 'reidentification', respectively. As described by Davis $(2010,5)$, individuation is originally an Aristotelian one that refers to the requirement for individuals-if they are indeed 'individual' - to "be represented as distinct and independent beings". Reidentification requires that this 'distinctness' be maintained across time and change. Thus, an individual, if they are in fact truly an individual, does not "dissolve or disappear into the mass of people or society generally but can be reidentified as enduringly distinct individuals" (Davis 2010, 10). In general, these 'identity criteria' reflect the need to pick an individual from many, and pick that same individual at some point in the future.

\subsubsection{The economics of institutions}

Social identities, such as kinship, ethnic or other categorisations, have been examined as informal institutions which exist and persist for the purposes of transaction cost economising. ${ }^{28}$ Broadly speaking, these social identities act as institutions in that they afford

${ }^{28}$ Chapter 3 provides an overview of transaction cost economics (Commons 1932, Coase 1937, Williamson 1985), as well as the role of identity in exchange from a transaction cost perspective. In brief, transaction costs 
interacting agents "rules of the game" (North 1990, 3) which shape and provide some degree of certainty over human interaction. This includes behavioural prescriptions commonly used by a "set of participants" (Ostrom 1986, 5) that limits the choice sets of those individuals who share some group membership (see, also Bates 2014, Crawford and Ostrom 1995). Group membership, perhaps defined by a racial or ethnic social identity, delineates the rules of the game unique to that group. These rules might consist of behavioural constraints and prescriptions (Ostrom 1986), as well as applicable sanctions in the event of a breach. Sanctions could include, for example, a loss of reputation or status amongst group members (see, for instance Akerlof 1980, Bernheim 1994, Dellarocas 2006). In general, owing to both ex-ante and ex-post transaction costs (Arrow 1969, Coase 1937, Williamson 1985), along with the resultant contract uncertainty and high cost of private information, these institutions which are characterised by group membership exist to economise on such costs (Landa 2016b, see, also Carr and Landa 1983, Posner 1980).

Such institutions can also be viewed from a game theoretic perspective. Individuals who are members of ethnic, religious, or other groups are often observed to undertake cooperative, rather than defective behaviour. Cooperation becomes the dominant strategy as it is "individually rational" (Posner 1996, 140). This cooperative behaviour is likely to be sustained even if any single individual from that group trades infrequently, so long as the other members of the group interact with sufficient frequency to transmit information and apply sanctions (Ali and Miller 2016, Jackson, Rodriguez-Barraquer, and Tan 2012, Kandori 1992, Tirole 1996). Membership in the groups examined throughout this literature might be defined by ethnic or racial identity, and where membership might be further restricted by "dietary restrictions, and religious rituals", and so forth (Cooter and Landa 1984, 21).

To illustrate, Jack Carr and Janet Landa $(1983,136)$ take issue with mainstream theories of impersonal exchange, and examine the economic functions of institutions including "kinship and ethnic groups, clan names, symbols of group identity, and religious practices". Using the economic theory of clubs (see, Buchanan 1965), they demonstrate the role such institutions play in reducing transaction costs, including by restraining the opportunistic behaviour of individuals who have some shared identity. Membership in kinship groups, in this case designated by clan names, are used to restrict membership in a sort of 'mutual aid society'. Similarly, the use of these names to designate a social identity-where these names serve as a type of "information transmission device" (Kandori 1992, 65)-aids in the detection of freeriding by members (Olson 1965), and the facilitation of sanctions for any violations of group norms (Carr and Landa 1983, see, also Posner 1996, Eckel and Grossman 2005).

Richard Posner $(1980,23)$ takes a similar approach, examining kinship groups-another manifestation of group membership and therefore social identity-as "primitive adaptations

are the 'frictions' associated with economic exchange (Williamson 1985), and represent the "costs of running the economic system" (Arrow 1969, 501). They can be broken down into ex-ante variants, including those related to search and negotiation, as well as ex-post variants, such as those associated with the costs of monitoring a contractual arrangement and its associated governance structure (Williamson 1985). These costs are themselves derived from two behavioural assumptions which typify transaction cost economics; bounded rationality and opportunism. Bounded rationality refers to the limited cognitive capacity of humans (Simon 1957, 1961, Williamson 1975), while opportunism relates to the propensity for individuals to act out of selfinterest, for instance through the selective revelation, or manipulation of, information (Williamson 1975, 1985). 
to high information costs", for the provision of insurance against misfortune amongst group members (see, also Ben-Porath 1980, Fafchamps 2003, Kinnan and Townsend 2012). Likewise, Bowles and Gintis (2000) deem the enforcement of certain behaviours which are beneficial to other members of a group as 'parochial'. That is, ethnic, religious, or other, groups who artificially restrict their membership, can benefit through the "enforcement of prosocial behaviour among network members", even while economies of scale are limited by these institutions (Bowles and Gintis 2000, 22). ${ }^{29}$

Another (related) indirect treatment of identity can be seen in the literature on reputation (see, Klein 1997b, Origgi 2017). The role of reputation has been examined as a mechanism by which dishonest, or opportunistic (Williamson 1985), behaviour can be tempered; that is, reputation acts "as an effective means of enforcing cooperation" (Bolton, Katok, and Ockenfels 2005, 1458). A favourable reputation acts as a promoter of exchange, if information about the past behaviour of the economic agent in question is easily distributed amongst other economic agents (Benson 1989, Greif 1989, Milgrom, North, and Weingast 1990). ${ }^{30}$ Reputation can be immediately seen as an aspect of the 'individual' identity of an economic agent. In Chapter 4, I contribute a new hostage model of identity, where economic agents contribute identity hostages as a type of credible commitment. I suggest that these identity hostages might consist of an individual's reputation. Later in this section, I discuss how group or 'collective' reputations can also be derived from firms who operate in regional areas, for instance (see, Winfree and McCluskey 2005).

It should be noted that the concept of reputation is closely linked to indirect reciprocity as described in evolutionary biology (Alexander 1987 see, also Engelmann and Fischbacher 2009, Nowak and Sigmund 2005, Origgi 2017). Indirect reciprocity helps to explain cooperation as "friendly or hostile acts of one person towards another are rewarded or punished by a third party", if information about those acts is disseminated throughout the relevant population (Engelmann and Fischbacher 2009, 399). This is in contrast with direct reciprocity (Trivers 1971), which sees rewards or punishments for behaviour delivered by one directly involved with that act. Thus, direct and indirect instances of reciprocity are characterised by the principles of: "You scratch my back, and I'll scratch yours" and; "You scratch my back and l'll scratch someone else's" or "I scratch your back and someone else will scratch mine", respectively (Nowak and Sigmund 2005, 1291, see, also Binmore 1994). In this respect, traditional marketplaces where physical interactions are characteristic rely more on direct

\footnotetext{
${ }^{29}$ Such institutions studied as part of this broader literature include; that of the 'ethnically homogenous middleman group' (EHMG) (Landa 1981, see, also Landa 2016a, Choi, Lee, and Oh 1995); Jewish merchants in the $11^{\text {th }}$ century Muslim world (Greif 1989, 1994, 2012, cf. Edwards and Ogilvie 2012a); family and kinship networks (Ben-Porath 1980, Carr and Landa 1983, Landa and Salaff 2016, Posner 1980, see, also Merry 1997); 'old boy networks' (Saloner 1985, Taylor 2000); religious groups (Berman 2000, Bowles and Gintis 2000, Ensminger 1997, lannaccone 1992, 1998, Platteau 1994, Sosis 2005); as well as the nation state (Pagano 1995).

30 The concept of reputation is closely linked to that of 'trust' (Dasgupta 2000, Williamson 1993), where the former refers to a belief held by others that a particular economic agent "to be something", while the latter is the expectation that an economic agent has the propensity "to do something" (Cabral 2005, 3 emphasis in original). In this respect, Davidson, Novak, and Potts (2018) provide a good overview of the economic literature on trust. The literature on trust and reputation have the tendency to be conflated (Cabral 2005), although the distinction is simple in that one follows the other; trust follows reputation (Bolton, Katok, and Ockenfels 2005).
} 
reciprocity, while online marketplaces such as eBay rely more on indirect reciprocity, in part due to the feedback made publicly available on sellers' sites (see, for instance Bolton, Katok, and Ockenfels 2004, Brynjolfsson and Smith 2000). This is derived from the higher availability and dissemination of information in online, as compared to physical, marketplaces.

Reputation is similarly 'indirect', in that it does not (solely) rely on direct instances of exchange among economic actors to disseminate information. Rather, "reputations embody and communicate collectively gathered information and collectively shared evaluations" (Origgi 2017, 39), and where the absence of such information would likely restrict the interactions of economic agents (see, for instance Akerlof and Kranton 2000, Arrow 1972c, Ben-Porath 1980). The dissemination of this information from which a reputation is derived, has been studied by scholars who look at the way in which the conduct of economic agents is made known to a wider population. How information about past behaviour is distributed is significant; completely unobserved behaviour sees no incentive for behaviour apart from that which is self-serving (Tirole 1996). Mechanisms might include gossip or online reviews. ${ }^{31}$ Of course, the information produced by these mechanisms have varying degrees of 'noisiness', owing to unavoidably incomplete information about previous trades, as well as the strategic motivations of economic agents (Bolton, Katok, and Ockenfels 2005).

To illustrate the role which reputation plays in exchange, first consider the counterfactual in a model of 'perfect decentralisation' (Demsetz 1988). In such a model, economic agents and the goods and services they trade are perfectly homogenous, with economic decisions being made purely based on prices, tastes and technologies (Telser and Higinbotham 1977, see, also Salop and Salop 1976, Williamson 1985). However, owing to the propensity for economic agents to act out of self-interest, as well as the presence of information asymmetry (Akerlof 1970), reputation mechanisms are necessary for the proliferation of trade (Dellarocas 2006). The presence of information asymmetries along with opportunistic actors, results in the necessity for reputation and other identity 'technologies' to facilitate exchange, particularly when trade and settlement are not simultaneous. This point is examined in Chapter 3.

Reputation can be thought of as a way in which economic agents "identify their trading partners" (Dulleck, Kerschbamer, and Sutter 2011, 2). In general, reputation plays a role in models of exchange where there is asymmetric information (Akerlof 1970), while 'reputation mechanisms' play a role in transmitting information about previous instances of trade, including "in circumstances where interactions take place among essentially strangers" (Bolton, Katok, and Ockenfels 2005, 1457). By linking past behaviour, to expected ex-post behaviour, reputation plays a role in differentiating (potential) counterparties to exchange (Cabral 2005, Rogerson 1983, Shapiro 1983b). In general, this means that economic agents are perceived to have a 'type'. For instance, an economic agent, who is perceived by others to in general match their ex-post actions to their ex-ante promises, will be deemed to have a

\footnotetext{
${ }^{31}$ A more exhaustive list might include gossip (Burt and Knez 1996, Ellickson 1985, Merry 1997, Rooks, Tazelaar, and Snijders 2010, Solove 2007, Waddington 2016); credit bureaus (Klein 1992, Brown, Jappelli, and Pagano 2009, Djankov, McLiesh, and Shleifer 2007, Jappelli and Pagano 2000, 2002, Padilla and Pagano 2000, see, also Klein 1997c); accounting and financial reporting (Fombrun and Shanley 1990, Roberts and Dowling 2002, McGuire, Schneeweis, and Branch 1990); brand names (Cabral 2000, Erdem and Swait 1998, Klein and Leffler 1981, Sellers-Rubio, Mas-Ruiz, and Sancho-Esper 2018, see, also Choi, Lee, and Oh 1995); online reviews (Anderson and Magruder 2012, Luca and Zervas 2016); and advertising (Hoch and Ha 1986, Nelson 1974).
} 
'good' reputation. In contrast, those who deviate markedly will have a 'bad' reputation. Of course, previous instances of behaviour might be difficult to judge, including when the quality of a good or service consumed is difficult to measure. This is particularly so in the service markets, including for instance, plumbing, mechanics, computer services, and medicine (see, Dulleck and Kerschbamer 2006). Dulleck, Kerschbamer, and Sutter (2011), Mimra, Rasch, and Waibel (2016) and Schneider (2012) provide overviews of reputation as it relates to credence goods.

Within the economics literature, reputation has been studied as a marker of identity. This is well illustrated by Greif $(1989,1993)$, who looked at the role of information transmission via a network of Jewish merchants that acted to deter opportunistic behaviour (see, also Greif 2012). Within this coalition of merchants, accusations of bad behaviour would be disseminated and result in a loss of trade for the accused party. After one instance of alleged malfeasance by a merchant in 1055 CE Jerusalem, "merchants as far away as Sicily canceled their agency relations with him" (Greif 1989, 868-869). In this case, information was exchanged via a system of letters. This reputation mechanism attached information about past instances of trade to an economic agent that then had a tangible impact on their future economic outcomes (Greif 2000). This system of personal reputation illustrates the ability for private governance structures to resolve agency problems in the absence of formal legal mechanisms (see, also Greif 2000, Klein 1997a, McMillan and Woodruff 2000, Telser 1980, Zhang and Elsner 2017, cf. Edwards and Ogilvie 2012a). ${ }^{32}$

'Good' reputations have been similarly treated as a type of 'bond' that can be deployed in an exchange relationship. If an economic agent builds up a reputation-a valuable intangible asset-they will be unlikely to destroy this through opportunistic behaviour, unless the "gain from dishonest behaviour was large" (Milgrom, North, and Weingast 1990, 1, see, also Greif 2005, Klein and Leffler 1981, Shapiro 1983b, Wernerfelt 1988). One simple model of reputation sees an individual "endowed with a level of reputational capital" which commensurately decreases as a result of a contract breach (MacLeod 2007, 603). These are also referred to as contract enforcement institutions (CEIs) in the literature. In general, these bonds, or CEIs, are necessary due to the temporal disparity between "the quid and the quo, providing one with the opportunity to renege" (Greif 2005, 730 emphasis in original, see, also Aoki 2001, Dixit 2011, Williamson 1985). As many exchange relationships are sequential (Greif 2000, 2005), one party to exchange has an opportunity to renege. For instance, a debtor might go into arrears on a loan contract, or an employer might deny payment for work already completed. Corporate reputation as an intangible asset has been studied extensively by management scholars in a similar manner (see, for instance Deephouse 2000, Ponzi, Fombrun, and Gardberg 2011, Rindova, Williamson, and Petkova 2010). This management literature attributes competitive advantage, in part, to the presence of a 'good' corporate

\footnotetext{
${ }^{32}$ Similar instances of reputation exchange systems have been examined in; medieval Europe (Greif, Milgrom, and Weingast 1994); along the Silk Road in the latter part of the $1^{\text {st }}$ millennium (Zhang and Elsner 2017); 19 ${ }^{\text {th }}$ century Mexico (Clay 1997); Vietnam (McMillan and Woodruff 2000); Kenya and Zimbabwe (Fafchamps 2000); amongst diamond dealers (Granovetter 1985); in criminal organisations (Gambetta 1993, 2006); on ecommerce sites (Cabral and Hortacsu 2010, Fan, Ju, and Xiao 2016, Jolivet, Jullien, and Postel-Vinay 2016, Pavlou and Dimoka 2006, Resnick et al. 2006, Bolton, Katok, and Ockenfels 2004); between neighbouring cattle ranchers (Ellickson 1985); as well as in Soviet economies (Litwack 1991, see, also Dinello 1999).
} 
reputation (Boyd, Bergh, and Ketchen Jr 2010, Flanagan and O'Shaughnessy 2005, Roberts and Dowling 2002).

As a good reputation is liable to afford the individual in question favourable treatment by other economic agents, reputation can in part be 'produced'. That is, an individual might take steps to cultivate their reputation within the bounds of contextual and socially accepted norms. In this respect, the hostage model of identity developed in Chapter 4 illustrates how reputation-which can constitute what I term an identity hostage-can be produced and used in subsequent transactions. As such, there is a wide range of theoretical work and field experiments which examine this phenomena across the economic literature. In this respect, Bursztyn and Jensen (2017) provide a good overview, examining the ways in which 'social image' is produced. In general, this concept of social image is defined as that individuals 'type'. The type-which can be referred to as a label or a part of that individual's identitycan be derived from the "actions that one might undertake [and which] are observable by others and may send other a signal about one's type" (Bursztyn and Jensen 2017, 133). To be sure, this literature should be considered alongside the role of costly 'signalling' to reduce instances of information asymmetry (Stiglitz and Weiss 1990). ${ }^{33}$

This literature described above is broadly concerned with the (outwardly visible) behaviours which are used to signal some status or type, and how these actions are predicated on the external observation of those behaviours. To illustrate, consider the installation of solar panels on shaded roof spaces so they are visible by neighbours (Sexton and Sexton 2014), or the purchase of a Toyota Prius to signal environmental credentials (Brooks and Wilson 2015, Brisman 2009). These examples illustrate that consumers are willing to undertake costly behaviours to show off their "environmental bona fides" (Brooks and Wilson 2015, 110). At the same time, the context within which these conspicuous consumption behaviours occur is important; the value to the signaller increases the more the signal matches the preferences of neighbours (Sexton and Sexton 2014).

Reputation as a marker of identity is given similar treatment from a game theoretic perspective, including the manner in which reputation acts as a 'label' by which economic agents derive information about their partners in games (see, for instance Bolton, Katok, and Ockenfels 2005, Dasgupta 2000, Engelmann and Fischbacher 2009, Kandori 1992, Milinski, Semmann, and Krambeck 2002, Neral and Ochs 1992, Okuno-Fujiwara and Postlewaite 1995, Tullock 1985), including when the reputation is that of a firm (Kreps and Wilson 1982). A subset of this literature is devoted to the study of reputation and the cooperative behaviour of nodes in peer to peer computer networks (see, for instance Agah and Das 2007, Gupta and Somani 2005, Jaramillo and Srikant 2010, Michiardi and Molva 2003, Refaei et al. 2005, Trestian, Ormond, and Muntean 2011). These examples are novel in that they depart from

\footnotetext{
${ }^{33}$ Behaviours which are used to produce an image of a particular 'type' include; voting and other political statements (see, for instance DellaVigna et al. 2017, Funk 2010, Gerber, Green, and Larimer 2008, Gerber et al. 2016); observed efforts in educational and workplace settings (see, for instance Ashraf, Bandiera, and Lee 2014, Bursztyn and Jensen 2015, Bursztyn, Fujiwara, and Pallais 2017, Bursztyn, Egorov, and Jensen 2018, Kosfeld and Neckermann 2011, see, also Austen-Smith and Fryer Jr 2005, Fryer Jr and Torelli 2010); altruism (see, for instance DellaVigna, List, and Malmendier 2012, Meer 2011); and 'conspicuous' consumption (see, for instance Veblen 1899, Charles, Hurst, and Roussanov 2009, Clingingsmith and Sheremeta 2018, Heffetz 2011, Jaikumar, Singh, and Sarin 2018, Kaus 2013, Sexton and Sexton 2014).
} 
perfect knowledge assumptions of 'traditional game theory', in which "details of every encounter are common knowledge in a society consisting perhaps of millions of people" (Okuno-Fujiwara and Postlewaite 1995, 80).

While the previous paragraphs have focused on the reputation as it pertains to an individual economic agent, reputations can similarly be 'collective' (see, Tirole 1996). In this respect, the reputation of a member of some group is derived from the past actions of other's in that group, rather than from their own individual actions. Group reputation is thus based on the "group's past average quality" (Winfree and McCluskey 2005, 206 emphasis in original). Oftentimes the past behaviour of an economic agent is unobservable to a potential counterparty, in which case a "consumer uses the past behaviour of the member's group to predict the individual firm's future behaviour" (Loureiro and McCluskey 2000, 311). In this respect, the collective reputation literature is closely related to the statistical discrimination literature as described in section 2.2.3 (see, Levin 2009). Similarly, Megyesi and Mike (2016) examine collective reputations as common pool resources (CPR) that require rules and norms to constrain instances of free-riding and depletion. Practical manifestations of collective reputation can be most readily seen as it relates to regional agricultural products, including; wine (Costanigro, McCluskey, and Goemans 2010, Combris, Lecocq, and Visser 1997, Schamel and Anderson 2003, Landon and Smith 1997); olive oil (Van der Lans et al. 2001); meat products (Loureiro and McCluskey 2000); and apples (Fotopoulos and Krystallis 2003). From this perspective, consumers use the reputation of a nation state or a region as a proxy for the "underlying characteristics of the good they are buying" (Allen, Berg, and Markey-Towler $2019,62)$. Similar phenomena can be seen in the collective reputation of franchised, or chain, restaurants. In markets with a high degree of product differentiation, franchised restaurants derive their reputation from that of the wider chain. In this respect, there is some evidence to suggest that the proliferation of online review mechanisms has reduced the market share of franchised restaurants (Luca 2016).

Finally, the matching theory literature

\subsection{The wider social sciences}

\subsubsection{Sociology, ethnography and anthropology}

Development economists and social economists have acknowledged the removal of some of the barriers between the economics literature and the wider social sciences. As Barrett (2013b, xviii) states at the beginning of his edited volume The Social Economics of Poverty, "economists working in this nascent field of social economics are taking the other social sciences-anthropology, political science, psychology, and sociology-seriously". The same can be said for the study of identity and its role in behaviour and human action (see, for instance Akerlof and Kranton 2000, 2002, 2005, 2010, Barrett 2013a, Esteban and Ray 1994, Sen 1977, 1985, 1999, 2008). In explaining poverty, for instance, sociologists, ethnographers and anthropologists have attributed 'backwards' or 'dysfunctional' social identities to its existence and persistence. This includes attributing the 'urban crisis' in the United States to the 'dysfunction' of certain social identities (Banfield 1970, Rainwater 1970), AfricanAmerican poverty to a 'victimhood culture' (McWhorter 2000), and the lack of achievement 
of minority students to a rejection of the 'dominant culture' (Bisin et al. 2011, Delpit 2006, Fordham and Ogbu 1986, Ogbu 1999, Ogbu 2003, Whyte 2012).

As has already been highlighted, contributions to the study of identity in the economics literature benefitted from earlier sociological works. Becker (1957) cites the 'social distance' literature, while other contributors similarly incorporate sociological concepts (see, for instance Akerlof and Kranton 2000, Barrett 2013b, Folbre 1994). The concept of social distance, first discussed by Robert Park (1924) and Emory Bogardus (1933), relates to the 'intimacy' individuals have towards others based on group membership, and was adopted for the analysis of the economics of discrimination (see, also Akerlof 1997, Wark and Galliher 2007).

Another related sociological concept, while not specifically cited in the economics of discrimination literature, is that of 'virtual social identity' (Goffman 1963). This relates to the heuristics an individual might use in interactions, and can readily be compared to the statistical discrimination literature of Arrow (1972b, 1973) and Phelps (1972b), as well as the signalling literature exemplified by Spence (1973). In these literatures, decisions about interactions in the presence of private information rely on some "easily observable indicators that may lie on hand" (Loury 2002, 9), including race, gender or other indicator of group membership. These 'indicators', or 'indices' (see Spence 1973) can of course be imperfect at communicating the underlying characteristics or qualities of an individual (Grossman and Stiglitz 1980), which result in the divergence between an individual's 'virtual' and actual identity (Goffman 1963).

\subsubsection{Identity politics}

Similarly, the concept of identity politics is an expansive one in the social sciences, with a multitude of meanings embedded in neo-Marxist, new social movement, social constructionist, postmodernist and poststructuralist theories (Bernstein 2005). The concept itself has as its origins the civil rights and feminist movements of the $20^{\text {th }}$ century (Bliss 2013), and broadly speaking, the term refers to the explicit use of, and group expression of, a cultural, religious, ethnic or other trait in the pursuit of political ends (Bliss 2013, Gutmann 2009, Klandermans 2014, Orjuela 2014). The use of identity politics by such movements is typically associated with narratives that certain groups, whether distinguished by ethnicity, gender, sexuality, class or otherwise, lack power or opportunity in a political system. Those driving for political change are members of a certain group who are pushing for some change in favour of the collective group, typically through protest. This is often followed by, or has as its goals, policies of affirmative action (Bliss 2013), or policies of redistribution (Gutmann 2009). The discourse of identity politics is now so pervasive throughout academia and popular culture, that studies into the identity politics in the Star Wars movie franchise have been published (see McDowell 2016).

\subsubsection{Psychology}

Finally, psychology also provides several identity concepts which have been drawn upon in the economics literature (see Akerlof and Kranton 2010). Social identity theory was developed by scholars of social psychology to offer an explanation as to the perceived 
'uniformity' of the behaviour of individuals within groups, as well as the behaviours of interaction between groups (Pearce 2013). At the outset, it should also be noted that, in the development of this theory, constructs from sociology were also incorporated (Hogg and Ridgeway 2003, Stryker and Stryker 2017). Social identity theory suggests that the self-esteem of an individual is in part derived from the image of the groups with which that individual identifies (Turner 1975, Turner, Brown, and Tajfel 1979). According to Gumusluoglu, Karakitapoğlu-Aygün, and Scandura (2017, 481), "a person who identifies with a group perceives himself or herself as psychologically intertwined with the fate of that entity". This theory also seeks to explain inter-group dynamics (Pearce 2013). The theory implies that the self-esteem of an individual may increase, or decrease with that of the social group with which they identify, whether categorised by sex, gender, ethnicity, religion or otherwise. It is therefore in an individual's interest to enhance the image of their own social group (Ellemers and Haslam 2012, Tajfel and Turner 1986).

Early scholarship on social identity theory was directed at explaining the discriminating behaviour against 'outgroups', by members of an 'ingroup' (Tajfel et al. 1971). This literature includes experiments which lend support to the hypothesis that groups depart from strategies of 'fairness' when individuals are categorised into groups. These experiments show the results of 'ingroup favouritism' in the doling out of small measures of value amongst the wider population of the experiment (Tajfel 1978a, 1978b). In one early set of experiments this involved assigning school children to groups based on trivial criteria-via estimations of dots on a screen or their preference for one of two abstract painters-yet it still resulted in marked disparity in the way these children treated others based on which group they had been allocated (Tajfel et al. 1971). Crucially, from these experiments the researchers concluded that the absolute gains of the group were not the only motivating factor; relative gains as compared to the other group substantially influenced behaviours displayed (see Haslam 2004). Similar behaviours were observed in a workplace setting, with employees in an aircraft factory seemingly motivated by maintaining relative levels of remuneration (Brown 1978). The maintenance of this wage differential was even preferred to an absolute gain in wages. In the words of one (high paid) employee, "the status of the job is more important than the actual wage" (Brown 1978, 421). ${ }^{34}$

While social identity theory uses identity as a construct in relation to groups and categories, 'identity theory' attempts to explain behaviours by examining how social structures affect 'self', which in turn influences those behaviours (Stryker and Burke 2000). This theory, developed by George Mead (see Mead et al. 2015), can be simplified as one where "Society shapes self shapes social behaviour" (Stryker and Burke 2000, 285). Identity theory emphasises the impact that the multiple roles one might occupy-father, son, teacher, football player and so forth-have on an individual's behaviour, and how each role in turn

\footnotetext{
${ }^{34}$ Social identity theory has been the subject of further scholarship, including in the context of; the group formation of norms and values in corporate decision making (Pearce 2013, see, also Tyler and Blader 2000); motivation within an organisational context (Van Knippenberg 2000, Wegge et al. 2006); employee responses to mergers and acquisitions (Lipponen, Wisse, and Jetten 2017, Terry and Callan 1998, Van Knippenberg et al. 2002); group dynamics and leadership in the military (Shamir et al. 2000, Jansen and Delahaij 2019); as well as relative preferences for foreign and domestic manufactured goods (Riefler, Diamantopoulos, and Siguaw 2012, Verlegh 2007, Zeugner-Roth, Žabkar, and Diamantopoulos 2015).
} 
constitute some part of a person's identity (Hogg, Terry, and White 1995). This contrasts with the group dynamics which contribute to one's identity in social identity theory.

\subsection{Conclusion}

In this review of the economics literature addressing identity, a litany of usages has become apparent across a diverse range of sub-fields. In general, much of the literature has regarded identity as group membership, as well as a single characteristic related to the individual. It has been similarly concerned with the ways in which that group membership causes the individual to act, as well as be acted upon, due to various non-pecuniary motivations. The former can be readily characterised by the identity economics literature (Akerlof and Kranton 2000), along with the literature concerning the economics of institutions (see, for instance Carr and Landa 1983). In both literatures, group membership is associated with behavioural norms which restrict the choice set of individuals in those groups, along with sanctions in the event of a breach of those prescriptions. The latter consequence of group membership, being acted upon, is more reminiscent of the economics of discrimination literature (Becker 1957, Arrow 1973), and sees individuals discriminated against due to membership in that group, either due to animus or imperfect information. My contribution of a new definition of identity $-a$ vector of characteristics associated with a unique individual that allows other individuals to recognise them, or allow differentiation from other individuals-is a contribution to the economic literature which I hope will overcome the limitations of identity being associated with only a single characteristic.

Identity is also captured as an individual concept, in that it acts as a label that other economic agents can use in interactions. The need for such labels owes to the inherent uncertainty in economic exchange, in part owing to behavioural uncertainties. These behavioural uncertainties can be seen first through the lens of the literature on information asymmetry, where private information precipitates 'hidden information' and 'hidden actions' (Cohen and Siegelman 2010). Similarly, in the reputation literature, a label acts to deter opportunistic behaviour by an economic actor, as past instances of contract breach will have a negative impact on their future economic outcomes (see, for instance Greif 2000). 


\section{Chapter 3. An identity cost model of exchange}

\subsection{Introduction}

Using the new institutional economics as developed by Coase $(1937,1960)$, Klein, Crawford, and Alchian (1978), Williamson (1971, 1975, 1979, 1985, 2002, 2007, 2010) and North (1990), as well as literature concerning information asymmetry (see Akerlof 1970, Spence 1973) I contribute to the literature an identity cost model of exchange. Here, and throughout the thesis, identity is a vector of characteristics associated with a unique individual that allows other individuals to recognise them, or allow differentiation from other individuals. The model I contribute in this chapter describes the demand for identity, where the demand for identity is a positive function of the need to recognise, and distinguish between, trading partners. The transaction cost theory of identity which follows will incorporate a transaction cost theory of exchange which relies on the inclusion of transaction costs alongside transformation costs (North 1990). The model set out in this chapter relies on behavioural assumptions including bounded rationality and opportunism.

Underpinning this chapter, and the thesis, is the premise that human behaviour is a source of uncertainty; human behaviour is difficult to predict and without mitigating institutions barriers to trade would be extensive. The origins and consequences of this unmitigated uncertainty was discussed in the previous chapter (Section 2.2.1). According to North (1990, 11), much economic theory which ignores these behavioural realities is ignorant "of the nature of human coordination and cooperation." As I shall develop, aspects of one's identity serves to reduce this uncertainty, and so build "a structure to everyday life" (North 1990, 3). These uncertainties exist in the economic, political, and social spheres, and identity institutions exist to reassure economic and political actors as to the future state of the world. Where the endowments, tastes, and motivations of heterogeneous actors are private information, understanding the distinctiveness of those you interact with limits their choice set and hence increases the predictability of future states.

Identity, and coming to a level of assurance over the relevant, and context dependent, characteristics of a counterparty is integral to most economic, social and political exchange. As examined in this chapter, the demand for identity is a positive function of the need to recognise, and distinguish between, trading partners. This chapter will demonstrate that the demand for identity can be both private and public. In the context of a credit contract, the private demand for identity is derived from the need of a lender to verify the willingness and ability of a borrower to repay a loan. The public demand for identity is derived from state requirements to monitor borrowers on an ongoing basis, to determine the existence of illegal activity. This demand for identity information is an effort to reduce the effect of uncertainty.

Any sort of contractual exchange where uncertainty is present necessitates the exchange of identity information related to individuals, organisations, and the good or service involved. Without such information, commercial activity would be limited (Akerlof 1970); identity information serves to reduce information asymmetry and its attendant negative impacts. 
A main contribution of this chapter is the development of a two-period model to illustrate the existence of 'identity costs' as a distinct subset of transaction costs. In the first period buyers take costly action to ascertain information about contract relevant characteristics of a seller. These characteristics might include a seller's ability and willingness to repay a loan. Such costly actions have the effect of revealing private information and overcoming market limiting effects, including adverse selection. In the second period, buyers make decisions to enter into contracts, while pricing decisions are made based on those identity characteristics as revealed in the prior period. This model makes predictions for the existence of organisational structures which economise on identity costs.

The identity cost model of exchange anticipates that understanding the identity of a counterparty to exchange is costly, and therefore certain organisational arrangements might be seen from an identity cost perspective. That is, a secondary contribution of this chapter is an explanation of the existence of banks due to identity cost economising. In general, and according to the transaction costs school (see Williamson 1985) a contractual arrangement and its underlying institutional context can be understood as being the result of transaction cost economising (Fallan 2000, Kemp 2006, Klein, Crawford, and Alchian 1978). The model in this chapter predicts that certain institutional arrangements can be considered as the result of identity cost economising. Here I suggest that the existence of financial institutions as an aggregation of holders of surplus financial capital can, in part, be attributed to identity cost economising. I suggest that credit transactions are facilitated within these organisational hierarchies, rather than via markets, due to the existence of identity costs and attempts by lenders to economise on these costs (see also MacDonald, Allen and Potts 2016).

This chapter proceeds as follows. Section 3.2 outlines the basic model, while Section 3.3 provides background to the transaction cost framework used in the chapter. Section 3.4 examines the existence of identity costs in exchange, and provides some examples of how identity information is transmitted during a credit transaction. Section 3.5 suggests ways in which identity costs might be measured, while discussing methodologies previously used to measure transaction costs. Section 3.6 examines identity costs and vertical integration. Section 3.7 concludes.

\subsection{The identity cost model of exchange}

The model I contribute in this chapter uses two distinct (but related) literatures. The first is the new institutional economics, including the transaction costs framework developed by Williamson (1979). This framework comprises uncertainty, frequency of exchange, and asset specificity. The second is the information asymmetry literature (Akerlof 1970). Here I draw attention to the literature associated with 'signalling' as it is used to overcome the negative effects of private information (see Spence 1973, 1974, Section 2.2.1). The model I develop sees counterparties to exchange undertake costly action related to the initial identification, and subsequent verification of counterparties to an exchange, as well as that which is being traded. Such actions to identify the relevant, and context dependent, characteristics of counterparties incur what I term identity costs.

In this two period model, there are buyers and sellers. Owing to the behavioural assumptions of bounded rationality (Simon 1957, 1961) and opportunism (Williamson 1985), there is 
uncertainty as to the future state of the world. The existence of private information means that sellers might conduct themselves opportunistically. That is, they might use their informational advantage to trade at circumstances favourable to themselves, while ex-post contractual effects are also present. These ex-post contractual effects are the result of 'hidden actions' (Cohen and Siegelman 2010) which might see counterparties to exchange act in contrast to their ex-ante promises, in part owing to opportunism (Williamson 1985).

The model uses a credit transaction to demonstrate the existence of identity costs, which are incurred by the buyer of a credit contract. In this credit contract, the 'buyer' is the lender, while the 'seller' is the borrower. In contrast to the signalling model of Spence $(1973,1974)$, where the cost is borne by the bearer in communicating their 'type', identity costs are incurred by a buyer-the lender-in divining the private information of a borrower. This private information is related to the ability and willingness of the seller-the borrower-to repay the loan. To be sure, that all the relevant private information of a borrower might be revealed to the uninformed party is perhaps not a realistic assumption (Grossman and Stiglitz 1980). A buyer of credit contracts is also assumed to be motivated by profit and commercial imperatives. That is, they are not under any legal obligation to lend.

The model is comprised of two periods. In the first period a buyer takes costly steps to identify the relevant, and context dependent, characteristics of a seller. This is what I have already characterised as the demand for identity. Buyers demand such information because they are at the outset unable to distinguish between good quality and bad quality sellers. That is, a lender has little or no understanding of a borrower's willingness and ability to repay a loan. Borrowers might be high risk or low risk. However, a lender has at the outset no measuring stick by which to distinguish between different risk types. Of course, the absence of risk metrics will likely have a negative impact on their ability to set an appropriate rate of interest. With no mitigating mechanisms, such a credit market might produce only 'lemons' (Akerlof 1970). As I develop in the remainder of this chapter, identity costs incurred in this period are derived from both commercial, as well as legislative and regulatory requirements. That is, this model illustrates both the private, and public, demand for identity. The second period sees buyers of credit contracts enter contracts with sellers, at market terms based on the private information revealed in the first period.

Finally, it should be stressed that the characteristics which comprise a seller's private information are assumed to be exogenous to this model. That is, in the first period a seller's 'type'-'good' versus 'bad' credit risk-is taken as given. This does not suggest that borrowers cannot undertake costly action that will grant themselves with certain characteristics like a reputation of some type (the literature on reputation was reviewed in Section 2.2). For instance, in the context of a credit relationship, a borrower could take costly actions in prior periods to 'label' themselves as a trustworthy borrower. These costly actions could consist of fulfilling the terms of prior credit contracts, thereby labelling themselves as a 'good' credit risk. In addition, they might increase the size of their asset pool which would then be available to post as collateral, and so forth. Rather than considering these aspects here, I assume that these are exogenous to the model. In Chapter 4 this assumption is relaxed, and I examine how identity characteristics might be 'produced' for the purposes of engendering trust between counterparties to exchange. The next section of this chapter outlines the transaction costs 
literature, including the framework of uncertainty, frequency of exchange, and asset specificity as developed by Williamson (1979).

\subsection{Transaction costs}

Commons (1932) first defined the transaction as the primary unit of economic analysis. Coase (1937) subsequently offered an explanation as to the existence of hierarchical firms due to the cost of market based exchange. Transaction cost economics seeks to explain organisational variety through the context of economising on transaction costs (Williamson 1985). The same is sought with respect to vertical integration, the make or buy decision, and sourcing in the literature, and all follow the same broad approach (see Kulkarni and Heriot 1999). Transaction costs refer to the 'friction' emblematic in all economic transactions, being analogous to friction in mechanical and physical systems (Williamson 1985). These are the "costs of running the economic system" (Arrow 1969, 501). According to Williamson (1985) transaction costs can be delineated into both ex-ante and ex-post variants. Ex-ante transaction costs consist of search costs, costs associated with negotiating, or the drafting of agreements, while ex-post transaction costs include those associated with the governance structure related to the monitoring of an agreement and dispute resolution (Arrow 1969). The introduction of transaction costs into the economic literature has given rise to new schools of economic thought, including that of the new institutional economics, a term coined by Williamson (1975).

According to Williamson (1985), the behavioural assumptions upon which transaction cost economics relies are that of bounded rationality and opportunism. Bounded rationality acknowledges the intended rationality of economic actors, but stresses the limits of cognitive competence (Simon 1957, 1961). Rationality is limited by both cognitive ability, as well as aspects of language; cognitive ability is a limited resource (Williamson 1975). Opportunism reflects the uncertainty of ex-post behaviour due to self-interest, or what Williamson (1985, 47) referred to as "self-interest seeking with guile". In this context, and as discussed in Chapter 2, ex-post 'hidden actions'-moral hazards-are related effects of uncertainty of behaviour and private information. Considering these "characteristics of the human decision makers who are involved with the transaction" (Williamson 1975, 8) allows for a transaction cost framework with which to examine economic (and other) interactions. The inclusion of these behavioural assumptions is important such as they relate to "economic activity that involves transaction-specific investments in human and physical capital" (Williamson 1979, 234), or asset specificity. These behavioural assumptions provide a framework in which we can "study man as he is" (Coase 1984, 231), and therefore develop a meaningful exposition of identity as it relates to economic and political transactions.

Transaction costs, along with the behavioural assumptions of bounded rationality and opportunism are a useful way to distinguish a transaction cost approach from early interpretations of Adam Smith and other mainstream economists; interpretations which neglect his examination of "certain essential components of human behaviour" (Rosenberg $1960,557)$. That is, Smith (1776b, 300) emphasised the imperfections in human behaviour. For instance, he recognised that individuals lack 'vigilance' when they are placed in charge of other people's property, which can be associated with problems of moral hazard. Yet rather than recognising Smith's understanding of behavioural realities, much of the post-Smith 
literature focuses on conclusions that the productivity, and hence the welfare of a society is determined largely by specialisation and trade, which itself results in "a proportionable increase of the productive powers of labour" (Smith 1776a, 110).

Smith's contributions, and much of the literature interpreting Smith, resulted in a substantial economic literature which examined the nature and functioning of the price system (Demsetz 1988). Yet this literature paid little regard to the costs involved in market functionality, often neglecting the importance Smith placed on other institutional factors in promoting economic growth (see Rosenberg 1960, Shearmur and Klein 1997b, Tullock 1985). Introducing transaction costs allows us to examine the cost of exchange, and the institutions-legal, political and social-which in turn impact on the performance of an economy (Coase 1984, North 1990). The identity cost model of exchange, where identity costs exist as a distinct subset of transaction costs, will contribute to the transaction cost literature as it explains the governance of exchange through varied organisational means.

\subsection{The existence of identity costs}

The identity cost model of exchange I contribute as part of this chapter determines that transactions may comprise both a value, as well as an identity, component. This builds on the work of North (1990), who determined that production costs are a function of not only the transformation of land, labour and capital, but also of transaction costs. These transaction costs are those associated with "defining, protecting, and enforcing the property rights to goods" (North 1990, 28). My introduction of identity costs into the transaction costs school builds on several related literatures. This includes that of Ben-Porath (1980) and Akerlof and Kranton (2000) who determined that an absence of knowledge as to the identity of a counterparty, and characteristics related to them, would restrict or curtail the propensity to transact. In short, the presence of private information, absent any supporting mechanisms or institutions might lead to widespread instances of markets in which only 'lemons' are traded (Akerlof 1970, Section 2.2.1). This is supportive of the emphasis that Arrow (1972c) placed on trust in enabling exchange, and whose absence goes some way in explaining an absence of exchange. Others have examined the importance of trust in economic exchange in a variety of contexts (see Greif 1989, Klein 1992, 1997c, Shearmur and Klein 1997). Here identity costs are those transaction costs which are related to the initial identification, and subsequent verification of parties to an exchange, as well as that which is being traded. Consistent with this thesis, in this chapter identity is a vector of characteristics associated with a unique individual that allows other individuals to recognise them, or allow differentiation from other individuals. Incurring an identity cost has as its objective the discovery of private information, or the reduction in information asymmetry between two parties to exchange.

I use the transaction cost framework first developed by Williamson (1979) and build on the construct of 'contractual man' to determine the nature, and existence of identity costs in economic, social and political transactions. This framework uses the dimensions of 1) uncertainty, 2) frequency of exchange, and 3) asset specificity. Thus, I use the behavioural insights of bounded rationality and opportunism as they relate to the identity costs inherent to exchange. 
Uncertainty is important to consider as it applies to ex-post contractual difficulties, arising from an asynchronous knowledge of circumstances (Hayek 1945), behavioural uncertainties attributable to bounded rationality and opportunism (Williamson 1985), along with instances of adverse selection and moral hazards derived from private information (see for instance Stiglitz 2000). This dimension of the framework concerns itself with uncertainty as to the future state of the world; how that will impact on the fulfilment of ex-ante exchange agreements, including changes due to ex-post exogenous shocks. Uncertainty arises in large part through the existence of the behavioural assumptions common in transaction costs economics, and gives rise to the necessity for safeguards, or credible commitments for the facilitation of exchange (Williamson 1985, see, also Chapter 4). Frequency of exchange, and the recurrence of exchange, relates to the ex-ante costs of establishing a governance structure, and whether the cost of setting up such a structure can be justified, or reasonably amortised over the course of a relationship. The prospect of justifying large establishment costs is more likely for frequent, uniform exchanges, as opposed to one-off occurrences (Williamson 1979, 1985). A high frequency of transactions is "often associated with internalization of economic activities" within an organisational hierarchy like a firm (Kulkarni and Heriot 1999, 45). The final dimension is that of asset specificity, where the investment in transaction specific assets may sit across a spectrum ranging from one which is highly idiosyncratic, to one which is highly fungible (Williamson 1985). This dimension refers to the ease with which physical, human and dedicated assets can be redeployed in alternate uses "without sacrifice of productive value" (Williamson 1991, 281).

\subsubsection{Zero identity costs}

To provide validity for the model, I now depict a purposively counterfactual transaction in which the identity cost incurred is zero, or close to it. In a subsequent section I will provide a description of a more realistic, albeit stylised, credit transaction to justify my inclusion of identity costs as part of exchange. The findings are summarised in Table 1. below, and are elaborated on throughout the remainder of this section.

\begin{tabular}{|l|l|l|}
\hline Uncertainty & Spot market transaction & Credit transaction \\
\hline $\begin{array}{l}\text { Frequency of } \\
\text { exchange }\end{array}$ & $\begin{array}{l}\text { Uncertainty absent, no potential for } \\
\text { ex-post divergence from ex-ante } \\
\text { expectations. Necessarily involves a } \\
\text { 'search' good. }\end{array}$ & $\begin{array}{l}\text { Uncertainty present, potential for ex-post } \\
\text { divergence from ex-ante expectations. } \\
\text { Necessarily involves an 'experience' good. }\end{array}$ \\
\hline $\begin{array}{l}\text { Aarge establishment and ongoing } \\
\text { identity costs not justified. No } \\
\text { identity costs to amortize over the } \\
\text { course of a relationship. }\end{array}$ & $\begin{array}{l}\text { Large establishment and ongoing identity } \\
\text { costs justified. Significant fixed and } \\
\text { variable identity costs to amortize over } \\
\text { the course of a relationship. }\end{array}$ \\
\hline Identity costs & $\begin{array}{l}\text { No necessity for investment in } \\
\text { specialised assets to determine, and } \\
\text { monitor, identity of counterparties. }\end{array}$ & $\begin{array}{l}\text { Specific assets necessary to determine, } \\
\text { and monitor, identity of counterparties. }\end{array}$ \\
\hline
\end{tabular}

Table 1 . The existence of identity costs in a spot market transaction and a credit transaction

Idealised market transactions in mainstream economics simultaneously treat the identities of the parties concerned, as well as the item to be exchanged, as homogenous (Williamson 1985). This assumption is often associated with the functioning of a 'perfectly competitive market' as described in introductory economics textbooks. In such a transaction both 
participants and commodities are infinitely interchangeable (Telser and Higinbotham 1977). Described by Demsetz (1988) as a model of 'perfect decentralisation', choices are guided only by prices, tastes and technologies. In this respect the identity of buyer, seller, and commodity are treated as irrelevant (Williamson 1985). I shall examine, using the transaction cost framework as described above, an idealised transaction inspired by mainstream economic thought. That is, I shall describe a transaction where the identity cost is effectively zero. The purpose of this is to provide a baseline transaction, from which I can then justify the model described earlier in this chapter, and hence my introduction to the literature of identity costs, and how they relate to economic, social and political institutions as well as governance structures.

The analysis of the nature of identity costs begins with an examination of uncertainty. Uncertainty exists in a world of bounded rationality and opportunism, as the ex-post behaviours of parties to a transaction are somewhat unknown. In addition to the uncertainty assumed under these behavioural assumptions, exogenous shocks can also influence the congruence of ex-ante expectations and ex-post reality. However, for the purposes of this analysis consider a spot market transaction where the good or service is of low value, and where the characteristics, and quality, of the item in question can be determined without the requirement for any specialist knowledge or equipment. ${ }^{35}$ Using the taxonomy of Nelson (1970), this good or service would be necessity be of the 'search' variety. In this scenario, I assume that all the relevant characteristics of the product in question can be determined prior to purchase.

A spot market is one where trade and settlement occur instantaneously. In such a transaction, no credit arrangement will be entered into, and there is no demand for identity information as to the ability and willingness to repay in the future. The spot market nature of the transaction, and the unique qualities of the good or service determines that no certainty over the identity of the counterparty is necessary. I also assume another aspect of such a transaction, one in which little, or minimal information asymmetry exists between parties. For this last condition to be satisfied, such a transaction would require the opportunity for visual inspection prior to purchase, and at little to no cost. I assert that the purchase of a search good such as a bunch of flowers is a suitable analogy; it is trivial for a visual inspection to determine quality, with no need for specialist equipment. I thereby assume that there is no need for specialist knowledge or equipment to determine the quality of the good to be transacted. Thus, a situation of asymmetric information (Akerlof 1970) in the determination of quality does not exist. There is no private information, as both the buyer and seller are in possession of equal information pertaining to all applicable information about the quality of the good.

Finally, in the examination of uncertainty as it relates to a low value spot market transaction, here I also assume that the medium of exchange used to settle such a transaction is completely fungible. In this respect, previous transactions conducted using that medium of exchange are not known to either of the parties, nor will its history effect its future

\footnotetext{
${ }^{35}$ While acknowledging the existence of high value spot markets such as those trading in stocks and commodities, this model only considers spot markets where the good exchanged is low value.
} 
acceptance in economic exchange. ${ }^{36}$ In such a scenario uncertainty over the identity of counterparties, the item to be traded, and the medium of exchange, is reduced to something very close to zero. The nonspecific nature of the transaction neither requires, nor results in, any sort of ongoing relationship between counterparties, as new relations are easily entered (Williamson 1979). Uncertainty is trivial or non-existent in such a transaction, and conditions derived from behavioural assumptions of bounded rationality and opportunism can be considered irrelevant; no safeguards or credible commitments are required for such a transaction to proceed. That is, ex-ante expectations can, to a very high degree of probability, be expected to coincide with ex-post reality. Hence parties to the exchange incur minimal or no identity related expense. That is, there are no identity related costs owing to a lack of private information which would incur identity costs to overcome. Costs incurred in identifying a counterparty, the item to be exchanged, as well as the medium of exchange are close to zero.

The second dimension to be considered is that of frequency of exchange, and the establishment costs related to the identification of a counterparty to complete a transaction. For the purposes of analysis consider a market based transaction in which there are many homogenous buyers and sellers, and one in which the item to be exchanged is common, that is, non-specialised. As this market is comprised of many homogenous actors-and homogenous prices-buyers and sellers do not seek to establish ongoing relationships with one another, as the items exchanged are of such a nature that their quality can be instantly verified without any requisite knowledge or equipment. That is, the goods have search qualities. Similarly, new relations can quickly be entered due to the nonspecific nature of the transaction (Williamson 1979).

In such a spot market transaction, with homogenous participants and prices, buyers and sellers have little incentive to establish the identity of their counterparties. Thus, indirect measures of quality-such as country of origin-are not important (see for instance Allen, Berg, and Markey-Towler 2019, Winfree and McCluskey 2005). This is so as the quality of goods can be determined directly, through inspection, rather than through reputation, trademark or other similar mechanisms and institutions. In addition, the transaction is of such a nature where neither party to the transaction is restricted in their participation by age, credential, regulation, legislation or any other requirement. That is, there is no public demand for identity related to this transaction; there is no reason to identity a counterparty to satisfy any legal or regulatory requirements. In this way there are neither commercial, nor

\footnotetext{
${ }^{36}$ If the transaction is instantaneously settled using a widely accepted and trusted fiat currency, the history of the medium of exchange used is of little concern (Fox 2008). The introduction of and the use of cryptocurrencies, including Bitcoin (see Nakamoto 2008), where the transaction history of an individual 'coin' can be viewed by all participants in the network raises interesting questions as to their fungibility. Users of various cryptocurrencies have reported seeing discrimination in the use of some coins based on their history, while some exchanges will actively prevent coins known to have been stolen from being traded (Vorick 2016). Privacy coins allow for the trade of cryptocurrencies uncoupled from any knowledge of the transaction history of individual coins (Narayanan et al. 2016). In Berg (2020) I examine the identity, fungibility, and anonymity of different money technologies.
} 
compliance incentives to come to any sort of level of assurance over the identity of counterparties.

Finally, the absolute fungibility of the medium of exchange is assumed, in that no specialised payment mechanism needs to be established which might require any sort of identification, verification, or authentication process. In Berg (2020), I relax this assumption. ${ }^{37}$ In such a transaction, there are no identity costs to amortise over the course of the relationship; fixed identity costs are negligible, while variable identity costs are uniform across any scale of exchange relationship. This latter assumption is key as uniform variable identity costs (which in any case are close to zero in this example), mean there are no economies of scale to be had from multiple or frequent transactions between buyers and sellers.

The final dimension to be discussed as part of the identity cost framework is that of asset specificity. Asset specificity refers to the necessity for durable investment in support of a transaction (Williamson 1985). Specific assets are referred to as idiosyncratic in the literature, and are those assets which "have little or no general purpose outside the relationship between buyer and supplier" (Fallan 2000,60). As identity costs are concerned, a transaction which has an identity cost of close to zero would require any investment in assets to have a high value in alternate uses with little or no loss of productivity, in the event those assets need to be redeployed ex-post (Williamson 1985). For the purposes of such a spot market transaction, with identity costs close to zero, I suggest a scenario where neither party has need to affirm the identity of either party, as fulfilling the ex-ante requirements of the transaction requires only standardised site, physical, human and dedicated assets (Williamson 1985). In practice, such a spot transaction, and investment in assets required to fulfil said transaction, are investments in general purpose assets due to interchangeability among a large and heterogeneous complement of potential counterparties.

I also assume, in the examination of a spot market transaction with identity costs as close as to zero as is practicable, that the good is private property. As private property, it is necessary to satisfy three criteria. The first is that the owner has exclusive rights over the use of the good, including the right to exclude others from using it. The second is the right to receive income from the use of the good. Third is the right to transfer ownership of that good as the owner sees fit, and in a contractual arrangement of their choosing (Cheung 1974, 1983). As the transaction involves the outright transfer of the property rights associated with the item of value, that is the item is not being leased or hired, the identity of the property rights associated with that good are trivial to ascertain, that is, those property rights are absolute.

However, as I shall now show, in transactions where trade and settlement are separated by time, the value of the good or services are of higher value, and where it is more difficult to

\footnotetext{
${ }^{37}$ As an aside, the use of fiat cash and other forms of currency (including cryptocurrencies) can be used to hide past instances of exchange, and therefore 'mask' one's identity. If the common assumption of fungibilityhomogeneity-of money holds, there is nothing to trace a unit of currency to any transaction for which it has served as a medium of exchange. If I wish to conceal sexual, health, or other matters I can choose to transact using cash. That is, a truly fungible and therefore untraceable form of currency would serve to overcome a negative externality; concealing aspects of one's personal life helps to cultivate a 'good reputation' (Posner 1979). To be sure, this assumption of homogeneity does not hold true in many circumstances, and I explore the implications of individual units of currency as having their own identity-history-at length in Berg (2020).
} 
ascertain the quality of the goods to be transacted, as well as the property rights associated with them, the identity component will be greater than zero. This circumstance might occur in contractual arrangements such as an employment contract, or a credit arrangement. I use a credit transaction as part of my model. In this type of transaction parties will require a level of assurance over the identity of the other party, as well as the good or service itself. The demand for identity, and the actual level of assurance required will depend commensurately on the complexity and value of the exchange.

\subsubsection{Positive identity costs}

In this section, I provide some validity for the model using a stylised description of a credit transaction. The spot market transaction with zero identity costs as described above is close to the idealised market exchange of homogenous commodities combined with interchangeable buyers and sellers as defined by Telser and Higinbotham (1977 see also Salop and Salop 1976). While illustrative for benchmarking and counterfactual purposes, it is not illustrative or analogous to most economic, political and social transactions. Most exchange occurs under a veil of uncertainty, while disparities in access to information are clearly endemic. It is reasonable to expect that many transactions will incur identity costs to degrees which vary according to their complexity as well as their nature. I shall now illustrate the model by describing a transaction in which the identity cost is greater than zero.

One such economic exchange which will incur positive identity costs is that of a credit transaction, whereby trade and settlement are separated by time. Here, identity costs will be substantially greater than that of a spot market transaction. I shall thus examine the nature of the costs involved in establishing the identity of counterparties, as well as the commodity to be exchanged itself, while assuming the fungibility of the medium of exchange. I relax this assumption in Berg (2020). As is intuitively apparent, choices and decisions to transact, or otherwise, are derived from more than simply prices, tastes and technologies (Demsetz 1988); the identity of counterparties and commodity are of paramount importance to exchange (Williamson 1985). A simple description of the nature of credit transactions, and how they relate to my model follows. I shall then analyse this type of transaction using the framework set out in Williamson (1979) of uncertainty, frequency and asset specificity. Then I shall discuss how market-prices and indeed the availability of goods and services are derived in part from identity information, and then discuss the nature of identity in exchange.

Consider the stylised nature of a credit transaction. For the purposes of this model I have assumed that the amount lent is non-trivial, while the creditor is motivated to lend to the borrower for purely profit maximising reasons; they are under no legislative or other compulsion to enter a credit arrangement. In return, a lender expects to receive an amount of interest commensurate to the risk involved in entering such a contract, along with the repaid principal after some period. In comparison to a spot market transaction, a credit transaction such as this differs substantially in its complexity, and in the emphasis the parties involved will place on reaching some level of assurance over the vector of characteristicsthe identity- of their counterparty; parties will subsequently be motivated to take steps to ameliorate information asymmetries and expose private information about their counterpart. In a credit transaction, while a borrower receives the principal at origination, the lender will not receive the total value of their asset-the loan-for some contractually designated 
period, notwithstanding any default prior to settlement. Lenders must therefore consider two types of risk before they enter a credit arrangement with a borrower, namely credit risk, and market risk (McDonald and Thornton 2008). Credit risk, the risk that the borrower will not meet their obligations to repay the loan, is the risk that I am concerned with in this model. Market risk is a risk largely relevant to credit arrangements with fixed rates of interest and shall not form part of the analysis. It is credit risk which produces the private demand for identity on behalf of the lender.

A credit transaction involves a relationship between two parties which may last many years. As a result, the lender will seek to verify the identity of the borrower. A borrower's identity from a commercial perspective is largely comprised of their distinct characteristics related to their willingness and ability to repay (Qi 2013). Similarly, a lender will need to quickly differentiate 'their' borrower from the larger population. That is, a lender needs the ability to pick out their borrower from a crowd.

A standard framework used by a lender is that of the ' 5 Cs of Credit', which uses the metrics of capacity, character, capital, collateral and condition to assess credit risk (see Qi 2013, Strischek 2000). In addition, banks will typically evaluate (non-financial) personal information to determine the credit risk of borrowers. Identity characteristics including a borrower's employment status, age, and number of dependents are typically used in such calculations (Ferreira et al. 2014). The difference between financial and non-financial metrics used to evaluate credit risk should also be considered as being somewhat analogous to that which differentiates between information contained in 'signals' and 'indices' (Spence 1973). With signals, an individual can take costly action to signal themselves as being an attractive counterparty, such as via having a significant amount of collateral available in the event of default. In contrast, many non-financial risk metrics examined by creditors, such as age or number of dependents, are immutable characteristics and serve as a proxy for unobservable characteristics (Phelps 1972a, 1972b, Arrow 1972a, 1972b, 1973). As described in this model, the production of such information is exogenous. This assumption is relaxed in Chapter 4.

Frameworks such as the ' 5 Cs of Credit' seek to determine factors which may impact on the borrower's willingness and ability to repay, and hence determine their credit risk. In utilising such a framework, lenders will typically require potential borrowers to supply substantial documentation to attest to their claims, such as proof of income (Murphy 2011), while also allow access to external credit scores (Crawford, Meh, and Zhou 2013, McDonald and Thornton 2008). These identity characteristics are passed on to relevant parties in the form of income related paperwork, electronic files, and government issued identification; all this documentation comprise the identity technologies employed in such credit transactions.

In addition to the practices associated with determining whether a borrower is able and willing to pay according to the conditions set out in the credit contract, lenders must also typically address legislative and regulatory requirements to fulfil 'Know Your Customer' (KYC) obligations. These requirements are an example of the public demand for identity. KYC requirements, such as those arising from the Bank Secrecy Act and the Patriot Act in the United States (see Bilali 2011), as well as the Anti-Money Laundering and Counter-Terrorism Financing Act in Australia (see Deitz and McLeod 2007) have their origins in efforts to counter illegal activity such as illicit drug trafficking and terrorist activity. Thus, both commercial and 
regulatory imperatives oblige lenders to identify their customers prior to entering a financial relationship, their ability to repay at the origination of a loan, and monitor their borrower's behaviour and circumstances on an ongoing basis (Bilali 2011). These legislative and regulatory practices - the public demand for identity-are instances of a state actor assigning the responsibility to derive private information about criminal activities to commercial actors such as banks.

Due to the presence of uncertainty, itself derived from the behavioural assumptions of bounded rationality and opportunism, ex-post behaviours of parties to a transaction are unknown. Thus, in a credit transaction, for reasons of asynchronous knowledge of circumstances (Hayek 1945), along with bounded rationality and opportunism (Williamson 1985) and information asymmetry (Akerlof 1970) lenders are required to come to a level of assurance over the identity of their counterparty. These commercial requirements are further extended by legislative and regulatory mandates to understand the identity of counterparties in financial relationships such as credit contracts.

As determined by my model, the uncertainty involved in such a credit transaction, the possibility that ex-ante contractual expectations will not be satisfied ex-post, require that profit maximising lenders take commercial considerations into account and evaluate the ability and willingness for the borrower to repay. These ex-ante costs take the form of collecting and extracting information from documentation and attestations by the borrowers that they have the capacity, character and capital to make required repayments, as well as sufficient collateral in the event of default; collateral inspections and verifications are particularly important for long term credit arrangements such as mortgages. Collateral in this case should be considered as a type of contractual safeguard to manage hazards arising from uncertainty (Williamson 1985). Identifying the nature and value of items committed as collateral incurs additional identity costs which manifest in physical inspections and documentation including property titles and deeds. Similarly, costs in identifying counterparties are also incurred to satisfy compliance obligations as discussed earlier.

In the case of a credit transaction, and in contrast to the spot market transaction described earlier, information asymmetry is acknowledged and addressed by the identification of counterparties, and the characteristics of counterparties, such as their ability and willingness to repay. In addition, and in a case where a good or service is to be exchanged, identity costs to determine quality also become apparent. In the presence of asymmetric information (Akerlof 1970) in the determination of quality, identity costs are incurred where non-trivial assessment of quality takes place; this may include the use of specialist knowledge or equipment. I posit that, in the presence of uncertainty, addressing these commercial and compliance obligations incurs positive identity costs that are endogenous to most classes of transactions.

Frequency of exchange, and the establishment costs relating to the identification of counterparties are similarly non-trivial in a credit relationship. As discussed earlier, those parties to a credit transaction have significant incentive, both commercial and in some cases compliance related, to come to some level of assurance over the identity of their counterparty. Consider the lender in my model, who must incur ex-ante identity costs related to the governance structure of contractual arrangements, whose costs must then be 
amortised over the course of any relationship. These identity costs, as discussed, take the form of collecting documentation and attestations related to the ability and willingness of a borrower to meet their financial obligations. In some circumstances the identification of, and assurance over, any collateral put at risk as part of the credit arrangement also incurs positive identity costs. In contrast to the spot transaction examined earlier, there is a significant degree of heterogeneity amongst market participants; parties to a transaction have significant incentive to establish the identity of their counterpart. Thus, in such a transaction, there are positive identity costs to amortise over the course of the relationship. Fixed identity costs, perhaps in the form of KYC obligations on the behalf of financial institutions, are positive, while variable identity costs may exist to some degree across such an exchange relationship, such as those related to anti-money laundering efforts. Variable costs are variable in the sense they are ongoing across a relationship; money transacted or deposited must be screened for its association with illegal activities. The presence of identity costs (both fixed and variable), and the specialised human capital and equipment required to process attestations related to identity, mean there are identity cost minimising economies of scale to be had in the case of credit transactions.

Asset specificity, the necessity for durable investments in support of transactions, exists on a spectrum from general purpose assets, to idiosyncratic assets which "have little or no general purpose outside the relationship between buyer and supplier" (Fallan 2000, 60). In examining the credit transaction illustrated by the model, highly idiosyncratic investments are made in support of the transaction. As discussed, commercial and compliance requirements dictate that lenders incur non-zero identity costs to enter such transactions, evaluating credit risk, fulfilling KYC obligations, and so forth. Incurring these identity costs require specialist knowledge and equipment in the form of human capital and information technology, and have little or no value outside of the bounds of these transactions. There is no value to be derived from alternate uses of attestations as to a counterparties willingness and ability to repay outside of a transaction. ${ }^{38}$ In practice, assets employed for the purposes of credit transactions are highly idiosyncratic.

The occurrence of identity costs, and the information derived from incurring those costs, have commercial and compliance origins, as well as commercial and compliance implications. Commercial origins refer to the need to establish a borrower's willingness and ability to repay. The ' 5 Cs of Credit', (see Qi 2013, Strischek 2000), as well as personal information like age and number of dependents (Ferreira et al. 2014) are used by financial institutions to price financial products. This is intuitive; there is a risk premium applied to high risk borrowers as compared to low risk borrowers in the form of increased interest rates (Magri and Pico 2011). Lenders require higher returns from a loan asset which comes with a higher likelihood of default. The commercial implications of this are clear, lenders price their products based on the identity of their borrowers; credit markets are not made up of homogenous participants. In addition,

\footnotetext{
${ }^{38}$ New regulations, including the Payment Services Directive (PSD2) in the EU, mandate that financial institutions allow third party access to customer banking data. This data could relate to KYC checks, as well as transaction based data (Jackson 2018). Through such 'Open Banking' initiatives, which are designed to increase innovation in the financial sector, banks may be able to derive revenue from selling identity information related to their current customers, thereby providing alternate uses of attestations as to a counterparties willingness and ability to repay.
} 
identity costs preclude many individuals from accessing banking and financial services. High costs of compliance in the form of KYC requirements can become barriers for certain classes of consumers; if marginal identity costs incurred are larger than marginal benefits received, lenders will not enter certain transactions. In this way, the unbanked and the underbanked have identity origins (Durner and Shetret 2015).

The positive nature of identity costs is readily understood when one considers the human and information technology resources that are used to provide some security against the uncertainty which is endemic in a world of bounded rationality, opportunism and informational asymmetry. One can readily understand the nature of the identity costs which traditional financial institutions incur in satisfying these commercial and compliance considerations which are required when entering such a credit relationship.

\subsection{The nature and measurement of identity costs}

I have now given a stylised description of a credit transaction, and established that transactions include an identity component. That is, I have contributed the existence of identity costs to the transaction cost literature. This is so because there are frictions, costs and other impediments involved in establishing the identity of; a counterparty; the item of value to be exchanged; and the medium of exchange used as part of the transaction. The identity of money was assumed to be outside the scope of this model. The measurement of transaction costs as they relate to resource allocation has been highlighted as an important and worthy research area since Arrow $(1969)$. Coase $(1988,6)$ similarly describes transaction costs and their measurement as key to understanding the economic system, as well as "a basis for determining policy". To this end scholars since Wallis and North (1986) have made attempts to measure the extent of transaction costs.

Wallis and North (1986) first attempted to formally measure the extent of transaction costs across an economy, using transaction services as a proxy. It is important to note that transaction services incur only those transaction costs that result in a market exchange, and they concede that other transaction costs not resulting in any market exchange are excluded using their methodology. Wallis and North (1986) conclude that transaction services comprised 45 per cent of the US economy in 1970, up from 25 per cent in 1870 . To come to this calculation, they used as a proxy 'transaction services' which can be delineated into two types. The first arises from 'transaction industries', which include the National Income and Produce Accounts (NIPA) of "Finance, insurance and real estate; Wholesale Trade; and Retail Trade" (Wallis and North 1986, 103). The second type of transaction services they define are those observable transaction costs which are incurred in industries outside of the transaction sector. The wages of those workers engaged in these two types of transaction services are then estimated, and aggregated.

In addition to that of Wallis and North (1986), other studies have since attempted to measure the extent to which transaction costs comprise market based economic activity. Dollery and Leong (1998) used the same methodology as Wallis and North (1986) to measure the level of transaction costs in the Australian economy. Polski (2001) attempted to quantify transaction costs in a more precise way, studying the level of transaction costs within the financial industry. The variation between the methodology used by Wallis and North (1986) and 
Dollery and Leong (1998), compared to that used by Polski (2001) should be apparent; while the former three studies defined the finance sector as a pure transaction industry, the latter characterised the industry was comprised of both transformation and transaction components.

Scholars have since attempted to include non-market transactions in their measurement of transaction costs. According to de Soto (1989) these include estimating time engaged in administrative activities, paying bribes to officials, obtaining permits and other non-market costs as described by. Other scholars have concluded that ex-ante, non-market transaction costs may be higher in developing, rather than developed, economies (Kachwamba and Sæb $\varnothing$ 2011). I have introduced identity costs as a subset of transaction costs, and I now suggest their nature and provide some brief illustrations as to how they might be measured in the future.

Using the Polski (2001) methodology, it might be feasible to identify, and suggest how to quantify the level of identity costs in an industry. For instance, Polski (2001) described the commercial banking sector as generating two types of transaction costs. One, the interest expense, is the cost of borrowing funds, while the second are those which "reflects the costs of information and coordination" (Polski 2001, 4). As discussed earlier, credit transactions incur both private and public demand for identity; financial institutions incur identity costs related to both commercial and regulatory considerations. As I have shown in my model, prior to entering credit relationships with borrowers, profit maximising firms in the finance industry seek to determine the willingness and ability of borrowers to repay, and enter contracts with them that are priced based on metrics derived from credit checks. Similarly, financial institutions are also typically required by financial regulators to conduct KYC checks of customers which relate to anti-money laundering and counter-terrorism financing (AML/CTF) requirements. These commercial and regulatory requirements incur identity costs. These are substantial. Globally, KYC requirements are a substantial burden on financial institutions. According to Thomson Reuters (2016), financial firms spend on average USD60 million a year complying with KYC requirements, and for some firms this can reach USD500 million. Compliance costs are in some cases so high that they are cited by some financial institutions as the reason they do not serve some markets; high, and rising, identity costs preclude many individuals from accessing banking and financial services (Durner and Shetret 2015). As KYC costs function as a proxy for identity costs, total identity costs just in the financial sector can be assumed to be substantial if calculated using the methodology of Polski (2001).

Likewise, measuring identity costs may also be approached using the methodology of Wallis and North (1986) and Dollery and Leong (1998). This methodology determines that transaction costs which are incurred in industries outside of the transaction sector can be determined by "costs borne by the consumer that are not transferred to the seller of the good" (Wallis and North 1986, 98). It might be feasible to determine the identity costs that are borne by a bank in entering a credit contract that are not then transferred to a borrower through transfer of principal. An opportunity to examine identity costs across industries or even an entire economy would be a rich area for future research. 


\subsection{Identity costs and the nature of the firm}

Another contribution of this chapter is that certain hierarchical organisations-banks-exist because of identity cost economising. The transaction cost theory of the firm maintains that vertically integrated organisations exist because of transaction cost economising (Fallan 2000, Kemp 2006, Klein, Crawford, and Alchian 1978). ${ }^{39}$ Contractual arrangements, and their institutional context, whether market or hierarchy based, are in this way determined by "underlying differences in the attributes of transactions" (Williamson 1985, 68). Earlier in this chapter I raised the likelihood that different organisational arrangements might be considered from the context of identity cost economising. If the costs of determining contract relevant characteristics of a counterparty to exchange are sufficiently high, it might be advantageous to structure governance arrangements to economise on these costs. As described in this chapter, due to both commercial and regulatory reasons, identity costs in credit transactions are indeed high. I shall now briefly use the example of the financial industry, and retail banking more generally, to illustrate the ways in which certain hierarchical organisations exist because of identity cost economising.

Retail banking, or commercial banking firms, offer financial products including personal loans, mortgage loans, credit cards, and so forth. The model I have contributed as part of this chapter can be used as a lens to view hierarchical organisations, such as retail banks, in the context of identity cost economising (see Williamson 1985). Such an approach, using the broader category of transaction costs, has been used previously to examine integration and hierarchical organisation, for instance; in the automotive industry (Argyres and Mostafa 2016); the semi-conductor industry (Leiblein and Miller 2003); and to examine potentially anticompetitive behaviour (Levy, Spiegel, and Gilo 2018, Williamson 1985). What I now seek to do is describe retail banking from an identity cost perspective, and trace the existence of such banking firms to reasons of identity costs minimisation and conditions of asset specificity. I outline the key finding from this section in Table 2. below.

\begin{tabular}{|c|c|c|}
\hline & Spot market transaction & Credit transaction \\
\hline Uncertainty & $\begin{array}{l}\text { Uncertainty absent, no potential for } \\
\text { ex-post divergence from ex-ante } \\
\text { expectations. Necessarily involves a } \\
\text { 'search' good. }\end{array}$ & $\begin{array}{l}\text { Uncertainty present, potential for ex-post } \\
\text { divergence from ex-ante expectations. } \\
\text { Necessarily involves an 'experience' good. }\end{array}$ \\
\hline $\begin{array}{l}\text { Frequency of } \\
\text { exchange }\end{array}$ & $\begin{array}{l}\text { Large establishment and ongoing } \\
\text { identity costs not justified. No } \\
\text { identity costs to amortize over the } \\
\text { course of a relationship. }\end{array}$ & $\begin{array}{l}\text { Large establishment and ongoing identity } \\
\text { costs justified. Significant fixed and variable } \\
\text { identity costs to amortize over the course of } \\
\text { a relationship. }\end{array}$ \\
\hline Asset specificity & $\begin{array}{l}\text { No necessity for investment in } \\
\text { specialised assets to determine, and } \\
\text { monitor, identity of counterparties. }\end{array}$ & $\begin{array}{l}\text { Specific assets necessary to determine, and } \\
\text { monitor, identity of counterparties. }\end{array}$ \\
\hline Identity costs & Zero & Positive \\
\hline Governance structure & $\begin{array}{l}\text { Market. No value in identity cost } \\
\text { economising. }\end{array}$ & $\begin{array}{l}\text { Hierarchy (bank). Value in identity cost } \\
\text { economising. }\end{array}$ \\
\hline
\end{tabular}

\footnotetext{
${ }^{39}$ Here I examine the implications for economies of scale in certain types of organisations. Economies of scope are not considered as part of this analysis.
} 
In a highly-stylised view of retail banking, financial institutions seek to aggregate surplus financial capital, and allocate that capital to individuals and organisations who require it. The holders of surplus capital-lenders-deposit their excess capital into financial institutions, which then lend out those funds to borrowers. A difference between the interest paid, and that received, is the net interest income for a bank which offers these simple financial products. However, in principle, such an arrangement might occur through decentralised market based interactions. I shall briefly describe how this might work.

In a decentralised fashion, an individual lender advertises the amount they are willing to lend, the duration of any credit relationship they are willing to enter, and the price they are willing to receive (the rate of interest). It should be noted that such a rate of interest might itself be based on a credit check to determine the relevant risk premium. In the event there is a double coincidence of wants-a borrower is found who satisfies the lenders criteria-a credit contract is created. Now consider identity costs which might be incurred in the process of such a decentralised market based transaction. Recall that ex-ante transaction costs may consist of search costs, costs associated with negotiating, or the drafting of agreements, while ex-post transaction costs include those associated with the governance structure related to the monitoring of an agreement and dispute resolution (Arrow 1969). Also recall that identity costs are those transaction costs which relate to reaching a level of assurance over the identity of one's counterparty, the nature of the good or service to be exchanged, and so forth.

I have already determined that in a credit transaction, identity costs are greater than zero, without yet offering a determination as to why such credit transactions might typically be conducted through hierarchical organisations, rather than through decentralised market exchange. The commercial and compliance considerations discussed earlier are the origins of such identity costs, which must be met and satisfied by any lender with profit motives, and who also has a desire to operate within legal limitations. Credit checks, obtaining documentation and attestations as to the willingness and ability for borrowers to repay, are ex-ante identity costs, to which must be added search costs to find suitable borrowers in the first place. Similarly, ex-post identity costs pertaining to monitoring a borrower throughout the course of a contract are also incurred. To perform these requires specialist knowledge; the pricing of credit risk for instance, and the knowledge required to comply with complicated financial legislation and regulations require significant investment in human capital and information technologies. Such asset specific investments related to credit risk and compliance obligations imply that for reasons of identity cost economising, such tasks will be carried out within a hierarchical firm. In effect, lenders amalgamate within the hierarchy of a commercial bank to economise on both ex-ante and ex-post identity costs (Klein, Crawford, and Alchian 1978).

As I have shown with my model, a transaction cost, and now identity cost, theory of the firm suggests that institutions such as banks amalgamate groups of lenders-or more accurately, they amalgamate their surplus financial capital-into one organisational entity due to identity cost economising. Identity technologies like government issued identification, as well as income statements and credit reports are expensive to collect, verify, and therefore utilise to 
coordinate commercial activity; banks economise on these costs. Vertical integration to save on such identity costs is also dependent on the identity technologies available. New ways to coordinate economic activity, and costlessly verify identity information passed on by counterparties may cause such economies of scale to disappear. Blockchain and distributed ledger technology, first seen in the Bitcoin cryptocurrency (Nakamoto 2008), along with associated technologies like public key cryptography and zero knowledge proofs may allow counterparties to provide attestations about themselves with probabilistic certainty that the relevant attribute is correct, reducing identity costs substantially (Casey and Vigna 2018, Swan 2015). In this respect Berg, Markey-Towler and Novak (2020) provide an overview of the way blockchain technology might provide new infrastructure for the purposes of identity attestations and management, including as it relates to 'self-sovereign identity'. Such blockchain applications might allow individuals or organisations to makes claims as to their income, past credit history and pass on other relevant identity information at greatly reduced cost.

\subsection{Conclusion}

The underlying theme of this thesis posits that economic and political actors are heterogeneous; they have varied endowments, tastes, and preferences. This heterogeneity breeds uncertainty. As such, the absence of countervailing institutions would likely stifle human interaction. One major contribution of this chapter has been to develop an identity cost model of exchange, and outline one such mechanism by which economic actors purchase predictability as to the future state of the world, by divining private information from a counterparty to exchange. This desire for predictability manifests itself in the demand for identity, which as I have shown can be both private and public. This private information is related to an individual's willingness and ability to repay a loan, in part based on their previous actions. These previous actions make this model 'backward looking', as identity costs incurred reveal private information which is derived from what an economic agent has done in the past. That is, if you have acted this way in the past, I can reduce uncertainty as to the future state of the world by assuming you will act in a similar way in the future. An identity institution which is 'forward looking' is examined in Chapter 4.

The mainstream view of economic exchange, whose contributions resulted in a substantial economic literature examining the price system (Demsetz 1988), paid little regard to the costs involved in market functionality. Indeed, if such a price-centred theory of exchange was comprehensive, reputation mechanisms, credit reports, government issued identification, and other identity technologies with which to transmit non-price information would be superfluous. From such a perspective, a decentralised market economy would function to allocate resources based solely on information transmission through relative prices (see Hayek 1945). To be sure, this is not the world in which most exchange occurs. Acknowledging the deficiencies in such an analysis, and through the inclusion of identity costs, reveals that during most exchange, information related to the identity of people, goods and things is exchanged concurrent to the exchange of value.

Using the transaction cost framework of uncertainty, frequency and asset specificity (Williamson 1985), I have developed a model which determines that transactions incur identity costs, and that those identity costs are present in all but the most trivial forms of 
exchange. This model uses a highly-stylised credit contract to show the way in which lenders incur non-trivial costs to counteract-and reveal-private information held by borrowers. To be sure, the 'production', purchase, or attainment of such private information is assumed to be exogenous for the purposes of this model. In Chapter 4 I relax this assumption and describe the way individuals can cultivate a reputation as a trustworthy borrower, and so forth.

Individuals and institutions, for commercial and compliance reasons, are incentivised to come to a level of assurance over the identity of their counterparty, as well as the item to be exchanged, which varies according to the complexity of the transaction. These same identity characteristics can also impact on the price at which exchange occurs, particularly in credit transactions. Identity information is exchanged via identity technologies, which include government identification and reputation. Identity costs are also quantifiable, and warrant further study. Proxy measurements, including the expense involved with satisfying KYC regulations, suggests that identity costs are substantial, especially in the finance industry.

As identity costs are a distinct and significant subset of transactions costs, another contribution of this chapter is that hierarchical organisations like retail banks exist to economise on identity costs. Groups of lenders aggregate the expense involved in determining the identity of borrowers, and the basis over which they transact. Such vertical integration is dependent to a great degree on available technology, with new ways to assert claims about oneself, including using blockchain technology, presenting ways in which such hierarchical organisations might see institutional competition (see Berg, Markey-Towler and Novak 2020). 


\section{Chapter 4. A hostage model of identity}

\subsection{Introduction}

The main contribution of this chapter is to advance a private ordering mechanism of hostage exchange where identity assets are offered as credible commitments. These identity assets are supplied as part of exchange because there is value to the offeror in doing so. As I shall demonstrate, the supply of identity can lead to access to closed networks, while favourable pricing decisions can be reached through their use. These identity assets are then at riskthis is what I term 'identity at risk' - of exploitation by the wronged party in the event of noncompliance with ex-ante expectations.

Credible commitments have long been understood to constrain the actions of counterparties (see, for instance Schelling 1960). Owing to the heterogeneous nature of economic and political actors, human behaviour is difficult to predict; the endowments, tastes, and motivations of heterogeneous actors are private information. Underpinning this thesis is the idea that identity serves to overcome this inherent uncertainty. Here, and throughout the thesis, identity is a vector of characteristics associated with a unique individual that allows other individuals to recognise them, or allow differentiation from other individuals.

Without mechanisms by which uncertainty might be overcome, the ability to "truck, barter, and exchange" is constrained (see Smith 1776a, 117). As described in this chapter, one mitigative form are those motivational constraints on the future actions of individuals. Constraining the actions of a counterparty to exchange limits their choice set, and therefore increases the predictability as to the future state of the world. In contrast to the role of identity as examined in the previous chapter, this current chapter sees an individual's identity-as derived from past actions and therefore their history-as 'forward looking'. That is, placing what I describe as an 'identity asset' at risk restricts the choice set of an individual, and therefore increases the predictability of the future state of the world.

Crucially, the constraints I describe in this chapter form a type of privately devised and enforced apparatus which is not derived, or dependent, on state authority (Stringham 2002, 2015). As developed by Williamson (1983, 1984), the exchange of hostages is one such mechanism used to support exchange in the presence of uncertainty, as derived from the combined behavioural assumptions of bounded rationality and opportunism. Williamson's original model sees those hostages placed 'at risk' by the posting party, and subsequently at the disposal of the other party should there be ex-post deviations from contractual specifications. In this respect, these hostages bear similarity to a 'bond' or a 'deposit' common in many bilateral contracting arrangements (see, Milgrom, North, and Weingast 1990).

The role that these identity assets play in economic exchange (offered as credible commitments) is important for several reasons. The first of these is that exchange relationships in the absence of perfect information rely on institutions to "substitute for this knowledge" (Benson 2000, 26). Without these institutions trade is subdued, with good quality products 'driven' out of the market (Akerlof 1970). Here, the identity of counterparties to exchange is a fundamental aspect of most trading relationships. An absence of knowledge as 
to the identity characteristics of a counterparty would likely rule out otherwise profitable trades (Akerlof and Kranton 2000, Ben-Porath 1980) owing to the prevalence of informational asymmetry (Akerlof 1970, Spence 1973, 1974, Rothschild and Stiglitz 1976, Section 2.2.1). Markets in their various physical and virtual forms are not comprised of anonymous and homogenous participants (Demsetz 1988, Williamson 1985).

A second (related) reason for the consideration of identity in economic exchange is that pricing decisions are not made solely on the attributes of that which is traded (Allen, Berg, and Markey-Towler 2019). This reflects pricing decisions which in turn echo the probabilistic likelihood of opportunism and other uncertainties in future behaviour.

A final reason reflects the importance of the exchange of identity assets in the absence of efficient or costless public ordering mechanisms. As the private ordering literature makes clear, efficient public ordering solutions to contractual disputes are not always applicable. Yet the absence of enforceable international commercial law (see Rasmussen 2000), the 'low trust environment' of the internet (see Benson 2000), as well as dysfunctional systems of public courts in developing nations (see McMillan and Woodruff 2000) does not result in an absence of productive activity in these areas. Rather, contractual relationships emerge and persist, facilitated via private ordering solutions which make these contractual relationships worth establishing in the first place. As Stringham $(2015,59)$ notes, the cooperation observed in economic exchange cannot simply and solely be attributed to the "threat of law". This is in no small part due to the advantages contracting parties have in monitoring and evaluating the actions of their counterparties over time, compared with the more limited ability of a public institution to do so (Charny 1990).

This chapter provides a logical extension to the original hostage model of exchange. My contribution is a model with a three-part contracting period to demonstrate the supply of identity. In the first, traders incur costs to manufacture identity assets which can then be used in future transactions. In the second, traders negotiate contracts, in part based on these identity assets. These are then placed at risk of exploitation in the event of ex-post divergence from ex-ante expectations. Crucially, the presence or absence of those identity assets allows for the participation in certain activities or networks. In the third part of the contracting period, identity assets are either returned unharmed, or exploited if those contractual expectations are not met. As I shall discuss later in this chapter, this model anticipates that individuals might be seen to place certain aspects of their identity 'at risk', to participate in certain transactions, as well as be accepted into certain networks.

The model I have developed, where individuals place their 'identity at risk' as a prerequisite to participate in certain human interactions, predicts and explains some common behavioural practices. For instance, it is difficult to explain the value of a letter of recommendation without considering the use of an identity hostage. If there were no motivational constraints on the issuance of a recommendation, there would be little to prevent an individual from writing them for every person who asks for one. Only when there is the potential for reputational (or other) damage might this practice be expected to be constrained. As popularised by Donnie Brasco, the 1997 film starring Johnny Depp and Al Pacino, when the mafia member who vouched for the undercover FBI was murdered, sanctions can in some cases be extreme. The film 'Donnie Brasco' was of course a product of Hollywood, however it 
portrayed real life events by the New York mafia in the 1970s, and revealed the ways in which closed networks protect their exclusivity.

Restricted computer networks would similarly lose the value of exclusivity in the absence of such a behavioural constraint on gatekeepers. If a gatekeeper to a closed network could grant access to anyone they so choose with no negative consequences to themselves, such a network would soon become little distinguishable from an open one. Some asset of the gatekeeper must be available for exploitation to constrain indiscriminate access to permissioned networks. Examples throughout this chapter will further elaborate on these predictions.

This chapter proceeds as follows. Section 4.2 introduces and outlines the original model of hostages as credible commitments as originally set out by Williamson. Section 4.3 introduces the hostage model of identity. Here I contribute two versions of my model, provide examples to illustrate, and discuss interesting aspects of the model. Section 4.4 concludes the chapter.

\subsection{Hostages as contractual safeguards}

The exchange of hostages as a means to 'tie ones hands' (Schelling 1956, 1960) is a private ordering solution to (contract) uncertainty. This uncertainty is derived from the behavioural attributes commonly assumed in transaction cost economics. As such, rather than being a quaint holdover from a bygone era (Schelling 1956 footnote 17), the use of hostages in supporting "exchange is widespread and economically important" (Williamson 1983, 537, see, also Williamson 1984). As originally set out by Williamson (1983), the use of hostages is a model which rejects theories of exchange in which contract disputes are assumed to be able to be cheaply, reliably and impartially settled through courts.

Hostage exchange therefore runs counter to any tradition of 'legal centralism', where judgement is administered authoritatively and expertly by the state (Galanter 1981). That is, their use consists of a type of 'contractual safeguard' (Williamson 1985) which incentivises one or both parties to a transaction to continue with the contractual agreement without deferring to a third-party (state) actor (Hayek 1948, Klein and Leffler 1981, Telser 1980). According to the model I develop in this chapter, these types of commitments incentivise cooperation even in circumstances where recourse to courts of law and other legal mechanisms are not available (see, for instance Schelling 2006, Campana and Varese 2013, Gambetta 2011). ${ }^{40}$

Williamson's original model sees a hostage situation as a viable governance arrangement due to the combined consequences of bounded rationality and opportunism. Bounded rationality

\footnotetext{
${ }^{40}$ The implications arising from the use of commitment devices-of which hostages are one type-have been studied in literatures including; development and new institutional economics (see, for instance Acemoglu and Robinson 2006, Boettke 2011, Coyne and Boettke 2009, Klein 1980, Klein and Saft 1985, North 1993, 2005, Williamson 1994); game theory (see, for instance Mlicki 1996, Nakayachi and Watabe 2005, Schelling 1960, Swedberg 2001, Weesie and Raub 1996, Raub and Keren 1993); marketing (see, for instance Dwyer, Schurr, and Oh 1987, Rokkan, Heide, and Wathne 2003, Wetzels, De Ruyter, and Van Birgelen 1998, Williamson and Ghani 2012); as well as social psychology and sociology (see, for instance Sabatelli and Cecil-Pigo 1985, Scanzoni 1979).
} 
acknowledges the intendedly rational but limited cognitive abilities of economic agents (Simon 1957, 1961, Williamson 1975), while opportunism describes "self-interest seeking with guile" (Williamson 1985, 47). To these should be added a third aspect of the transaction costs framework, that of asset specificity. This describes a spectrum where, at the extreme, assets specific to some exchange have little or no use outside that relationship (Williamson 1985). To be sure, they might be redeployed, but at heavy productive discount to their original intended use. Chapter 3 of this thesis examines these elements as they relate to transaction cost economics, and particularly identity costs, which I have contributed to the literature. I now briefly describe the hostage model as set out by Williamson $(1983,1984)$.

Williamson's hostage model consists of two-periods with buyers and sellers. Buyers and sellers are both risk-neutral and profit-maximising. In the first period buyers order the product. Any necessary investments in productive capacity are made in this first period by the seller. These investments can be of the general purpose, or specialised, type. In the second period, the buyer makes the decision to confirm the order and take delivery of the good in question, or not. As is typical of the transaction costs literature, the assumptions of bounded rationality (Simon 1957, 1961) and opportunism (Williamson 1985) are employed. These have the consequence of creating uncertainty as to the future state of the world.

Williamson's hostage model broadly considers two potential contract fulfilment arrangements, which largely differ depending on the technological alternatives used. In the first circumstance a general-purpose technology can be deployed to produce the good in question. This general-purpose technology is, by definition, largely fungible across uses; it can be redeployed to other uses with no material loss of productive capacity. In contrast, a special-purpose technology might also be used to fulfil the terms of the contract (Williamson $1985,1991)$. The special-purpose technology differs in productive efficiency, being better able to produce the requisite good than the general-purpose technology. However, one cost incurred by the producer is the exposure to the risk of reduced value in alternate. Here it is illustrative to view the investment in such a special-purpose technology as being at least in part 'sunk', or 'non-salvageable' (Klein and Leffler 1981). In comparison, the general-purpose technology, when used in some other process, has a near absolute salvage value.

To illustrate the trade-offs between these two technologies, Williamson demarcates the two periods of a model contract. In the first, buyers place an order. It is here also where productive technologies are deployed, and where associated costs are incurred. The second period is where buyers take delivery, or choose not to. In contrast to a general-purpose technology, whose entire value-at the extremity of the asset specificity spectrum-can be realised through redeployment to an alternative use, a special-purpose asset can only be redeployed at a material loss of productive value. Thus, as the use of the specialised technology increases, vertical integration becomes a more attractive governance arrangement due to the increased (opportunism) cost of contracting (Klein, Crawford, and Alchian 1978, Williamson 1985). However, by offering a hostage, the buyer presents a credible commitment which is a contractual safeguard from the perspective of the seller. This model sees the seller indifferent to the use of technology, as the hostage-appropriately valued by the buyer (Raub and Keren 1993, Williamson 1983)-provides sufficient incentive to abide ex-post with the ex-ante contractual arrangements. 
The posting of hostages is not necessarily the sole purview of the buyer. Mutual hostage posting is also a viable governance arrangement. This arrangement sees both buyer and seller exchange valuable resources which would be lost in the event of ex-post opportunism (Milgrom and Roberts 1992, Williamson 1985). The use of hostages is therefore motivationally credible, rather than imperatively so (Shepsle 1991, see, also North 1993). ${ }^{41}$ As such, absent the provision of a hostage, goods produced by specialised technology will see a higher price charged to the buyer; buyers "should not expect to have their cake (low price) and eat it too (no hostage)" (Williamson 1983, 538).

\subsection{A hostage model of identity}

The exchange of hostages as a commitment device is a means by which one's exchange 'opportunity set' is expanded (Shepsle 1991). Rather than being a historical oddity from the ancient world (see, for instance Panagópoulos 1978, Allen 2006), hostages are an effective means to commit not to "renege on the promises made in the past" (Coyne and Boettke 2009, 5). Importantly, this also has some effect on the price of that which is exchanged, depending on the presence or absence of the hostage, as well as the value of that hostage (Williamson 1983). How, therefore, can hostage taking be extended to a more generalised model of exchange? In this section I develop a hostage model of identity, and subsequently describe some aspects and novel variants of this simple model. The development of this hostage model of identity is the main contribution of this chapter. In addition, I expand on the concept of identity assets-information assets-as they relate to this (modified) hostage model. As I will set out, a simple hostage model of identity sees hostages posted in a motivationally credible way. In addition, and dependent on the governance arrangement of the exchange scenario, hostages can be either exploited through execution, or revelation.

As my contribution to this literature will demonstrate, the model I set out is more dynamic as compared to the original. The nature of this dynamism will become apparent throughout the chapter. While the original model concerns unilateral or bilateral trade, the model I set out below is multilateral; it considers $n$-sided interactions (Origgi 2017). The nature of $n$-sided interactions is set out in Section 2.2. I assert that this is more realistic in that it accounts for the role in which information dissemination networks, and indirect interactions (see, Alexander 1987), play in screening, constraining behaviour (Ostrom 1986), as well as delivering sanctions (Carr and Landa 1983, Posner 1996). In addition, the identity hostages used in my model are information assets, in contrast to the financial-or otherwise tangibleassets as used in Williamson's model. This point is further expanded upon in the remainder of the chapter.

\footnotetext{
${ }^{41}$ Odysseus having himself tied-up by his crew to resist the temptations of the Sirens would be an example of a commitment having imperative; he had no agency to act otherwise as he was physically incapacitated (see, for instance Boettke 2011, Shepsle 1991). William the Conqueror burning his ships after landing in England was similarly imperatively credible (Milgrom and Roberts 1992).
} 


\subsubsection{The basic hostage model of identity}

In my model there are buyers and sellers. Both are risk-neutral and profit maximising. The model consists of a contracting period broken up into three parts. In the first, individuals make decisions to purchase, and are otherwise allocated, identity attributes. In the second, decisions to enter a contract to purchase a product are made. This second period sees any investment in productive capacity made by the seller, along with the posting of any hostages. In the third period, orders are confirmed, and delivery is taken, or not. In this third part, the fate of the hostage is decided. This is dependent on the ex-post state of the world, and how that conforms to ex-ante contractual expectations. I shall now elaborate on my hostage model of identity.

The first part sees individuals purchase, or have allocated to them, identity assets. Their purchase consists of both financial, temporal, and other sacrifices such as educational attainment to cultivate a reputation, and so forth. Identity assets are also allocated exogenously as I discuss later in this section. At the outset, it should be stressed that their nature is 'suggestive' rather than 'definitive' (Williamson 1983).

The second part of the model is where exchanges are negotiated and orders are placed. Crucially, identity assets serve to disaggregate economic actors on an ex-ante basis (Shapiro 1983b). That is, decisions to allocate resources will not just be made based on the vector of characteristics of the good or service in question (Lancaster 1966, 1971, Allen, Berg, and Markey-Towler 2019), but also on the qualities of the identity assets posted by counterparties to exchange. That is, decisions to allocate resources are made based on the identity of the individual-the vector of characteristics associated with that unique individual. It is the communication of identity assets that I characterise as the posting of hostages. Put another way, identity assets posted as hostages to facilitate some exchange consist of the identity at risk by the posting party. Another contribution of this chapter is the introduction of identity at risk, and the analysis of this identity institution in facilitating economic exchange.

What I define as identity at risk (laR) is an information asset subsequently put in a position where it is exploitable by the counterparty in the event a promise is reneged on. As I later explain, this exploitation can occur in one of two ways. This exploitation can be via execution, or revelation, depending on the context of the original underlying transaction or exchange relationship. The perceived value of the identity assets posted is reflexive of the 'trust' stimulated by the observation of those characteristics by other economic actors (Bolton, Katok, and Ockenfels 2005). That is, positive (negative) identity assets posted are likely to engender trust (distrust).

As Cabral $(2005,3)$ notes when talking about reputation, identity characteristics communicate the idea that another "is something", while 'trust' is the anticipation that they will "do something". Hence trust follows reputation. In this respect, Section 2.2 of the thesis outlines the economic literature on reputation. To be sure, identity characteristics and the trust they engender will be entirely context dependent. The acts involved with cultivating a violent reputation (Silverman 2004) will have an entirely different motivation to those acts involved with cultivating a reputation as an honest seller on an online marketplace (see, for instance Bolton, Katok, and Ockenfels 2004, Brynjolfsson and Smith 2000), or displaying a 
medical degree on an office wall. That is, these motivations-and hence the categorisation of what comprises 'good' or 'bad' identity characteristics in differing contexts-will be derived in large part by the 'group' in which the individual in question resides (Akerlof and Kranton 2000), as well as the exchanges they might be trying to pursue. This aspect is reminiscent of the behavioural prescriptions relevant to different social groups as set out in the 'identity economics' literature, which is outlined in Section 2.2.2.

Here it is also important to emphasise the pricing decisions made based on the identity assets posted by the negotiating parties. Absent any identity at risk, buyers "should not expect to have their cake (low price) and eat it too (no hostage)" (Williamson 1983, 538). To be sure, these identity assets - of which reputation is surely a critical one-can be derived from both the previous actions of that individual, as well as the previous actions of, or prejudice against (Becker 1957), the group which that individual is a member of. In this respect, Chapter 2 outlines the literature relating to the economics of discrimination, individual identity, group membership, and group identity.

The third and final part of the contracting period is where orders are fulfilled (or not). It is in this final part that any differences between ex-ante expectations and ex-post realities are evaluated, and which in turn impact on the wellbeing of the hostage, or alternatively its revelation to the world. The final part of the period also sees those evaluations function to produce assets which are then allocated as new identity characteristics to relevant parties. Due to the $n$-sided nature of this model, these exogenous allocations of identity characteristics are both direct, and indirect in nature. When they are direct, a counterparty harmed by divergence of expectations and actual performance will, say, refuse to engage in further exchange with the harmer (Trivers 1971). Indirect allocations of identity characteristics are enabled by information dissemination networks. These consist of characteristics being allocated to an economic agent, even by those who have not had direct past dealings with that individual (Alexander 1987, Nowak and Sigmund 2005).

Figure 2. on the next page illustrates a simple contracting schema of the hostage model of identity. In part 1, identity characteristics are allocated, either endogenously through costly action, or exogenously, as derived from actions taken in previous exchanges. In part 2, these are put at risk. It is here where pricing and other contractual decisions are made based both on the attributes of the good or service in question, and on the qualities of the identity assets posted. In part 3, the identity assets are exploited, or not. As I shall now discuss, this exploitation can the form of execution, or revelation. Exogenous allocations of identity characteristics made in the third part are consequently made available in subsequent periods. 

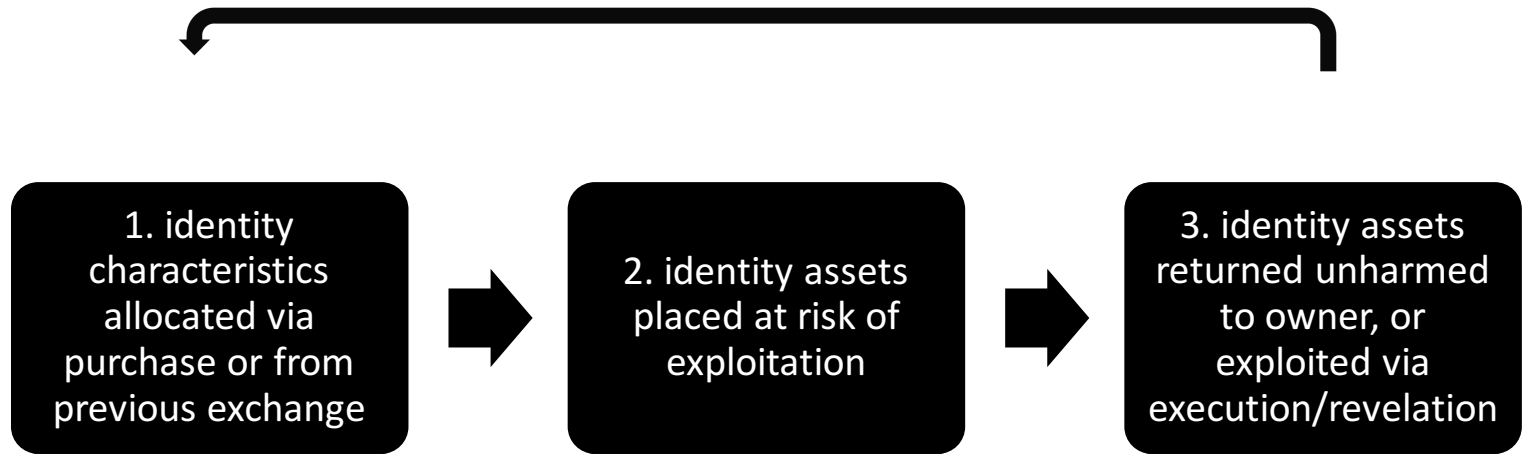

Figure 2. The three-part identity hostage period

\subsubsection{A scenario where the hostage is not exploited}

To further illustrate this model, consider situation (1) where some exchange is negotiated in the second part of a contracting period. As discussed earlier, an exchange will be entered into, whose terms are negotiated based on the attributes of that which is traded, as well as the qualities of the identity assets offered up by each counterparty. This exchange will include identity characteristics posted as hostage, at-risk of exploitation until the fulfilment (or not) of ex-ante expectations. During the third part of the period, assume satisfactory delivery of that which was promised by both parties to the exact ex-ante specifications. That is, in circumstance (1) there was no perceived ex-post divergence by either contracting party. Depending on the original contractual arrangements, this might mean that the relevant identity assets are released, unharmed and well-fed, with the possibility they might be used in the fulfilment of some future exchange by the posting party. To be sure, this circumstance might readily result in the manufacture of newly minted identity characteristics which can then be used in some future exchange. For instance, as an indicator that its possessor is a trustworthy counterpart, or something similar.

The allocation of new identity characteristics can be demonstrated in the case there is a positive divergence from the specified contractual arrangements. That is, over fulfilling contractual terms consists of a costly, and visible, action (Brooks and Wilson 2015) which can be used to allocate new identity characteristics. Indeed, this relates to a well-known customer service maxim; to 'underpromise and overdeliver' (Davidow and Uttal 1989) simply reflects the costly actions undertaken to be allocated new identity characteristics in the third part of the identity hostage period. A simple example from the management literature illustrates this: "I left my portfolio on top of a cab. The hotel broke its neck to get it back to me. Now, whenever I go to Chicago I stay at that same hotel" (Parasuraman, Berry, and Zeithaml 1991, 47). ${ }^{42}$

\footnotetext{
${ }^{42}$ There is also an inherent danger in underpromising. An exchange seen as unattractive will not be entered in the first place. To be given the opportunity to overdeliver-and hence manufacture new identity attributes-
} 


\subsubsection{A scenario where the hostage is executed}

In contrast, consider situation (2) in which a contract specifies the delivery of goods or services of specified characteristics, to a stated location, for an agreed upon price, and so forth. As per the model, the exchange has been entered, not only based on the express terms of the contract, but also upon the identity characteristics of the counterparties to exchange. It is these identity assets which are at risk, contingent on the fulfilment of the contract. In situation (2) assume a (negative) ex-post divergence is observed. Now the wronged party executes the posted identity hostages, in a manner which is visible to all future trading partners. In general terms, this simply means that identity assets that relate to, for instance, an entity's reputation as an honest merchant is 'executed' after they act deceptively, or otherwise in contrast to their reputation. This of course means that the positive reputation which they traded off in the past is no longer available to them.

As an aside, and with all respect to Oliver Williamson, this extension to his model of 'hostage as credible commitment', to a more general hostage model of exchange, is more akin to a hostage situation as it is generally understood. In the Williamson $(1983,1984)$ model, that which is posted as a hostage is more akin to a 'bond' (Milgrom, North, and Weingast 1990), or a deposit which is then available for use by the retaining party in the event it is forfeit. In contrast, the identity assets posted as hostage in my version of the model are inherently useless to the other party, and are hence 'executed' in the event ex-post realities differ from ex-ante expectations.

Some simple examples of this scenario now follow. First, consider an internet auction site. As described by Baron (2002), such a market, with trade occurring between anonymous participants, and in often disparate geographical locations and legal jurisdictions, provides ample opportunity for fraud. Yet sites like eBay have supported a flourishing ecosystem for trade. Even as the global nature of internet commerce meant that public courts were unable to costlessly enforce contracts (Benson 2000), early users of eBay began to provide public feedback on other users of the site, allowing the production of user reputation, as well as sanctions in the case of those who acted contrary to their ex-ante promises (Baron 2002). As such, sellers of items on eBay might follow through on promises made because their identity is at risk should they renege. Ex-ante, this hostage posting becomes part of pricing decisions, with a close correlation between lower prices paid to sellers with negative (or no) reputations (McDonald and Slawson 2002, Lee, Im, and Lee 2006). This provides a clear incentive for sellers on sites like eBay to undertake costly activity to build a positive reputation. One should not expect to 'have their cake (charge high prices on internet marketplaces) and eat it too (no reputation at risk)' (Williamson 1983, 538).

A similar example of an identity hostage being conducive to exchange can be seen in private peer-to-peer file sharing networks. Without an incentive mechanism, such networks suffer from free-riding problems (see Olson 1965) as individuals "consume resources without contributing any" (Satsiou and Tassiulas 2010, 466). To overcome this problem, such networks work off a system whereby individuals must place their identity at risk to participate. These

some minimum expectations threshold must be met. That is, there is a delicate balancing act between underpromising and any subsequent opportunity to exceed ex-ante expectations. 
peer-to-peer networks offer users the ability to download files, conditional on a user contributing resources to the network (Zhou and Hwang 2007). If a user acts contrary to these ex-ante expectations, that user's identity hostage is executed, with their participation in the private network barred. One should not expect to 'have their cake (download films and music for free) and eat it too (not contribute resources to a file sharing network)' (Williamson 1983, 538).

Next, consider a physician who has passed all medical examinations in their jurisdiction and is licensed to practice by the relevant authorities. As part of the exchange between physician and patient, the physician will put at risk their medical license, under the assumption that in the event of malpractice that licence will be forfeit. This forfeiture might occur should they perform in contrast to the maxim of 'first do no harm' (see, for instance Sokol 2013), or in violation of any of the relevant licensing regulations. That is, the right to practise medicine, along with the pecuniary and prestige benefits that it endows, requires placing an artefacta medical license-at risk of execution. Indeed, this is why medical practitioners do not practise their craft anonymously. One should not expect to "have their cake (practise medicine) and eat it too (no medical license at risk)' (Williamson 1983, 538). To be sure, any other profession which requires a licence to operate in a particular jurisdiction-for instance, auditors, mechanics, crane operators, hairdressers, and so forth-might have been used to illustrate scenario (2) (see Law and Kim 2005, Potts 2009).

The practice of providing references, say as part of a job recruitment process, also illustrates the posting of an executable hostage in widespread usage. 'Vouching' as to the employability of someone not only acts as a screening mechanism for future employees, but also consists of an intangible hostage posted by the person who acts as a referee. This method of recruitment is particularly important for younger people, who typically lack an abundance of other metrics by which to judge their suitability for employment (see Bartram et al. 1995). Of course, if the employed individual does not live up to expectations, anyone vouched for by that same individual in the future will have their prospects for employment commensurately discounted. That is, if I state that Alice is diligent, mature and never late, and she then turns up late to work regularly, the subsequent recommendation I provide for Bob is likely to be ignored. The associated identity assets are therefore executed and unavailable for future use.

A related, yet more extreme example of the reference letter as explained earlier, and the type of sanction applicable in the case that the individuals does not live up to expectations, can be seen in mafia crime families. Recruitment into criminal organisations suffers from the inability to use traditional tools like academic qualifications and wages to reveal the private information of applicants (Catino 2015). For instance, the screening mechanism discussed in Section 2.2 would not be applicable in these sorts of illegal organisations. To mitigate the problems of this information asymmetry (see Akerlof 1970) the mafia requires existing members to 'vouch' for potential recruits. This makes it difficult for police and other law enforcement agencies to infiltrate closed criminal networks, while placing the responsibility of recruitment into the hands of individual members. In the case of the Italian-American mafia, to become a 'made-man' (see Catino 2015) an individual must first be vouched for. The act of vouching for a potential member is not one taken lightly, as future actions of the individual vouched for can result in sanctions applied to those who have vouched. That is, vouching as to the suitability of someone consists of an intangible hostage posted by the 
person who acts as a referee. The sanctions in the event of betrayal are extreme. Consider that made famous in the case of 'Donnie Brasco', an undercover FBI agent who infiltrated the Bonanno mafia family. After the FBI infiltration was revealed, Dominick 'Sonny Black' Napolitano was murdered as it was he who had vouched for Donnie Brasco (see Crittle 2006, DeStefano 2008). In this case, the posting of an identity hostage results in not only an identity assets at risk of execution, but also the execution of individual who owns them.

Finally, hostage taking with the threat of execution is also reflected in modern contract law. Consider a corporation, who as Schelling $(1956,299)$ noted, has both the right to sue, as well as the "right to be sued". For the purposes of illustrating scenario (2), the latter privilege is novel, as entering into a contract as a corporate entity gives a counterparty the right to be sued in the event of a contract breach. A corporation "as a real entity that existed independently of its members" (Schane 1987, 568) exists in part to allow contractual partners the right to exploit that corporate identity in the event of contract breach. This very corporate identity represents the identity attributes at risk, and can therefore be executed (sued). Again, an entity should not expect to 'have their cake (trade under the privileges that a corporate entity enjoys) and eat it too (not be liable to be sued)' (Williamson 1983, 538). To be sure, a corporate identity also acts as a shield for the individual identities of shareholders. After incorporation, those individual shareholders replace their own identity at risk, with that of the corporate identity. This of course has the effect of limiting their liability.

\subsubsection{A scenario where the hostage is revealed}

A special version of my hostage model of identity is illustrative of the differing types of identity hostages which are used as part of economic exchange. In the revelation version, the hostage posted-the identity at risk-is not executed as in situation (2). Rather, those previously known only to the counterparties to exchange are made public. I shall label this as situation (3) and briefly elaborate. As in situation (1) and (2), some contract might be reached in which specified goods are to be delivered on specified terms. The identity asset is posted, but with the understanding that in the event of ex-post divergence, rather than that hostage being publicly executed, the hostage is led out into the public square, and displayed for all to see. This simply means that, although the identity asset is at risk throughout the exchange, it is exploitable in a different way.

This situation is best illustrated by individuals "sharing evidence of their misdeeds" (Campana and Varese 2013, 271, see, also Schelling 1956) to ensure cooperation in the absence of legal recourse. As described by Saviano (2019), this might involve a murder being committed by a large group even when only one participant would have been warranted to perform this deed. By all participants firing a shot-and crucially, being witnessed doing so-the incentive to inform on their fellow criminals is reduced through this hostage mechanism. The shared knowledge of the shared actions of this crime acts as a constraint on the actions of a potential and future informant (Catino 2015). Gambetta (2011) describes these acts as the creation of 'skeletons in the closet'. These skeletons have the effect of limiting the choice sets of individual members, and so provide some certainty as to the future state of the world.

An analogous commitment mechanism to that illustrated in the murder above has also been documented in paedophile rings (Gambetta 2011). Similarly, Schelling $(2006,11)$ recounts an 
Alfred Hitchcock story in which the identity at risk of revelation is, in the literal sense, tangible. In this story, a priest witnesses a man dropping a body down a well. The man then gives the priest a choice; join the body down the well, or handle the weapon and leave his fingerprints on the axe used to commit the murder. These fingerprints consist of a tangible identity asset exploitable by revelation should the priest attempt to alert the authorities to the crime.

As a final example, consider a cartel which coordinates price setting and other anticompetitive behaviour amongst its members. The act of forming a cartel gives its constituent members the 'right' to sell goods and services above market rates, which is for those firms beneficial. Yet, being close competitors, each member of the cartel has an incentive to inform on the other firms. Reputational damage done to a rival firm might feasibly have a positive impact on the sales of a firm selling a similar product. However, the very act of informing on another member of that cartel reveals the informing firm as a member of the cartel. The very reputational damage that the informing firm might like to inflict on their competitor, would also be self-inflicted if they went ahead and alerted the authorities. Put another way, one should not expect to 'have their cake (benefit from price fixing) and eat it too (no corporate reputation at risk)' (Williamson 1983, 538).

\subsubsection{The nature of identity characteristics}

In this chapter I contributed a hostage model of identity to the literature, which sees buyers post an identity asset-the hostage-which is at risk of execution or revelation in the event of ex-post divergence from contractual expectations. I have deemed this to be their identity at risk (laR). The main characteristics of this model are set out in Table 3. below. The execution of the hostage, or its revelation to the world occurs when ex-post contractual outcomes are less than ex-ante expectations. In contrast, when ex-post outcomes exceed ex-ante expectations, new and valuable identity characteristics might be allocated to the bearer.

\begin{tabular}{|l|l|l|l|}
\hline & \multicolumn{3}{|c|}{ Contractual outcome } \\
\hline $\begin{array}{l}\text { Hostage } \\
\text { exploitation } \\
\text { type }\end{array}$ & Ex-post = ex-ante & Ex-post < ex-ante & Ex-post > ex-ante \\
\hline Execution & Hostage released & Hostage executed & $\begin{array}{l}\text { Allocation of new (positive) identity } \\
\text { characteristics }\end{array}$ \\
\hline Revelation & $\begin{array}{l}\text { Hostage remains } \\
\text { hidden }\end{array}$ & Hostage revealed & $\begin{array}{l}\text { Allocation of new (positive) identity } \\
\text { characteristics }\end{array}$ \\
\hline
\end{tabular}

Table 3. Contractual outcomes and the fate of the identity hostage

At the outset, it was explained that the posting of these identity assets is necessary to overcome the effects of the uncertainty as derived from behavioural assumptions of bounded rationality and opportunism. In addition, hostages of the type as used in this model should be considered in respect to information asymmetry as it is examined by Akerlof (1970), Spence (1973, 1974) and Stiglitz (Rothschild and Stiglitz 1976). These literatures were outlined extensively in Section 2.2.1. In this section I will further outline the nature of these identity characteristics.

Identity characteristics are both information assets and "information transmission devices" (Kandori 1992, 65) from which potential counterparties can derive information about past 
instances of exchange. This screening mechanism is also buttressed by their role in facilitating sanctions in the event of past malfeasance by an individual (Carr and Landa 1983, McMillan and Woodruff 2000). ${ }^{43}$ In this respect they are analogous to 'labels' (see Engelmann and Fischbacher 2009, Trestian, Ormond, and Muntean 2011, Tullock 1985), or 'types' (see Bolton, Katok, and Ockenfels 2005, Bursztyn and Jensen 2017) as examined in the game theory literature. Crucially, these are produced both endogenously and exogenously. When produced endogenously, identity characteristics are purchased by costly-and ultimately visible (Brooks and Wilson 2015) - actions which are undertaken by the individual purposively to endow themselves with some chosen characteristic(s) (see Spence 1973, 1974, Caplan 2017, Charles, Hurst, and Roussanov 2009, DellaVigna et al. 2017, Sexton and Sexton 2014). In this respect, Spence (1973) describes the way in which 'signals' are costly actions (such as attaining educational qualifications) one might undertake to indirectly demonstrate their productivity to a potential employer. (This literature on information asymmetry is outlined at length is Section 2.2.1.) In addition, de la Vega ([1688] 2013 p.7) shows how traders of financial instruments in $17^{\text {th }}$ century Amsterdam undertook initially risky or unprofitable trades to endow themselves with a reputation of 'generosity' (see also Stringham 2015). Finally, Silverman (2004) describes the investment in a violent reputation by members of an 'underclass'. To be sure, committing a violent act incurs a direct cost, yet it can also aid in the manufacture of a reputation which might have some value in future exchange (see, also Ferrer 2010, Massey 1994). What these three examples share is that they consist of a purposive, self-directed action which have as their aim the endogenous allocation of identity characteristics which might be useful for future exchange.

In contrast to the endogenous variety-allocated via self-directed and purposeful actionexogenously allocated identity characteristics are those which are perceived by potential counterparties to exchange, and include those communicated to an interested party through indirect interactions. As Origgi $(2017,39)$ puts it, in n-sided interactions, information about past exchange is derived from "collectively gathered information and collectively shared evaluations". That is, past interactions can be "rewarded or punished by third parties" (Engelmann and Fischbacher 2009, 399, see, also Nowak and Sigmund 2005) if information is able to be transmitted by mechanisms including gossip, letter exchange, online reviews, and so forth. For instance, Zhang and Elsner (2017) show how groups of traders in central Asia from the $7^{\text {th }}$ to $9^{\text {th }}$ centuries acted as $n$-sided reputational networks, providing for a collective threat of punishment based on prior interactions with any trader in that same network. A similar mechanism was used in early $19^{\text {th }}$ century Mexican California (Clay 1997).

As I have shown in this model, along with purposeful and costly action, those derived from previous contracting periods are also added to an economic actor's set of identity characteristics in subsequent periods. Initially, I assumed that the valuation of the identity asset was clearly communicable to counterparties to exchange. A similar assumption was made surrounding their costless communicated to all potential trading partners. I shall now discuss some implications of these assumptions being relaxed.

\footnotetext{
43 The economic literature on 'reputation', 'labels', 'types' and other devices used for the purposes of communicating information about counterparties to exchange, as well as constraining opportunism, is large. In this respect, Chapter 2 provides an extensive overview of these literatures.
} 


\subsubsection{Some other aspects of the model}

Up to this point, I have not considered the valuation of the identity assets taken hostage as part of exchange. To be sure, this is an important aspect of the model, as the pricing of goods or services in a negotiation are in part derived from the perceived valuation of the hostage posted. That is, if a seller considers that the identity hostage posted by a buyer has great value to the latter, they will likely offer a better price in comparison to a buyer who offers a lower quality hostage. Similarly, the owner of a hostage whose revelation will cause great cost to them will receive a better price as compared to one whose revelation will cause little or no harm. This brings up the inescapable issue of the perceived valuation of the hostage posted in this hostage model of identity. For the lower (higher) price offered to a buyer who posts a high (low) value hostage is contingent on the value which the seller perceives that the buyer places on it. To be sure, this is a matter of 'subjective opinion', rather than being based on any 'epistemically objective fact' (Searle 2005, 4).

The inherent valuation difficulties lead to the possibility of varying expectations of the valuation of the identity characteristic posted as hostage, and the opportunity for the appropriation of 'quasi-rent' (Klein, Crawford, and Alchian 1978) extracted from the relationship by one of the parties. As Milgrom, North, and Weingast $(1990,1)$ write, credible commitments of this type rely on the expectation that the value of that placed at risk will prevent opportunistic behaviour, "unless the gain from dishonest behaviour was large". As such, if there is a mismatch between the buyer's valuation of the identity asset, and the seller's perception of the buyer's valuation of the identity asset, there will be the potential for the good or service to be mispriced. Such a caveat aligns in general with the assumption that exchange relationships do not in fact occur in an environment where parties have access to perfect information (Akerlof 1970, Demsetz 1988).

Finally, it is pertinent to consider implications for the model where the communication of identity characteristic is given a somewhat more realistic treatment. Here I more generally refer to information costs related to the cognition of the identity attributes owned, displayed, and offered as hostages by other actors. Owing to both bounded rationality and opportunism, I assert that past actions undertaken by economic actors are inevitably obfuscated to some degree by 'noise' (Bolton, Katok, and Ockenfels 2005). Although individuals 'signal' (Spence 1973) their characteristics or qualities, these 'signals' are necessarily imperfect (Grossman and Stiglitz 1980). The result of this 'noisiness' is that any idealised conception of identity characteristic as reflective of every past occurrence by the individual in question, will be necessarily bounded by "technological, economic or cognitive limitations" (Berg, Davidson, and Potts 2018, 5).

In addition, in considering this 'noisiness' it is useful to consider 'idealised', versus 'actual' states of the world. As Berg, Davidson, and Potts (2018) put it, if all economic, social and political transactions could be recorded absent transaction costs, these could all be mapped onto a perfect ledger. This perfect ledger, among other things, corresponds to all past transactions, is constantly updated according to actual changes in state, and is accessible and understandable by all. For the purposes of this model, this would mean that the idealised ledger would contain suitable information about the existence, and crucially the valuations, of identity characteristics as they relate to each economic actor. 
To be sure, the idealised state of the world is not the state of the world. The proximity to which the information available on actual ledgers corresponds with that of the perfect ledger will necessarily be derived from the information costs incurred by participants in this model. This will in turn be contingent on the technologies used to transmit those attributes (Acquisti, Taylor, and Wagman 2016). Similarly, the role of privacy is important to consider as it relates to any variance between the perfect ledger, and actual, ledgers as they relate to this model. As Posner (1979) puts it, privacy is contingent on the 'concealment of personal facts' which in itself might assist in the manufacture of a positive reputation. This simply means that an individual might have some incentive to keep hidden certain aspects of their previous instances of exchange (see, also Posner 1981, Acquisti, Taylor, and Wagman 2016). In Berg (2020) I outline some of the privacy features of various types of money technologies, and how they can be used to obfuscate past transactions, and by implication cultivate a reputation by omission. That is, identity assets as I consider them in this model will not necessarily reflect that which would be captured by the perfect ledger.

\subsection{Discussion and conclusion}

As highlighted by Williamson's hostage model, much of the literature on contract and exchange-implicitly or explicitly-assumes that public institutions like courts of law 'work well' (Williamson 1983, 537). However common behavioural assumptions including bounded rationality and opportunism, along with the inherent costs associated with accessing the legal system, all necessitate private ordering governance arrangements-including the use of credible commitments - to constrain the actions of counterparties to exchange.

The hostage model of identity I have contributed to this literature describes motivational constraints on human behaviour. Owing to the heterogeneity of the human population, uncertainty as to the future state of the world is endemic. In contrast to the 'backwards looking' identity cost model of exchange from Chapter 3 , the hostage model of identity is 'forward looking'. It anticipates human behavioural realities, and provides a framework to understand how interaction can occur in an environment where endowments, tastes, and motivations of heterogeneous actors are private information.

In this simple identity hostage model of exchange, individuals place at risk some aspect of their identity-a vector of characteristics associated with a unique individual that allows other individuals to recognise them, or allow differentiation from other individuals-as a prerequisite to entering into exchange, such as their reputation, occupational licence, past criminal activity, and so forth. This is what I have previously characterised as the supply of identity. Quite simply, anonymous exchange is not the default because it is only through the 'reidentification' of a contracting entity (Davis 2003, Davis 2010, see also Berg 2020) that trust, and hence complex exchange, can develop (see, also Akerlof and Kranton 2000, Arrow 1972c, Ben-Porath 1980). The ability to 'reidentify' an entity is of course limited; the veil of privacy is one way in which individuals seek to obfuscate their past, along with their past instances of exchange. So, while privacy is 'subjectively desirable', along with being a 'subjective experience' (Berg 2018), the very existence of privacy may have the effect of 'mispricing' the goods and services exchanged according to this model. As alluded to earlier, privacy, along with differing expectations of the valuation of the identity asset posted as hostage due to this imperfect information, gives the opportunity for 'quasi-rent' to be 
extracted from exchange relationships (see, Klein, Crawford, and Alchian 1978). The exact nature of the relationship between obfuscated identity and resultant pricing decisions is however, a question for further research. Nonetheless, I make two brief concluding remarks on this.

First recall that it is the perceived valuation of an identity hostage posted that determines (in part) contractual terms. This is, of course, a subjective matter rather than based on anything approaching objectivity (Searle 2005). This is no small matter. Convincing others of the worth (to themselves) of the identity hostage they post as part of a bargain might have a material impact on the terms of that trade. Indeed, we already know that persuasion makes up a significant share of economic activity (McCloskey and Klamer 1995, see, also Antioch 2013).

The second point I offer is that privacy regulations which seek to materially alter the way firms collect personal data will have some impact on the pricing and contracting decisions made as understood by my hostage model of identity. Any regulatory barrier to collecting personal data, such as the European Union's far-reaching General Data Protection Regulation (GDPR) (see, for instance Allen et al 2019, O'Brien 2016), will alter the terms of contracts negotiated and entered. Regulations such as the GDPR, which include the so-called 'right to erasure', or 'right to be forgotten', conceivably prohibit firms from taking identity hostages on an ex-ante basis (see, Council of the European Union 2016). Not understanding the economic role which identity hostages occupy will conceivably result in significant public policy error. I suggest that the role of privacy regulations and the way identity attributes are used for exchange is a rich area for further research. 


\section{Chapter 5. An economic theory of surnames}

\subsection{Introduction}

Throughout this thesis I have characterised identity as a vector of characteristics associated with a unique individual that allows other individuals to recognise them, or allow differentiation from other individuals. In this chapter I again turn to the supply of identity, where the supply of identity is a function of the need to differentiate oneself. In the case of the model of intergenerational property ownership I now contribute to the literature, this relates to the differentiation of oneself as the owner of property. Here I discuss an identity institution developed by political entrepreneurs aimed at maintaining ownership over property in the face of sovereign risk. This chapter is concerned with the economic and political origins of names. A main contribution of this chapter is that heritable surnames are an identity technology used to overcome information asymmetry, sovereign opportunism, and legal uncertainty. ${ }^{44}$

While previous chapters have looked at identity institutions as providing for some degree of certainty as to the future state of the world in the economic sphere, this and the following chapter look at uncertainty of outcomes in the political realm. That is, this chapter continues with the overarching theme of the thesis that human behaviour is unpredictable, and without identity institutions the opportunities for human interaction would be constrained. Political, and not just economic, actors are in possession of private information. (The literature related to information asymmetry and political actors in outlined in Section 2.2.1.) Identity institutions bring to light this private information, as well as mitigate opportunistic behaviour. Mitigating the opportunistic behaviour of the sovereign was a catalyst for the development of heritable surnames in Norman England after 1066. In this manner, heritable surnames are an identity institution, being "rules of the game" (North 1990, 3) in the interactions between a ruler and their subjects as it related to property rights over land. In contrast to the next chapter, this sees an identity institution used by the ruled to protect themselves from the actions of the ruler.

In brief, the model I contribute in this chapter is a multi-period one with many heterogeneous buyers and a monopoly seller. It describes the private supply of identity information to overcome uncertainty as it relates to property ownership and sovereign risk. In my model, first generation buyers undertake costly action to purchase an asset. This asset exists in an environment with sovereign risk (nationalisation). Owing to this sovereign risk, and in the presence of private information relating to the intentions of the monopoly seller, buyers take steps to constrain the future actions of that sovereign in order that they might pass the asset onto future generations of buyers, and thereby retain private control of the asset. This model anticipates that buyers will privately supply identity information-heritable surnames-for

\footnotetext{
${ }^{44}$ Names can be considered near universal, and provide a robust means for indirect interaction. While much of the scholarly literature concerning names reflect the interests of psychologists, sociologists and genealogists, it is somewhat surprising that an examination of the institutional arrangements which have led to names in their current format is absent from the economic literature.
} 
the purposes of "defining, protecting, and enforcing the property rights" (North 1990, 28) to land given to them following the Norman invasion of England.

The framework for this chapter is in part influenced by economic historians within the school of new institutional economics (NIE). These scholars are characterised by their understanding that an examination of the "interaction between demographic, technological, and institutional factors...provide fundamental insights into societal evolution" (North 1994, 1). The fundamental insight that NIE can provide to the study of historical periods is that the constraints under which human interaction occurs has a powerful explanatory effect on economic performance (Richter 2005). In this chapter, I will show that these 'constraints' can take the form of devices by which claims to assets can be bolstered, including the ability to pass those assets onto heirs.

Similarly, the new institutional economics of history (NIEH) takes as given that economic decisions are often inexorably and dynamically linked to political ones (North 1971, North, Wallis, and Weingast 2006). NIEH examines the dynamism of the economic and political institutions that govern human interaction, rather than considering them as given, or static, constraints (Ménard and Shirley 2014). I use this literature to frame the emergence and use of surnames as an identity institution which seeks to constrain the actions of both private and state actors (North 1990) in the protection of property rights.

This chapter examines the way in which, immediately after the Norman conquest of England, those who followed William from Normandy adopted surnames which (often) took the name of lands they had just occupied. These major landholders used surnames to bolster their claims to property in the face of sovereign risk, and facilitate the transfer of ownership to heirs. This process was rapid and explicit, with surname changes of wealthy landholders and their heirs closely reflecting changes to land ownership, along with the likelihood of inheriting specific landholdings. The process for those who did not have significant landholdings was commensurately slower. Not until the $14^{\text {th }}$ century did surnames slowly begin to become common among the lower classes in England. For those without significant landholdings, the inheritance of property played only a small role in their adoption of surnames. Often it was the calculation and enforcement of taxation obligations that led to the state, rather than individuals operating out of their own self-interest, facilitating the adoption of the technology. This is an example of an identity technology being first used in the private supply of identity, and subsequently used for the public supply of identity.

I suggest that surnames are an identity technology which alter or otherwise define property rights. Put simply, a contribution of this chapter is a model that illustrates how names-in particular, heritable surnames-have been adopted in the past to increase some potential economic payoff, along with its likelihood, through the internalisation of the benefits associated with property ownership. The model this chapter contributes, and illustrates with a case study, is that surnames are used by landholders to bolster their claims to property in the face of sovereign opportunism and sovereign risk, and to therefore facilitate the transfer of ownership to heirs. I also use the property rights literature of Demsetz $(1964,1967)$ and Riker and Sened (1991) to examine this process. 
The chapter proceeds as follows. Section 5.2 introduces a model of intergenerational property ownership under sovereign risk. Section 5.3 places this model into the context of England following the Norman invasion of the $11^{\text {th }}$ century. Section 5.4 discusses some further institutional economics of names, including several areas in which further research might prove fruitful. Section 5.5 concludes the chapter.

\subsection{A model of intergenerational property ownership with sovereign risk}

This chapter advances the view that, after the Norman invasion of England, those who fought for William and benefitted from land redistribution sought to strengthen their intergenerational ownership of land through the adoption of heritable surnames. Sovereign risk makes property rights commensurately weak, and the emergent identity technology of surnames imported from France is anticipated to have been adopted by wealthy landholders as one way to ameliorate this risk. According to the model I develop, the private supply of identity information-the adoption of surnames-constitutes an act of political entrepreneurship to temper acts of sovereign opportunism, and ameliorate the uncertainty associated with poorly defined legal rights (Libecap 1978). In this section, I contribute a model of intergenerational property ownership under information asymmetry, alongside sovereign opportunism and legal uncertainty. I also adopt the property rights literature of Demsetz $(1964,1967)$ as well as Riker and Sened $(1991)$ to frame this process, and to understand the origins of heritable surnames in the context of England from the mid-11th century.

In the Demsetzian approach, property rights emerge through economic imperatives. They emerge endogenously through the actions of market participants who derive value from internalising costs, and where the benefits derived from that action is greater than these costs. This sees such rights "develop to internalize externalities when the gains of internalization become larger than the cost of internalization" (Demsetz 1967, 350). Origins to these changes include new technologies, new markets, and changes in relative prices. Key to understanding this view is that the conservation of property rights will impose costs on the bearer of those rights (Demsetz 1964). Adapting this Demsetzian property rights view to the use of the identity technology, the gains to the buyers from internalizing the externality-the benefit of having possession of land granted after the Conquest, along with the right to pass it on to subsequent generations-would be greater than any costs associated with policing the use of the land and other associated transaction costs.

However, the legal-centric view (Riker and Sened 1991, Sened 1997) sees an additional two conditions as necessary for the emergence of property rights. In this view, the economic conditions of Demsetz are buttressed by political conditions. According to the legal-centric view, the conditions under which property rights emerge are 1) valuable rights, 2) where right holders desire those rights, 3) rule makers recognise and enforce those rights, and finally 4), other participants recognise and respect those rights. That is, scarcity and the need for the internalisation of externalities (Demsetz 1967) are necessary but not sufficient to account for the emergence of property rights. The shortcomings to just these two conditions are derived from an understanding of the nature of the actors who exercise authority in a polity. These are explicated in the form of two assumptions, which consist of 1) utility maximisation by political actors, along with 2 ) their ability to muster more military force and legitimacy than 
other actors (Riker and Sened 1991, Sened 1997). It is these two assumptions from which the additional conditions-over the Demsetzian approach-are derived. The first assumption follows from how political actors seek to maximise their utility via the expropriation of resources and other benefits derived from being in a position of power. In the context of the model, this sees the monopoly seller in "need [of] popular support", which can be paid for through grants, and opportunities for monopoly rents given to their supporters (Riker and Sened 1991, 954). The second assumption, and the one which emphasises the importance of a central political authority in the emergence of property rights, is the possession of a monopoly, or at least a majority share, in the use of "coercive force" (Sened 1997, 78).

The additional (political) conditions-recognition by a ruler, and recognition by other participants-given by Riker and Sened emphasise the role of politics in the granting of property rights, and to further the analogy and the model I develop throughout this chapter, the emergence of heritable surnames as an identity technology to secure property rights over land. The Demsetzian view of the emergence of this technology would see landholdersbuyers-adopt heritable surnames to lay an intergenerational claim over a valuable resource with sufficient potential future payoff to justify their use. In contrast, the legal-centric view of Riker and Sened (1991) would see 'rule makers' - the monopoly seller-give value to such an identity technology by their enforcement of property rights secured in such a manner. That is, rule makers must "desire to enforce the right" and be able to force others to "respect rightholders' claims" (Sened 1997, 79). ${ }^{45}$ Here the state-the monopoly seller in this model-must first derive a net benefit from the enforcement of rights to compensate for costs it incurs in doing so. Yet as outlined in Section 2.2.1, rule makers themselves can act as a source of uncertainty (see for instance Libecap 1978). This uncertainty includes their possession of a monopoly share of force giving them the de facto ability to redistribute land at will. That is, assets are held under sovereign risk, or nationalisation.

In this chapter I contribute to the literature a multi-period model. There are many heterogeneous buyers' and a monopoly seller. Buyers act as multi-generational utility maximisers. In the first period, a first-generation buyer attempts to define property rights over an asset. In the second period, a first-generation buyer bequests an asset to a secondgeneration buyer. In the third period, a second-generation buyer bequests an asset to a thirdgeneration buyer, and so forth. That is, in each period a generation of buyers leaves assets to their successors. The monopoly seller has private information about the future state of the world. In this model, the seller's private information relates to their intention to seize the asset, or not. Private information also relates to the ease in which a buyer will be endorsed to bestow an asset to their descendant, as permitted by the monopoly seller. As the monopoly

\footnotetext{
45 The role of the state in the property rights literature is contested. Alchian $(1965,817)$ states that the attribution of property rights to the enforcement of "formal state power" is a "gross error". To this end, Alchian recognises the importance of non-legal means including social norms, etiquette and voluntary conduct enforced by the threat of "social ostracism" which all supplement state power in securing property rights.
} 
seller is the sovereign of a nation-state, this is analogous to a buyer being having their asset under constant threat of nationalisation. ${ }^{46}$

As the monopoly seller transacts with buyers with the advantage of private information over their own intentions, it should be expected that the seller will use this private information to trade at circumstances favourable to themselves. The assets in question ought to then be considered as 'experience' goods (Nelson 1970). That is, their 'quality' is known only after purchase. The qualities, or the characteristics of this good-for our purposes the property rights associated with the asset-are perhaps known only after multiple generations. There is therefore uncertainty associated with property ownership, with buyers calculating a probability of security of ownership as it is understood in decision theory (Spence 1973). This model is also dynamic, in the sense that profit maximising buyers endogenously seek to mitigate the effects of private information by taking steps to bolster their claims to the asset they have already purchased. These efforts to bolster claims on assets are what I characterise as the private supply of identity information.

In this model buyers use a simple identity technology-heritable surnames-to economise on transaction costs associated with "defining, protecting, and enforcing the property rights to goods" (North 1990, 28). In this respect, such an identity institution might be considered as dynamic rather than static (Ménard and Shirley 2014), as buyers seek to constrain the future actions of a seller, and thereby 'manufacture' certainty of outcome. That is, buyers act as institutional entrepreneurs as they attempt to change the institutional environment from one of uncertainty of ownership, to one of private property in an absolute sense. Such an institutional environment would see buyers as having exclusive control over the asset, the right to receive income from the asset, as well as the right to transfer ownership of that asset in the manner they deem fit (see for instance Cheung 1974, 1983). As shall become apparent through this chapter, it is transfer of ownership that I focus on.

All of this leads to a testable hypothesis: given the existence of private information, sovereign opportunism and legal uncertainty, surnames will be adopted as an identity technology to bolster property rights over land. A related question this chapter seeks to answer is whether the adoption of surnames can be analogised using the Demsetzian, or the legal-centric, approach to the origin of property rights. This question will determine whether the adoption of this technology is contingent on the desires and actions of the seller who possesses monopoly force.

Using the institutional framework of the new institutional economics of history (NIEH), I seek to use the period after the Norman invasion to examine the role that surnames played in altering or otherwise defining property rights in England. Surnames are an identity technology which is an input to exchange, but are also an institutional factor which can be seen through the prism of institutional design in which groups "seek both to increase the magnitude of future payoffs as well as the certainty with which they will occur" (Bates 2014, 11). This desire for certainty is particularly relevant to consider in the context of elites seeking to maintain

\footnotetext{
${ }^{46}$ A monopoly seller might also be considered from a 'multi-generational' perspective. However, as there is typically only one sovereign at a time-save for a time of civil war, or perhaps in the case of a regency periodthis model uses the simplifying assumption that there is only one seller of the property assets in question.
} 
access to rents they have derived from some past political or economic relationship (North, Wallis, and Weingast 2006). I therefore seek to understand and describe the 'founding' of heritable surnames as an institutional factor in the provision of identity for the purposes of political and economic exchange in post-1066 England.

\subsection{Surnames in post-1066 England}

This section uses the period after the Norman invasion of England to illustrate my model of intergenerational property ownership with sovereign risk. Here I also draw some further conclusions as to the economic and political institutional arrangements that led to their introduction. Post-1066 England is one of several pre-modern states via which such a review might have been conducted. For instance, the Qin Dynasty in China reportedly began requiring individuals to adopt surnames as a means for closer administrative control in the 4th century BCE (Scott 1998, Scott, Tehranian, and Mathias 2002). The Florentine state also attempted to give their citizens de facto surnames in the census of 1427 . Here they added second identifiers-occupations, nicknames, character traits and so forth-in an (ultimately unsuccessful) effort to record potential sources of revenue and men for conscription (Scott, Tehranian, and Mathias 2002). However, I have chosen England after the Norman invasion of 1066 due to the volume of administrative documents which survive and which have been studied from this period onwards.

Documents from the history of Anglo-Saxon England number around 2,000, compared to tens of thousands from the 13th century alone (Clanchy 2012). In addition, the use-and not just the survival-of administrative and legal documentation in post-1066 England far exceeded that of the Anglo-Saxon period. Clanchy (2012) estimates that up to eight million charters may have been created and used by peasants in the 13th century to record the sale, lease and ownership of property as small as half an acre. This sharp increase in the use of administrative records by the 13th century contrasts with the 11th, where much property transfer was undocumented (Holt 1972). Finally, the military conquest of 1066 coincides with the beginning of a clearly defined political era. This provides a valuable and interesting point of focus for such a study. The widespread introduction and use of a new (French) elite language in the region, as well as the vast administrative exercises Norman and subsequent rulers took to control and survey England have resulted in a numerous and well-researched literature from which to draw upon.

\subsubsection{Some commentary on pre-conquest naming conventions}

In pre-medieval Europe, the peoples under Roman rule commonly used the tria nomina naming convention. This contrasts with pre-Roman Italian and Greek communities, who would typically make use of just a single name (Pintens and Will 1995). For instance, the Roman consul and orator Cicero was also known as 'Marcus Tullius Cicero'. Made up of a praenomen, nomen gentilicium, and cognomen, the tria nomina was by no means the only naming convention used in western Europe in the Roman period (see Echavarren 2013), however it has been the most documented and studied of the period (Salway 1994). These naming conventions were often used as information transmission devices, providing details as to familial origins, birth precedence, and other important information about the bearer. 
Like the heritable surnames which emerged in Norman England, Roman naming conventions overcame problems of information asymmetry through the supply of identity information.

The praenomen was a personal name given to a child nine days after their birth (Chase 1897). Salway (1994) lists just seventeen praenomina during the Regnal and Republican periods, ${ }^{47}$ although other sources differ in their estimates of praenomina in common usage (see for instance Chase 1897, Petersen 1962). Echavarren (2013) attributes the diminishment of these names around the $1^{\text {st }}$ century due to their relatively limited stock; their usefulness in distinguishing between two individuals appears to have been limited. This problem was exacerbated by some families of the nobility, which tended to use only a small sample of the already limited number of praenomina in common usage; the patrician family 'Postumii Albini' almost entirely restricted themselves to using 'Aulus', 'Lucius' and 'Spurius' (Bailey 1976). These personal names saw little usage on a day to day basis, and tended to be abbreviated (Salway 1994). In addition, first born sons usually received the praenomen of their father, with subsequent sons receiving personal names subject to their precedence (Syme [1939] 2002). The use of a praenomina was often used to unambiguously indicate the month in which a child was born. The most common of these names were 'Quintus', 'Sextus' and 'Decimus'. The original meanings of these were to indicate birth in the Roman months of Quintilis, Sextilis and December respectively. Other praenomina including 'Octavus', 'Septimus' and 'Nonus' signified October, September and November respectively, but were far less common (Petersen 1962). ${ }^{48}$

Next in the tria nomina came the nomen gentilicium, which was considered the "central element" of the format (Salway 1994, 124). These names indicated the gens-clan or family group-into which a child was born (Chase 1897). Syme $(2009,40)$ equates these to a "family name", although it must be emphasised that they generally refer to a larger clan group rather than what we would consider a modern nuclear family (Salway 1994). Their importance, and the emphasis placed on them by prominent individuals reflected the ability for the nomen gentilicium to indicate familial "connections with illustrious figures from earlier history" (Salway 1994, 126). This is seen most notably at the top of the Roman power structure at the turn of the millennium, where the (previously) cognomen 'Caesar', was converted explicitly into a gentilicium. Hence, the adopted sons of 'Augustus' were 'Gaius Caesar', 'Lucius Caesar' and 'Tiberius Caesar' (Syme 2009). Likewise, to discard an unwanted clan name might help obfuscate one's humble origins for political purposes. 'Agrippa', contemporary and ally of 'Julius Caesar', chose to lose his gentilicium 'Vipsanius' for this reason (Syme [1939] 2002, 2009). To this end, adoption was often used as a way in which upward mobility for the adoptee, and the continuation of the gens for the adopting family, was realised (Lindsay

\footnotetext{
${ }^{47}$ These are, preceded by their abbreviations: “A. [Aulus]; Ap(p). [Appius]; C. [Gaius]; Cn. [Gnaeus]; D. [Decimus]; L. [Lucius]; M'. [Manius]; M. [Marcus]; N. [Nemerius]; P. [Publius]; Q. [Quintus]; Ser. [Servius]; Sex. [Sextus]; Sp. [Spurius]; T. [Titus]; Ti(b). [Tiberius]; V. [Vibius]" (Salway 1994, 125 note 9).

${ }^{48}$ This system originated when the Roman year was comprised of just ten months. For instance, Nonus (from the Latin for nine) indicated that the child who bore this praenomina was born in the ninth month, November. Similarly, Decimus (from the Latin for ten) was born in the tenth month, December.
} 
2011). This was done by the adopted son of 'Julius Caesar', who discarded any reference to the gens 'Octavianus', and with it indication of his biological heritage (Syme 2009).

Finally, the cognomen was another heritable name which was used to "denote a particular domus (family) amongst the broader gens" (Salway 1994, 127). Badian (1988) describes their use as another way in which individuals could emphasise their origins, and were likely used by the elite for that purpose. The earliest known cognomina are thought to have origins in nicknames (Salway 1994). Chase (1897) sets out a taxonomy comprising eight distinguishable categories, of which 'physical characteristics' is determined to be the most common. For instance, 'Sulla' and 'Rufus' indicate their (original) owners as having prominent calves and red hair, respectively. Notably, the second category set out is that relating to 'character', and it is in this that we find the name 'Augustus', translated as 'majestic'. Another category as laid out by Chase (1897) is that relating to familial relations, including 'Spurinus', 'Geminus' and 'Frater', denoting one who is illegitimate, a twin and a brother respectively. A set of names described in Petersen (1962) illustrate how these categories can relate to inheritance, and are 'Primus', 'Secundus', 'Tertius' and 'Quartus'. These of course delineate the order of birth for male siblings which are significant in that they also indicate the importance of individuals for matters relating to the intergenerational transfer of property. And although (especially during the Republic), for political and legal matters, as well as those relating to inheritance, females were subservient to their male counterparts, the cognomina 'Prima', 'Secunda', 'Tertia' and 'Quinta' were thought to have initially existed to clearly set out domestic primacy and authority. The other categories relate to office or occupation, metaphors relating to animals or objects, locality, those derived from other names, as well as foreign names. And because of the declining importance of the praenomina to distinguish two individuals-due to the small number of them in common usage as discussed earlier-the cognomen took the "role of the diacritic name and individual signifier" from the early $1^{\text {st }}$ century (Echavarren 2013, 353).

The three-name format of the tria nomina might also have further filial or tribal associations added to it. Thus, Cicero was more properly known as 'Marcus Tullius Marci filius Cornelia Cicero' (Cicero was the son of Marcus-Marci filius-and from the tribe Cornelia) (Wilson 2003). Similarly, individuals might also adopt an additional cognomen to signify a great personal achievement. 'Publius Cornelius Scipio', the general who defeated the Carthaginians at the end of the Second Punic War, famously added the name 'Africanus' to commemorate his victory. These additional cognomina are "distinguished by the grammarians as agnomina" (Salway 1994, 127). Interestingly, the use of the tria nomina was also a good indicator that its bearer had Roman citizenship (Bagnall and Frier 2006, Pothecary 1999) and therefore served as a sort of proto-passport (see Chapter 6). It remains to be seen whether the use of this naming convention, and the clan, tribal and family associations attached to it, might be studied from the perspective of mutual aid and insurance as discussed in Section 5.4.1.

The Roman tria nomina convention disappeared at a time of political, social and economic upheaval. As the western Roman Empire absorbed more and more foreigners from outside its borders, eventually collapsing as a cohesive political entity in the late $5^{\text {th }}$ century, a single name system became largely universal throughout western Europe until the $11^{\text {th }}$ century (Caplan 2001, Salway 1994, Wilson 2003). Depending on the economic and political complexity of the area, this single name system did not disappear until the $18^{\text {th }}$ century in 
rural France (Gersuny 1974), the $19^{\text {th }}$ century in parts of what is now northern Germany, and persisted at least until the late $20^{\text {th }}$ century in Iceland (Salway 1994, Scott 1998). The proliferation of surnames in medieval Europe is associated with both commercial sophistication, and the extent of administrative control in different parts of the continent.

\subsubsection{The emergence of heritable surnames after the Norman invasion}

The names common in England changed drastically in the decades and centuries after the Norman invasion (Freeman 1876, Redmonds, King, and Hey 2011, Reaney 1978, Reaney and Wilson 2006). Three quarters of the citizens in Canterbury had names of Norman origin within a century of the Battle of Hastings (Bartlett 2000). Similar figures are observed in the records of the Holm Cultram Abbey in Cumbria in the late $12^{\text {th }}$ century (Reaney and Wilson 2006). The same trend is seen in Winchester, where all children had French names by 1148, "whether their fathers had English, Scandinavian or French names", compared to just one in twelve at the time of the Conquest (Reaney 1978, 102). And while English names did not completely disappear-surnames such as 'Bishop', 'Grant', 'Swift' and 'Wade' all have their origins in old English personal names (see Reaney and Wilson 2006)-those of Norman origin quickly became the norm. Most of the population had names of Norman origin by early in the 13th century (Bartlett 2000).

Immediately prior to 1066 there was no consistent use of hereditary surnames in England (Freeman 1876, Gersuny 1974, McKinley 1990, Scott, Tehranian, and Mathias 2002). However, it was not unusual for individuals to make use of a second, non-hereditary identifier which might distinguish them from others based on their occupation, place of habitation, relationship or nickname. For instance, one might have had their name supplemented by an additional identifier such as 'sēo dæge' (the dairy maid) or 'sē hwīta' (the white-haired man) (Clark 1992).

The use of a second name has been described as of little consequence. Siblings from the same family often made use of different non-hereditary second identifiers. Pintens and Will (1995) recount one instance of eight sons, all with separate surnames of no association to that of their father. The point at which a second identifier can be categorically determined to have transformed into a hereditary surname is at times difficult to distinguish in the historical record. However, it surely comes around the point where that word loses its original personally descriptive properties in relation to the bearer. For instance, even when the same surname, occupational ${ }^{49}$ for instance, is used by successive generations, one can only be sure

\footnotetext{
49 In reference works and more general historical scholarship, surnames are typically classified into four types, descriptive, occupational, relational and locational (see Bartlett 2000, Hughes 1959, Matthews 2007, McKinley 1990, Reaney 1978, Reaney and Wilson 2006, Scott, Tehranian, and Mathias 2002). Caplan (2001) and McKinley (1990) delineate locational surname types into both locative and toponymic. In such a distinction, 'William Keevil' would have a locative surname, due to his origin in the region south-east of Bath. In contrast, 'Richard at the Green' has a toponymic surname, with 'Green' referring to a generic geographic feature. For reasons which shall become apparent in later sections of this chapter, a five-type taxonomy consisting of descriptive, occupational, relational, locative and toponymic is emphasised. To illustrate this taxonomy, take Hughes (1959) who gives the example of 'William Keevil' (locative - Keevil being south-east of Bath) and his sons 'William the Little', 'Henry Strong in the Arm' (both descriptive) and 'Richard at the Green' (toponymic). 'William Keevil' also had grandsons 'Hal the Page' (occupational) and 'John Richardson' (relational).
} 
that the name has truly become hereditary in the modern sense is if subsequent generations practice different vocations (Clark 1992). Thus, and as described by Freeman (1876), prior to the Conquest there is a high degree of certainty that 'Sired $Æ$ Elfred's Son' is indeed the son of 'Elfred', 'Godrel at Fecham' lived in Fecham, while 'Wulfric the Black' likely had a dark complexion. In England, the private supply of identity information via a system of hereditary surnames truly began with the Conquest.

The adoption of hereditary surnames associated with private property and its intergenerational ownership was a rapid one amongst wealthy individuals after the conquest. Indeed, so rapid was their adoption that, in contrast to the almost complete absence of them in 1066, it was thought to be a social disgrace for a large landholder not to have a heritable surname by the $12^{\text {th }}$ century (Hughes 1959). Evidence of this can be seen in the Domesday Book of 1086, ${ }^{50}$ in which Bartlett (2000) counts 398 major Norman landholders in England. Of these, only 13 per cent are identified with just a single identifier, while fully 33 per cent and 4 per cent of these landholders possessed toponymic and locative surnames respectively. This indicates how Norman landholders had begun to use names as a technology of identity to lay claim to private property.

The Norman invaders who conquered and subsequently ruled England were comparatively few in number. One estimate for the size of the invasion force is 10,000-15,000 men (Vincent 2011), while Tombs (2015) approximates just 8,000 Normans and hangers-on. This small force is compared to a native Anglo-Saxon population of between 2 and 2.5 million (Huscroft 2005). Yet in less than a decade this "small armed group speaking a language incomprehensible to the majority of the population" (Bartlett 2000,1) had economic and political control over the entire country. Many iconic medieval fortifications date from this period, ${ }^{51}$ illustrative of the way in which Norman kings used castles as a tool of control over the native population (Huscroft 2005). Importantly for the model in question, widespread redistribution of landed property was another way in which Norman control was exercised, with the clear majority of major Anglo-Saxon landholders dispossessed of their land to make way for the barons, knights and other settlers who followed William from Normandy (Vincent 2011).

Such an exercise of land redistribution was all but absolute, with an almost complete annihilation of "England's ruling class, physically and genetically". This was combined with huge tracts of land being placed under direct control of William (Tombs 2015, 157). All other "holders of land owed their rights and allegiance ultimately to him" (Tombs 2015, 164). The greatest redistribution of property in the history of the British Isles was the way in which William rewarded those who embarked with him from Normandy, and was likely the primary way that they were enticed to join him on the risky attempt at conquest. I characterise this

\footnotetext{
${ }^{50}$ Ordered by William shortly after the conquest, the Domesday Book is an important census of $11^{\text {th }}$ century England at the 'manorial level'. It provides documentary evidence for major landholders, with little information provided about individual peasants or small landholders. For instance villagers were counted (anonymously) along with ploughs, oxen and mills (Jones 2018).

51 Perhaps most iconic of these symbols of Norman conquest and rule is the White Tower of the Tower of London, built by William the Conqueror late in the $11^{\text {th }}$ century (Clanchy 2014).
} 
process as being analogous to the cardinal transaction as described in my model. By risking their lives in the conquest of England, William's followers 'purchased' property from him.

This process of land purchase via conquest and dispossession can be seen in the administrative records of the Domesday Book of $1086^{52}$; only four Anglo-Saxon landholders with any significant holdings are recorded (Huscroft 2005), with just two of those holding "tenancies of the first order under the king himself" (Clanchy 2014, 33). William used the granting of land to reward his followers virtually immediately after the conquest. It is in this period that we can see the way that hereditary surnames played a role in the protection of private property rights after this wholesale redistribution. Individuals granted land by William, and their descendants, lived under legal uncertainty as to whether their holdings would be honoured under subsequent administrations (McKinley 1990, Scott, Tehranian, and Mathias 2002). The adoption of surnames was hastened to maintain hereditary ownership claims to those properties.

Hereditary surnames in England were adopted first by Norman landholders. Although a small number of barons who crossed with William in 1066 had locative surnames referencing their landholdings in France (McKinley 1990, Redmonds, King, and Hey 2011), or relational surnames which usually provided genealogical evidence of the male line (Freeman 1876), they were the exception rather than the rule. To be sure, while the use of secondary identifiers among wealthy landholders was present in places such as Normandy, their hereditary use on the continent was 'tentative' (Clark 1992, 553)..$^{53}$ Reaney (1978) gives the example of the 'de Montgomeri' family, who took their name from near Falaise, Normandy; this name was said to have been used since the $10^{\text {th }}$ century. ${ }^{54}$ Rather, it was common among many of William's vassals and their descendants to adopt hereditary surnames after the conquest. This was the catalyst for the private supply of identity in this model; these individuals rapidly adopted surnames to "consolidate their position as hereditary property owners" (McKinley 1990, 30) over lands in both England and Normandy.

The Domesday Book has examples of the rapidity in which Norman landholders used surnames as such a tool of identification and to provide certainty of intergenerational ownership. 'Robert de Stafford', 'Robert de Hasting' and 'Robert de Olecumbe' from

\footnotetext{
52 The Domesday Book can be considered a competitor identity technology to heritable surnames. While the Domesday Book consists of a centralised and unalterable registry of property ownership, heritable surnames are decentralised. The production of heritable surnames was decentralised as they were adopted, maintained and modified by the property owners themselves, while the centralised Domesday Book was produced and maintained by the state.
}

53 Planché (1874) gives an illustrative example of this. The six sons of 'Richard de Courci', a major Norman landholder who accompanied William in 1066, all had different surnames derived from either their inherited landholdings or place of birth. These sons included 'Nicholas de Bacqueville', 'Fulk d'Aunou' and 'Baldric de Balgenzais', who had respectively inherited land in Bacqueville-en-Caux, Aunou le Faucon and Bouquence.

${ }^{54}$ Reaney (1978) in passing attributes the use of hereditary surnames in France to the 'Capitulary of Quierzy', signed by the Carolingian King Charles in 877. According to Freeman (1876) however, such a practice was still a 'novelty' leading up to 1066. This document was issued in order to guarantee the hereditary nature of secular office to his followers, and was used as a way to shore up support while he was away on campaign (see Gravel 2012, Nelson 2014). 
Staffordshire, Hastings and Ulcombe respectively, are plainly names adopted after the conquest and were not transported over from France along with the Norman army (McKinley 1990). These surnames became hereditary as they attempted to secure rights over English land which had been granted to them by William, those they still held in France, and as an identifying tool to successfully bequeath these rights to property to their heirs. The massive redistribution of land in England came at a time of great uncertainty for the newly installed Norman landholders; it was not clear that the land grants provided by William were permanent in nature, or if they would instead be temporary and subject to further redistribution by the current, or any future, monarch (McKinley 1990, Scott, Tehranian, and Mathias 2002).

Sovereign opportunism and uncertainty of legal rights to land assets was endemic. For instance, Bartlett (2000) provides a particularly illustrative example of successive redistributions with the case of Pevensey in modern day East Sussex. This territory was originally granted to William's half-brother Robert, the Count of Mortain, later to become the $1^{\text {st }}$ Earl of Cornwall, who was thought to have been at the Battle of Hastings (Cokayne, Gibbs, and Doubleday 1913, Cokayne and White 1959, Douglas 1943). The land was then given to 'Gilbert de Laigle' by Henry I following the Battle of Tinchenbray. They were then ceded to new owners twice in the 1140s, yet returned to the 'de Laigle' family when they were restored to 'Richer de Laigle' in 1166, being subsequently lost again by the same family in 1204. Finally, the lands around Pevensey were returned to (another) 'Gilbert de Laigle' who maintained Pevensey until his heirless death in 1231.

In addition to sovereign opportunism and legal insecurity, the tenuous nature of Norman rule after the conquest also provided uncertainty to the permanence of their landholdings; Norman England faced Anglo-Saxon rebellions, as well as military threats from Wales, Scotland, and Denmark (Clanchy 2014). Heritable surnames provided some way to "stress the hereditary character of tenure" (McKinley 1990, 30). What can be seen from administrative records of this period is a process whereby wealthy Norman landholders and their heirs adopted names corresponding to their landholdings. ${ }^{55}$

The fluid nature of the use of heritable surnames in England after 1066 is evident in the case where multiple tracts of land are held. 'Ricardus filius Gisleberti' is described in the Domesday Book in a patrilineal manner, being the son of 'Gilbert' Earl of Brion in Normandy (Parliament of Great Britain 1829). Yet in the same document this individual is given multiple designations, all locative and reflecting holdings of land in Normandy, Kent and Suffolk. They are also known

\footnotetext{
${ }^{55}$ It is prudent to acknowledge the spectrum along which newly installed Norman landholders fell, and how that impacted on both security of tenure, as well as the adoption of heritable surnames in England. Holt (1972) makes the case that security of succession weakened the further a landholder was from the top of the Norman power structure (which was of course closely correlated with how much land was held by the landholder in question). This discrepancy might be attributed to "knightly families" being "much less conscious of family traditions of hereditary property" (Holt 1972, 35) compared to larger baronial landholders, along with the presence of significant numbers of mercenaries within the Norman forces during the initial invasion and subsequent English campaigns (Harvey 1970, Prestwich 1954). The security of intergenerational tenure was "vulnerable" for those with smaller landholdings well into the second half of the $12^{\text {th }}$ century under Henry II (Holt 1972, 36).
} 
as 'Ricardus de Benefacta', 'Ricardus de Tonbrige' and 'Ricardus de Clara' (Reaney 1978). This individual was said to have been a kinsman of William the Conqueror who accompanied him to England and was then rewarded with land. This land included around Clare in Sussex, which were "of the greatest importance" (Cokayne, Gibbs, and Doubleday 1913, 242). The name 'de Clare' remained in use by this family until the death of 'Gilbert de Clare' in 1314, when his sister and heir married 'William de Burgh', Earl of Ulster (Cokayne, Gibbs, and Doubleday 1913, see also Cokayne and White 1959).

Similarly, another of those said to have fought at Hastings, 'Ralph de Toeni' (see Cokayne and White 1953 appendix L postscript) had this name perpetuated by heirs who retained their principal lands in Tosny, Normandy. Yet the younger brother of the 'de Toeni' family took the name 'Robert de Stafford' owing to his possession of Stafford Castle after 1066 (Burke 1831). This name and lands were held in concert by the 'de Stafford' family until the mid $17^{\text {th }}$ century, when the "male line of the Staffords became extinct" just prior to the civil war (Burke 1831, 492, see also Cokayne 1896). Another Norman contemporary of William whose heirs continued to use locative surnames derived from their newly acquired lands was 'Robert de Hastings'. His successors include a steward to Henry I (Burke 1831), and the 'de Hastings' held this barony until at least the mid $16^{\text {th }}$ century (see also Cokayne 1892, Burke 1831). Finally, in 1068, a 'Henry de Beaumont' - also known as 'Henry de Newburgh' (Cokayne 1898)-the youngest son of 'Roger de Beaumont' was gifted Warwick Castle and its surrounding lands (Douglas 1943). After this, and until 1242, the five successors of 'Henry de Beaumont' used the name 'de Warwick' in conjunction with the name 'de Newburgh', referring to lands in Neubourg, Normandy which the family also held (Cokayne 1898). This demonstrates how claims over real property can be enforced by the production and perpetuation of a heritable surname.

The relationship between the inheritance of property and the production of heritable surnames can be seen most clearly when different parts of a larger family might adopt different surnames to reflect claims on property. McKinley (1990) details how 'Richard de Trafford', a $13^{\text {th }}$ century landholder in Trafford corresponding to modern day Manchester, bequeathed land in Chadderton, modern day south Lancashire, to his youngest son. The major landholdings in Trafford were left to his eldest son. The youngest son then went by, and his descendants continue to use, the name 'de Chadderton'. At the same time the oldest son and his descendants continue to use 'de Trafford'. McKinley (1990) also recounts the adoption of the locative surname 'de Sokenerse' by a younger son of 'William de St Leger' in the late $11^{\text {th }}$ century, owing to his inheritance of land in the area around Sussex. The line of the eldest son continued to use the surname 'de St Leger' owing to their possession of the larger French estate.

Surname practices among the propertied class in post-1066 England also demonstrates the way in which efforts to bolster inheritance claims depended on using "the surname of the propertied parent, regardless of sex" (Frandina 2009, 161). Reaney $(1978,85)$ describes how by the $14^{\text {th }}$ century heiresses "so often keep their maiden names, while their husbands change theirs to their wives' names... In one entry, a woman takes her husband's name, but when her father dies and she inherits his property, they both change to the father's name." Bartlett (2000) similarly describes an earlier instance of the inheritance of land which coincides with the adoption of surnames associated with them, regardless of gender. 'Robert de 
Muschamps' passed on an estate in the late $12^{\text {th }}$ century to his daughter who subsequently became known as 'Cecily de Muschamps'. Her son and grandson who inherited land in Northumbria took the 'Muschamps' name, rather than that of her husband, 'Stephen de Bulmer'. This indicates the primacy that the claim on land took in the adoption of hereditary surnames.

The legal and economic claim on private property related to a surname trumped any patronymic tradition. Anthony (2016) shows how in the $13^{\text {th }}$ century 'Hugh le Keach' and 'John atta Grene' both adopted their (propertied) wives' surnames. Similarly, from the same records of the Chertsey Abbey in Surrey, Anthony (2016) describes how a married woman who had initially taken her husband's name reverted to her father's name when she inherited his estate. And while the ability for females to successfully lay claim to property was substantially more difficult compared to their male counterparts-in general "sons were favored over daughters" while older children were favored over their younger siblings (Thomas 1988, 98)-a significant number of examples exist of men adopting the surnames of their mothers, wives, and even grandmothers as part of their efforts to claim ownership over property.

Significantly, and contemporary to the widespread adoption of surnames by major landholders, the Magna Carta of 1215 reflected an additional political effort by major landholders to facilitate the direct transfer of intergenerational property ownership without interference from the monarch (Rowley and Wu 2014, for general works on the Magna Carta see Berg and Roskam 2015, McKechnie 1914, Vincent 2012). The importance the barons placed on matters of inheritance is reflected in the primacy these matters were given at the beginning of this document (Berg and Roskam 2015). The 'Great Charter' signed by King John and his rebellious barons at Runnymede contains detailed restraints on the actions of the king after the death of a property owner, and the process by which inheritance of that property was to take place as set out in clauses 2-7 (from the McKechnie 1914 translation).

Yet this 1215 document was only one of a series of proclamations by English kings to limit payment due on inheritances, including the Henry I coronation charter in 1100 (Berg and Roskam 2015). From the perspective of the barons, the necessity to specify the mechanics by which the endowment of their property was to occur was due to the nature of feudalism in England following the Norman invasion. This saw the barons "hold their lands from the king" (Vincent 2012, 6), which had the implication of giving the king the option to deprive an heir of their inheritance on their father's death. And although this right to deny inheritance was usually only exercised in the case of a revolt, a payment of 'relief' was required to inherit property. Prior to 1215 , this amount was "undefined, and the lord frequently asked exorbitant sums", sometimes along with an "annual acceptable present". This is as clear an instance of sovereign risk as any.

Exploitation of this source of revenue saw King John force 'John de Lacy' to pay him 7,000 marks to inherit his father's land in 1214 (Berg and Roskam 2015). ${ }^{56}$ To provide for some certainty in inheritance taxation arrangements between the king and major landholders, clause 2 explicitly sets out a relief of $£ 100$ for both "an earl's barony" and "a baron's barony",

${ }^{56}$ One mark was worth approximately thirteen shillings. 
and 100s for the land of a knight (McKechnie 1914, 59). And as a great deal of the Magna Carta was concerned with what the barons considered as abuses of their rights (Vincent 2012), this document should be understood in conjunction with the adoption of heritable surnames. Both heritable surnames and the Magna Carta are institutional factors which major landholders adopted to "increase the magnitude of future payoffs as well as the certainty in which they will occur" (Bates 2014, 11) when considered from the perspective of intergenerational property transfer.

Yet the success of such charters in restraining the ability of kings to interfere in the inheritance of lands was limited over the successive three centuries. It was not until the passing of the Statute of Wills by Henry VIII in 1540, that a legislative mechanism was provided, giving landholders "the power of devising by will the greater part of their lands" (Bean 1968, 293). Such legislative mechanisms should be considered alongside heritable surnames, whereby heritable surnames acted in concurrence as an economic and political tool that endeavoured to affirm intergenerational property rights over land.

\subsubsection{Adoption of heritable surnames by wider English society}

What has been described up until this point is an economic and political process whereby the production, adoption, and private supply of surnames has largely been confined to those who have significant property ownership and hence commensurate concern for inheritance; heritable aristocratic surnames emerged far earlier than those of other classes (Bartlett 2000, Clark 1992). Ewen (1931) notes how in the $11^{\text {th }}$ century, 62 per cent of instances of recorded names consisted of just a single identifier. Similarly, in one of the few instances of detailed information on the non-propertied class in the late $11^{\text {th }}$ century, the lack of heritable surname is stark. From the market town of Bury St Edmunds, Reaney $(1978,309)$ analyses Court Rolls and finds that 660 'peasants' have their names recorded. 359 of these are designated by a single name only, "104 were described by their father's name (Goduine Stanardi filius, Ulfuine Teperesune)" while the remainder had non-hereditary surnames, often locative or descriptive. These included 'de Mor' and 'Longus', likely referring to someone from the region in Brittany or someone who was 'long' respectively.

The process whereby those outside the landed aristocracy took on heritable surnames began following localised legal arrangements. One early instance of this can be seen in an act of enclosure from the $13^{\text {th }}$ century. In 1225 in Chester the local earl documented one of the earliest acts of enclosure, ${ }^{57}$ where the 102 free tenants who surrendered their rights to common ownership of land had their names recorded. Of these, just two were recorded by only a single identifier, while the rest had surnames (Bartlett 2000). Unfortunately, there is no evidence to indicate whether their children continued to use those surnames.

A rare instance of what appears to be the moment when a surname becomes hereditary by the non-wealthy can be seen in the case of three generations c. 1250. One 'Robert Hereward' is said to have had two sons, 'Richard' and 'Ascelin'. 'Ascelin' also had two sons, 'Warin' and

\footnotetext{
${ }^{57}$ Enclosure in England was largely facilitated through a series of Parliamentary Inclosure Acts in the $18^{\text {th }}$ and $19^{\text {th }}$ centuries (see McCloskey 1975), while prior to this it was more commonly enabled through localised agreements between large landholders and free tenants.
} 
'Matthew'. Reaney (1978) shows each of these five individuals except 'Richard' used the surname 'Hereward', giving a good indication of its evolution into a hereditary one. The somewhat fluid nature of this process can also be seen by the different names given to 'Warin'. This grandson of 'Robert Hereward' was referred to as "son of Ascelin Hereward de Glinton and Warin de Glinton" (Reaney 1978, 310), and 'Warin Hereward'. In contrast, by the $14^{\text {th }}$ century, claims were subject to rigorous legal requirements, with courts demanding written evidence of claims over land by free tenants. At this time even a 'humble peasant' could only claim his father's land through appeal to a court and by inspection of local records; this legally enforced primogeniture provided "a direct incentive to men to keep the same surname that had been put down on the roll for their father and grandfather" (Matthews $1966,44)$. In this way the transfer of land, and the parties involved in that exchange, came to be identified in large part by the surnames which were becoming more and more common (Reaney and Wilson 2006). This legal imperative was further enforced and codified by the actions of two English rulers in the $14^{\text {th }}$, and $16^{\text {th }}$, centuries, respectively.

Taxation arrangements during the reign of Richard II led to some of the first requirements for non-landholding individuals to adopt heritable surnames. A poll tax taken in $1381^{58}$ saw tax assessors apply and enforce the adoption of (patronymic) surnames by those peasants they surveyed (Matthews 1966) to "determine eligibility for the tax" (Rampton 1993, 50-51). The enforced adoption of patronymic surnames should be contrasted with the often-locative surnames adopted voluntarily by wealthy landholders immediately following 1066 . It must be noted however that their application was not universal in this context, indicating the somewhat slower and uneven growth of the surname in the less wealthy parts of society (Clark 1992). Not until the 16th century under the reign of Henry VIII was a nationwide system of parish registration for all inhabitants introduced (Szreter 2007).

This system of parish registration was developed by Thomas Cromwell, with Higgs $(2004,9)$ describing its purpose to preserve individual claims over inherited real property through the establishment of "state institutions for the recording and preservation of titles to property". From 1538 all births, deaths and marriages were to be recorded, for reasons of both inheritance and state legibility ${ }^{59}$; at the time Thomas Cromwell described it as a way in which legitimacy of property inheritance might be established, and as a way in which royal authorities might establish whether an individual was a subject of the crown (Higgs 2003).

Contemporaneous to this registration requirement was the passing of the Statute of Wills in 1540 , providing landholders with the ability to nominate an heir to inherit their land (Bean 1968). Camden ([1605] 1870, 157) provides a rare instance of concrete evidence as to the precise moment when state authorities imposed a hereditary surname on an individual. During the reign of Henry VIII a Welshmen announced himself in court, according to his

\footnotetext{
${ }^{58}$ Efforts by tax assessors to collect unpaid taxes contributed to the 'Peasant's Revolt' of 1381 (see Rampton 1993, Rowley and Wu 2014, Tombs 2015).

${ }^{59}$ Contemporaneously, the 1539 Edict of Villers-Cotterêts was passed by Francois I of France which included a requirement for the registration of surnames after baptisms. However this legal requirement did not immediately have a material impact on many rural areas in France which still continued to use a single name system well into the $18^{\text {th }}$ century (Gersuny 1974).
} 
patrilineal heritage, as "Thomas, Ap William, Ap Thomas, Ap Richard, Ap Hoel, Ap Evan Vaghan", and was subsequently ordered by a judge to call himself "Moston, according to the name of his principal house, and left that Surname to his Posterity".

Yet this legal process was imperfect and slower the further one travelled from urban centres. Clark $(1992,582)$ emphasises that "some of the humbler families as even in the seventeenth century still relying on true patronyms in -daughter / son" (emphasis in original). Finally, registration of foreign individuals was another consideration in the adoption of surnames throughout England. Surnames provide legibility to the state (Scott 1998), such that individuals can be later embraced in the sense of Torpey (2000). An instance of this can be clearly seen during the reign of Henry $\mathrm{VI}$, when a number of foreigners were registered in England as having "taken an oath of fealty, to inhabit the realm peacefully and enjoy his goods" (Public Record Office [1429-36] 1907, 537).

\subsubsection{Discussion of the model}

In the five centuries to the reign of Henry VIII, heritable surnames went from being a phenomenon largely confined to large landholders who used them as an identity technology to validate their claims to lands originally confiscated from a subjugated people, to one which was largely uniform, and enforced by nationwide registration practices. The most obvious link between the adoption of heritable surnames and claims over private property can be seen in the immediate aftermath of Norman invasion. Norman followers 'purchased' land assets from William by risking their lives in the Conquest, and many of them subsequently became large landholders in Norman England. These large landholders sought to cement their intergenerational claims over landed estates by adopting and promulgating often locative surnames which reflected the land itself. This was done under sovereign risk, and the constant threat of nationalisation. This process was later adopted as a nationwide institution, whereby state authorities used the identity technology to unambiguously identify individuals from all classes for the purposes of taxation, legibility (Scott 1998) as well as the legal enforcement of claims over landed property. The state requirement to use surnames in this way saw them transition from a privately supplied identity technology, to one which was public.

In this chapter I have contributed a model which shows that the heritable surname, and in the context of post-1066 England, is an institutional identity technology. Using the nexus of economic and political interaction implicit in NIEH (North 1971, North, Wallis, and Weingast 2006), I have established that surnames initially served as an identity technology with which to bolster the claims of (wealthy) heirs in their inheritance of property. Surnames-often locative and reflective of a geographic region in which the landholder held property-were used by wealthy landholders to reduce uncertainty over intergenerational ownership of property which was subject to the arbitrary actions of successive monarchs. This process occurred outside the purview of any central administrative authority, with landholders adopting surnames in a decentralised fashion; individuals changed their surnames at will to reflect claims over property without recourse to a central registry. That is, this was an instance of the private supply of identity. Such a process should be contrasted with centrally administered ones, for instance the Domesday Book which was a 'final authority' on matters relating to property ownership (Harvey 2014, Roffe 2000). 
The success of adopting surnames which would validate hereditary claims to land was moderately successful. This is evidenced by the need for further (political) constraints. These constraints include the Magna Carta and other charters, along with the Statute of Wills. Nevertheless, considering their near immediate after 1066, and by almost all major landholders, their adoption did provide users some certainty over the disposal of their property. Heritable surnames gave their users sufficient certainty of future benefit which justified their adoption and use.

The production and private supply of heritable surname by some wealthy landowners from the $11^{\text {th }}$ century in England-considered from the perspective of intergenerational property ownership-can be viewed as an attempt to exclude "nonpurchasers from the use of that which others have purchased" (Demsetz 1964, 18). By undertaking the Conquest with William in 1066, those of the Norman invasion force had risked death in battle and had anticipated rewards which generally came in the form of land which could in turn produce income, wealth, and prestige (see for instance Bartlett 2000 see also Myerson 2008). This anticipation of reward must have been buttressed by the knowledge that they were invading what had become one of the richest territories in Europe by the start of the $11^{\text {th }}$ century (Rowley and Wu 2014, Tombs 2015).

This redistribution was very much part of the generally accepted consideration expected from William, given to those who "did him good service" during and after the invasion (Freeman $1876,32)$. Afterwards they tried to protect, and exclude others from, those property rights. The exclusion of others, including the state, from the use of these property rights should be interpreted not only as an attempt to increase the value of their landholdings as private assets (Eggertsson 1990). They should also be considered a consequence of the relatively high value of English land in a European context (Rowley and Wu 2014, Tombs 2015). Here, the adoption of surnames can also be considered as one of the emergent and distinguishing features between 'primitive' and 'modern' societies (Posner 1980). The use of heritable surnames as a new technology from c.1066-or at least a long dormant technology, see the discussion on Roman naming conventions in section 5.3.1-acted as a driver, along with the exogenous shock of the invasion itself, for this identity technology to emerge in England. This identity technology was used to bolster the claims over property ownership by wealthy landholders, in the face of sovereign risk, following the Battle of Hastings.

Yet this did not provide for private ownership in any modern sense. The land initially granted was subject to the whims of William and his successors, while ownership rights were derived from the ultimate power in the English hierarchy-this was the nature of the system retrospectively named 'feudal' in the $18^{\text {th }}$ century (see Tombs 2015). Indeed, the governance of this land mirrors aspects of what would be considered state ownership (Demsetz 1967), with the landholder acting as agent for the king, while maintaining some ability to pass those agency rights onto heirs, albeit at times with difficulty and usually with a non-zero cost. As such, it is worth considering any 'private' aspect of this ownership as being nested within the (feudal) institutional system. For if we consider a key determinant of private ownership as being the right to sell property to others (Alchian 1965, Eggertsson 1990), or pass it onto heirs, the absence of this unencumbered right is clearly apparent in post-1066 England. 
This nested ownership reflects the nature of 'bundled' property rights (Alchian and Demsetz 1973), where landholders might maintain the right to cultivate and extract resources from the land, while the state-the monarch of England-often sought to exercise their right to dispose of that land for economic or political purposes. This is what North and Thomas (1971, 800 ) describe as "blurred' jurisdiction over "the same piece of land" common in the English feudal system. A similar dichotomy is described by Hudson $(2000,101)$, with the nature of land title in England for the century after the Conquest coming down to arguments between land "held for life" and land "held heritably". It is for this reason that the use of the heritable surname should be considered alongside other political tools which were used to promote the intergenerational nature of property, most notably the Magna Carta in 1215, and then the Statute of Wills in 1540.

A purely (endogenous) Demsetzian view of this process is therefore incomplete, and if we continue the property rights analogy such a view can be described as 'naïve'; it ignores "social and political institutions" (Eggertsson 1990, 250). The customs dictating succession of property were not subject to the rule of law, indeed such a concept was "barely and rarely tolerated by the despots who ruled the land" (Rowley and Wu 2014, 15). Wealthy individuals and families who hoped to pass on property were often unable to predict either their ability to do so, or accurately ascertain the payment due-the 'relief' - in the event they could even exercise that right. This is evidenced by the tenuous nature of landholdings after the conquest. Land granted by William and his heirs was liable for further redistribution, and there was (at least initially) a threat of Anglo-Saxon rebellions along with incursions from Wales, Scotland, and Denmark.

Therefore, there was the need for subsequent political negotiations over the coming centuries, including the Magna Carta. So, the economic condition of "scarcity and the need to internalize externalities" (Riker and Sened 1991, 953) are insufficient to account for the emergence of heritable surnames as an identity technology adequate to guarantee intergenerational property ownership. By introducing political conditions, Riker and Sened $(1991,953)$ overcome what they describe as a "defect of neoclassical political economy" by factoring in the recognition of property rights both by the state as well as other non-state participants. This is the approach I suggest is more appropriate to account for the emergence and production of such an identity technology.

The Riker and Sened (1991) legal-centric conditions of ruler enforcement, and the recognitions of other participants holds, but initially only weakly so. In a feudal system with decentralised power bases, the ability of the monarch to remain in power depended on the ongoing loyalty of enough barons and other powerful individuals (Rowley and Wu 2014). These individuals formed the 'selectorate'. This selectorate is the set of individuals that "choose the government's leadership and [whose membership is] necessary for gaining access to private benefits doled out by the government's leadership" (de Mesquita et al 2003, 42 see also Abdukadirov 2010). And as de Mesquita et al (2003) illustrates in the case of England under King John in the $13^{\text {th }}$ century, even a small subset of this selectorate could act 
as kingmakers owing to the high concentration of military power among some of the more powerful barons. $^{60}$

The legal-centric view, which includes the political conditions of ruler enforcement and the recognition of other participants, emphasises the role of politics in the granting of property rights, and to further the analogy, the production of heritable surnames to secure property rights over land. A Demsetzian view of the emergence of this technology sees landholders adopt heritable surnames to lay an intergenerational claim over a valuable resource with sufficient potential future payoff to justify their use. What the legal-centric view of Riker and Sened (1991) suggests is that 'rule makers' give value to such an identity technology by their enforcement of property rights secured in such a manner. That is, rule makers must "desire to enforce the right" and be able to force others to "respect right-holders' claims" (Sened $1997,79)$. In the case of post-1066 England the enforcement of property rights delineated by heritable surnames became somewhat widespread, even as the period was punctuated by frequent instances of further land redistribution. In addition, the numerous charters issued by monarchs, including the Magna Carta, make clear that the inheritance of property was an ongoing source of conflict between the head of state, their barons, and other landholders. If the legal-centric view were unambiguously applicable to the period in question, it might be satisfying to say that heritable surnames are established to make claim over 1) valuable rights, 2) where right holders desire those rights, 3) while rule makers recognise and enforce those rights, and finally 4), other participants recognise and respect those rights. These conditions are outlined in Table 4. on the next page. However, as has been illustrated, such a process cannot be described as linear from 1066.

\footnotetext{
${ }^{60}$ It must be acknowledged that the existence of a 'selectorate', in contrast to all powerful sovereign, somewhat weakens the assumption of a monopoly seller in this chapter's model. For simplicity of analysis I have chosen to retain this assumption.
} 


\begin{tabular}{|c|c|c|c|c|}
\hline \multirow[b]{2}{*}{$\begin{array}{l}\text { Conditions for } \\
\text { the emergence } \\
\text { of heritable } \\
\text { surnames \# }\end{array}$} & \multicolumn{2}{|l|}{ Economic $*$} & \multicolumn{2}{|l|}{ Political } \\
\hline & Rights have value & $\begin{array}{l}\text { Right holders } \\
\text { desire those rights }\end{array}$ & $\begin{array}{l}\text { Rule makers } \\
\text { recognise and } \\
\text { enforce rights }\end{array}$ & $\begin{array}{l}\text { Other participants } \\
\text { recognise and } \\
\text { enforce rights }\end{array}$ \\
\hline $\begin{array}{l}\text { Condition } \\
\text { met/not met in } \\
\text { post-1066 } \\
\text { England }\end{array}$ & Condition met & Condition met & $\begin{array}{l}\text { Condition not met } \\
\text { until the } 14^{\text {th }} \text { and } \\
16^{\text {th }} \text { centuries }\end{array}$ & Condition met \\
\hline Notes & $\begin{array}{l}\text { Valuable land } \\
\text { distributed to the } \\
\text { followers of } \\
\text { William in return } \\
\text { for participation in } \\
\text { Conquest. }\end{array}$ & $\begin{array}{l}\text { Desire for } \\
\text { intergenerational } \\
\text { property } \\
\text { ownership by } \\
\text { followers of } \\
\text { William. }\end{array}$ & $\begin{array}{l}\text { Continued ability } \\
\text { of the English } \\
\text { monarch to deny } \\
\text { inheritance. } \\
\text { Evidenced by the } \\
\text { need for the } \\
\text { Magna Carta in } \\
1215 . \\
\text { The poll tax } \\
\text { (1381), and a } \\
\text { nationwide parish } \\
\text { registration (1538) } \\
\text { saw the } \\
\text { codification of } \\
\text { naming } \\
\text { conventions. }\end{array}$ & $\begin{array}{l}\text { Clear desire by the } \\
\text { propertied classes for } \\
\text { intergenerational } \\
\text { property transfer. } \\
\text { Again, evidenced by } \\
\text { the introduction of } \\
\text { the Magna Carta. }\end{array}$ \\
\hline
\end{tabular}

* These conditions are those economic ones set out by Demsetz (1964, 1967), scarcity and the need for the internalisation of externalities.

\# Adapted from Riker and Sened (1991).

Table 4. A legal-centric view of the production of heritable surnames to secure property rights over land

As described in this model, heritable surnames were adopted to increase some potential payoff, along with its likelihood, through the internalisation of the benefits associated with property ownership. Indeed, the relative value of land in England rose from the $12^{\text {th }}$ century, partly in response to its relative scarcity compared to a growing population, but also due to the increasing reality of the private ownership of land (Rowley and Wu 2014, Tombs 2015). This private ownership included greater autonomy of intergenerational transfer. This is consistent with the model I have contributed in this chapter, which suggests that sovereign risk, in the form of land redistribution, would see the private supply of surnames to ameliorate this risk. Surnames were adopted not as an institution to protect private property in the absence of government (see, for instance Leeson 2007, 2014, Stringham 2002), rather they were adopted to protect private property despite government. That is, this chapter describes an identity institution which protects private property under the threat of sovereign opportunism and legal uncertainty. Yet the probability of intergenerational property transfer occurring successfully was less than one, despite the political entrepreneurship that saw wealthy and landed individuals lobby for the ability to maintain monopoly rents (Brooks, Davidson, and Faff 2003). Thus, what is apparent is that surnames as an identity technology 
emerged endogenously from 1066, and were subsequently recognised through legal-centric means when the technology was used by, or forced upon, less wealthy individuals. This was the process whereby the private supply of identity transitioned to a public supply of identity.

The adoption of heritable surnames by those in England who were outside the landed aristocracy took place over a longer period. This was in part due to the understandably diminished incentive of those who owned significantly less property which they might pass on to their heirs. Like their wealthier counterparts, those from the lower classes tended to adopt surnames as the incentive to do so arose, in the case of the lower classes, often because of some interaction with a state authority who demanded it for reasons of taxation, conscription and so forth.

In sum, heritable surnames in England after the Battle of Hastings arose as an informal institution, used by the propertied class to constrain the actions of William and his successors. The barons, knights and other hangers-on who followed the Conqueror from Normandy had benefitted from a massive redistribution of Anglo-Saxon land, and were eager to ensure that the land handed to them was held securely and was able to be passed on to their heirs. Only as those from the lower classes had property they could bequeath did they seek to adopt the same custom. Successive monarchs from the $14^{\text {th }}$ to $16^{\text {th }}$ centuries then saw their usefulness as a mechanism to aid them more efficiently levy taxes, transforming it into a formal institution. This gives the heritable surname the characteristics of what North (1990) would deem an 'evolved' rather than a 'created' institution, although this is not to say that at certain points along its evolution their nature has not been locked in a form of equilibrium via the actions of the legal system and organisation of the nation state. Requirements for the registration of births, deaths and marriages, along with legal requirements related to property inheritance (for all, rather than just major landholders) means that what was once an informal institution had become formalised within the operations of the state. This gives this identity institution characteristics of a spontaneous order (Hayek 1973, Polanyi 1948) which has subsequently been subsumed into formal institutional arrangements. An institution used by elites to mitigate sovereign risk and therefore maintain access to monopoly rents derived from their support of William during the Norman invasion (North, Wallis, and Weingast 2006) had been co-opted by the state to maintain tax revenue and legibility over its subjects for it to embrace them.

\subsection{Some further institutional economics of names}

The main contribution of this chapter has been a model which demonstrates the private supply and use of heritable surnames to mitigate the effects of sovereign risk and legal uncertainty. I also suggest that the broader study of names as an identity technology, and from an institutional perspective, might be a fruitful endeavour for further scholarship. The use of names to identify individuals has been ubiquitous in both primitive and modern society. Names have been described as the most basic and logical form of identification (Emens 2007, Scassa 1996). In the absence of other methods of identification, they provide a (relatively) robust means to allow one to map property rights and relationships back to others, as well as make sense of individual and institutional responsibilities and obligations (Scott, Tehranian, and Mathias 2002). 
Names allow for increasingly complex exchange as they enable indirect interactions. Rather than directly asking Bob to do X, you can instead ask Alice to ask Bob to do X, even without Bob's presence. In the absence of names, this seemingly insignificant exchange would present obvious informational difficulties. This ability to conduct indirect, impersonal exchange should also be considered in the context of long-term economic growth (see North 1981, Greif 2006). Yet despite their ubiquity, and early efforts via this chapter, an economic theory of the origin and function of names does not yet exist. This is not to suggest that names are not a topic of academic interest. They have been well documented as part of etymological and genealogical reference works, and are well studied in the broader social sciences.

Personal names have also been subjected to scholarly attention in departments of sociology (see Edwards and Caballero 2008, Elias 2001, Pilcher 2016, 2017, Sue and Telles 2007), psychology (see Busse and Seeaydarian 1979, Dion 1983, Twenge 1997), linguistics (see Robinson 2013, Tan 2006, Wilson 2005), as well as labour and demographic economics (see Bertrand and Mullainathan 2004, Clark 2014, Fryer and Levitt 2004). The social, psychological and anthropological aspects of personal names have further been subsumed into the field of identity economics, which sees names form part of an individual's identity - "a person's sense of self" (Akerlof and Kranton 2000, 715). According to this scholarship, names might form part of a social categorisation which influences one's utility as derived from some action, as well as that of the wider group which one identifies with (Akerlof and Kranton 2010, see also, Akerlof and Kranton 2000, Darity, Mason, and Stewart 2006, Davis 2014). In this respect, the field of identity economics is examined at length in Section 2.2.2.

The use of names - an aspect of identity-as outlined above is largely derived from identity constructs in psychology and sociology (Akerlof and Kranton 2000, Gely 2007). As such, names have principally been treated as sociological phenomena in the literature. For instance, the relationship between names and the popularity of children was examined by Busse and Seeaydarian $(1979,153)$, who determined that names are a minor determinant of popularity, along with "race, physical attractiveness, eyeglasses, stature, and hair color". Similarly, Edwards and Caballero (2008) examine the sociological determinants of children's names when those children have parents from different racial, ethnic or religious backgrounds. Dion (1983) treats names as an input to cognitive mapping (see Tolman 1948), in that they provide a means for individuals to access mental information while reducing cognitive load, while Pilcher $(2017,812)$ argues that naming practices are associated with "the reproduction of binary sex categories and to gendered identities, hierarchies, and inequalities." Finally, Wilson $(2005,40)$ examines the working names that dominatrices adopt, finding that they are typically a function of "class, femininity and mystery", while "they [also] play an important role in the construction and maintenance of this culture's identity."

The wider economics literature has largely examined names from a labour market perspective, as well as through identity economics literature as typified by Akerlof and Kranton (2000, 2010). Several labour market studies have determined evidence of discrimination in hiring practices directed against those perceived to have minority names (see Bertrand and Mullainathan 2004, Jowell and Prescott-Clarke 1970), although Fryer and Levitt $(2004,801)$ argue that carrying a 'minority-sounding name' is "primarily a consequence rather than a cause of poverty and segregation." Akerlof and Kranton (2010) attempt to explain these (contested) instances of discrimination through an identity economics lens. 
They argue that early economic theories of discrimination, including Gary Becker's (1957) 'taste-based discrimination' and Kenneth Arrow's (1972a, b, 1973) 'statistical discrimination' are inadequate, in part due to their inability to explain the observed behaviours of those discriminated against. Akerlof and Kranton (2010) instead suggest that discrimination is the product of antagonism between oppositional groups. Here, discrimination based on different styles of personal names might be explained by "negative opinions about those assigned to different groups" (Akerlof and Kranton 2010, 100), and the choice to adopt "oppositional identities by those in excluded groups" (Akerlof and Kranton 2000, 739). As such, differences and discrimination associated with naming practices would be explained in the identity economics framework by changes in the payoffs resulting from an individual's actions, as well as that of others. In the former, this would suggest that perpetuating a name that resulted in discrimination might be utility maximising for that individual even if a standard utility function would suggest otherwise. Likewise, and in the latter, the utility of group members might be contingent on the conformity of other members of that group to established norms, in this case through their use of naming practices.

This chapter asserts that this literature, as outlined above, is inadequate for any explanatory analysis of the emergence and use of names as an identity technology contemporaneously and throughout history. Names play a fundamental role in exchange, in that they constitute an identity technology that is used by counterparties to provide some assurance of who they are, along with any attributes that might be relevant to that instance of exchange (see Carr and Landa 1983).

Here, I shall provide some instances in which names might be examined as a transaction cost economising identity technology. I suggest the use or existence of names might be examined in several ways, and give examples. These are via 1) informal insurance mechanisms, 2) reducing information and search costs, 3 ) indicators of occupational licensing, and finally 4) the facilitation of taxation and other political exchange.

\subsubsection{Clan names and informal insurance mechanisms}

Carr and Landa (1983) determine that clan names ${ }^{61}$ constitute an intangible asset which provides the possibility of mutual aid amongst members of a group. This itself builds on the work of Posner (1980) and Buchanan (1965), and their work on, respectively, the role of informal insurance mechanisms, and the economic theory of clubs. Clan names are used as an information cost economising mechanism to determine eligible recipients for mutual aid in the face of calamitous events. The risk of such events can be spread across members of a group, with names determining eligibility to "an insurance policy which protects club members against declines in their income." (Carr and Landa 1983, 153). Names thus provide a mechanism by which mutual insurance can be provided in times of need, while also providing some way in which free-riding can be detected and punished, preventing fraudulent claims of group status and the benefits of membership (see also Posner 1996).

${ }^{61}$ Here, clan names should be considered as interchangeable with surnames. 


\subsubsection{Surnames as a mechanism to reduce information and search costs}

The use of single names presents cognitive and administrative limitations. As an example, take that of a small community, one which is comprised of perhaps no more than 150 people. An individual might be reasonably expected to know everyone in that community. The use of facial features, memory and a single name might suffice for the purposes of political, economic and social exchange-an analogue form of biometric identification. In this community, even a single identifier-such as a single name-would likely be sufficient to distinguish between individuals in most contexts; "a single attribute may define an identity" for the purposes of exchange (Chango 2012, 39).

Yet an individual's cognitive ability to simultaneously monitor and maintain relationships numbering greater than 150 is limited due to the size of the human neocortex (Dunbar 1992, Hill and Dunbar 2003). The information and search costs associated with finding 'the' individual you are looking for become commensurately larger as population size increases. In addition to cognitive limits, ambiguity is avoided, or at least limited using additional identifiers and additional complexity of naming practices. For instance, it has been estimated that in what is now modern day Britain 90 per cent of the male population shared just six names in the $12^{\text {th }}$ century (Scott 1998), while 15 per cent were called William (Hughes 1959). Such limited naming practices sees a relationship between the density of population, the distribution of names, and the need for a second identifier. ${ }^{62} 63$ For this reason, surnames "began to be added, as a kind of adjective modifying and extending the limited stock of baptismal names" (Caplan 2001, 54). Subsequently, the expansion of commercial activity and the administrative state closely tracks the proliferation of the use of a second identifier-a surname-as an attribute used to assist individuals and authorities unambiguously and indirectly identify individuals for the purposes of contracting, as well as the maintenance of tax and property registers, conscription lists, and censuses (Gersuny 1974, Scott 1998).

\footnotetext{
${ }^{62}$ Scott, Tehranian, and Mathias (2002) provide an example of how difficult finding an individual amongst a population might be in a situation where only a small number of names are shared, and where none have a second identifier. For instance, they estimate that in 1700, most small communities in England shared just eight male names. Those names were John, Edward, William, Henry, Charles, James, Richard and Robert. If the community numbers 1,000 male inhabitants, and those names are evenly distributed, you would expect to have 125 individuals with each name. If an official is looking for one 'Henry', 124 of those he comes across will not be the 'Henry' he is looking for, and he is unlikely to find his man without local knowledge and assistance. With more realistic assumptions, the difficulty of finding an individual will vary with the popularity of the name. If half the male population bears the name William, the chances of the official finding the correct 'William' will vary accordingly.

${ }^{63}$ Mill ([1843] 1974, 980) provides an example which shows the difficulty of distinguishing individuals even when the relevant population size is limited. In this case, the example is distinguishing between monarchs. Identifying a particular individual as the 'Monarch of England' presents difficulties as it could apply to an inordinate number of people, in whatever way it is defined. Mill defines such a term as a 'general' one. This can be rectified in several ways. The first is to identify an individual as the 'present Monarch of England', as such a title is granted "in succession, however, not simultaneously"; England has one monarch at a time. The second way is to use a name in addition to the title. Thus, 'Queen Elizabeth II' conveys far more distinguishing information than does 'Monarch of England'.
} 
The process of adding surnames was a disparate one in, and amongst, regions. What this suggests is that the incentive to add these second identifiers, and thereby reduce information and search costs, is predicated on the economic and political sophistication of the region and society in question. Their adoption would typically reflect the social, political and economic conditions of the region (Caplan 2001), as well as changes in population density and mobility (Hughes 1959). The adoption of surnames reflects both the ability of a central state authority to project their power into a region, as well as the emergence of systems of private property and the sophistication of exchange (Scott, Tehranian, and Mathias 2002).

So, while some localities have up until relatively recently largely eschewed the use of a surname, others were known to have used them well into the ancient past. Nielsen (2010) dates the use of hereditary surnames in Babylon as early as the $15^{\text {th }}$ century BCE, reflecting the early urbanisation of many areas in Mesopotamia, as well as the projective power of the state. In contrast, peasant farmers in rural France did not begin to use a surname until the $18^{\text {th }}$ century, even though Parisian tax registers listed them from the $13^{\text {th }}$ (Gersuny 1974). Even contemporaneously, individuals in some areas of Asia and Africa consider their use as "unknown or exotic" (Pintens and Will 1995, 45).

\subsubsection{Surnames as a proxy for occupational licensing}

"There can be some sorts of industry, even of the lowest kind, which can be carried on nowhere but in a great town. A porter, for example, can find employment and subsistence in no other place. A village is by much too narrow a sphere for him; even an ordinary market town is scarce large enough to afford him constant occupation. In the lone houses and very small villages which are scattered about in so desert a country as the Highlands of Scotland, every farmer must be butcher, baker, and brewer for his own family. In such situations we can scarce expect to find even a smith, a carpenter, or a mason."

(Smith 1776a, 121-122).

The growth in distinct occupational types has been attributed to increased agricultural productivity and market size (Gersuny 1974), as well as changes in population size and improved transportation technology as discussed by Smith above. Gersuny (1974) notes that in the passage above from Smith, he recognises eight occupational specialisations. Even in the medieval period, the variety of minutely specialised occupational surnames is significant; Reaney and Wilson (2006) note 165 different English surnames just for the cloth industry. As discussed earlier, occupational types form one of the categories of the typical surname taxonomy. These occupational surnames serve a fundamental purpose for economic exchange. Used as an identity technology, they substantially reduce the search costs associated with finding a butcher, baker or brewer (at least while that surname maps to its owner's occupation, rather than simply to that of an ancestor).

I suggest that occupational surnames might have also functioned as a primitive form of occupational licencing. The types of occupational surnames seen in and amongst locales can be taken as a proxy not only of the extent of the market (Smith 1776a), but can also explain the types of goods and services that were produced in certain regions, and at certain times. 
Gersuny (1974) shows how most European languages have surnames that correspond with the English 'Baker', 'Carpenter', 'Smith' and 'Miller'; bakers, carpenters, metalworkers and millers are largely universal professions. Similarly, the presence or absence of certain surnames can be explained through regional preferences for goods and services. The absence of the Spanish or Italian equivalent of the surname 'Brewer' might be due to the preference for wine over beer at the time when surnames were acquired. Likewise, the absence of an English surname corresponding to the occupation of bricklayer might be due to the types of construction material typically used before the $15^{\text {th }}$ century in England.

The timing of adoption between localities is also apparent when you examine the typical surnames in different regions. 'Taylor' was adopted as a surname in England at a time when tailors would have made a wide range of items from clothing to shoes. In Germany however, the surnames 'Schumacher' (shoemaker) and 'Schumann' (shoeman) are common, which reflects the fact that in what is now Germany, surnames were not adopted until tailors and shoemakers had become distinct occupations (Matthews 2007). And while the link between occupational surname and actual occupation is severed when an individual no longer practices the craft associated with their name, prior to this break the use of a surname might have served to associate an individual with "the excellence of the craft and the reputation of the guild." (Nicolainsen 1980, 127). If occupational surnames functioned as a proxy for quality or reputation in some field, it could be that they were used to overcome information asymmetries as described by Akerlof (1970), while also serving to maintain access to monopoly rents. It remains to be seen if medieval guilds, for example, were actively involved in the monitoring and policing of surnames associated with their craft.

\subsubsection{Surnames facilitate taxation and other extractive activity}

Surnames also function to facilitate political exchange. States provision public goods and services to their subjects, and in return extract resources in the form of taxation and labour (including military service). A central authority has an interest in having a clear and easily comprehensible understanding of the numbers and nature of their resident population. That is, they serve as an information cost minimising device, overcoming information asymmetries between the ruler and the ruled. In this respect, the need for the state to comprehend their population is examined at length in Chapter 6 . Surnames provide a way in which a population is legible to the state (Scott 1998), and, in the sense of Torpey (2000), can be embraced by its authority. State authorities have an interest in ensuring that individuals maintain a single identity that can be used for taxation, conscription, and entitlement purposes. In this way, the state might ensure it collects taxation along with military services from all eligible citizens, while it simultaneously seeks to prevent individuals from illegitimately lessening their progressive tax burden, or illegitimately increasing their access to welfare entitlements and voting property rights.

Aside from enabling efficient taxation, conscription and welfare provision, surnames also provide a tool through which political ends might be achieved. This might include providing a way to distinguish between certain family, ethnic or other defined groups against which the state wishes to favour or discriminate against. Instances of the latter are evident in polities dating as far back as the Persian Empire of the 6th century BCE (see Nielsen 2010). In addition to enabling overt discrimination, surnames can be imposed by a state to ensure standard 
naming practices, including as a way of pursuing a political agenda. The wholesale modification of (or adoption of new) surnames has occurred up until relatively recently as a means of enforcing "cultural and social hegemony" (Hametz 2002, 6). Turkish name policies in the early 20th century dictated that individuals only use approved names, with Armenian, Slavic, Greek, Persian and Arab endings forbidden in favour of Turkish ones such as '-oğlu' (Türköz 2007). In addition, border regions which have been subject to annexation have seen similar impositions of standardised naming practices.

Following the transfer of the city of Trieste to Italy following the defeat and dissolution of the Austro-Hungarian Empire at the end of World War I, residents were first encouraged, and then forced, to adopt modified names to reflect geopolitical realities. This culminated in the Fascist period in Italy where surnames were forcibly changed by decree. In some cases, spellings of names were changed to reflect Italian endings. To this end, 'Arko', 'Bresciak', 'Gutty' and 'Marinschegg' became 'Arco', 'Brescia', 'Gutti' and 'Marini' respectively. Other changes were more radical, with names translated into Italian; 'Golob' (dove) became 'Colombi', and 'Wodopivec' (drink water) became 'Bevilacqua' (Hametz 2002). Similarly, yet in magnitudes more disastrous for those in question, the Nazi regime in Germany sought to better identify the Jewish population through naming practices; a decree in 1938 compelled those of Jewish origin to append their names with either 'Israel' or 'Sara' if their original names were not sufficiently Jewish (Casquete 2016, Kershaw 2008, Rennick 1970). ${ }^{64}$

\subsection{Conclusion}

The contribution of this chapter is a simple one; heritable surnames are an identity technology which provides reference to the past, and in doing so overcomes uncertainty of outcome. That is, they provide their users a reference point to past economic, social and political events. Incorporating the economic and political analysis from the NIEH, along with the origin of property rights literature, I have contextualised the origin of heritable surnames in the context of England from the mid-11th century. In the model I have developed, intergenerational property ownership existed in an environment under sovereign risk. The monopoly seller described in this model possesses private information related to their future intentions to nationalise land, or not. To constrain this opportunism, buyers of land assets produced heritable surnames - an institutional identity technology-as one means to provide certainty. To be sure, this was less than perfectly successful. Yet as imperfect as it was in practice, such an identity institution was used as a measure of protection against state action. To pre-empt the next chapter, identity institutions have also been used for the opposite effect. State actors also suffer from the effects of private information and hence supply and use identity institutions for reasons of 'legibility' (in the manner of Scott 1998 see also Torpey 2000) over their citizenry.

What is apparent from the analysis is that the institution in question was employed first by political entrepreneurs eager to maintain the monopoly rents they had purchased from the state as part of their involvement in the Conquest. This saw them rapidly employ these

\footnotetext{
64 The Nazi regime also forced their Jewish victims to wear identifying armbands (Szarota 2004) while simultaneously employing sophisticated information processing technologies (Dillard 2003). Thus, they used multiple identity technologies to efficiently enact their horrid racial programs.
} 
surnames to reference their predecessors. In the case of locative surnames the reference was explicit. The use of such a surname being a clear signal to both state and non-state actors of the legitimacy of their claim to that land. The technique was not a complete success however, owing not least to the numerous instances of land redistribution and other arbitrary actions by English monarchs. The extant evidence is therefore inconsistent with a Demsetzian view of the emergence of heritable surnames. The redistribution of land by successive monarchs indicates the validity of a legal-centrist view; political considerations dictate that the state must recognise surnames as legitimate markers of property ownership for them to have consistent effect. The Magna Carta and the Statute of Wills are two examples of further political interventions which were necessary to facilitate inheritance within the rule of law. The further evolution of this identity technology was the eventual appropriation by the state, owing to their desire and need for legibility over the population for extractive purposes. 


\section{Chapter 6. The stationary bandit with stationary captives}

\subsection{Introduction}

Using an expanded version of the stationary bandit model, this chapter contributes an examination of the way states have used means of administrative identity to distinguish between individuals for extractive and other purposes. In my model, states first demand identity information related to their population, which they then seek to satisfy via the public supply and use of identity technologies. A main contribution of this chapter is that, in contrast to the homogeneity assumed in the original model, the heterogeneity of a population means that different individuals provide varied value to a stationary bandit, and are treated accordingly. To discriminate between individuals within a population for the purposes of resource extraction, as well as the allocation of public goods, rulers use identity technologies such as sauf-conduit, passports, and other administrative means. Rulers can similarly use these identity technologies to increase their extractive capacity.

I have defined identity as a vector of characteristics associated with a unique individual that allows other individuals to recognise them, or allow differentiation from other individuals. I have already demonstrated how identity can mitigate information asymmetry, and the way identity operates in a transaction cost minimising manner. Here the overarching theme is that identity institutions are used to overcome the effects of uncertainty, as well as overcome opportunism by heterogeneous actors with varied endowments, tastes, and motivations. Complementing this depiction, and as described by Scott (1998), nation-states seek to make their populations 'legible' to better extract labour and other resources from them. This chapter focuses on the implicit political exchange between a populace and a stationary bandit (Olson 1993, 1995), where the stationary bandit has monopolised tax theft over the populace. That is, this chapter explains the use of identity institutions to overcome the effects of private information between a ruler and the ruled. In contrast to the previous chapter, this results in the public supply of identity. The motivations for this are reasons of state legibility (Scott 1998) and subsequent control over a population.

The model I contribute in this chapter involves a monopoly seller with many heterogeneous buyers. In exchange for the provision of public goods, heterogeneous buyers are preyed upon in the form of resource extraction. Consistent with the theme of this thesis, buyers are assumed to be heterogeneous owing to a rejection of economic and political models which sees interaction occurring between 'anonymous partners' (Carr and Landa 1983, see also Demsetz 1988, Williamson 1985, Telser and Higinbotham 1977). That is, the seller is under a veil of uncertainty owing to the private information possessed by the buyers in this model. Consistent with the assumption of self-interest in Olson's $(1993,1995)$ model, the monopoly seller finds it worthwhile to increase their extractive capacity through various means, including greater 'legibility' (Scott 1998) over their population, as well as the accumulation of greater numbers of citizens into their population stock.

My model therefore has predictive capability. Owing to the heterogeneous nature of a captive population, rulers have an incentive to supply and deploy identity technology to distinguish 
between low value and high value individuals. It is also predicted that the provision of public goods will be commensurately rationed, owing to the varied values which individual citizens have to the ruler. I assert that these identity technologies, and instances of this discrimination, will be seen at points throughout history.

This chapter is set out as follows. In Section 6.2 I develop an expanded stationary bandit model of government. This model sees a ruler actively distinguish between members of their captive population for the purposes of predation. Sections 6.3-6.6 comprise case studies with which to evaluate this model. Section 6.7 concludes.

\subsection{The model}

The main contribution of this chapter is a simple model of discriminatory resource extraction. It describes some of the ways states have distinguished between members of their populations to fulfil economic and political goals. The model I develop in the following pages is a logical extension of the 'stationary bandit' model of government initially developed by Mancur Olson $(1993,1995)$. Olson's model is an "antisocial contract model of the origin of government" (Davidson and Potts 2017, 70 see also Stiglitz 2002), which sees a stationary bandit monopolise tax theft within a territory. Crucially, from the perspectives of both the bandit (ruler) and those from whom they extract resources, they might both be better off (Curott and Fink 2012, cf. Chen 2004). This is due to the economic incentives available to the population within a polity under a stationary bandit, along with the 'encompassing interests' of both the ruler and the ruled (Olson 1982). By protecting citizens from the predations of roving bandits, the stationary bandit increases the profitability of income generating activities, part of which can then be confiscated (Olson 1993, 1995, McGuire and Olson 1996, Dixit 1999, Murtazashvili and Murtazashvili 2016).

The model I develop, and that originally advanced by Olson, assumes a self-interested ruler which is consistent with models of state formation put forth by Barzel $(2002,2003)$, North, Wallis, and Weingast (2009), Acemoglu and Robinson (2012), amongst others. It addresses Sened's $(1997,15)$ critique of the Hobbesian notion of a "benevolent sovereign who protects the rights of his or her subjects, instead of explaining the motivation of the sovereign to do so". This is analogous to the approach taken by Geoffrey Brennan and James Buchanan (1980), and their rejection of a 'social welfare function' (Bergson 1938, Samuelson 1947) along with any relationship it might have to theories of the state. In the stationary bandit model, rulers refrain from stealing everything, not out of their benevolence, but rather out of self-interest (Dixit 1999, Chen 2004, Murtazashvili and Murtazashvili 2016). ${ }^{65}$ Over the longrun, providing public goods, and simultaneously leaving some income producing assets in private hands, comprise justifiable costs as they promote private investment and commercial activity within a polity, a part of which can then be taken through regular taxation (McLean 2000, Polishchuk and Syunyaev 2011). Here, the rate of taxation will differ from that of the roving bandit. This can be illustrated using the Laffer curve, which sees a roving bandit steal

\footnotetext{
${ }^{65}$ As McLean (2000) points out, this has parallels with some economic theories of organised crime (see, for instance Gambetta 1993, Varese 2001).
} 
resources at the right-hand side of the curve, while their stationary counterpart will "cultivate the economy over which he has control for the longer run" (Dixit 1999, F450).

The shortcoming my models addresses, is that the standard stationary bandit model of government treats the implicit exchange as being one between a ruler, and an anonymous citizenry. Such a model is analogous with mainstream economic models which sees exchange as occurring between 'anonymous partners' (Carr and Landa 1983). Yet such impersonal models of exchange ignore the importance of identity in economic and political exchange. That is, mainstream economics ignores the vectors of characteristics which comprise the identity of individuals, and where uncertainty over those characteristics would likely diminish instances of exchange (Akerlof and Kranton 2000, Arrow 1972c, Ben-Porath 1980, Carr and Landa 1983). Quite simply, market exchange does not typically occur between homogenous entities (Demsetz 1988, Williamson 1985) in an idealised spot-market transaction (Telser and Higinbotham 1977). I suggest the exchange described under my modified stationary bandit model will see the ruler first take an interest in the heterogeneous nature of their citizens due to their varying abilities to pay tribute, and then treat them differently according to those abilities.

The model I develop in this chapter is simple. There are many heterogeneous buyers and a monopoly seller. In exchange for public goods, buyers are taxed at some level short of resource exhaustion. This, along with benefits derived from public goods provided, sees the monopoly seller maintain access to extractable resources over a longer time horizon than would a roving bandit. Buyers have access to private information, such as that related to their own ability to provide tribute. As a result, the monopoly seller might find it worthwhile to label, or otherwise increase their 'legibility' (Scott 1998) over, a captive population. That is, the public demand for identity is satisfied by the public supply of identity. In addition to providing for more efficient resource extraction, the monopoly seller also discriminates in the provision of public goods. This discrimination in public good provision is in part based on a buyer's value to the seller.

Stationary bandits - the monopoly seller-monopolise resource extraction from a polity-the group of heterogeneous buyers. In exchange the monopoly seller provides public goods to the buyers. The level of predation under the stationary bandit is lower than that of their roving counterparts, due to the encompassing interests of the ruler, and the ruled, to maintain some stock of productive assets from which future income streams might be derived. Yet there will always be some degree of heterogeneity within a population preyed upon by a stationary bandit. Hence it is in the interest of a ruler to distinguish between citizens. Rulers seek not only to extract resources in the form of money and other capital, they also extract labour resources, for instance through conscription. As such, states seek to maintain some degree of 'legibility' (Scott 1998) over their citizens, as the heterogeneous nature of their citizenry means they have varying capacities to transfer monetary, labour and other resources to the state.

In addition, stationary bandits derive their wealth from a monopoly on theft, and as such it is trivial to demonstrate the incentives under which a ruler will increase the number of captives from whom they can plunder. Rulers will continue to add additional citizens to their polity so long as the value they can extract from them is greater than the cost of providing public goods 
to them. Put another way, up until the point where the marginal cost of providing public goods to each additional citizen equals the marginal revenue extractable, it will be in the interest of a ruler to increase the population of their captives. Apart from natural means, methods by which rulers can increase their population size might be territorial conquest, along with policies to encourage immigration. Maximising their resource base might also be achieved by preventing current captives leaving the polity. In addition, as the heterogeneous nature of individuals means that they have varying capacities to pay (monetary and labour) tribute, it is in the interest of rulers to maintain legibility over who crosses their borders.

I have described a model of government where a stationary bandit has an incentive to maintain legibility over their population due to the varying abilities of their citizenry to pay tribute. However as discussed earlier, rulers also provide security and other benefits to the extent that those public goods increase the capacity of the citizenry to produce income which can then be exploited. The model I have developed further suggests that the public goods provided are not equitably distributed, but rather discriminatorily supplied. That is, certain members of the captive population receive more favourable treatment from the stationary bandit than do others. To this end, rulers must also be able to distinguish between citizens due to heterogeneous nature of the provision of public goods they are willing to provide.

The model I seek to advance therefore leads to two testable hypotheses. The first of these is that 1) stationary bandits value members of their population differently, and use identity technologies to control higher value individuals. If the heterogeneous nature of the citizenry within a polity means that a stationary bandit values them commensurately, there will be historical instances of identity technologies employed to this effect. That is, a stationary bandit will likely desire greater control over the movements of citizens of greater value, than their lower value counterparts. The second hypothesis is that 2) stationary bandits use identity technologies to discriminatorily supply public goods and access to other services. The public goods provided to citizens under a stationary bandit will similarly be discriminatorily supplied, again owing to their varying ability in creating future income streams for taxation purposes. This chapter shall now examine four historical instances-Ancient Rome, early Medieval Europe, revolutionary France, and Communist China-as case studies for the model.

\subsection{Citizenship and mobility in the Roman Republic and Empire}

This section examines the Roman state and the way that identity institutions were used to distinguish between individuals for resource extraction and for the provision of public goods. The institutions of citizenship, the diploma, and the tractorium were how, respectively, the Roman state distinguished between its populace, as well as afforded users access to the infrastructure of the cursus publicus - the Roman transportation system. Together, these institutions attempted to confer a form of administrative identity upon citizens to ensure rights and responsibilities were discriminatorily applied.

The ability to move relatively freely was open to many, and closely linked to the concept of Roman citizenship. Scheidel $(2004,20)$ considers mobility as "one of the most essential characteristics of Roman citizenship". This characteristic of a mobile citizenry stemmed primarily from the practicalities of waging war across a vast and growing empire with a citizen army (Speidel 1976), along with resettlement for the purposes of state-building (Scheidel 
2004). Yet aside from the propensity to move as part of the legions, or as part of mass resettlement programs, Roman citizenship also brought with it privileges and responsibilities, albeit ones that were not static over the course of the Roman period.

One of the primary privileges of citizenship was that of provocatio ad populum, later provocatio ad Caesarum under the Empire (Keener 2015). This right of petition to the Emperor (to the Roman people during the Republic) could in theory be exercised by any citizen, resulting in the cessation of local court proceedings in what Nicolet $(1980,20)$ describes as a "civil and juridical safeguard". As a Roman citizen, St Paul could exercise his right to provocatio in the $1^{\text {st }}$ century after his arrest in Jerusalem.

Paul answered: 'I am now standing before Caesar's court, where I ought to be tried. I have not done any wrong to the Jews, as you yourself know very well. If, however, I am guilty of doing anything deserving death, I do not refuse to die. But if the charges brought against me by these Jews are not true, no one has the right to hand me over to them. I appeal to Caesar!' After Festus had conferred with his council, he declared: 'You have appealed to Caesar. To Caesar you will go!' (Acts 25:10-12).

Similar rights were reserved to citizens who were caught up in prosecutions of Christians under Pliny the Younger. Those Christians deemed to be citizens were sent for trial in Rome (Nicolet 1980). Citizens were thus in theory protected from "summary violence" and had the right of appeal in legal matters (Lavan 2016, 35). Aside from this early form of habeas corpus available only to citizens (Nicolet 1980), citizenship conferred to its beneficiaries' rights in the form of subsidies and tax benefits, as well as access to civil and military offices.

The ability to purchase subsidised grain in Rome was another right restricted to citizens (Garnsey and Rathbone 1985), while Roman citizenship conferred to the holder tax benefits (and obligations). Roman citizens were exempt from certain taxes (Sherwin-White 1973), including the land and the poll tax, along with most direct taxes (Ando 2006)-although they were subject to others including the inheritance tax (Günther 2016).

Access to civil and military organisations was largely restricted by citizenship status. The ability to vote and be elected to office were confined to those recognised as Roman citizens (Cooper 2018, Nicolet 1980). Martial rights and responsibilities were also generally delineated via citizenship. Both the Republican and Imperial legions were largely restricted to recruits holding citizenship (Speidel 1976), with service in auxiliary units open to those outside the franchise (Nicolet 1980, Webster 1998). And as distinguished service in auxiliary units would often result in the granting of citizenship (Webster 1998), employment in the military and citizenship were further linked (Nicolet 1980). Enlistment in the legions may have also offered greater pay that their auxiliary counterparts (Speidel $1992 \mathrm{cf}$. Alston 1994). Indeed, the expansion of Roman citizenship, first from Rome to Italy, and then gradually to outlying provinces, resulted in an "increasingly demilitarized core and an expanding periphery that picked up much of the burden" (Scheidel 2004, 20). This link between martial service and citizenship could be broken however, with citizenship lost by those soldiers taken prisoner in wartime (Balsdon 1979). This general association between military service and citizenship held true until the $3^{\text {rd }}$ century (Scheidel 2004). 
This process of the expansion of citizenship to those outside of Italy culminated in 212 with the 'Edict of Caracella', whereby all free residents across the Empire were granted citizenship (Bagnall and Frier 2006, Killgrove 2010). It has been suggested that this expansion may have had the effect of increasing the tax revenue of the state, due to the increased collection of taxes borne by citizens only (de Blois 2014, cf. Ando 2006, Sherwin-White 1973). The Edict itself followed a long tradition of the granting of such citizenship rights to non-violently subordinate previously independent populations (Cooper 2018). This technique had been notably used prior to the Edict at the end of the so-called 'Social War' in the early $1^{\text {st }}$ century $\mathrm{BCE}$, with Umbrian and Etruscan tribes granted citizenship en masse in return for the cessation of hostilities against the Republic (Kuiper 2011). The 'Romanization' of previously independent populations brought to them "censuses, taxation, and the Roman law that came with Roman citizenship" (Woolf 1998, 40).

Some method of proving citizenship was therefore necessary to gain access to certain privileges, including the provocatio, access to the subsidised grain in the city of Rome, tax benefits-and obligations (see, de Blois 2014, Woolf 1998)-along with access to civil and military offices earlier described. Citizenship needed to be defined and recorded (Cooper 2018) for as "a soldier, a taxpayer or recipient of public bounty, and an elector, the Roman was made to realize at every stage of his life that he was a civis, a member of a community that existed because of him and for his benefit" (Nicolet 1980, 317). Proof of citizenship, along with the rights and tax exemptions it granted, was therefore valued commensurately (Ando 2000).

The primary way in which the Roman Republic, and subsequently the Roman Empire, gathered information about population-including citizenship status-and property ownership was via the census (Ando 2006, Brunt 1990, Nicolet 1980). The census counted individuals along with their "age, sex, parentage, family relations, civil status, domicile, tribal membership, and property" (Cooper 2018, 32). Although the purpose and format of these censuses changed throughout the long history of the Mediterranean civilization, they were primarily used to identify rights and obligations due; these included identifying men eligible for service in the legions, establishing taxation obligations, as well as voting rights and access to elected offices (Hin, Conde, and Lenart 2016).

Some of the most well preserved census records come from Egypt, owing to the dry conditions which have allowed many of these documents to survive the intervening centuries (Hin, Conde, and Lenart 2016). The Egyptian census is thought to have taken place every 14 years (Rathbone 1993), in contrast to those which occurred every five in Italy (Bagnall and Frier 2006). It is thought this longer time lag was due to poll tax liabilities which did not come due until an individual turned 14 years of age (Hin, Conde, and Lenart 2016). Extracts from the census were used as a proof of citizenship, as along with records of property, they recorded the civil status of persons (Ando 2000). One example from Egypt carefully records the birth of one 'Julia Ammonus' to parents 'Tiberius Julius Discorides' and 'Julia Ammonarius' in the $2^{\text {nd }}$ century CE. Ando (2000) shows how personal extracts of the official census conducted by the Roman authorities - such as that of 'Julia Ammonus' - served as physical artefacts with which to claim rights and other privileges which came with citizenship. 
Perhaps a more pragmatic-albeit imperfect-way of proving citizenship was via the tria nomina naming convention prevalent throughout the Roman world. Chapter 5 provides a useful overview of this naming system. Especially in the periphery of the Roman world, this convention served to distinguish the citizen from the non-citizen, and the rights and responsibilities which came with it (Salway 1994). Wilson (2003) discusses the significance of the name 'Marcus Tullius Cicero', respectively consisting of the praenomen, nomen gentilicium, and cognomen. Detailed provenance of the individual could be indicated in more formalised naming conventions. Thus, Cicero would also have been known as 'Marcus Tullius Marci filius Cornelia Cicero', the additions reflecting both paternal lineage and tribal affiliations-Cicero being the son of Marci and from the tribe Cornelia. Such a convention reflects the importance of naming taxonomy in "indicating a person's lineage, place of origin, and social status" (Cranford 2012, 2), while crucially providing a reliable indication of citizenship (Bagnall and Frier 2006).

The importance of the tria nomina in delineating citizenship can be clearly seen in the naturalisation process of citizens admitted to the Roman citizenry. Two Greeks, 'Theophanes' and 'Theopompus', adopted the tria nomina upon being granted citizenship. These individuals used their existing (single) names as their cognomen, and simultaneously adopted the names of those who granted them citizenship. Thus 'Theophanes' became 'Gnaeus Pompeius Theophanes', while 'Theopompus' became 'Gaius Julius Theopompus', having been granted citizenship, respectively, under Pompey, and Julius Caesar, in the $1^{\text {st }}$ century BCE (Pothecary 1999). This process was then deployed on an industrial scale with the Edict of Caracalla at the start of the $3^{\text {rd }}$ century. On this occasion, all newly enfranchised citizens across the empire adopted the regnal names of their sponsor Marcus Aurelius (Salway 1994).

Changing one's name to reflect citizenship in such a manner became even more important in the case of auxiliary soldiers who had completed their service. This is so, as in the second half of the $1^{\text {st }}$ century citizenship was inheritable by the children of those granted it through military service, whereas prior it had "died with the man himself" (Mann and Roxan 1988, 344). Proving the right to use the tria nomina, along with the citizenship it implied, was itself done via physical artefacts which allowed the bearer access to those rights.

Mann and Roxan $(1988,344)$ describe the diploma as a "document proving the possession of Roman citizenship" whose "value lay in its recording the grants of those privileges". Such documents would typically consist of "two copies of the imperial grant on two separate sheets of bronze, tied together so that one copy faced out and one was protected inside" (Ando $2000,356)$. After the $1^{\text {st }}$ century reforms which made this citizenship automatically inheritable by the children of a discharged auxiliary, men took great care to ensure that the rights of their children were formally recognised by making a formal declaration of birth-testatio. Such a declaration is made by one ' $M$. Lucretius Clemens' in the early $2^{\text {nd }}$ century, who in front of six witnesses and swearing to the god Jupiter as well as the Emperor Hadrian, states that he is "the father of a natural son (Serenus) born six days previously (25 April) to Octavia Tamusta" (Mann and Roxan 1988, 345). Such documents afforded access to certain rights as a citizen, and provided proof of such a claim which was more robust than simply using the tria nomina (Salway 1994). 
After citizenship, the second institution in the Roman state which was used in the discriminatory provision of public goods was the tractorium. (Some, including Skeel (1901), Ramsay (1925) and Moatti (2006) also refer to the tractorium as a diploma, although this should not be confused with the military diploma discussed earlier). This physical artefact afforded its bearer the right to use the cursus publicus, the state communications system in the Roman world consisting of a network of transport and accommodation infrastructure that messengers, the military, and other officials could use for official purposes (see Adams and Laurence 2012, Black 1995b, van Tilburg 2007). Skeel (1901) describes a complex (and presumably expensive) infrastructure where fresh horses and mules, along with carts and slaves were kept at regular intervals and put at the disposal of those using the system. Such a system facilitated the bureaucratic organisation of the vast Roman state, including the dissemination of legislation, reports and other official communications (Lemcke 2016). And while the precise speed of journeys across the cursus publicus are the subject of scholarly debate (see for instance Eliot 1955, Ramsay 1925), the infrastructure of roads, resting and change stations, formed a crucial part of state operations by facilitating the flow of information and tax revenues (Lemcke 2016). Use of this "state-organized information and transportation system" (Lemcke 2016, 1) was restricted to those granted permission by Emperor or his delegates. In part, due to the expense of its maintenance and operation, use of the cursus publicus was restricted to those bearing the tractorium.

The tractorium itself was a physical artefact consisting of two tablets, with the name of the current emperor, the bearer, and the length of time it was valid for (Lloyd 2005, Skeel 1901). Provincial authorities were delegated authority to issue tractorium, and were sent dated documents for this purpose, with the death of an emperor rendering any outstanding documents bearing the late emperor's name invalid (Skeel 1901). Due to this delegated authority, the ability for provincial authorities to make use of this public infrastructure for private matters was apparent, with the Younger Pliny explaining to the Emperor Trajan that he had issued his wife a tractorium so she could visit a mourning relative (with Trajan responding with his approval) (Skeel 1901). The cost of maintaining this infrastructure was shared between the provincial authorities and the central authority in Rome, hence the tractorium was in effect a permission to compulsorily requisition supplies from provinces which the bearer was passing through (Moatti 2006).

Thus, the Roman state used the public supply of several identity technologies by which a heterogeneous population was labelled, with resource extraction and the availability of public goods dependent on the label applied. Citizens were afforded access to civil and military office, while public goods including the cursus publicus were available only to a select few.

\subsection{Ne exeat regno and sauf conduit: medieval regulations on movement}

The common-law doctrine of ne exeat regno, along with the institution of sauf conduit, were two ways by which medieval rulers extracted resources from their populations, as well as visiting foreigners. Following the fall of Rome, and the disappearance of Roman citizenship and the tractorium, travel throughout medieval Europe became rarer, and commensurately more dangerous for those individuals who attempted it (Doulman and Lee 2008, Lloyd 2005). As travel between populated areas diminished, many of those settlements which had serviced 
the Roman civil and military communication networks were abandoned (Abu-Lughod 1989). Similarly, travel had become far less frequent such that it became "practical to have documents issued by one person upon demand" rather than pre-emptively as had occurred in the Roman era (Lloyd 2005, 27). This section shall examine how these mechanisms were, respectively, used by medieval rulers to maintain control over their native populations for resource extraction, and for the purposes of tax collection from (primarily) foreign merchants.

Ne exeat regno-literally "let him not go out of the kingdom" (Garner 2009, 1131)-is an English common law tradition which prevents individuals leaving the territory of a ruler without their explicit permission (Salter 2003, Torpey 2000, see, also Boudin 1956). ${ }^{66}$ From the early medieval period, ne exeat regno ensured populations were able to fulfil the needs of the ruler of that jurisdiction; "the 'principal' duty of a subject was to be at the service of his king" (Doulman and Lee 2008, 5, see, also Parker 1954, Sibley 1906, cf. Beames 1821). This legal construct was primarily used to ensure all individuals were subservient to the "best interests' of the state, and was a means to ensure that skilled civilian and military workers were kept within a kingdom (Diplock 1946, McBain 2011, McKechnie 1914, Sibley 1906). In addition, ne exeat regno was used to diminish the influence of the papacy on the secular authority of the English monarchy (Turack 1970). To aid the chronological narrative in this section, it is this latter function of ne exeat regno that shall be examined first.

Following the Norman invasion, William the Conqueror immediately attempted to temper the influence of the Holy See on the English state (see, Freeman 1876). According to Turack (1970), this involved five clerical restrictions;

a) No appeals to the Papal Court without the king's permission

b) No papal representative is to set foot in England without a licence

c) No papal bull or letter is permitted in England without the king's permission

d) No Pope is recognised in England unless approved by the king

e) No ecclesiastic is permitted to leave England without the king's permission (adapted from Turack 1970, 138-39)

Both b) and e) constitute explicit mobility restrictions on a discrete class of individuals, while c) does so implicitly. Yet according to Turack (1970), no explicit and extant evidence for the existence of these restrictions exists. However, by examining correspondence between Rome and the English monarch their existence becomes clear. Pope Gregory VII wrote to Lanfranc, Archbishop of Canterbury in March of 1079, warning that his "presence had been denied" in Rome as he had not been granted leave to depart England (Douglas and Greenaway 1996, 742). Similarly, further correspondence between Popes and rulers in England confirm these travel restrictions. This is seen in letters from Pope Gregory VII in September of 1079, where he complains of the way William acts "to forbid the bishops and archbishops to frequent the threshold of the apostles" (Douglas and Greenaway 1996, 743). On the occasion an ecclesiastical representative could leave for Rome, they were often searched for valuables

\footnotetext{
${ }^{66}$ According to McBain $(2011,26)$ it is "remarkable that, in modern times, the Crown can still prohibit subjects from leaving the UK, and that it need give no reason". Regardless of the uncertain constitutional outcome should the Crown try and assert this power today (see, for instance Williams 1974), this section shall examine ne exeat regno from an early medieval (and English) perspective.
} 
"lest the king be deprived of any riches" (Turack 1970, 145). Similar occasions are recounted by Turack (1970) in the reigns of William Rufus, Henry I, Stephen, and Henry II. These instances include the (ultimately unsuccessful) effort by Stephen to have all exit ports watched to prevent Theobold, Archbishop of Canterbury, from attending Rheims to meet Pope Eugenius III in 1148 (Spigelman 2004, Turack 1970). ${ }^{67}$ However, it was not until the second half of the $12^{\text {th }}$ century that this prohibition was explicitly made a part of the historical record.

According to Warneke (as cited in Torpey 2000, 22) early medieval English monarchs were concerned with 'religious deviance' should there be unregulated travel by the clergy to the continent. The 1164 'Constitutions of Clarendon' (see, for instance Hudson 2012, Huscroft 2005, Mulligan 2005) explicitly legislated against the movement of 'turbulent priests' (McBain 2011, McKechnie 1914, Williams 1974). Issued by Henry II, this document was used to curb the power of the Church domestically, and in Rome (Mulligan 2005) at a time when there was intense jurisdictional competition between the secular and the ecclesiastical (Board 1962, Doulman and Lee 2008, Salter 2003). Article 4 of this document prevents clergy of all ranks from leaving "the kingdom without the lord king's permission" (as cited in McBain 2011, 26).

Transgressions were liable to be met with a fine, as was issued to 'Randolph, son of Walther' when he departed England without a licence (Board 1962, 44). The legislative instrument introduced in 1164 was determined to be avitae consuetudines-ancestral customsindicating a 'historical justification' for their introduction by Henry II (Turack 1970, cf. Beames 1821). Yet according to McBain $(2011,27)$, these restrictions throughout early medieval English history were in fact of a more general nature, and reflected a widespread "concern about a shortage of labour and of people taking their skills, and money, out of the realm". ${ }^{68}$ These licences were priced at 2 shillings during the reign of John, with a typical licence reading as follows:

\footnotetext{
${ }^{67}$ To be sure, there were journeys by the clergy from England to Rome in the early medieval period. However, when permission to travel was granted they were often handpicked envoys, while English bishops seldom made the regular journeys to Rome that were expected of them. In this respect Parks (1954) provides a good overview of some of the trips made during this period.

${ }^{68}$ The 'general' nature of these restrictions can also be noted by their (somewhat temporary) abolition in the early $13^{\text {th }}$ century CE. Clause 42 of the Magna Carta of 1215 states that it "shall be lawful for any one (excepting always those imprisoned or outlawed in accordance with the law of the kingdom, and natives of any country at war with us, and merchants, who shall be treated as is above provided) to leave our kingdom and to return, safe and secure by land and water" (as cited in McKechnie 1914, 407-08). Interestingly, clause 41 of this document specifically provides a similar permission to merchants (Berg and Roskam 2015, McKechnie 1914). However, the significance of clause 42 on the freedom of movement from England in the $13^{\text {th }}$ century was limited. Reissues of the document, including those in 1216 and 1297, were absent the clause providing for such a right to travel (McBain 2011, Williams 1974).
} 
John, by the grace of God, King of England, Lord of Ireland, Duke of Normandy and of Aquitaine and Count of Anjou, to the bailiffs of the port of Lynn greetings. Let it be known that we give to Robert son of Sunolf licence to take one ship load of corn into Norway. And therefore we command you that you allow him to take the ships thither without hindrance. And keep these letters in your possession. Witnessed ourself at Westminster, 19th April.

(Turack 1970, 157)

The concern with a shortage of military manpower was of concern to monarchs in the early medieval period. Ne exeat regno is largely derived from an attempt to ameliorate this martial concern (Board 1962, Diplock 1946, Lloyd 2005, McBain 2011). Those capable of military duties, including knights and archers, were subject to restrictions on their departure as doing so would deprive the monarch of their services in time of war (Boudin 1956, Sibley 1906). These duties included the ability to produce longbows (Lloyd 2005), such was their importance for English warfare during the $14^{\text {th }}$ and $15^{\text {th }}$ centuries. Archers with their technologically advanced longbows provided a critical advantage to English armies in battles in Scotland and in France throughout this period; they were "by far the most effective missile troops of their day" (Rogers 1994, 99, see, also Rogers 1998, cf. DeVries 1997). This can be most readily seen at the Battles of Crecy and Agincourt, in 1346 and 1415, respectively. At Crecy, the English army defeated a French force three times in number, in significant part with the use of archers (Rogers 1993).

The retention of military skills, along with labourers and other skilled workers, was of heightened importance in the $14^{\text {th }}$ and $15^{\text {th }}$ centuries. Civil war, pandemic-level illnesses, and foreign wars meant that skilled labour was in short supply (McBain 2011). Reiterative declarations to this effect were made by Edward III in 1352 (Board 1962, Coke 1797, McBain 2011, McKechnie 1914), and Richard II in 1381 (Williams 1974). It was not until 1606 that Richard's statue was repealed, owing to the unification of England and Scotland, and the need for the removal of impediments of travel across the British landmass (McBain 2011, McKechnie 1914, Parker 1954). To be sure, the restrictions on 'exit' (see Hirschman 1970) can also be considered as a characteristic of 'proto-mercantilism', in which English rulers barred productive and valuable individuals from leaving their jurisdiction (see Dowty 1989, Moya 1998, Zolberg 1978). Restrictions on emigration due to mercantilist concerns are considered in more detail in the following section. Suffice to say, English rulers in the early medieval period deployed such restrictions in an explicit effort to retain these skilled workers, and more generally in pursuit of a demographic balance of trade (Smith 1776b, see, also Zolberg 1978).

The sauf conduit-safe conduct pass ${ }^{69}$ - was another early medieval mechanism by which rulers could derive revenue from individuals travelling within their territory, including foreign merchants (Lane 1958, Salter 2003). In general terms sauf-conduit consisted of "a letter of [patent] that included the name of bearer and the purpose of his mission" (Frey and Frey $1999,94)$. These were available for a defined period, or on an annual basis (Smith 2014). These artefacts emerged as necessary tools via which "diplomats, couriers, and especially merchants in the High and Late Middle Ages" could facilitate their travel in foreign states

${ }^{69}$ Variously referred to as guidatica, guiatage, aman, widad (Smith 2014), and epistola (Middleton 2005). 
(Groebner 2001, 20), including those which might be considered 'hostile' (Lloyd 2005, McBain 2011). For these classes of users, they facilitated passage in sovereign territory, and thus share some functionality with the passport in its modern-day usage (Lloyd 2005, Robertson 2010, Torpey 2000). According to McBain (2011) they were issued only by the sovereign in the English context. This however was not consistent with the practice in other jurisdictions. For instance, in medieval Spain sauf-conduit might be issued by local officials (Burns 1995), as was also the case in parts of France (Abu-Lughod 1989). In contrast, throughout Muslim territories the right to issue such a document was available to any Muslim of age (Rodriguez 2007, Schacht 1982, see, also Wansbrough 1971).

According to Kadens (2004), throughout Europe, sauf-conduit were used relatively uniformly, and constituted one aspect of lex mercatoria (Berman 2009, Milgrom, North, and Weingast 1990, Trakman 1983). Alongside "trading rights and protections, and extraordinary remissions of normal laws" (Kadens 2004, 48), sauf-conduit were deployed to encourage international trade within a jurisdiction. Burns $(2001,1058)$ recounts a sauf-conduit issued in one Spanish jurisdiction, explicitly providing for the protection of the merchant class; "We also forbid anyone to dare to employ violence against them, or do them wrong or injury whatever". Sanctions for those who stole from merchants, or otherwise interfered with their activities were severe. Writing in the mid-12 ${ }^{\text {th }}$ century, one observer described the case of ten knights found guilty of stealing from a merchant travelling to a market fair in Thorout. According to this source, after they were hung in a well-publicised and suitably gruesome manner, future trade at that market town flourished (de Tournai 1996).

Sauf-conduit can therefore be considered to represent one side of a simple transaction in which monarchs and other authorities provide protection to foreign merchants, in exchange for revenue derived from tolls and other taxes (Abu-Lughod 1989, Burns 2001, Kadens 2004, Middleton 2005, Smith 2014). To use the terminology of Lane $(1958,412)$, this represents a stage of state development in which rulers entice individuals to their polity to increase "the amount of tribute" available to them. In this respect, local rulers committed to "indirectly exchanging coercion (safe-conducts and market police) for capital (levies, taxes, and market tariffs)" (Salter 2003, 14). Indeed, both Abu-Lughod (1989) as well as Edwards and Ogilvie (2012b) credit this institution for the success of the Champagne market fairs which helped revive French commercial trade in the $12^{\text {th }}$ and $13^{\text {th }}$ centuries. Likewise, sauf-conduit contributed to the relatively peaceful coexistence, and flourishing trade relationships between Christians, Jews and Muslims on the Iberian Peninsula from the $11^{\text {th }}$ century (Smith 2014). Local rulers "accorded to the merchants attending the fairs very active protection of their persons, their men and their goods" (Boutiot, 1870, as cited by Abu-Lughod 1989, 58). This protection also extended to a transfer of risk, as local rulers reimbursed merchants for any goods stolen while conducting business in their territory (Kadens 2004). Importantly, sauf-conduit also acted to "increase sovereign presence even in his physical absence" (Salter $2003,15)$, with a merchant falling under a jurisdictions protection even while outside that territory (Abu-Lughod 1989). In this respect, local lords from the Champagne region had extended their protections under sauf-conduit reportedly as far as the Italian peninsula in the $13^{\text {th }}$ century (Edwards and Ogilvie 2012b).

Ne exeat regno and sauf-conduit therefore constituted institutions by which early medieval rulers sought to maintain an element of mobility control over their local populations, while 
also attracting foreign merchants who could provide them with additional taxation revenue. Ne exeat regno was a default setting requiring would-be emigrants to receive explicit permission from a ruler. This process of 'sedentarization' (Scott 1998) enhanced the ability of the state to conscript skilled military aged men, while also improving the demographic balance of trade (Smith 1776b). The sauf-conduit, while serving a broadly related functionthe maximisation of extractable resources available to a ruler-did so by subtly different means. Rather than keeping individuals within a polity based on their value in warfare, commercial value, and so forth, this was an institution designed to provide protection to foreigners to then derive revenue from them.

\subsection{Revolutionary France ${ }^{70}$}

Revolutionary events in late $18^{\text {th }}$ century France saw the use of identification documents take on growing importance in fulfilling the aims of the state (Fahrmeir 2001, Geselle 2001, Torpey $1997,1998,2000$, Woloch 1986, 1995). The passport played a particularly important role in the achievement of various political ends during the French Revolution. Fahrmeir (2001) gives the French passport legislation of 1792 the mantle as the first of the modern era. Both external and internal controls on the free movement of the population were emblematic of the domination of the ancien régime (Doulman and Lee 2008, Torpey 2000), while their reintroduction after a short-lived abolition during the events of the revolution reflected the desires of the new state to monitor population movements and administer conscription (Torpey 2000, Woloch 1995). Woloch (1995) regards the use of passports and other forms of identification as being the most permanent organisational achievement of the French Revolution, which is notable, due to the "revolutionaries' considerable initial antipathy toward such means" (Torpey 1997, 844). In this section, I examine the changing nature of, and the role of, mobility controls in the context of the French Revolution towards the end of the $18^{\text {th }}$ century. In doing so I examine the use of these identity technologies first by the ancien régime in addition to some other European mercantilist states. I then look at the changing use of such technologies throughout the revolutionary events.

The ancien régime in France, like many across Europe, sought to control and monitor travel both within, and across, its borders (Geselle 2001). Mercantilist policies saw states attempt to retain productive members within their polity, attract those from outside of it, while simultaneously try to increase the birth rate (Dowty 1989, Zolberg 1978). Importantly, and according to this view, policies which restricted migration would result in lower wages, which was at the time an end seen as vital for a successful mercantilist economy (Schultz 1978). This orthodoxy was reflected by two $17^{\text {th }}$ century quotes given by Moya $(1998,19)$, respectively from the Prussian political economist Johannes von Justi, and the French economist Marquis

\footnotetext{
${ }^{70}$ This section has benefitted from the work of John Torpey, including The Invention of the Passport (2000), as well as Revolutions and freedom of movement: An analysis of passport controls in the French, Russian, and Chinese Revolutions (1997), and Coming and Going: On the State Monopolization of the Legitimate "Means of Movement" (1998).
} 
de Vauban: "No nation can have too many inhabitants", and "By the number of their subjects is measured the grandeur of kings". Other mercantilists, including Philipp von Hörnigk (1684), saw a large population as one of the key tenets of this economic system (see Monroe 2011). Similarly, and as Dowty $(1989,27)$ noted in his description of 'demographic mercantilism', "people are wealth". Individuals who were confined to any one geographic locale constituted not only a source of revenue, but were also, and crucially, a source of military manpower.

In the case of France, restrictions on emigration-'exit' to use the language of Albert Hirschman (1970)-are reflected in some of the 'grievances' which were presented to the government at the assembly of the Estates General in 1789. One such cahiers de doléances from a parish on the outskirts of Paris explicitly objects to the requirement for a passport both for internal, and external, travel, and "other formalities that tend to hamper the liberty" of citizens (as cited in Torpey 2000, 28). France was a pioneer of this identity technology, with the word 'passport' first used in the kingdom in the late medieval period according to Daniel Nordman (as cited in Torpey 2000 supra note 43). These restrictions and 'other formalities' were derived from ordinances such as those issued by Louis XIV in 1623 and 1669, requiring those leaving the kingdom to be in possession of a passport (Lloyd 2005, see also, Torpey 2000). The latter was designed to keep skilled workers in the kingdom. Those employed in the maritime industries, including "navigators, shipbuilders, pilots, sailors, and fisherman [were ordered] to remain in France or to return if they had left" (Dowty 1989, 29).

These ancien régime restrictions on movement were consistent with the prevalent orthodoxy of mercantilism around Europe which extended not just to a balance of trade in hard currency, but also in population. Adam Smith (1776b) noted that the dominant economic policy throughout Europe at the time meant that skilled craftsmen were subject to strict emigration controls (see also, Zolberg 1978). In England, in addition to restrictions on the "exportation of the dead instruments of trade", skilled tradesmen were "obliged to give security at the discretion that he shall not go beyond the seas, and may be committed to prison until he give such security" (Smith 1776b, 244-245). As described by Smith, such edicts also applied to any party who might conspire to entice craftsmen to leave England, with first offences attracting a penalty of up to one hundred pounds, in addition to three months in prison.

In addition to legislative and regulatory restrictions on 'exit' (Hirschman 1970, see also, Zolberg 1978), the pursuit of a demographic balance of trade could also be achieved by encouraging those from outside the polity to immigrate, as well as by incentivising larger families. Such encouragements were seen in early $17^{\text {th }}$ century Spain, with skilled agricultural and industrial workers exempt from several taxes if they immigrated (Zolberg 1978). This type of strategy was also employed in France under the economic stewardship of Jean-Baptiste Colbert. In the $17^{\text {th }}$ century he "granted tax for early marriages and provided a sizeable bounty for large families", while also restricted the size of the religious orders who for reasons of faith had fewer children (Dowty 1989, 28, see also, Zolberg 1978). These financial arrangements were extended to French settlers in Canada in 1669 to encourage larger family sizes (Zolberg 1978).

As such, along with other mercantilist states in Europe, the ancien régime in France had reason to control the free movement of people, both within and across its borders. According 
to Torpey $(2000,26)$ documentation requirements and related regulations were "a vital mechanism of domination under the old regime in France" (see also, Geselle 2001). This domination was exemplified by the need for a passport to leave France, as well as the requirement to have official documentation for movement within France. In the case of the latter, this was in the form of either a passport-issued by a local government official-or an aveu-issued by the local clergy or nobility attesting to the travellers "upright character" (Torpey 2000, 27, see also, Lefebvre 2005). The content of these internal passports was largely dictated by local circumstances, with general descriptions of the individual in question sufficing for identification, including "residence, occupation, family status", and so forth (Torpey 1998, 248). Restrictions on internal movement were primarily designed to prevent peasants and other rural dwellers moving to the larger cities, and placing strains on welfare services as delivered by ecclesiastical and other authorities (Lloyd 2005). Although it should from the outset be noted that the success of these restrictions was mixed, in part due to the difficulty in regulating the movement of 'pedestrians' (Cobb 1970). Authorities were left with little ability to restrict entry into towns aside from by barring the gates to those travelling by foot (Torpey 2000).

The primary and immediate effect of the Revolution on the use of passports in France, and other internal and external controls on movement, was first and foremost their (temporary) elimination. As shall become apparent, and according to Torpey $(1997,848)$, from this point onwards the "legal fortunes of the freedom of movement rose and fell - but mostly fell". As highlighted earlier, some of the cahiers de doléances delivered to the Estates General called for the abolishment of restrictions on the free movement of people (Torpey 2000). To be sure, these lists of grievances should not be taken to be entirely indicative of the overall mood of wider French society, due to the propensity for Estates General representatives to retain or discard items at will (Lefebvre 2005, Schama 1990). Nonetheless restrictions on movement were the subject of many cahiers presented in early 1789 (Torpey 1997).

Such protestations had the effect of these restrictions being abolished following the events at the Bastille on July 14, 1789 (Torpey 1997). The primacy of these passport reforms was such that the first paragraph of the September 1791 Constitution had the nominal effect of "the complete abolition of any passport obligations" (Geselle 2001, 205). According to Greer $(1951,26)$, from the fall of the Bastille up to the year 1792, "Frenchmen were free to go and come as they pleased". However, as I now show, while the initial instincts of the revolutionaries were for the abolition of passports and other impediments to the free movement of people (Torpey 1997), the events following the fall of the Bastille, including both internal and external threats to France, in fact led to the first modern passports and systematic controls on the movement of people (Fahrmeir 2001, Woloch 1995).

While the Constitution of 1791 had expressly forbidden 'passport obligations' (Geselle 2001), this disguised the restrictions which revolutionary bodies almost immediately placed on internal movements. As Torpey (2000) describes it, the view that there was complete freedom of movement amongst the resident French population between 1789 and 1792 (see Greer 1951) is incomplete and potentially misleading. Internal restrictions on movement were reintroduced only six months after the Constitution of September 1791 (Torpey 1997). Travelling in this period, the English agriculturist Arthur Young noted the contrast between the oratory emanating from revolutionaries in Paris, and the impositions placed on those 
moving throughout France. He found himself repeatedly delayed by "passport-obsessed petty officials far more obstructive and obtuse than anything he had experienced under the old regime" (Schama 1990, 436). Torpey $(2000,30)$ similarly cites evidence given to the National Assembly in mid-1790 of strains placed on welfare services, primarily by 'foreigners' who were gaining access to poor-relief. Here, it should be noted that in the period in question food shortages in rural areas was endemic, which resulted in high levels of migration to large cities including Paris (Lefebvre 2005, Schama 1990). Because of these concerns, these 'foreigners' who had lived in Paris for less than a year-defined in this circumstance as being foreign to Paris rather than foreign to France-were ordered to leave the city and obtain a passport from their local authorities (Torpey 2000).

Crucially, these documents were to indicate the direction and route they would take, with those "who departed from the route indicated in their passports, or who stopped along the way for any length of time" to be arrested (Torpey 2000, 30). Similarly, lawlessness of criminal groups, aided in part by the recent inability of police to track the movements of those who no longer needed documentation to travel, began to spread throughout France in the chaos of the revolution (Lloyd 2005). So, while some historians maintain that between 1789 and 1792 freedom of movement was enshrined in revolutionary reforms, restrictions on internal movements were rapidly reintroduced as high levels of migration due to food shortages, as well as instances of lawlessness, spread. Similarly, and as we shall now see, restrictions on external movements were rapidly reintroduced.

Another consequence of the revolutionary unrest was the emigration of much of the French nobility-the so-called émigrés (see Lefebvre 2005, Schama 1990)-along with a great deal of their wealth (Lloyd 2005). Between 1789 and 1792 something like 8,000 French refugees arrived in Britain alone (Zolberg 1978), 5,000 émigrés were through to have fled to Switzerland (Lloyd 2005), while the 'epidemic' scale of army officer emigration from frontier regions led to fears of a counter-revolutionary invasion (Schama 1990). That they could leave the near bankrupt French state unhindered, with no requirement for a passport or indeed permission from any authority, was in part due to the abolition of such requirements shortly after the fall of the Bastille (Torpey 1997). Debates in the revolutionary press centred around the dichotomy of eliminating the "freedom-choking strictures of the ancien régime", and the prospect of allowing those alleged to have committed counter-revolutionary acts to escape from France (Torpey 2000, 20, see also, Lucassen 2001). This question was in effect put to rest after the popular backlash to the events of the night of 20-21 June 1791, when Louis XVI, along with his family and a small entourage, attempted to flee France in the so-called 'Flight to Varennes' (see Lefebvre 2005, Schama 1990). The unsuccessful escape attempt led to an immediate ban on individuals leaving the French kingdom, and the threat of arrest of anyone who made such an attempt (Torpey 1997, 2000). And while constitutional change shortly after the Flight to Varennes seemed to indicate that these bans would be short-lived, new passport legislation was soon drafted that imposed strict impositions on both internal and external movement.

Soon after the Flight to Varennes, the National Assembly began writing up the new Constitution of September 1791, which as mentioned earlier, removed any 'passport obligations' to travel (Geselle 2001). This document nominally guaranteed freedom of movement; the freedom "to go, to remain, [and] to depart" (The Constitution of 1791, as 
cited in Torpey $(1997,845))$. Yet its effects were short-lived, as the threat of émigré armies on the borders saw the reintroduction of documentation requirements for travel. While restrictions on movement went through multiple iterations throughout 1789-1792, the overall effect of the revolutionary period was to impose more stringent restrictions (Torpey 1997, 2000). For instance, while some internal restrictions on the movement of people, as well as tradeable goods, were removed temporarily in late 1792 (Torpey 2000), the overall impact of the revolution was for the introduction of the first modern requirements to carry identification documentation while travelling (Fahrmeir 2001). For most of the post-1791 period travellers within France, and those who wished to leave France, were required to be in possession of a such a passport. In the latter case a civil authority in their place of residence would need to affix their authority which would allow them to cross a border. Crucially, these documents would be granted on an individual, rather than group, basis. This was designed to prevent a repeat of the Flight to Varennes, where the King had been travelling in disguise as an employee listed in someone else's travel documentation (Torpey 2000). For the remainder of the revolutionary period, and indeed into the reign of Napoléon Bonaparte, controls on movement remained in place, strengthened (Torpey 1997), and subsequently used to target specific individuals based on their political views and affiliations (Lloyd 2005).

In practical terms, while previously passports had contained general descriptions of an individual, "residence, occupation, family status", and so forth (Torpey 1998, 248), those issued after 1792 were substantially more detailed, requiring a description of physical characteristics, in addition to a name and place of residence (Geselle 2001). One, issued to the rural worker 'Robert Plancheon' in 1795 contains a quaintly detailed description of the individual in question. He is "aged forty eight years height four feet eleven inches brown hair and eyebrows brown eyes flat nose large mouth wide chin round forehead round face with a small spot on the right cheek and going a bit grey" (Lloyd 2005, 53). This stands in contrast to the passport Louis XVI had used in his escape attempt. In his case, he had travelled pseudonymously as an employee of the 'Baroness de Korff', following the then usual practice of issuing them on a group, rather than an individual, basis (Torpey 2000). Passports were similarly required to have details of destination escribed on them (Torpey 2000), while foreign residents living in, or travelling through France, were required to register with authorities and hand in their passports because of ordinances issued in 1795 and 1796 (Zolberg 1978). Cumulatively, these requirements had the effect of facilitating more detailed surveillance measures, while also enabling specific targeting of individuals for political purposes. This targeting includes the Napoleonic Minister of Police in Paris using the system to limit the ability of one 'Madame de Stael' to travel to Geneva owing to her political leanings, described by Lloyd $(2005,57)$ as "a symbol of repression and an example of all that was wrong in Europe with the passport system."

\subsection{Modern China}

China's hukou ${ }^{71}$-household registration-system acts as a control on internal population movements (Cai 1999, Chan 2010, Liu 2005). The system itself is not unique to China, nor to the current system of Chinese government. The hukou is in part modelled on the Soviet

\footnotetext{
${ }^{71}$ Alternatively known as the huji system (see, Wang 2005).
} 
propiska system of internal passports (Chan and Buckingham 2008, Chan 2010, Matthews 1993, Solinger 1999), while the hoju system of North Korea (Lijiang 2003, Ma and Zeng 2015), and the ho khau of Vietnam (Haughton and Sun 2018, Karis 2013) serve broadly similar functions (see, also Chan 2009). Alexander and Chan (2004) similarly compare the hukou to the now abolished South African system of apartheid. In more historical terms, the Chinese hukou system has origins dating back as far as the Xia Dynasty from the $21^{\text {st }}$ century BCE (Wang 2005, see, also Cheng and Selden 1994, Lijiang 2003, Torpey 1997). Particularly in the Imperial era of Chinese history, such as that of the Han Dynasty (206 BCE-220 CE), the hukou system was integral to fulfilling taxation and conscription requirements (see, Scott 1998, Wang 2005). During the Han period, annual reporting requirements dictated that information related to "household income figures, marriage conditions, additions or losses of family members, and everyone's physical features such as height and skin color" was communicated to the Imperial bureaucracy (Wang 2005, 36). The control and facilitation of significant population movements was similarly facilitated using the registration system. More recently, the Qing dynasty (1644-1912) used the registration system to help them first move-and then keep-more than one million peasants to a newly repopulated area of Sichuan province (Wang 2005, see, also Hsu 2012).

In the communist era, the Chinese hukou has served two broadly related functions. The first has been to delineate the eligibility to migrate internally and monitor populations, while the second segregates access to welfare services and other public goods (Chan 2010) ${ }^{72}$. In practice these two functions are closely linked, as should become apparent throughout the remainder of this section. In fulfilling the function of migration restriction and monitoring, the hukou requires individuals to be registered to a place of residence, either 'rural' or 'urban' (Chan 2009). This "hukou-based social control" (Wang 2004, 129) has more recently been used as a tool against Falun Gong, as well as Uyghur Muslims in Xinjiang. The public goods function, where the hukou system restricts access to government welfare provisions and other services, delineates the population by 'agricultural' or 'non-agricultural' type (Chan 2009, Naughton 2007). Up until the late 1980s, those designated 'non-agricultural' were eligible for "stateprovided housing, employment, grain rations, education, and access to medical care as well as other social welfare benefits" (Chan and Buckingham 2008, 588). And while the hukou system has been relaxed, reformed, and ignored at various stages in the 70-year history of communist China, (see Chan 2009, Wang 2004, 2005), the system still restricts access to public goods and opportunities depending on how an individual is registered (Liu 2005). The purpose of these functions remains officially 'unchanged' in the $21^{\text {st }}$ century according to Wang (2004). I shall now outline each of these functions in turn.

An individual's place of registration is in practice near permanent (Chan and Buckingham 2008, see, also Chan 2013), with few opportunities available for 'rural' residents to obtain an 'urban' hukou. Especially in the first two decades of the communist era, those designated as 'rural' residents had no official right of access to 'urban' areas (Chan 2010). More recently, the limited ways such an individual might obtain urban status include by gaining employment at a state-owned enterprise, receiving an advanced degree, completing military service, or via exceptional sporting achievements (Liu 2005, Torpey 1997, Wang 2005). For instance, some

\footnotetext{
72 While a public good is usually defined as non-excludable and non-rivalrous, here the term more generally relates to those goods provided by the government.
} 
localities will entice Olympic medallists or PhD graduates with 'urban' hukou for their immediate family members (Wang 2004). In any case, changing hukou residence is only granted if "the move serves (or at least is not at odds with) the central or local state interests and policies" (Chan 2013, 2). That is not to say that in recent times 'rural' workers have not been able to work in urban areas. There is significant non-hukou migration to Chinese cities, although the resulting liudong renkou-'floating population' -is generally denied access to education, health and other social services (Chan 2013).

As Liu (2005) describes it, the migration restrictions within the hukou system are the logical conclusion to a centrally planned economy. The allocation of resources-absent a price mechanism (see Hayek 1945)-requires an apparatus whereby labour allocation, and therefore mobility, can be directed by fiat (Chan 2009). In the Mao era, and before the partial liberalisation of the labour market from the latter half of the 1970s (see, Cai, Park, and Zhao 2008), the centrally planned economy required "the ability to allocate human resources not only at the enterprise and sectoral levels but also across geographic locations" (Liu 2005, 135). Individual workers were allocated to an employer by the 'Bureau of Labor and Personnel' until the economic reforms of the 1970s. Workers allocated by this government department were subsequently left with "little possibility for further mobility" (Cai, Park, and Zhao 2008, 171). The 1958 Regulations of Hukou Registration - the first of two main legislative sources of the registration regime (see, Wang 2004, 2005)-led to a dual approval process for officially sanctioned migration; an individual needed the approval of both the origin, and destination, local government (Cai, Park, and Zhao 2008).

By the beginning of the new millennium, as market reforms have replaced some aspects of central planning in the Chinese labour market (see, for instance Cai, Park, and Zhao 2008, Wang 2005), non-hukou migrant workers have made up around 80 per cent of all migration from rural to urban areas (Cai, Park, and Zhao 2008). As a result, as of 2009 there were up to 150 million non-hukou workers employed in urban industry. This us up from 50 million in the early 1990s (Chan 2013, see, also Chan 2009). However, the Chinese state has still reserved the system as a tool of central planning. For instance, in the face of declining house prices around 2008, the hukou system was employed to 'stimulate' the Chinese property market (Chan 2013).

According to Wang (2005), the need for a mechanism to control the movement of, and monitor, the population has been in part ideological. The hukou system was explicitly developed to monitor specific segments of the population, including 'questionable persons', tens of thousands of which were rounded up using this system in the first years of the communist regime alone (Wang 2005). These 'questionable persons' included former Kuomintang members following the end of the civil war from 1949 (Chan and Zhang 1999). More recently, zhongdian renkou - 'targeted people' - have been monitored by special hukou police (Wang 2005). Hukou police are attached to every police station, and are typically responsible for around 500-700 households (this number varies region by region). Permanent records document an individual's categorisations ('urban' or 'rural', 'agricultural' or 'nonagricultural'), physical features, legal address, religious denomination, political activities, and "other 'consequential' past activities" (Wang 2004, 125). This segmentation of the population has been used most notably at the turn of the millennium when Falun Gong members in major urban areas were first registered as 'targeted persons'. This has allowed Chinese authorities 
to maintain an active police presence at their residences, and even prevent them from leaving their homes during holiday periods (Wang 2005, see also Wang 2004).

Monitoring of 'targeted persons' has been in recent years supplemented by a move to realtime and active monitoring of individuals using an increasingly complex and interconnected network of street cameras, facial recognition software, and mobile phone technology (Creemers 2018, Liang et al. 2018). This coincides with a general increase in the size and scope of the Chinese security bureaucracy (Wang and Minzner 2015). The so called 'Social Credit System' (SCS) is an instance of emerging technologies being deployed by the ruling party to "supplement traditional means of governing state and society" (Creemers 2018, 1). And while the SCS is not explicitly a part of the hukou registration system, it does share the dual aims of the older system. To be sure, the mechanisms embedded with the SCS are 'nascent' (Liang et al. 2018), and as such much of the commentary surrounding it has been through the news media (see, for instance Botsman 2017, Douthat 2019, The Economist 2019, Hodson 2015, Kobie 2019, Leigh and Li 2018).

Yet as far as can be determined, the SCS comprises a system whereby individuals are tracked and monitored by its surveillance infrastructure, while simultaneously "providing rewards or punishments as feedback to actors, based not just on lawfulness, but also the morality of their actions, covering economic, social and political conduct" (Creemers 2018, 2, see, also Diab 2017). In general, the SCS comprises a metric based on "online purchases, posted content on social media, and the sort of friends one has" (Creemers 2018, 3). According to Hodson (2015) the system comprises an extension of financial credit reporting and monitoring, into one which also considers character and political traits. Individuals receive scores which are between 350 and 950, while the score is calculated not just based on an individual's own activities, but based on the activities of their friends and wider networks (Stanley 2015). The SCS is now in operation, while "the general framework and key mechanisms have been established" (Drinhausen and Brussee 2021, 3). It is thought that scores greater than 600 allow users to rent cars without a deposit, scores over 650 are used to access better services at hotels, while scores over 700 afford a bearer easier access to visas to travel to overseas destinations (Hodson 2015, see also The Economist 2019). On the other hand, by 2019, 17 million air and rail tickets purchases had been blocked owing to insufficient social credit scores according to the government department which manages the system (The Economist 2019, see, also Creemers 2018 supra note 67). The use of sophisticated surveillance technology-reportedly including DNA databases (De Bourmont 2018)-has similarly been deployed against the Muslim Uyghur population in recent years. The Uyghur reportedly "face severe economic, racial, social, and cultural discrimination" by the Chinese state (Concepcion 2000, 20, see, also Han 2010, Kaltman 2014, cf. Maurer-Fazio 2012). It is thought that an ideological determinant of some of this discrimination relates to the Muslim faith of the Uyghur population (Concepcion 2000, see, also Wang 2004, 131).

Related to these ideological determinants of migration controls, the historical desire to favour urban and industrial development at the expense of rural and agricultural regions has similarly seen the hukou deployed to monitor and control movement. In this respect, Cheng and Selden (1994), and Wang (2005), provide overviews of the relationship between Chinese industrialisation and the hukou system. The need to control movement was a direct consequence of the push by the Chinese state to enact rapid industrialisation in the period 
up until the 1980s (Cai, Park, and Zhao 2008, Wang 2005, Chan 2009). The accumulation of capital goods was primary to the needs of the state, and "Squeezing the generally uneducated, unorganised peasantry became Beijing's chief means of quickly accumulating capital" (Wang 2005, 88, see also Chan and Zhang 1999, Cheng and Selden 1994, Fan 2001). This "industrialization on the cheap" (Fan 2001, 483) involved artificially low prices paid by the state for agricultural produce, alongside the high prices of industrial goods - the so-called 'scissors gap' (see, also Chan 2009). This disparity resulted in a massive transfer of wealth from the countryside to urban areas as the rural population was forced to pay for "manufactured goods at inflated prices, although they were forced to sell grain and other foodstuffs to the state at rock-bottom prices" (Dikötter 2010, 137).

According to Potter and Potter $(1990,301)$ "the government intended to treat peasants and workers differently" to enact economic and social goals. Based on the needs of the Chinese state, the rural population was primarily seen as a "provider of cheap raw materials (including food grain), labor, and capital for the urban-industrial sector" (Chan 2009, 200). Low wages paid to urban workers were similarly a product of the low food prices in cities made possible by the extraction of 'surplus' grain from the countryside (Cai, Park, and Zhao 2008). The characteristics of what constituted a 'surplus' was, however, a political decision, rather than one which considered the nutritional needs of rural residents. As a result, local officials became increasingly competitive as to how much output they could deliver to meet quotas (Dikötter 2010). This urban-rural divide resulted in what Chan (2009) terms a 'dual economy', with the peasantry living at subsistence levels to provide social welfare to the minority urban population. The low returns available to agricultural producers were maintained by a pricing system whereby farmers were forced to sell their produce to the state at low and fixed prices (Naughton 2007). In the Mao era, and according to Fang Cai (as cited in Chan 2009 supra note 9), this resulted in the equivalent of "three times the estimated value of all assets except land in the rural sector" being extracted from these areas. At the same time, urban residents were eligible to receive welfare benefits which were not available to the rural population (Banister 1987, Chan 2009, Cheng and Selden 1994).

The hukou system delineates eligibility for welfare provision and other privileges by designating individuals as 'agricultural'-nongye-or 'non-agricultural'-fei nongyeworkers (Chan 2009). Along with the rural and urban divide, the agricultural and nonagricultural designation is the second axis upon which the hukou system operates. However, the two are closely correlated. Having a 'rural' hukou gives one a high likelihood of having an 'agricultural' designation, while being registered in an 'urban' hukou similarly makes one likely to have a 'non-agricultural' designation (Chan 2009, Wang 2005). To make this urban welfare system affordable to the Chinese state, in the three decades from the 1950s a process of restricting the size of the urban population was enacted. This was designed to reduce the "financial responsibilities of the state and [has] shifted the burden of feeding and employing repatriated people from the state to rural society" (Cheng and Selden 1994, 650-651).

The effects of this strict monitoring and population control was most readily seen during the famine events during the 'Great Leap Forward'. Dikötter (2010) and Jisheng (2012) provide detailed overviews of these events from 1958 to 1962. Collectivisation, compulsive steel production targets, and ultimately unsuccessful experimental farming techniques all contributed to a collapse in grain production and millions of deaths. During the famine, grain 
production dropped to 30 per cent of 1958 levels (Dikötter 2010), while estimates of total deaths indicate they should be measured in the tens of millions. These estimates include 30 million (Ashton et al 1992), and upwards of 45 million (Dikötter 2010). Yang (2008) provides a survey of estimates of the death toll from this period.

The famine events of the Great Leap Forward saw millions of rural residents move to the cities at the end of the 1950s (Banister 1987). This traditional coping mechanism to famine was buttressed by industrial targets which saw millions more recruited into urban factories despite the formal restrictions on migration (Dikötter 2010). According to Banister (1987) this saw the urban population increase from 99 million to 130 million in the three years to 1960 . At the same time, employment in state owned enterprises increased by almost 70 per cent in 1957 alone, such that 21 million additional workers were employed in the state sector by 1958 (Cheng and Selden 1994). This increase in the urban population, and the migration from which it was derived, was temporarily overlooked due to the industrialisation strategy. Hukou restrictions were in effect disregarded between 1957 and 1959, although this amnesty was ultimately short-lived, and rapidly reversed (Cheng and Selden 1994, Dikötter 2010, Lardy 1983, Wang 2005).

As discussed earlier, the state provided welfare services to city dwellers-including housing, food, employment opportunities, education, and medical services (Chan and Buckingham 2008, Chan 2009, Cheng and Selden 1994)-which were not available to rural residents. According to Torpey $(1997,857)$, 'rural' and 'agricultural' residents living in urban areas referred to themselves as zi li kou liang jiumin - "town citizens responsible for their own rice" (see also Potter and Potter 1990). As the urban population grew, this placed strain on this welfare provision. Many rural refugees from the famine were unable to find shelter or adequate provisions in the urban centres. Dikötter (2010) recounts the 70,000 refugees who overwhelmed shelters set up in Nanjing in 1959, while the lack of food for those who were not local hukou residents saw young women offer their bodies "for a ration coupon worth ten or twenty cents or for a pound of rice" (Dikötter 2010, 196). Despite such desperate measures, up to twenty bodies a week were collected from one park in Nanjing alone during this period (Dikötter 2010). To remedy this, the Chinese government relocated up to 48 million workers from urban to rural areas in the first three years of the 1960s (Wang 2005). Most of these workers were those the state considered "non-productive elements" and in practice were those who lacked hukou registration in urban centres (Cheng and Selden 1994, 664). As a result the workforce employed in industry dropped down to 6 per cent of the total by 1965, from a high of 16.6 per cent in 1958 (Wang 2005). The effects of this segregation were far more than employment related however, as the death toll in the countryside was severe. Indeed, the clear majority of deaths during this famine period were of 'rural' hukou residents denied access to the rations granted to their 'urban' counterparts (Jisheng 2012).

This is not to say that in the post-Mao era internal migration is not permitted. According to Chan (2013) migration has been the root cause of most of the increase of the urban population around the turn of the millennium; almost 80 per cent of the increase in the urban population from 1979 to 2009 has been due to "net migration and urban reclassification" (Chan 2013, 1). Evidence of this can be most readily seen in the annual Lunar New Year migration-chunyan, or 'Spring Movement' - which is the "world's greatest annual human migration" (Mitchell 2006, np.). The annual chunyan sees more than 100 million migrant 
workers return home to their families (Chan 2009). Rather, beginning in the 1980s, workers have been permitted to move from their hukou registration areas to different (usually urban) areas to fill industrial positions as part of the central governments export oriented economic policy (see Lin, Cai, and Li 2003). Most of these migrants are considered 'floating' - renkou liudong-however, as they are officially "considered transients who are not supposed (and are not legally entitled) to stay at the destination permanently", even while they may have been in that locale for many years (Chan and Buckingham 2008, 590, see, also Chan 1996). As such, temporary migration to urban areas in the post-1970s reform period still sees rural hukou residents placed in a "disadvantaged position in social and economic terms" (Liu 2005, 134).

Along with favourable access to goods and services including housing, employment opportunities, and medical services, urban hukou residents receive favourable treatment from employers and educational institutions. For instance, Fan (2001) finds that labour market returns to a migrant granted urban hukou status is significantly higher than one who is considered renkou liudong, or 'temporary'. The difference in income from employment for these two groups is stark, with a 'permanent' migrant typically receiving twice as much as their 'floating' counterpart. This difference in income is largely derived from many requirements in job vacancies for an urban, 'non-agricultural' classification (Huang 2001), and which sees 'agricultural' workers limited to "dirty, heavy exhausting, low-paying jobs" (Wang $2005, \mathrm{xi})$ These types of workers are analogous to the limitchiki, rural migrant workers who performed the difficult and dangerous tasks in Soviet cities, and for low wages (see, Matthews 1993, Torpey 1997). Similarly, discrimination in educational institutions is evident as related to an individual's hukou registration (Ling 2017). The hukou system in this respect plays a role in the distribution of public goods at the expense of the 'rural' population. For instance, 'urban' hukou holders are reportedly able to enter a top Beijing university with a score 20 per cent lower than their rural counterparts (Wang 2005, 222). Similarly, university placements markedly favour urban areas; on a per capita basis, and compared to Shandong Province, Beijing receives almost three times as many admissions per year as part of university entrance quotas (Wang 2005, see also Ling 2017).

\subsection{Discussion and conclusion}

The model I have contributed as part of this chapter is that of a stationary bandit with an incentive to distinguish between their citizenry owing to their varying abilities to pay tribute. In addition, the stationary bandit seeks to discriminatorily supply public goods and access to other services to its citizenry. According to my original hypotheses, this would see a stationary bandit 1) value members of their population differently, using identity technologies to control higher value individuals, and 2) use identity technologies to discriminatorily supply public goods and access to other services. In Table 5 . on the next page, I summarise the identity technologies used to distinguish between members of their population to fulfil these economic and political goals. 


\begin{tabular}{|c|c|c|}
\hline & $\begin{array}{l}\text { Hypothesis 1: Stationary bandits value } \\
\text { members of their population differently, } \\
\text { and use identity technologies to control } \\
\text { higher value individuals }\end{array}$ & $\begin{array}{l}\text { Hypothesis 2: Stationary bandits use identity } \\
\text { technologies to discriminatorily supply public } \\
\text { goods and access to other services }\end{array}$ \\
\hline Rome & & $\begin{array}{ll}- & \text { Census } \\
\text { - } & \text { Tria nomina } \\
\text { - } & \text { Diploma } \\
\text { - } & \text { Tractorium }\end{array}$ \\
\hline $\begin{array}{l}\text { Mediaeval } \\
\text { Europe }\end{array}$ & $\begin{array}{ll}- & \text { Ne exeat regno } \\
- & \text { Sauf-conduit }\end{array}$ & - $\quad$ Sauf-conduit \\
\hline $\begin{array}{l}\text { Revolutionary } \\
\text { France }\end{array}$ & - $\quad$ External passport & - Internal passport \\
\hline $\begin{array}{l}\text { Modern } \\
\text { China }\end{array}$ & - $\quad$ Hukou & - $\quad$ Hukou \\
\hline
\end{tabular}

Table 5 . Use of identity technologies by stationary bandits

The logic behind my modification to Olson's (1993) original model is straightforward. As there will always be heterogeneity amongst a captive population, the tax theft available to a ruler will vary accordingly. Hence, a ruler will have an incentive to distinguish between individuals in some manner to maximise their extractive capacity.

The motivating factor in the use of identity institutions by a stationary bandit is in stark contrast to that described in the previous chapter. Following the Norman invasion of England, those who had purchased land from William lived under the threat of nationalisation, and hence tried to ameliorate that risk by adopting heritable surnames. In contrast, stationary bandits suffer from information asymmetry. That information relates to the large and diverse population they have monopolised tax theft over; each of their citizenry have diverse extractive potential, while public goods are to be discriminatorily applied. This sees identity institutions-such as the sauf conduit, passports, the hukou system and so forth-used for the purposes of more efficient extraction.

This incentive has seen rulers enact technologies and policies to ensure skilled civilian and military workers are kept within their state. For instance, in early medieval England the reliance on longbows for military advantage saw archers, and those capable of making this weaponry, subject to restrictions on leaving the kingdom (Lloyd 2005, McBain 2011). Similarly, the 'proto-mercantilist' concerns endemic throughout Europe from the $16^{\text {th }}$ century saw the introduction of many emigration restrictions (Dowty 1989, Zolberg 1978, Moya 1998). These restrictions included the requirement for those wishing to leave a jurisdiction to be in possession of licence or a passport, and were designed to prevent skilled workers and craftsmen from leaving (Smith 1776b). To be sure, such restrictions have not only sought to control movement between jurisdictions, but have also dictated that individuals are confined to certain regions within a polity.

The rationale, consequences, and methods by which stationary bandits confine individuals to defined regions can be seen most readily in the revolutionary case studies (sections 6.5 and 
6.6). In the first instance, after initially abolishing ancien régime passport restrictions, the revolutionary regime in France quickly reintroduced them as refugees from the countryside placed strains on welfare services within the cities (Lefebvre 2005, Schama 1990, Torpey 2000). The exodus of wealthy émigrés along with much of their wealth was also of concern to the new French government. Not only did the emigration of wealthy citizens deprive the new regime of taxable wealth (Lloyd 2005), their presence outside French borders made them a military threat (Schama 1990).

Similarly, and from its founding, the Chinese communist regime has co-opted the historical hukou system to control population movement as well as discriminate in its delivery of public goods (Chan 2010, Liu 2005). In the Chinese case, the desire to favour the (minority) urban population at the expense of the (majority) rural population has seen the hukou administrative apparatus facilitate a massive transfer of wealth from the latter to the former (Chan 2009). It should also be emphasised that in the Chinese case, the system has not just served to ensure a captive population from which wealth is easily extracted, but it has also served ideological purposes (Wang 2004, 2005). The Chinese hukou system also provides an illustrative example of the way in which stationary bandits identify their citizenry such that they can discriminatorily be supplied with public goods. By delineating the population as either 'agricultural' or 'non-agricultural', this urban welfare system has been made commensurately more affordable from the perspective of the Chinese state (Cheng and Selden 1994).

Finally, stationary bandits might also employ administrative means with which to expand their extractive jurisdiction. I emphasise two historical instances of this. As discussed in section 6.3, the Roman Republic and Empire used the institution of citizenship as a form of administrative identity, and to ensure rights and responsibilities were discriminatorily applied. The needs of the Roman state saw the franchise regularly expanded, in part to increase the supply of manpower available for conscription (Scheidel 2004). In addition, by increasing the citizen population it has been suggested that this increased the tax base of the Roman state (de Blois 2014, Woolf 1998), although the evidence for this is not conclusive (Ando 2006, Sherwin-White 1973). In the same light, and as discussed in section 6.4, medieval monarchs and other authorities used sauf-conduit as part of an exchange in which they provided protection to merchants in return for revenue in the form of tolls and taxes (Abu-Lughod 1989, Burns 2001, Kadens 2004, Middleton 2005, Smith 2014). Indeed, this mechanism worked to increase the extractive capacity of the state, even outside of their own territory (Abu-Lughod 1989, Salter 2003), as was the case with Champagne lords providing protection to merchants as far away as Italy (Edwards and Ogilvie 2012b). 


\section{Chapter 7. Summary and conclusions}

\subsection{Introduction}

This thesis began with the premise that there is much uncertainty as to the future state of the world. This is in large part due to the differences between individuals. That is, economic and political actors are heterogeneous, in that they do not share the same set of endowments, tastes, and motivations. In fact, each of these has an identity, a vector of characteristics associated with a unique individual that allows other individuals to recognise them, or allow differentiation from other individuals. If individuals did not possess their own unique identity, one individual could be expected to act in the same way as every other individual. The former would have the same taste in clothing as the latter, while the latter would have the same likelihood to default on their mortgage as the former. In addition, one individual would know what another would do in the future, as it would be the same as whatever they would do. Broadly, my contributions have consisted of the refutation of this widespread assumption of mainstream economics, and to introduce a new institutional economics of identity. At the start of this thesis I reviewed the economic literature which provides the theoretical basis for such a refutation. This includes, but is not limited to, that related to the economics of information, along with the new institutional economics.

Much economic literature has addressed the general problem of information asymmetry and uncertainty in behavioural outcomes. The economics of information can be characterised by the work of George Akerlof (1970), Michael Spence (1973), and Joseph Stiglitz (1975). These three jointly won the 2001 Economics Nobel for their theorising and examination of markets with asymmetric information. In general, this literature examines problems of adverse selection and moral hazard, along with the resultant market failures which may subsequently arise in the absence of countervailing institutions.

A second major economic literature which examines the same general problem is the new institutional economics (see Williamson 1985). This literature takes a similar approach to the future state of the world, grounding economic analysis within a state of uncertainty. This is achieved largely through dual behavioural assumptions of bounded rationality and opportunism. Bounded rationality sees economic actors as imperfectly rational due to cognitive and other limitations, while opportunism assumes the potential for, but does not guarantee, self-interested behaviour with guile. This literature similarly examines the institutional arrangements which mitigate these behavioural realities.

A common theme across both literatures is that, unlike in mainstream economic thought, the participants and commodities traded in the real world are not perfect substitutes. Economic and political exchange occurs outside the idealised perfectly competitive marketplace. This thesis has continued in this tradition, treating the identity of the buyer and seller as a fundamental part of economic analysis. The main contributions of this thesis have been to introduce the basic economics of the demand and supply for the identity of the individual, understand the role which identity plays in economic and political exchange, and to understand the nature of the identity institutions which overcome information asymmetry and behavioural uncertainties. 


\subsection{Contributions}

In this thesis I developed a theoretical and practical understanding of how identity can overcome uncertainty and mitigate instances of information asymmetry in economic exchange. This began with a new, economic definition of identity (Chapter 1). This was in large part inspired by a widespread review of the use of identity in a broad range of economic, and related, literatures (Chapter 2). I then developed an identity cost model of exchange, which determined that identity costs are a distinct subset of transactions costs. Incurring identity costs serves to provide a measure of past behaviour, and allows for the ex-ante differentiation of economic actors (Chapter 3 ). This identity cost model of exchange also demonstrated that the demand for identity-both private and public-is a positive function of the need to recognise, and distinguish between, trading partners. In addition, I discovered the existence of certain hierarchical organisations is in part due to identity cost economising. Identity as information exchange was further characterised using identity hostages. These identity hostages are information assets that serve as commitment devices by contracting parties (Chapter 4). I characterised the use of these identity hostages as placing 'identity at risk', which serves a useful economic purpose. The hostage model of identity demonstrated that the private supply of identity information can constrain opportunistic behaviour. Similarly, participation in certain interactions is contingent on the supply of identity.

I next examined the way identity overcomes uncertainty and information asymmetry in the political realm. The development of heritable surnames was examined as a mechanism to overcome uncertainty in intergenerational property ownership. This saw heritable surnames deployed to protect private property in post-1066 England, and hence mitigate the risk of nationalisation (Chapter 5). Here, the private supply of identity was used to overcome the consequences of sovereign risk. This identity institution was subsequently adopted by the state for its own purposes. I then looked at the way that identity institutions have been used for state legibility, and therefore population control. By means of four historic periods, I examined how state actors have used identity technologies to discriminate between heterogeneous members of their population for the purposes of resource extraction and the allocation of public goods (Chapter 6). Here, the state had a demand for identity due to the heterogeneous nature of their citizenry. The state subsequently met their own demand by producing identity technologies to satisfy that demand.

\subsubsection{Identity and economic exchange}

I now return to the questions I raised at the beginning of the thesis. As I wrote in Chapter 2, the widespread usage of the identity in the economic literature has resulted in considerable ambiguity. This is in part due to its varied usage, and relationship, to the economics of information, the identity economics literature, the economics of discrimination, politics, philosophy and economics, the economics of institutions, as well as the broader social science literatures. Much of this defined identity as a group phenomenon. This saw an association with some group as causing the individual to act in a certain way, or be acted upon in some manner. These actions might be associated with behavioural norms, or the application of sanctions. In contrast, a subset of this literature defined identity as an individual concept, in that it acted as a label which distinguished between economic actors. Crucially, and in contrast to my contributions, much of this literature limited their analysis to just one 
characteristics of the individual. To overcome this limitation, I contributed a new, economic definition of identity as a vector of characteristics associated with a unique individual that allows other individuals to recognise them, or allow differentiation from other individuals.

Following this I can now address the first research question, how can identity be characterised as overcoming uncertainty and mitigating instances of information asymmetry in economic exchange? The key theme underpinning this thesis has been that, due to the heterogeneity of economic and political actors, behavioural outcomes are difficult to predict. This heterogeneity is derived from the private information related to the endowments, tastes and motivations of individuals. In chapters 3 and 4, I examined the way in which identity is, respectively, a means to obtain the private information of economic actors, and a means to restrain opportunistic behaviour in a world of uncertainty. The divining of private information can be characterised as the demand for identity, which is a function of the need to recognise, and distinguish between, trading partners. The restraint of opportunism relates to the value economic actors gain from supplying identity information. By supplying an identity hostage, for instance, traders can receive more favourable terms, or access otherwise inaccessible networks or markets. Participation in many economic transactions is contingent on the supply of identity information.

In Chapter 3, I established that coming to a level of assurance as to the contract relevant characteristics of one's counterparty, as well as that which is traded, is a prerequisite for all but the most trivial spot market transactions. To reach some required level of assurance requires the exchange of identity information which, for instance, is subsequently used to price a credit transaction. Here, identity exchange serves to provide a measure of past behaviour. This sees, for example, a lender demand identity information relating to a borrower's willingness and ability to repay a loan. Hence, I will lend you money today, because your ex-ante promises typically align with your ex-post behaviours. This reflects the heterogeneity of buyers and sellers in a market, giving a realistic treatment of most exchange. This is also the same treatment which goods and services are typically given as they are priced in the marketplace based on their vectors of attributes. "Consumers observe those attributes to make subjective perceptions of the value of goods" (Allen, Berg, and Markey-Towler 2019, $62)$, just like lenders 'value' borrowers based on their credit history.

I developed an identity cost model of exchange to characterise this process. Consequently, I contribute identity costs as a distinct subset of transaction costs. The theoretical underpinnings of this model included the transaction cost framework of uncertainty, frequency of exchange, and asset specificity. This model saw buyers take costly action-in doing so incurring identity costs - to understand contract relevant characteristics of a seller. In my model, relevant characteristics were those related to a borrower's willingness and ability to repay a loan. I determined that incurring identity costs was 'backwards looking' as it reveals the past action(s) of an economic actor, and thus reveals private information. According to my model buyers reduce uncertainty by assuming a seller will act in a similar way to which they have acted in the past.

As I developed in Chapter 4, the exchange of identity information does not just provide 'comfort' to an exchange partner as they run the risk of suffering from opportunism. Identity exchange can also act as a commitment device which 'ties ones hands' (Schelling 1956). That 
is, rather than merely advertising the trustworthiness (or not) of an economic actor, exchanging identity information can also act as a motivationally credible commitment device. As I described it, exchange partners post identity hostages which consist of information assets that are exploitable in the event of non-compliance with contractual terms. These exploitable identity assets are valuable to the poster as they have been purchased through past financial and other sacrifice. Here, supplying identity can be valuable as it provides information to counterparties, which might result in beneficial pricing, or access to networks.

The model I developed in Chapter 4 saw individuals place an identity hostage at risk of exploitation in the event of ex-ante divergence from contractual expectations. The theoretical underpinnings of this chapter included that of credible commitments as they have been studied in the new institutional economics, and the game theory, literatures. These are devices which can overcome the uncertainty endemic when operating in a trading environment with heterogeneous economic actors. This model determined that this use of identity information exchange is not only used as part of pricing decisions, but also to grant access to closed networks. The hostage model of identity I developed is 'forward looking', in the sense that it provides for motivational constraints on human interaction. Put another way, and as I have described in Chapters 3 and 4, respectively, the exchange of identity in its various technological guises screens potential counterparties to exchange, while it also places constraints on human behaviour and delivers applicable sanctions.

The second research question was how can the use of identity in economic exchange be characterised as transaction cost economising? As I explained in Chapter 3, an identity cost model of exchange determines that buyers of credit contracts demand identity information and hence undertake costly action to understand a borrower's willingness and ability to repay a loan based on their past actions. These costly actions I deemed to be identity costs, which are a distinct subset of transaction costs. I determined that due to the significant identity costs inherent in credit transactions, certain hierarchical organisations can be attributed to identity cost economising. That is, many credit contracts take place within hierarchical firmsbanks - rather than through decentralised market based interactions, due to the existence of identity costs.

\subsubsection{Identity and political exchange}

The final research question addressed in the thesis was how can identity be characterised as being used by individuals and states to access economic rents and other privileges? Once more, the key theme of this thesis has been the problem of uncertainty in economic and political exchange. This uncertainty is derived from the private information related to heterogeneous individuals' endowments, tastes and motivations. In Chapter 5, I examined uncertainty related to sovereign risk, and the way that heritable surnames have been used to mitigate the threat of nationalisation. The model I developed in this chapter was one of intergenerational property ownership, with the property rights purchased by political entrepreneurs bolstered using such an identity technology. In this case, buyers of land attempted to constrain the actions of a ruler by taking on new surnames, often locative, or related to the area of the land in question. Here, the private supply of identity was used to overcome sovereign risk. The theoretical underpinnings of this model included the new institutional economics of history, as well as the property rights literature. 
This model was examined in the context of post-1066 England, and determined that heritable surnames were adopted by political elites to maintain access to rents and other economic benefits they had 'purchased' by supporting William in his conquest. However, they can also be more widely interpreted as an institution which supported and protected private property under the threat of nationalisation. Owners of property lived under the threat of nationalisation as the future actions of the English monarch was veiled in uncertainty. This saw an identity technology-heritable surnames-used to constrain the arbitrary redistribution of land by a ruler. This initially private institution was subsequently adopted by the state for different purposes.

In contrast to Chapter 5, Chapter 6 examined the way identity technologies have been used to exploit the endowments of a heterogeneous population, and simultaneously discriminate in the allocation of public goods. That is, while Chapter 5 examined the way identity can be used to prevent the predations of the state, Chapter 6 looked at the way the state can use identity technologies to prey upon its populace. Similarly, while Chapter 5 showed how an identity technology could reduce uncertainty to the benefit of a wider populace, Chapter 6 showed how identity technologies could reduce uncertainty to the benefit of the state. Developing a modified stationary bandit model of government, I determined that governments have used sauf-conduit, passports, and other administrative means to extract resources from a heterogeneous population. Here, the state has a demand for identity, which is then satisfied by the public supply of identity technologies.

Using this modified stationary bandit model of government, I determined that, as the individuals within a population have varying means by which to satisfy the needs and desires of the stationary bandit, the stationary bandit has an incentive to distinguish between their captives. Similarly, I determined that a stationary bandit can also use identity technologies to increase their extractive capacity by restricting, or encouraging, the movement of certain groups within a population. From this analysis, I determined that the state will use these identity technologies to supply varying amounts of public goods to those population segments. Case studies in Ancient Rome, Mediaeval Europe, Revolutionary France, and Revolutionary China were used to evaluate this model of a stationary bandit with stationary captives.

\subsubsection{Summary of contributions}

The widespread usage of the identity in the economic literature has resulted in significant ambiguity. Much of the reviewed literature saw it as a group concept, with association with a group causing an individual to act in a certain way.

- Inspired by this ambiguity, I contributed a new, economic definition of identity as a vector of characteristics associated with a unique individual that allows other individuals to recognise them, or allow differentiation from other individuals.

The first research question then asked how can identity be characterised as overcoming uncertainty and mitigating instances of information asymmetry in economic exchange? 
- To answer this I first developed an identity cost model of exchange using the transaction cost framework of uncertainty, frequency of exchange, and asset specificity (Williamson 1979, 1985). This model saw traders demand identity information and then take costly action-in doing so incurring identity costs - to understand contract relevant characteristics of a seller.

- I then extended Williamson's $(1983,1984)$ hostage model to incorporate the identity of trading partners. In this expanded model, exchange partners find it beneficial to supply identity information and then post identity hostages - what I termed 'identity at risk' - which consist of information assets that are exploitable in the event of non-compliance with contractual terms.

The second research question was how can the use of identity in economic exchange be characterised as transaction cost economising?

- A significant contribution of this thesis has been the introduction of identity costs as a distinct subset of transaction costs. I then determined that due to the significant identity costs inherent in credit transactions, the existence of certain hierarchical organisations-bankscan be attributed to identity cost economising.

The final research question addressed in the thesis was how can identity be characterised as being used by individuals and states to access economic rents and other privileges?

- To answer this I first examined uncertainty related to sovereign risk, and the way that the private supply of identity in the form of heritable surnames have been used to mitigate the threat of nationalisation. The model I developed in this chapter was one of intergenerational property ownership, with the property rights purchased by political entrepreneurs bolstered using such an identity technology.

- Next, I expanded Olson's stationary bandit model of government $(1993,1995)$ to show how the state can satisfy its own demand for identity. Here, they use identity technologies to increase their extractive capacity, and discriminatorily supply public goods. I determined that governments have used technologies including sauf-conduit, passports, and other administrative means to do so.

\subsection{Limitations of the study}

This thesis has focused on identity, and the way it might overcome the problems of information asymmetry and uncertainty as it is faced in both economic and political life. In contrast to economic and political models with anonymous partners common in mainstream economics, I have assumed heterogeneity amongst participants. The identity of an individual and the way in which knowledge of that identity promotes human interaction was examined from several related perspectives. The analytical approach I have taken has seen me apply these disparate literatures to a broad range of applications to examine the way in which identity institutions exist for the purposes of overcoming information asymmetry and uncertainty. Using such a broad range of literatures-including that related to asymmetric information, the new institutional economics, property rights literature, theories of government-while combining them into a coherent whole with necessary restraints on word 
count has led to some unavoidable limitations. I have addressed these throughout the thesis and repeat some of them here.

My development of an identity cost model of exchange suggested that identity costs constitute a considerable expense in certain industries. My approach to this model was analytical but not empirical. That is, I did not formally quantify those identity costs that are related to the initial identification, and subsequent verification, of sellers of a credit contract. Similarly, when I developed my identity hostage model of exchange, I alluded to, but did not include in my model, the differing expectations of the valuation of an identity hostage. I suggested that this might result in the appropriation of 'quasi-rent' from an exchange relationship. Finally, and related to my examinations of identity as it relates to mitigating uncertainty in political exchange, was the unavoidable limitation derived from any choice of historical period. As I suggested in my examination of heritable surnames, post-1066 England was one of many periods in which such a study could have been focussed. This limitation could just as easily be extended to any of the four historical periods studied in my examination of a stationary bandit with a captive population.

What I suggest however, and discuss in the subsequent section, is that these limitations are also an opportunity for further study. This thesis has amalgamated a broad range of literatures in the examination of identity and the way it might overcome information asymmetry and uncertainty in economic and political exchange. This leaves much scope for subsequent study.

\subsection{Further study}

Further to this thesis, I suggest that the study of identity, information asymmetry and behavioural uncertainty reveal two broad future areas of economic enquiry. The first is empirical, and initially related to the calculation of identity costs across a range of industries. As I have determined, financial institutions like banks exist in part for identity cost economising. The calculation of these costs would be a promising place to start. Furthermore, such institutional arrangements also arise from available technologies and regulatory environments, and innovation in both the former and the latter should be the subject of further scholarship, especially as it relates to an understanding of the implications of such change in the financial industry. ${ }^{73}$

The second broad area for future enquiry relates to further historical periods which identity, information asymmetry and uncertainty might be examined. I have looked at five historical time periods across this thesis, but as I suggested when examining the role of hereditary surnames, other societies have attempted to use them for the mitigation of uncertainty in political exchange. I have previously mentioned Qin Dynasty China, as well as Renaissance

\footnotetext{
${ }^{73}$ Another empirical question relates to the quantification of the cost of homogenising different forms of money technologies. As I have discussed in Berg (2020), institutional competition in money creation has seen various money technologies exist across a spectrum of transaction cost economising potential. Quantifying the regulatory and technical costs of the act of homogenising-de-identifying-different forms of money might be the subject of fruitful research.
} 
Florence in this context. Applying a similar analytical framework to that deployed in this thesis will likely result in interesting future scholarship. Finally, and in addition to the time periods just mentioned, I have earlier suggested that surnames might also be examined from several different viewpoints. From an institutional perspective, surnames might also be examined as; informal insurance mechanisms; reducing information and search costs; indicators of occupational licensing, and; for the facilitation of taxation and other political exchange. 


\section{References}

Abu-Lughod, JL 1989, Before European Hegemony: The World System A.D. 1250-1350, Oxford University Press, Oxford, UK.

Abdukadirov, S 2010, 'The Problem of Political Calculation in Autocracies', Constitutional Political Economy, vol. 21, no. 4, pp. 360-73.

Abdulkadiroglu, A and Sonmez T 1999, 'House Allocation with Existing Tenants', Journal of Economic Theory, vol. 88, no. 2, pp. 233-60.

---- 2003, 'School Choice: A Mechanism Design Approach', The American Economic Review, vol. 93, no. 3, pp. 729-47.

Abdulkadiroglu, A, Pathak, PA and Roth, AE 2005, 'The New York City High School Match', The American Economic Review, vol. 95, no. 2, pp. 364-67.

Acchiardo, C 2013, 'Power, Philanthropy, and Prestige: Three Essays on the Economics of Non-Priced Environments', Doctoral Thesis, George Mason University, Fairfax.

---- 2019, 'The Dictator's Knowledge Problem', in JC Hall \& S Harper (eds), Economic and Political Institutions and Development, Springer, Berlin, Germany, pp. 1-20.

Acemoglu, D and Robinson J 2006, Economic Origins of Dictatorship and Democracy, Cambridge University Press, Cambridge, UK.

---- 2012, Why Nations Fail: The Origins of Power, Prosperity and Poverty, Crown Publishing Group, New York, NY, USA.

Acquisti, A, Taylor, C and Wagman L 2016, 'The Economics of Privacy', Journal of Economic Literature, vol. 54, no. 2, pp. 442-92.

Adams, C and Laurence R 2012, Travel and Geography in the Roman Empire, Taylor \& Francis, Milton Park, UK.

Agah, A and Das SK 2007, 'Preventing DoS Attacks in Wireless Sensor Networks: A Repeated Game Theory Approach', IJ Network Security, vol. 5, no. 2, pp. 145-53.

Aguiar, F, Brañas-Garza, P, Espinosa, MP and Miller, LM 2010, 'Personal Identity: A Theoretical and Experimental Analysis', Journal of Economic Methodology, vol. 17, no. 3, pp. 261-75.

Aguiar, F and de Francisco, A 2009, 'Rational Choice, Social Identity, and Beliefs About Oneself', Philosophy of the Social Sciences, vol. 39, no. 4, pp. 547-71.

Aigner, DJ and Cain, GG 1977, 'Statistical Theories of Discrimination in Labor Markets', ILR Review, vol. 30, no. 2, pp. 175-87. 
Akerlof, GA 1970, 'The Market for Lemons', The Quarterly Journal of Economics, vol. 84, no. 3, pp. 488-500.

---- 1976, 'The Economics of Caste and of the Rat Race and Other Woeful Tales', The Quarterly Journal of Economics, vol. 90, no. 4, pp. 599-617.

---- 1980, 'A Theory of Social Custom, of Which Unemployment May Be One Consequence', The Quarterly Journal of Economics, vol. 94, no. 4, pp. 749-75.

---- 1985, 'Discriminatory, Status-Based Wages Among Tradition-Oriented, Stochastically Trading Coconut Producers', Journal of Political Economy, vol. 93, no. 2, pp. 265-76.

---- 1997, 'Social Distance and Social Decisions', Econometrica, vol. 65, no. 5, pp. 1005-27.

Akerlof, GA and Kranton, RE 2000, 'Economics and Identity', The Quarterly Journal of Economics, vol. 115, no. 3, pp. 715-53.

---- 2002, Identity and Schooling: Some Lessons for the Economics of Education', Journal of Economic Literature, vol. XL, December 2002, pp. 1167-201.

---- 2005, 'Identity and the Economics of Organizations', Journal of Economic Perspectives, vol. 19 , no. 1 , pp. 9-32.

---- 2010, Identity Economics: How Our Identities Shape Our Work, Wages, and Well-Being, Princeton University Press, NJ, USA.

Akerlof, GA, Romer, PM, Hall, RE and Mankiw, G 1993, 'Looting: The Economic Underworld of Bankruptcy for Profit', Brookings Papers on Economic Activity, vol. 24, no. 2, pp. 173.

Albanesi, S, and Olivetti, C 2009, 'Home Production, Market Production and the Gender Wage Gap: Incentives and Expectations', Review of Economic Dynamics, vol. 12, no. 1, pp. 80-107.

Alchian, AA 1965, 'Some Economics of Property Rights', Il Politico, vol. 30, no. 4, pp. 816-29.

Alchian, AA and Demsetz, H 1972, 'Production, Information Costs, and Economic Organization', The American Economic Review, vol. 62, no. 5, pp. 777-95.

---- 1973, 'The Property Right Paradigm', The Journal of Economic History, vol. 33, no. 1, pp. 16-27.

Alesina, A, Devleeschauwer, A, Easterly, Kurlat, WS and Wacziarg, R 2003, 'Fractionalization', Journal of Economic Growth, vol. 8, no. 2, pp. 155-94.

Alexander, P and Chan, A 2004, 'Does China Have an Apartheid Pass System?', Journal of Ethnic and Migration Studies, vol. 30, no. 4, pp. 609-29. 
Alexander, RD 1987, The Biology of Moral Systems, Walter de Gruyter, Berlin, Germany.

Alger, I, and Ma, CA 2003, 'Moral Hazard, Insurance, and Some Collusion', Journal of Economic Behaviour and Organisation, vol. 50, no. 2, pp. 225-47.

Ali, SN, and Miller, DA 2016, 'Ostracism and Forgiveness', The American Economic Review, vol. 106, no. 8 , pp. 2329-48.

Allard, M, Cresta, JP and Rochet, JC 1997, 'Pooling and Separating Equilibria in Insurance Markets with Adverse Selection and Distribution Costs', The Geneva Papers on Risk and Insurance Theory, vol. 22, no. 2, pp.103-20.

Allen, DWE, Berg, A Berg, C, Markey-Towler, B and Potts, J 2019, 'Some Economic Consequences of the GDPR', Economics Bulletin, vol. 39, no. 2, pp. 785-97.

Allen, DWE, Berg, A and Markey-Towler, B 2019, 'Blockchain and Supply Chains: V-form Organisations, Value Redistributions, De-commoditisation and Quality Proxies', The Journal of the British Blockchain Association, vol. 2, no. 1, pp. 57-65.

Allen, J 2006, Hostages and Hostage-Taking in the Roman Empire, Cambridge University Press, Cambridge, UK.

Alston, R 1994, 'Roman Military Pay from Caesar to Diocletian', The Journal of Roman Studies, vol. 84, pp. 113-23.

Altonji, JG, and Blank, RM 1999, 'Race and Gender in the Labor Market', in (eds), O Ashenfelter \& D Card, Handbook of Labor Economics. Volume 3, Part C, North Holland, Amsterdam, Netherlands, pp. 3143-259.

Altonji, JG and Pierret, CR 2001, 'Employer Learning and Statistical Discrimination', The Quarterly Journal of Economics, vol. 116, no. 1, pp. 313-50.

Anand, BN and Shachar, R 2009, 'Targeted Advertising as a Signal', Quantitative Marketing and Economics, vol. 7, no. 3, pp. 237-66.

Anderson, B 2006, Imagined Communities: Reflections on the Origin and Spread of Nationalism, Verso, NY, USA.

Anderson, M and Magruder, J 2012, 'Learning from the Crowd: Regression Discontinuity Estimates of the Effects of an Online Review Database', The Economic Journal, vol. 122 , no. 563, pp. 957-89.

Ando, C 2000, Imperial Ideology and Provincial Loyalty in the Roman Empire, University of California Press, Berkeley, California, USA.

---- 2006, 'The Administration of the Provinces', in D Potter (ed), A Companion to the Roman Empire, Blackwell, Hoboken, NJ, USA, pp. 177-92. 
Anthony, DJ 2016, 'To Have, to Hold, and to Vanquish: Property and Inheritance in the History of Marriage and Surnames', British Journal of American Legal Studies, vol. 5, no. 1, pp. 217-39.

Antioch, G, 2013, 'Persuasion is Now 30 Per Cent of US GDP: Revisiting McCloskey and Klamer After a Quarter of a Century', Economic Round-Up, no. 1, pp. 1-10.

Aoki, M 2001, Toward a Comparative Institutional Analysis, MIT Press, Cambridge, MA, USA

Appelcline, S, Crocker, D, Farmer, R and Newton, J 2015, Rebranding the Web of Trust, viewed 1 September $2020<$ http://www.weboftrust.info/downloads/rebrandingweb-of-trust.pdf>

Appiah, K 2008, 'Bending Towards Justice', Journal of Human Development, vol. 9, no. 3, pp. 343-55.

---- 2009, 'Sen's Identities', in K Basu \& R Kanbur (eds), Arguments for a Better World: Essays in Honor of Amartya Sen. Volume I: Ethics, Welfare and Measurement, Oxford University Press, Oxford, UK.

Arestis, P, Charles, A and Fontana, G 2014, 'Identity Economics Meets Financialisation: Gender, Race and Occupational Stratification in the US Labour Market', Cambridge Journal of Economics, vol. 38, no. 6, pp. 1471-91.

Argyres, N and Mostafa, R 2016, 'Knowledge Inheritance, Vertical Integration, and Entrant Survival in the Early US Auto Industry', Academy of Management Journal, vol. 59, no. 4, pp. 1474-92.

Armey, L and Melese, F 2018, 'Minimizing Public Sector Corruption: The Economics of Crime, Identity Economics, and Money Laundering', Defence and Peace Economics, vol. 29, no. 7, pp. 840-52.

Arrow, KJ 1963, 'Uncertainty and the Welfare Economics of Medical Care', The American Economic Review, vol. 53, no. 5, pp. 941-73.

---- 1969 'The Organization of Economic Activity: Issues Pertinent to the Choice of Market Versus Nonmarket Allocation', The Analysis and Evaluation of Public Expenditure: The PPB System, 91 Congress, $1^{\text {st }}$ Session, vol. 1, pp. 59-73.

---- 1970, 'Political and Economic Evaluation of Social Effects and Externalities', in J Margolis (ed), The Analysis of Public Output, Columbia University Press, New York, USA, pp. 130.

---- 1972a, 'Models of Job Discrimination', in AH Pascal (ed), Racial Discrimination in Economic Life, Lexington, MA, USA, pp. 83-102.

---- 1972b, 'Some Mathematical Models of Race Discrimination in the Labor Market', in AH Pascal (ed), Racial Discrimination in Economic Life, Lexington, MA, USA, pp. 187-204. 
---- 1972c, 'Gifts and Exchanges', Philosophy \& Public Affairs, vol. 1, no. 4, pp. 343-62.

---- 1973, 'The Theory of Discrimination', in O Ashenfelter \& A Rees (eds), Discrimination in Labor Markets, Princeton University Press, Princeton, USA, pp. 3-33

---- 1998, 'What has Economics to Say About Racial Discrimination?', Journal of Economic Perspectives, vol. 12, no. 2, pp. 91-100.

Ashlagi, I and Roth, AE 2021, 'Kidney Exchange: an Operations Perspective', Management Science, vol. 67, no. 9, pp. 5455-78.

Ashraf, N, Bandiera, O and Lee, SS 2014, 'Awards Unbundled: Evidence from a Natural Field Experiment', Journal of Economic Behavior \& Organization, vol. 100, pp. 44-63.

Ashton, B, Hill, K, Piazza, A and Zeitz, R 1992, 'Famine in China, 1958-61', Population and Development Review, vol. 10, no. 4, pp. 613-45.

Austen-Smith, D and Fryer RJ 2005, 'An Economic Analysis of "Acting White"', The Quarterly Journal of Economics, vol. 120, no. 2, pp. 551-83.

Autor, DH and Scarborough, D 2008, 'Does Job Testing Harm Minority Workers? Evidence from Retail Establishments', The Quarterly Journal of Economics, vol. 123, no. 1, pp. 219-77.

Ayres, I 1995, 'Further Evidence of Discrimination in New Car Negotiations and Estimates of its Cause', Michigan Law Review, vol. 94, no. 1, pp. 109-47.

Ayres, I and Siegelman, P 1995, 'Race and Gender Discrimination in Bargaining for a New Car', The American Economic Review, vol. 85, no. 3, pp. 304-21.

Ayres, I and Waldfogel, J 1993, 'A Market Test for Race Discrimination in Bail Setting', Stan. L. Rev, vol. 46, no. 5, pp. 987-1047.

Badian, E 1988, 'The Clever and the Wise: Two Roman Cognomina in Context', Bulletin of the Institute of Classical Studies, vol. 35, no. S51, pp. 6-12.

Baert, S and De Pauw, AS 2014, 'Is Ethnic Discrimination Due to Distaste or Statistics?', Economics Letters, vol. 125, no. 2, pp. 270-73.

Bagnall, RS and Frier, BW 2006, The Demography of Roman Egypt, Cambridge University Press, Cambridge, UK.

Bagwell, K and Ramey G, 1994, 'Coordination Economies, Advertising, and Search Behavior in Retail Markets', The American Economic Review, vol. 84, no. 3, pp. 498-517.

Bailey, DRS 1976, Two Studies in Roman nomenclature, American Philological Association, New York, USA. 
Bajaj, M and Vijh A 1990, 'Dividend Clienteles and the Information Content of Dividend Changes', Journal of Financial Economics, vol. 26, no. 2, pp. 193-219.

Baker, T 1996, 'On the Geneology of Moral Hazard', Texas Law Review, vol. 75, no. 2, pp. 237-92.

Balsdon, JPVD 1979, Romans and Aliens, Duckworth, London, UK.

Banerjee, R, Baul, T and Rosenblat, T 2015, 'On Self Selection of the Corrupt into the Public Sector', Economics Letters, vol. 127, pp. 43-6.

Banfield, EC 1970, The Unheavenly City: The Nature and Future of Our Urban Crisis, Little, Brown, Boston, MA, USA.

Banister, J, 1987, China's Changing Population, Stanford University Press, Palo Alto, CA, USA.

Baron, D 2002, 'Private Ordering on the Internet: The eBay Community of Traders', Business and Politics, vol. 4, no. 3, pp. 245-74.

Barrett, CB 2013a, 'Smallholder Identities and Social Networks', in CB Barrett (ed), The Social Economics of Poverty, Routledge, Abingdon, UK, pp. 204-31.

---- 2013b, The Social Economics of Poverty, Taylor \& Francis, Milton Park, UK.

Bartlett, R 2000, England Under the Norman and Angevin Kings, 1075-1225, Clarendon Press, Oxford, UK.

Bartram, D, Lindley, PA, Marshall, L and Foster J 1995, 'The Recruitment and Selection of Young People by Small Businesses', Journal of Occupational and Organizational Psychology, vol. 68, no. 4, pp. 339-58.

Barzel, Y 2002, A Theory of the State, Cambridge University Press, Cambridge, UK.

---- 2003, 'Property Rights and the Evolution of the State', Economics of Governance, vol. 1, no. 1 , pp. 25-51.

Bastani, S, Blumkin, T and Micheletto, L 2015, 'Optimal Wage Redistribution in the Presence of Adverse Selection in the Labor Market', Journal of Public Economics, vol. 131, pp. 41-57.

Bates, R 2014, 'The New Institutionalism', in S Galiani \& I Sened (eds), Institutions, Property Rights, and Economic Growth: The Legacy of Douglass North, Cambridge University Press, Cambridge, UK, pp. 50-65.

Battaglini, M 2006, 'Joint Production in Teams', Journal of Economic Theory, vol. 130, no. 1, pp. 138-67. 
Battu, H, Mwale, M and Zenou, Y 2007, 'Oppositional Identities and the Labor Market, Journal of Population Economics, vol. 20, no. 3, pp. 643-67.

Baumol, WJ 1951, 'The Neumann-Morgenstern Utility Index-An Ordinalist View', Journal of Political Economy, vol. 59, no. 1, pp. 61-6.

---- 1996, 'Entrepreneurship: Productive, Unproductive, and Destructive', Journal of Business Venturing, vol. 11, no. 1, pp. 3-22.

Beames, J 1821, A Brief View of the Writ Ne Exeat Regno: With Practical Remarks Upon it as an Equitable Process, S Gould, New York, USA.

Bean, JMW 1968, The Decline of English Feudalism, 1215-1540, Manchester University Press, Manchester, UK.

Becker, GS 1957, The Economics of Discrimination, University of Chicago Press, Chicago, USA.

---- 1962, 'Investment in Human Capital: A Theoretical Analysis', Journal of Political Economy, vol. 70, no. 5, pp. 9-49.

---- 1971. The Economics of Discrimination, University of Chicago Press, Chicago, USA.

---- 1996, Accounting for Tastes, Harvard University Press, Cambridge, USA.

Bediou, B, Comeig, I, Jaramillo-Gutiérrez, A and Sander, D 2013, 'The Role of «Perceived Loss» Aversion on Credit Screening: An Experiment', Spanish Journal of Finance and Accounting, vol. 42, no. 157, pp. 83-97.

Bedos-Rezak, BM 2000, 'Medieval Identity: A Sign and a Concept', The American Historical Review, vol. 105, no. 5, pp. 1489-533.

Ben-Porath, Y 1980, 'The F-connection: Families, Friends, and Firms and the Organization of Exchange', Population and Development Review, vol. 6, no. 1, pp. 1-30.

Bendle, MF 2002, 'The Crisis of identity in High Modernity', The British Journal of Sociology, vol. 53 , no. 1 , pp. 1-18.

Benjamin, DJ, Choi, JJ and Strickland, AJ 2010, 'Social Identity and Preferences', The American Economic Review, vol. 100, no. 4, pp. 1913-28.

Benjamin, J, de la Torre, C and Musumeci, J 1995, 'Controlling the Incentive Problems in Real Estate Leasing', Journal of Real Estate Finance and Economics, vol. 10, no. 2, pp. 17791.

Benson, BL 1989, 'The Spontaneous Evolution of Commercial Law', Southern Economic Journal, vol. 55 , no. 3 , pp. 644-61. 
---- 2000, 'Private Sources of Trust and Recourse: Prerequisites for the Successful Emergence of Markets in Cyberspace', Journal of Private Enterprise, vol. 16, no. 1, pp. 23-46.

Berg, A 2020, 'The Identity, Fungibility, and Anonymity of Money', Economic Papers, vol. 39, no. 2, pp. 104-17.

Berg, A, Markey-Towler, B and Novak, M 2020, 'Blockchains = Less Government, More Market', The Journal of Private Enterprise, vol. 35, no. 2, pp. 1-21.

Berg, C 2017, 'What Diplomacy in the Ancient Near East Can Tell Us About Blockchain Technology', Ledger, vol. 2, pp. 55-64.

---- 2018, The Classical Liberal Case for Privacy in a World of Surveillance and Technological Change, Palgrave Macmillan, London, UK.

Berg, C and Roskam, J 2015, Magna Carta: The Tax Revolt That Gave Us Liberty, Institute of Public Affairs, Melbourne, Australia.

Berg, C, Davidson, S and Potts, J 2018, 'Ledgers', Available at SSRN 3157421.

Bergson, A 1938, 'A Reformulation of Certain Aspects of Welfare Economics', The Quarterly Journal of Economics, vol. 52, no. 2, pp. 310-34.

Berkovec, JA, Canner, GB, Gabriel, SA and Hannan, TH 1994, 'Race, Redlining, and Residential Mortgage Loan Performance', The Journal of Real Estate Finance and Economics, vol. 9, no. 3, pp. 263-94.

Berman, E 2000, 'Sect, Subsidy, and Sacrifice: An Economist's View of Ultra-Orthodox Jews', The Quarterly Journal of Economics, vol. 115 no. 3, pp. 905-53.

Berman, HJ 2009, Law and Revolution, the Formation of the Western Legal Tradition, Harvard University Press, Cambridge, MA, USA.

Berndt, A and Gupta, A 2009, 'Moral Hazard and Adverse Selection in the Originate-toDistribute Model of Bank Credit', Journal of Monetary Economics, vol. 56, no. 5, pp. 725-43.

Bernheim, BD 1994, 'A Theory of Conformity', Journal of Political Economy, vol. 102, no. 5, pp. 841-77.

Bernstein, M 2005, 'Identity Politics', Annu. Rev. Sociol, vol. 31, pp. 47-74.

Bertrand, M and Mullainathan, S 2004, 'Are Emily and Greg More Employable Than Lakisha and Jamal? A Field Experiment on Labor Market Discrimination', The American Economic Review, vol. 94, no. 4, pp. 991-1013.

Bester, H 1985, 'Screening vs. Rationing in Credit Markets with Imperfect Information', The American Economic Review, vol. 75, no. 4, pp. 850-55. 
Bhattacharya, S 1980, 'Nondissipative Signaling Structures and Dividend Policy', The Quarterly Journal of Economics, vol. 95, no. 1, pp. 1-24.

Bianchi, J 2016, 'Efficient Bailouts?', The American Economic Review, vol. 106, no. 12, pp. 3607-59.

Bilali, G 2011, 'Know Your Customer-or Not', U. Tol. L. Rev, vol. 43, no. 2, pp. 319-66.

Binmore, KG 1994, Game Theory and the Social Contract: Playing Fair, MIT Press, Cambridge, MA, USA.

Biong, H 2012, 'Choice of Subcontractor in Markets with Asymmetric Information: Reputation and Price Effects', Journal of Business \& Industrial Marketing, vol. 28, no. 1, pp. 60-71.

Bisin, A, Patacchini, E, Verdier, T and Zenou, Y 2011, 'Formation and Persistence of Oppositional Identities', European Economic Review, vol. 55, no. 8, pp. 1046-71.

Black, DA 1995a, 'Discrimination in an Equilibrium Search Model', Journal of Labor Economics, vol. 13, no. 2, pp. 309-34.

Black, EW 1995b, Cursus Publicus: The Infrastructure of Government in Roman Britain, BAR, Oxford, UK.

Bliss, C 2013, 'The Marketization of Identity Politics.', Sociology, vol. 47, no. 5, pp. 1011-25.

Blum, J 1999, 'Do Capital Adequacy Requirements Reduce Risks in Banking?', Journal of Banking and Finance, vol. 23, no. 5, pp. 755-71.

---- 2002, 'Subordinated Debt, Market Discipline, and Banks' Risk Taking', Journal of Banking and Finance, vol. 26, no. 7, pp. 1427-41.

Bó, PD 2005, 'Cooperation Under the Shadow of the Future: Experimental Evidence from Infinitely Repeated Games', The American Economic Review, vol. 95, no. 5, pp. 1591604.

Board, JB 1962, 'The State and Travel: A Study in the Development of Travel as an Instrument of State Policy', Indiana University Press, Indiana, USA.

Boettke, PJ 2011, 'Institutional Transition and the Problem of Credible Commitment', Annual Proceedings of the Wealth and Well-Being of Nations, p. 41.

Bogardus, E 1933, 'A Social Distance Scale', Sociology and Social Research, vol. 17, pp. 26571.

Boix, C and Svolik, MW 2013, 'The Foundations of Limited Authoritarian Government: Institutions, Commitment, and Power-Sharing in Dictatorships', The Journal of Politics, vol. 75, no. 2, pp. 300-16. 
Bolton, GE, Katok, E and Ockenfels, A 2004, 'How Effective Are Online Reputation Mechanisms? An Experimental Investigation', Management Science, vol. 50, no. 11, pp. 1587-602.

---- 2005, 'Cooperation Among Strangers with Limited Information About Reputation', Journal of Public Economics, vol. 89, no. 8, pp. 1457-68.

Bond, EW 1982, 'A Direct Test of the "Lemons" Model: The Market for Used Pickup Trucks', The American Economic Review, vol. 72, no. 4, pp. 836-40.

Borjas, GJ and Bronars, SG 1989, 'Consumer Discrimination and Self-Employment', Journal of Political Economy, vol. 97, no. 3, pp. 581-605.

Botsman, R 2017, 'Big Data Meets Big Brother as China Moves to Rate its Citizens', Wired, 21 October 2017.

Boudin, LB 1956, 'The Constitutional Right to Travel', Columbia Law Review, vol. 56, no. 1, pp. 47-75.

Bowles, S and Gintis, H 2000, 'Optimal Parochialism: The Dynamics of Trust and Exclusion in Networks', Sante Fe Institute, Economics Department Working Paper Series, 86.

Bowlus, AJ and Eckstein, Z 2002, 'Discrimination and Skill Differences in an Equilibrium Search Model', International Economic Review, vol. 43, no. 4, pp. 1309-45.

Boyd, BK, Bergh, DD and Ketchen Jr, DJ 2010, 'Reconsidering the Reputation-Performance Relationship: A Resource-Based View', Journal of Management, vol. 36, no. 3, pp. 588-609.

Boyer, MM and Laffont, JJ 1989, 'Expanding the Informativeness of the Price System with Law', The Canadian Journal of Economics, vol. 22, no. 2, pp. 217-27.

Brennan, G and Buchanan, JM 1980, The Power to Tax: Analytic Foundations of a Fiscal Constitution, Cambridge University Press, Cambridge, UK.

Brisman, A 2009, 'It Takes Green to be Green: Environmental Elitism, Ritual Displays, and Conspicuous Non-Consumption', NDL Rev, vol. 85, pp. 329-70.

Brooks, JS and Wilson, C 2015, 'The Influence of Contextual Cues on the Perceived Status of Consumption-Reducing Behavior', Ecological Economics, vol. 117, pp. 108-117.

Brooks, R, Davidson, S and Faff, R 2003, 'Sudden Changes in Property Rights: The Case of Australian Native Title', Journal of Economic Behavior \& Organization, vol. 52, no. 4, pp. 427-42.

Brown, M, Jappelli, T and Pagano, M 2009, 'Information Sharing and Credit: Firm-Level Evidence from Transition Countries', Journal of Financial Intermediation, vol. 18, no. 2, pp. 151-72. 
Brown, RJ 1978, 'Divided We Fall: Analysis of Relations Between Different Sections of a Factory Workforce', in H Tajfel (ed), Differentiation Between Social Groups: Studies in the Social Psycholog y of Intergroup Relations, Academic Press, London, UK, 395-429.

Brubaker, R and Cooper, F 2000, 'Beyond "identity"', Theory and society, vol. 29, no. 1, pp. 1-47.

Brunt, PA 1990, Roman Imperial Themes, Clarendon Press, Oxford, UK.

Brynjolfsson, E and Smith, MD 2000, 'Frictionless Commerce? A Comparison of Internet and Conventional Retailers', Management Science, vol. 46, no. 4, pp. 563-85.

Bryson, A and Chevalier, A 2015, 'Is There a Taste for Racial Discrimination Amongst Employers', Labour Economics, vol. 34, pp. 51-63.

Buchanan, JM 1965, 'An Economic Theory of Clubs', Economica, vol. 32, no. 125, pp. 1-14.

Buchanan, JM and Tullock, G 1962, The Calculus of Consent, University of Michigan Press Ann Arbor, USA.

Bump, M 2007, 'Immigration, Technology, and the Worksite: The Challenges of Electronic Employment Verification', Geo. Immigr. LJ, vol. 22, pp. 391-403.

Bundorf, MK, Levin, J and Mahoney, N 2012, 'Pricing and Welfare in Health Plan Choice', The American Economic Review, vol. 102, no. 7, pp. 3214-48.

Burdett K and Coles, MG 1999, 'Long-Term Partnership Formation: Marriage and Employment', The Economic Journal, vol. 109, no. 456, pp. F307-F334.

Burke, J 1831, A General and Heraldic Dictionary of the Peerages of England, Ireland, and Scotland. Extinct, Dormant, and in Abeyance, Henry Colburn \& Richard Bentley, London, UK.

Burns, R 1995, 'The Guidaticum Safe-Conduct in Medieval Arago-Catlonia; A Mini-Institution for Muslims, Christians and Jews', Medieval Encounters; Jewish, Christian and Muslim Culture in Confluence and Dialogue, vol. 1, no. 1, pp. 51-113.

---- (ed), 2001, Las Siete Partidas, Volume 4: Family, Commerce, and the Sea: The Worlds of Women and Merchants, University of Pennsylvania Press, Philadelphia, USA.

Bursztyn, L, Egorov, G and Jensen, R 2018, 'Cool to be Smart or Smart to be Cool? Understanding Peer Pressure in Education', The Review of Economic Studies, vol. 86, no. 4, pp. 1487-526.

Bursztyn, L, Fujiwara, T and Pallais, A 2017, "Acting Wife': Marriage Market Incentives and Labor Market Investments', The American Economic Review, vol. 107, no. 11, pp. 3288-319. 
Bursztyn, L and Jensen, R 2015, 'How Does Peer Pressure Affect Educational Investments?', The Quarterly Journal of Economics, vol. 130, no. 3, pp. 1329-67.

---- 2017, 'Social Image and Economic Behavior in the Field: Identifying, Understanding, and Shaping Social Pressure', Annual Review of Economics, vol. 9, pp. 131-53.

Burt, RS and Knez, M 1996, 'Trust and Third-Party Gossip', in R Kramer \& T Tyler (eds), Trust in Organizations: Frontiers of Theory and Research, SAGE, Newcastle, UK, pp. 68-89.

Busse, TV and Seeaydarian, L 1979, 'First Names and Popularity in Grade School Children', Psychology in the Schools, vol. 16, no. 1, pp. 149-53.

Cabral, L 2000, 'Stretching Firm and Brand Reputation', RAND Journal of Economics, vol. 31, no. 4, pp. 658-73.

---- 2005, 'The Economics of Trust and Reputation: A Primer', New York University and CEPR Working Paper.

Cabral, L and Hortacsu, A 2010, 'The Dynamics of Seller Reputation: Evidence from eBay', The Journal of Industrial Economics, vol. 58, no. 1, pp. 54-78.

Cai, F 1999, 'Spatial Patterns of Migration Under China's Reform Period', Asian and Pacific Migration Journal, vol. 8, no. 3, pp. 313-27.

Cai, F, Park, A and Zhao, Y 2008, 'The Chinese Labor Market in the Reform Era', in L Brandt \& T Rawski (eds), China's Great Economic Transformation, Cambridge University Press, Cambridge, UK, pp. 167-214.

Calomiris, C and Kahn, C 1991, 'The Role of Demandable Debt in Structuring Optimal Banking Arrangements', The American Economic Review, vol. 81, no. 3, pp. 497-513.

Camden, W [1605] 1870, Remains Concerning Britain. J. R. Smith, London, UK.

Campana, P and Varese, F 2013, 'Cooperation in Criminal Organizations: Kinship and Violence as Credible Commitments', Rationality and Society, vol. 25, no. 3, pp. 26389.

Canner, GB, Gabriel, SA and Woolley, JM 1991, 'Race, Default Risk and Mortgage Lending: A Study of the FHA and Conventional Loan Markets', Southern Economic Journal, vol. 58, no. 1, pp. 249-62.

Caplan, BD 2017, The Case Against Education, Princeton University Press, Princeton, USA.

Caplan, J 2001, “This or That Particular Person': Protocols of Identification in NineteenthCentury Europe', in J Caplan \& J Torpey (eds), Documenting Individual Identity, Princeton University Press, Princeton, USA, pp. 49-66. 
Cardon, JH and Hendel, I 2001, 'Asymmetric Information in Health Insurance: Evidence from the National Medical Expenditure Survey', RAND Journal of Economics, vol. 32, no. 3, pp. 408-27

Carr, JL and Landa., JT 1983, 'The Economics of Symbols, Clan Names, and Religion', The Journal of Legal Studies, vol. 12, no. 1, pp. 135-56.

Carter, RB and Power, ML 2012, 'Reputational Signals and Capital Acquisition When Insurance Companies Go Public', The Geneva Papers on Risk and Insurance-Issues and Practice, vol. 37, no. 3, pp. 485-508.

Casey, MJ and Vigna, P 2018, The Truth Machine: The Blockchain and the Future of Everything, HarperCollins, New York, USA.

Casquete, J 2016, 'The Omportance of Being Horst: Popular Support and Given Names in Nazi Germany', European Journal of Cultural and Political Sociology, vol. 3, no. 1, pp. 97-118.

Catino, M 2015, 'Mafia Rules. The Role of Criminal Codes in Mafia Organizations', Scandinavian Journal of Management, vol. 31, no. 4, pp. 536-48.

Chambers, RG 1989, 'Insurability and Moral Hazard in Agricultural Insurance Markets', American Journals of Agricultural Economics, vol. 71, no. 3, pp. 604-16.

Chan, KW 1996, 'Post-Mao China: A Two-Class Urban Society in the Making', International Journal of Urban and Regional Research, vol. 20, no. 1, pp. 134-50.

---- 2009, 'The Chinese Hukou System at 50', Eurasian Geography and Economics, vol. 50, no. 2, pp. 197-221.

---- 2010, 'The Household Registration System and Migrant Labor in China: Notes on a Debate', Population and Development Review, vol. 36, no. 2, pp. 357-64.

---- 2013, 'China: Internal Migration', in I Ness (ed), The Encyclopedia of Global Human Migration, Wiley-Blackwell, Hoboken, NJ, USA, pp. 1-15.

Chan, KW and Buckingham, W 2008, 'Is China Abolishing the Hukou System?', The China Quarterly, vol. 195, pp. 582-606.

Chan, KW and Zhang, Li 1999, 'The Hukou System and Rural-Urban Migration in China: Processes and Changes', The China Quarterly, vol. 160, pp. 818-55.

Chango, M 2012, 'Becoming Artifacts: Medieval Seals, Passports and the Future of Digital Identity', Doctoral Thesis, School of Information Studies, Syracuse University, NY, USA.

Charles, CZ 2000, 'Neighborhood Racial-Composition Preferences: Evidence from a Multiethnic Metropolis', Social Problems, vol. 47, no. 3, pp. 379-407. 
Charles, KK and Guryan, J 2008, 'Prejudice and Wages: An Empirical Assessment of Becker's The Economics of Discrimination', Journal of Political Economy, vol. 116, no. 5, pp. 773-809.

---- 2011, 'Studying Discrimination: Fundamental Challenges and Recent Progress', Annu. Rev. Econ, vol. 3, no. 1, pp. 479-511.

Charles, KK, Hurst, E and Roussanov, N 2009, 'Conspicuous Consumption and Race', The Quarterly Journal of Economics, vol. 124, no. 2, pp. 425-67.

Charness, G, Rigotti, L and Rustichini, A 2007, 'Individual Behavior and Group Membership', The American Economic Review, vol. 97, no. 4, pp. 1340-52.

Charny, D 1990, 'Nonlegal Sanctions in Commercial Relationships', Harvard Law Review, vol. 104, no. 2, pp. 373-467.

Chase, GD 1897, 'The Origin of Roman Praenomina', Harvard Studies in Classical Philology, vol. 8, pp. 103-184.

Chau, D, Firth, M and Srinidhi, B 2006, 'Leases with Purchase Options and Double Moral Hazard', Journal of Business Finance \& Accounting, vol. 33, no. 9-10, pp. 1390-401.

Che, YK 1996, 'Customer Return Policies for Experience Goods', The Journal of Industrial Economics, vol. 64, no. 1, pp. 17-24.

Chemla, G and Tinn, K 2020, 'Learning Through Crowdfunding', Management Science, vol. 66 , no. 5 , pp. $1783-801$.

Chen, K 2004, 'Fiscal Centralization and the Form of Corruption in China', European Journal of Political Economy, vol. 20, no. 4, pp. 1001-9.

Chenavaz, R 2017, 'Better Product Quality May Lead to Lower Product Price', The B.E. Journal of Theoretical Economics, vol. 17, no. 1, pp. 187-94.

Cheng, T and Selden, M 1994, 'The Origins and Social Consequences of China's Hukou System', The China Quarterly, vol. 139, pp. 644-68.

Chesterman, J and Galligan, B 1997, Citizens Without Rights: Aborigines and Australian Citizenship, Cambridge University Press, Cambridge, UK.

Chetty, R 2008, 'Moral Hazard versus Liquidity and Optimal Unemployment Insurance', Journal of Political Economy, vol. 116, no. 2, pp. 173-234.

Cheung, SNS 1974, 'A Theory of Price Control', The Journal of Law and Economics, vol. 17, no. 1 , pp. 53-71.

--- 1983, 'The Contractual Nature of the Firm', The Journal of Law and Economics, vol. 26, no. 1, pp. 1-21. 
Chevalier, A, Harmon, C, Walker, I and Zhu, Y 2004, 'Does Education Raise Productivity, or Just Reflect ir?', The Economic Journal, vol. 114, no. 499, pp. 499-517.

Chiappori, P and Bernard, S 2000, 'Testing for Asymmetric Information in Insurance Markets', Journal of Political Economy, vol. 108, no. 1, pp. 56-78.

Chiesa, G 2001, 'Incentive-Based Lending Capacity, Competition and Regulation in Banking', Journal of Financial Intermediation, vol. 10, no. 1, pp. 28-53.

Choi, CJ, Lee, SH and Oh, D 1995, 'The Strategy of Grouping and Reputation Linkage in Clubs and Multi-Product Firms', European Journal of Political Economy, vol. 11, no. 3, pp. 521-33.

Christofides, LN and McKenna, CJ 1995, 'Unemployment Insurance and Moral Hazard in Employment', Economics Letters, vol. 49, no. 2, pp. 205-10.

Clanchy, MT 2012, From Memory to Written Record: England 1066-1307, John Wiley \& Sons, Hoboken, NJ, USA.

---- 2014, England and its Rulers: 1066 - 1307, Wiley, Hoboken, NJ, USA.

Clark, C 1992, 'Onomastics', in N Blake (ed), The Cambridge History of the English Language: Volume II 1066-1476, Cambridge University Press, Cambridge, UK, pp. 542-606.

Clark, G 2014, The Son Also Rises: Surnames and the History of Social Mobility, Princeton University Press, Princeton, USA.

Clarke, R 1994, 'Human Identification in Information Systems', Information Technology \& People, vol. 7, no. 4, pp. 6-37.

Clay, K 1997, 'Trade Without Law: Private-Order Institutions in Mexican California', The Journal of Law, Economics, \& Organization, vol. 13, no. 1, pp. 202-31.

Clingingsmith, D and Sheremeta, RM 2018, 'Status and the Demand for Visible Goods: Experimental Evidence on Conspicuous Consumption', Experimental Economics, vol. 21, no. 4, pp. 877-904.

Coase, RH 1937, 'The Nature of the Firm', Economica, vol. 4, no. 16, pp. 386-405.

---- 1960, 'The Problem of Social Cost', The Journal of Law and Economics, vol. 56, no. 4, pp. 837-77.

---- 1984, 'The New Institutional Economics', Zeitschrift für die gesamte Staatswissenschaft/Journal of Institutional and Theoretical Economics, vol. 140, no. H.1, pp. 229-231.

---- 1988, The Firm, the Market, and the Law, University of Chicago Press, Chicago, USA. 
---- 1998, 'The New Institutional Economics', The American Economic Review, vol. 88, no. 2, pp. 72-4.

Coate, S and Loury, G 1993a, 'Antidiscrimination Enforcement and the Problem of Patronization', The American Economic Review, vol. 83, no. 2, pp. 92-8.

---- 1993b, 'Will Affirmative-Action Policies Eliminate Negative Stereotypes?', The American Economic Review, vol. 83, no. 5, pp. 1220-40.

Cobb, R 1970, The Police and the People: French Popular Protest, 1789-1820., Clarendon Press, Oxford, UK.

Cochet, O and Ehrmann, T 2007, 'Preliminary Evidence on the Appointment of Institutional Solutions to Franchisor Moral Hazard-The Case of Franchisee Councils', Managerial and Decision Economics, vol. 28, no. 1, pp. 41-55.

Cohen, A and Siegelman, P 2010, 'Testing for Adverse Selection in Insurance Markets', Journal of Risk and insurance, vol. 77, no. 1, pp. 39-84.

Cokayne, GE 1892, Complete Peerage of England, Scotland, Ireland, Great Britain and the United Kingdom. Extand, Extinct, or Dormant. Volume IV G to K, George Bell \& Sons, London, UK.

---- 1896, Complete Peerage of England, Scotland, Ireland, Great Britain and the United Kingdom. Extant, Extinct, or Dormant. Volume VII S to I, George Bell \& Sons, London, UK.

---- 1898, Complete Peerage of England, Scotland, Ireland, Great Britain and the United Kingdom. Extant, Extinct, or Dormant. Volume VIII U to Z, George Bell \& Sons, London, UK.

Cokayne, GE, Gibbs, V and Doubleday, HA 1913, The Complete Peerage of England, Scotland, Ireland, Great Britain and the United Kingdom. New Edition, Revised and Much Enlarged. Volume III Canonteign to Cutts, The St Catherine Press, London, UK.

Cokayne GE and White, G 1953, The Complete Peerage or a History of The House of Lords and all its Members from the Earliest Times. Volume XII Part I Skelmersdale to Towton, The St Catherine Press, London, UK.

---- 1959, The Complete Peerage or a History of The House of Lords and all the Members from the Earliest Times. Volume XII Part II Tracton to Zouche, The St Catherine Press, London, UK.

Coke, E 1797, Institutes of the Laws of England: Containg the Exposition of Many Ancient and Other Statutes, E. \& R. Brooke, London, UK. 
Combris, P, Lecocq, S and Visser, M 1997, 'Estimation of a Hedonic Price Equation for Bordeaux Wine: Does Quality Matter?', The Economic Journal, vol. 107, no. 441, pp. 390-402.

Commons, 1932, 'The Problem of Correlating Law Economics and Ethics', Wis. L. Rev, vol. 8, pp. 3-26.

Concepcion, NP, 2000, 'Human Rights Violations Against Muslims in the Xinjiang Uighur Autonomous Region of Western China', Human Rights Brief, vol. 8, no. 1, pp.19-21.

Congleton, R 2001, 'On the Durability of King and Council: The Continuum Between

Dictatorship and Democracy', Constitutional Political Economy, vol. 12, no. 3, pp. 193-215.

Connelly, BS, Certo, T, Ireland, RD and Reutzel, CR 2011, 'Signaling Theory: A Review and Assessment', Journal of Management, vol. 37, no. 1, pp. 39-67.

Cooper, F 2018, Citizenship, Inequality, and Difference: Historical Perspectives, Princeton University Press, Princeton, USA.

Cooter, R and Landa, JT 1984, 'Personal Versus Impersonal Trade: The Size of Trading Groups and Contract Law', International Review of Law and Economics, vol. 4, no. 1, pp. 15-22.

Cornell, B and Welch, I 1996, 'Culture, Information, and Screening Discrimination', Journal of Political Economy, vol. 104, no. 3, pp. 542-571.

Costanigro, M, McCluskey, JJ and Goemans, C 2010, 'The Economics of Nested Names: Name Specificity, Reputations, and Price Premia', American Journal of Agricultural Economics, vol. 92, no. 5, pp. 1339-50.

Council of the European Union 2016, Position of the Council at First Reading with a View to the Adoption of a Regulation of the European Parliament and of the Council on the Protection of Natural Persons with Regard to the Processing of Personal Data and on the Free Movement of Such Data, and Repealing Directive 95/46/EC (General Data Protection Regulation), in 5419/16, edited by Council of the European Union.

Courant, PN 1978, 'Racial Prejudice in a Search Model of the Urban Housing Market', Journal of Urban Economics, vol. 5, no. 3, pp. 329-345.

Courty, P and Marschke, G 1997, 'Measuring Government Performance: Lessons from a Federal Job-Training Program', The American Economic Review, vol. 87, no. 2, pp. 383-388.

Cox, GW 2011, 'War, Moral Hazard, and Ministerial Responsibility: England After the Glorious Revolution', The Journal of Economic History, vol. 71, no. 1, pp. 133-61. 
Coyne, CJ and Boettke, PJ 2009, 'The Problem of Credible Commitment in Reconstruction', Journal of Institutional Economics, vol. 5, no. 1, pp. 1-23.

Coyne, CJ and Coyne, RL 2014, 'The Identity Economics of Female Genital Mutilation', The Journal of Developing Areas, vol. 48, no. 2, pp. 137-52.

Cranford, D 2012, 'A Roman in Name Only: An Onomastic Study of Cultural Assimilation and Integration in Roman Spain', Eras, vol. 13, no. 2, pp. 1-45.

Crawford, A Meh, C and Zhou, J 2013, 'The Residential Mortgage Market in Canada: A Primer', Financial System Review, vol. 3, pp. 53-63.

Crawford, GS, Pavanini, N and Schivardi, F 2018, 'Asymmetric Information and Imperfect Competition in Lending Markets', The American Economic Review, vol. 108, no. 7, pp. 1659-701.

Crawford, SES and Ostrom, E 1995, 'A Grammar of Institutions', American Political Science Review, vol. 89, no. 3, pp. 582-600.

Creemers, R 2018, 'China's Social Credit System: An Evolving Practice of Control', Available at SSRN 3175792.

Crittle, S 2006, The Last Godfather: The Rise and Fall of Joey Massino, Berkley, New York, NY, USA.

Cronin, FJ 1982, 'Racial Differences in the Search for Housing', in W Clark (ed), Modeling Housing Market Search, St. Martin's Press, New York, USA, pp. 81-105.

Curott, NA and Fink, A 2012, 'Bandit Heroes: Social, Mythical, or Rational?', American Journal of Economics and Sociology, vol. 71, no. 2, pp. 470-97.

Cuvigny, H 1996, 'The Amount of Wages Paid to the Quarry-Workers at Mons Claudianus', The Journal of Roman Studies, vol. 86, pp. 139-45.

Darby, MR and Karni, E 1973, 'Free Competition and the Optimal Amount of Fraud', The Journal of Law and Economics, vol. 16, no. 1, pp. 67-88.

Darity, WA and Mason, PL 1998, 'Evidence on Discrimination in Employment: Codes of Color, Codes of Gender', Journal of Economic Perspectives, vol. 12, no. 2, pp. 63-90.

Darity, WA, Mason, PL and Stewart, JB 2006, 'The Economics of Identity: The Origin and Persistence of Racial Identity Norms', Journal of Economic Behavior \& Organization, vol. 60, no. 3, pp. 283-305.

Dasgupta, P 2000, 'Trust as a Commodity', in D Gambetta (ed), Trust: Making and Breaking Cooperative Relations, Blackwell's, Oxford, UK, pp. 49-72. 
Davidow, WH and Uttal, B 1989, 'Service Companies: Focus or Falter', Harvard Business Review, vol. 67, no. 4, pp. 77-85.

Davidson, S, Novak, M and Potts, J 2018, 'The Cost of Trust: A Pilot Study', The Journal of the British Blockchain Association, vol. 1, no. 2, pp. 21-7.

Davidson, S and Potts, J 2017, 'The Stationary Bandit Model of Intellectual Property', Cato Journal, vol. 37, no. 1, pp. 69-88.

Davis, JB 2003, The Theory of the Individual in Economics: Identity and Value, Routledge, Abingdon, UK.

---- 2006, 'Social Identity Strategies in Recent Economics', Journal of Economic Methodology, vol. 13 , no. 3, pp. 371-90.

---- 2007, 'Akerlof and Kranton on Identity in Economics: Inverting the Analysis', Cambridge Journal of Economics, vol. 31, no. 3, pp. 349-362.

---- 2010, Individuals and Identity in Economics, Cambridge University Press, Cambridge, UK.

---- 2014, 'Stratification Economics and Identity Economics', Cambridge Journal of Economics, vol. 39, no. 5, pp. 1215-29.

de Blois, L 2014, 'The Constitutio Antoniniana (ad 212): Taxes or Religion?', Mnemosyne, vol. 67, no. 6, pp. 1014-21.

de Bourmont, M 2018, 'China's Campaign Against Uighur Diaspora Ramps Up', Foreign Policy, 3 April 2018.

Decamps, JP, Rochet, JC and Roger, B 2004, 'The Three Pillars of Basel II: Optimizing the Mix', Journal of Financial Intermediation, vol. 13, no. 2, pp. 132-55.

de la Vega, JP [1688] 2013, Confusion de Confusiones, Martino Publishing, Eastford, USA.

de Mesquita, BB, Smith, A, Siverson, RM and Morrow, JD 2003, The Logic of Political Survival, MIT Press, Cambridge, MA, USA.

de Meza, D and Webb, D 1988, 'Credit Market Efficiency and Tax Policy in the Presence of Screening Costs', Journal of Public Economics, vol. 36, no. 1, pp. 1-22.

de Soto, H 1989, The Other Path, Harper \& Row, New York, USA.

de Tournai, H 1996, The Restoration of the Monastery of Saint Martin of Tournai, translated by LH Nelson, Catholic University of America Press, Washington DC, USA.

de Vroey, M 2003, 'Perfect Information à la Walras versus perfect information à la Marshall', Journal of Economic Methodology, vol. 10, no. 4, pp. 465-92. 
Deephouse, DL 2000, 'Media Reputation as a Strategic Resource: An Integration of Mass Communication and Resource-Based Theories', Journal of Management, vol. 26, no. 6, pp. 1091-112.

Deitz, A and McLeod, C 2007, 'Anti-Money Laundering and Counter-Terrorism Financing Act 2006', Australian Insolvency Journal, vol. 19, no. 3, pp. 18-23.

Dellarocas, C 2006, 'Reputation Mechanisms', in T Hendershott (ed), Economics and Information Systems, Emerald, Bingley, UK, pp. 629-660.

DellaVigna, S, List, JA and Malmendier, U 2012, 'Testing for Altruism and Social Pressure in Charitable Giving', The Quarterly Journal of Economics, vol. 127, no. 1, pp. 1-56.

DellaVigna, S, List, JA, Malmendier, U and Rao, G 2017, 'Voting to Tell Others', The Review of Economic Studies, vol. 84, no. 1, pp. 143-81.

Delpit, L 2006, Other People's Children: Cultural Conflict in the Classroom, New Press, New York, USA.

Dembe, AE and Boden, LI 2000, 'Moral Hazard: A Question of Morality?', New Solutions: A Journal of Environmental and Occupational Health Policy, vol. 10, no. 3, pp. 257-79.

Demougin, D and Helm, C 2006, 'Moral Hazard and Bargaining Power', German Economic Review, vol. 7, no. 4, pp. 463-70.

Demsetz, H 1964, 'The Exchange and Enforcement of Property Rights', The Journal of Law and Economics, vol. 7, pp. 11-26.

---- 1967, 'Toward a Theory of Property Rights', The American Economic Review, vol. 57, no. 2, pp. 347-59.

---- 1988, 'The Theory of the Firm Revisited', Journal of Law, Economics, \& Organization, vol. 4, no. 1 , pp. 141-61.

Demski, J and Sappington, D 1991, 'Resolving Double Moral Hazard Problems with Buyout Agreements', The RAND Journal of Economics, vol. 22, no. 2, pp. 232-40.

den Haan, WJ, Ramey, G and Watson, J 2003, 'Liquidity Flows and Fragility of Business Enterprises', Journal of Monetary Economics, vol. 50, no. 6, pp. 1215-41.

DeStefano, A 2008, King of the Godfathers: Joseph Massino and the Fall of the Bonanno Crime, Citadel Press, New York, NY, USA.

DeVries, K 1997, 'Catapults Are Not Atomic Bombs: Towards a Redefinition of Effectiveness' in Premodern Military Technology', War in History, vol. 4, no. 4, pp. 454-70.

Diab, RS 2017, 'Becoming-Infrastructure: Datafication, Deactivation, and the Social Credit System', Journal of Critical Library and Information Studies, vol. 1, no. 1, pp. 1-23. 
Diamond, DW 1984, 'Financial Intermediation and Delegated Monitoring', The Review of Economic Studies, vol. 51, no. 3, pp. 393-414.

Dikötter, F 2010, Mao's Great Famine: The History of China's Most Devastating Catastrophe, 1958-62, Bloomsbury, London, UK.

Dillard, JF 2003, 'Professional Services, IBM, and the Holocaust', Journal of Information Systems, vol. 17, no. 2, pp. 1-16.

Dinello, N 1999, 'The Russian F-Connection: Finance, Firms, Friends, Families, and Favorites', Problems of Post-Communism, vol. 46, no. 1, pp. 24-33.

Dion, KL 1983, 'Names, Identity, and Self', Names, vol. 31, no. 4, pp. 245-57.

Diplock, K 1946, 'Passports and Protection in International Law', Transactions of the Grotius Society, vol. 32, pp. 42-59.

Dixit, AK 1999, 'Mancur Olson-Social Scientist', The Economic Journal, vol. 109, no. 456, pp. 443-452.

---- 2011, Lawlessness and Economics: Alternative Modes of Governance, Princeton University Press, Princeton, USA.

Djankov, S, McLiesh, C and Shleifer, A 2007, 'Private Credit in 129 Countries', Journal of Financial Economics, vol. 84, no. 2, pp. 299-329.

Dodds, WB, Monroe, KB and Grewal, D 1991, 'Effects of Price, Brand, and Store Information on Buyers' Product Evaluations', Journal of Marketing Research, vol. 28, no. 3, pp. 307-19.

Doherty, NA and Thistle, PD 1996, 'Adverse Selection with Endogenous Information in Insurance Markets', Journal of Public Economics, vol. 63, no. 1, pp. 83-102.

Doiron, DJ 1995, 'Lay-Offs as Signals: The Canadian Evidence', Canadian Journal of Economics', vol. 28, no. 4, pp. 899-913

Doleac, JL and Stein, LCD 2013, 'The Visible Hand: Race and Online Market Outcomes', The Economic Journal, vol. 123, no. 572, pp. F469-F492.

Dollery, B and Leong, WH 1998, 'Measuring the Transaction Sector in the Australian Economy, 1911-1991', Australian Economic History Review, vol. 38, no. 3, pp. 20731.

Douglas, DC and Greenaway, GW 1996, English Historical Documents, 1042-1189, Routledge, Abingdon, UK.

Douglas, DC 1943, 'Companions of the Conqueror', History, vol. 28, no. 108, pp. 129-47. 
Doulman, J and Lee, D 2008, Every Assistance \& Protection: A History of the Australian Passport, Federation Press, Alexandria, Australia.

Douthat, R 2019, 'The Only Answer Is Less Internet', The New York Times, 13 April 2019.

Dowty, A 1989, Closed Borders: The Contemporary Assault on Freedom of Movement, Yale University Press, London, UK.

Drinhausen J and Brussee, V 2021, 'China's Social Credit System in 2021: From Fragmentation Towards Integration', MERICS China Monitor, March 32021.

Dulleck, U and Kerschbamer, R 2006, 'On Doctors, Mechanics, and Computer Specialists: The Economics of Credence Goods', Journal of Economic literature, vol. 44, no. 1, pp. 542.

Dulleck, U, Kerschbamer, R and Sutter, M 2011, 'The Economics of Credence Goods: On the Role of Liability, Verifiability, Reputation and Competition', The American Economic Review, vol. 101, no. 2, pp. 526-55.

Dunbar, RIM 1992, 'Neocortex Size as a Constraint on Group Size in Primates', Journal of Human Evolution, vol. 22, no. 6, pp. 469-93.

Duncan-Jones, R 1982, The Economy of the Roman Empire, Cambridge University Press, Cambridge, UK.

Durner, T and Shetret, L 2015, 'Understanding Bank De-Risking and its Effects on Financial Inclusion: An exploratory study', Global Center on Cooperative Security and Oxfam. <https://www-cdn.oxfam.org/s3fs-public/file_attachments/rr-bank-de-risking181115-en_0.pdf>

Dwyer, RF, Schurr, PH and Oh, S 1987, 'Developing Buyer-Seller Relationships', Journal of Marketing, vol. 51, no. 2, pp. 11-27.

Dymski, GA 1995, 'The Theory of Bank Redlining and Discrimination: An Exploration', The Review of Black Political Economy, vol. 23, no. 3, pp. 37-74.

---- 2006, 'Disrimination in the Credit and Housing Markets: Findings and Challenges', in WM Rodgers (ed), Handbook on the Economics of Discrimination, Edward Elgar, Cheltenham, UK, pp. 215-59.

Eades, K 1982, 'Empirical Evidence on Dividends as a Signal of Firm Value', Journal of Financial and Quantitative Analysis, vol. 17, no. 4, pp. 471-500.

Easterly, W and Levine, R 1997, 'Africa's Growth Tragedy: Policies and Ethnic Divisions', The Quarterly Journal of Economics, vol. 112, no. 4, pp. 1203-50.

Echavarren, A 2013, 'The Emergence of a Novel Onomastic Pattern: Cognomen+ Nomen in Seneca the Elder', The Classical Quarterly, vol. 63, no. 1, pp. 353-60. 
Eckel, CC and Grossman, PJ 2005, 'Managing Diversity by Creating Team Identity', Journal of Economic Behavior \& Organization, vol. 58, no. 3, pp. 371-92.

Edwards, J and Ogilvie, S 2012a, 'Contract Enforcement, Institutions, and Social Capital: The Maghribi Traders Reappraised', Economic History Review, vol. 65, no. 2, pp. 421-44.

---- 2012b, 'What Lessons for Economic Development Can we Draw from the Champagne Fairs?', Explorations in Economic History, vol. 49, no. 2, pp. 131-48.

Edwards, R and Caballero, C 2008, 'What's in a Name? An Exploration of the Significance of Personal Naming of 'Mixed' Children for Parents from Different Racial, Ethnic and Faith Backgrounds', The Sociological Review, vol. 56, no. 1, pp. 39-60.

Eggertsson, T 1990, Economic Behavior and Institutions: Principles of Neoinstitutional Economics, Cambridge University Press, Cambridge, UK.

Egorov, G, Guriev, S and Sonin, K 2009, 'Why Resource-poor Dictators Allow Freer Media: A Theory and Evidence from Panel Data', American Political Science Review, vol. 103, no. 4, pp. 645-68.

Ehrlich, I and Becker, G 1972, 'Market Insurance, Self-Insurance, and Self-Protection', Journal of Political Economy, vol. 80, no. 4, pp. 623-48.

Einav, L and Finkelstein, A 2018, 'Moral Hazard in Health Insurance: What We Know and How We Know It', Journal of the European Economic Association, vol. 16, no. 4, pp. 957-82.

Einav, L, Finkelstein, A and Levin, J 2010, 'Beyond Testing: Empirical Models of Insurance Markets', Annual Review of Economics, vol. 2, no. 1, pp. 311-36.

Einav, L, Finkelstein, A, Ryan, SP, Schrimpf, P and Cullen, MR 2013, 'Selection on Moral Hazard in Health Insurance', The American Economic Review, vol. 103, no. 1, pp. 178-219.

Eisenhardt, KM 1989, 'Agency Theory: An Assessment and Review', The Academy of Management Review, vol. 14, no. 1, pp. 57-74.

Elias, N 2001, Society of Individuals, Bloomsbury Publishing, London, UK.

Eliason, M, Johansson, P and Nilsson, M 2019, 'Forward-Looking Moral Hazard in Social Insurance', Labour Economics, vol. 60, pp. 84-98.

Eliot, CWJ 1955, 'New Evidence for the Speed of the Roman Imperial Post', Phoenix, vol. 9, no. 2 , pp. 76-80.

Ellemers, N and Haslam, S 2012, 'Social Identity Theory', in P Van Lange, A Kruglanski \& E Higgins (eds), Handbook of Theories of Social Psychology, SAGE, Thousand Oaks, CA, USA, pp. 379-98. 
Ellickson, RC 1985, 'Of Coase and Cattle: Dispute Resolution Among Neighbors in Shasta County', Stan. L. Rev, vol. 38, pp. 623-87.

Elton, GR 1976, England 1200-1640, Cambridge University Press, Cambridge, UK.

Emens, EF 2007, 'Changing Name Changing: Framing Rules and the Future of Marital Names', U. Chi. L. Rev, vol. 74, no. 3, pp. 761-863.

Emons, W 1997, 'Credence Goods and Fraudulent Experts', The RAND Journal of Economics, vol. 28 , no. 1 , pp. 107-19.

Emons, W and Sheldon, G 2009 'The Market for Used Cars: New Evidence of the Lemons Phenomenon', Applied Economics, vol. 41, no. 22, pp. 2867-85.

Engelmann, D and Fischbacher, U 2009, 'Indirect Reciprocity and Strategic Reputation Building in an Experimental Helping Game', Games and Economic Behavior, vol. 67, no. 2, pp. 399-407.

Ensminger, J 1997, 'Transaction Costs and Islam: Explaining Conversion in Africa', Journal of Institutional and Theoretical Economics (JITE)/Zeitschrift für die gesamte Staatswissenschaft, vol. 153, no. 1, pp. 4-29.

Erdem, T, Katz, M and Sun, B 2010, 'A Simple Test for Distinguishing Between Internal Reference Price Theories', Quantitative Marketing and Economics, vol. 8, no. 3, pp. 303-32.

Erdem, T and Swait, J 1998, 'Brand Equity as a Signaling Phenomenon', Journal of Consumer Psychology, vol. 7, no. 2, pp. 131-57.

Erikson, EH 1968, Identity: Youth, and Crisis, WW Norton, New York, NY, USA.

Esteban, JM and Ray, D 1994, 'On the Measurement of Polarization', Econometrica, vol. 62, no. 4 , pp. 819-51.

Ewen, CLE 1931, A History of Surnames of the British Isles: A Concise Account of Their Origin, Evolution, Etymology, and Legal Status, K Paul, Trench, Trubner \& Company, London, UK.

Fafchamps, M 2000, 'Ethnicity and Credit in African Manufacturing', Journal of Development Economics, vol. 61, no. 1, pp. 205-35.

---- 2003, Market Institutions in Sub-Saharan Africa: Theory and Evidence, MIT Press, Cambridge, MA, USA.

Fahrmeir, A 2001, 'Governments and Forgers: Nineteenth-Century Europe', in J Caplan \& J Torpey (eds), Documenting Individual Identity, Princeton University Press, Princeton, NJ, USA, pp. 218-34. 
Fallan, L 2000, 'Understanding Governance Structures of Accounting: Trust Relationships, Transaction Costs, and the Make-or-Buy Decision', Journal of Applied Accounting Research, vol. 6, no. 1, pp. 52-84.

Fan, CC 2001, 'Migration and Labor-Market Returns in Urban China: Results From a Recent Survey in Guangzhou', Environment and Planning A, vol. 33, no. 3, pp. 479-508.

Fan, Y, Ju, J and Xiao, M 2016, 'Reputation Premium and Reputation Management: Evidence From the Largest e-Commerce Platform in China', International Journal of Industrial Organization, vol. 46, pp. 63-76.

Fan, Y, Kühn, KU and Lafontaine, F 2017, 'Financial Constraints and Moral Hazard: The Case of Franchising', Journal of Political Economy, vol. 125, no. 6, pp. 2082-125.

Farhi, E and Tirole, J 2012, 'Collective Moral Hazard, Maturity Mismatch, and Systemic Bailouts', The American Economic Review, vol. 102, no. 1, pp. 60-93.

Ferguson, MF and Peters, SR 1997, 'Cultural Affinity and Lending Discrimination: The Impact of Underwriting Errors and Credit Risk Distribution on Applicant Denial Rates', Journal of Financial Services Research, vol. 11, no. 1-2, pp. 153-68.

Ferreira, AFF, Santos, PS, Marques, SEC and Ferreira, J 2014, 'Assessing Credit Risk of Mortgage Lending Using MACBETH: A Methodological Framework', Management Decision, vol. 52, no. 2, pp. 182-206.

Ferrer, R 2010, 'Breaking the Law When Others Do: A Model of Law Enforcement with Neighborhood Externalities', European Economic Review, vol. 54, no. 2, pp. 163-80.

Fine, B 2008, 'The Economics of Identity and the Identity of Economics?', Cambridge Journal of Economics, vol. 33, no. 2, pp. 175-91.

Fisher, I 1894, 'The Mechanics of Bimetallism', The Economic Journal, vol. 4, no. 15, pp. 52737.

Flabbi, L 2010, 'Gender Discrimination Estimation in a Search Model with Matching and Bargaining', International Economic Review, vol. 51, no. 3, pp. 745-83.

Flanagan, DJ and O'Shaughnessy, KC 2005, 'The Effect of Layoffs on Firm Reputation', Journal of Management, vol. 31, no. 3, pp. 445-63.

Flannery, MJ 1986, 'Asymmetric Information and Risky Debt Maturity Choice', The Journal of Finance, vol. 41, no. 1, pp. 19-37.

Flinn, CJ 2015, 'Gary Becker's Contributions to the Analysis of Discrimination', Journal of Demographic Economics, vol. 81, no. 1, pp. 45-50.

Folbre, N 1994, Who Pays for the Kids?: Gender and the Structures of Constraint, Taylor \& Francis, Milton Park, UK. 
Fombrun, C and Shanley, M 1990, 'What's in a Name? Reputation Building and Corporate Strategy', Academy of Management Journal, vol. 33, no. 2, pp. 233-58.

Fordham, S and Ogbu, JU 1986, 'Black Students' School Success: Coping with the "Burden of 'Acting white'"', The Urban Review, vol. 18, no. 3, pp. 176-206.

Fotopoulos, C and Krystallis, A 2003, 'Quality Labels as a Marketing Advantage: The Case of the "PDO Zagora" Apples in the Greek Market', European Journal of Marketing, vol. 37, no. 10, pp. 1350-74.

Fox, D 2008, Property Rights in Money, Oxford University Press, Oxford, UK.

Franco, A, Mitchell, M and Vereshchagina, G 2011, 'Incentives and the Structure of Teams', Journal of Economic Theory, vol. 146, no. 6, pp. 2307-32.

Frandina, MM 2009, 'A Man's Right to Choose His Surname in Marriage: A Proposal', Duke J. Gender L. \& Pol'y, vol. 16, pp. 155-68.

Frankfurter, G and Wood, B 2002, 'Dividend Policy Theories and their Empirical Tests', International Review of Financial Analysis, vol. 11, no. 2, pp. 111-38.

Freeman, EA 1876, The History of the Norman Conquest of England: Its Causes and Its Results. Volume V. The Effects of the Norman Conquest, Oxford University Press, Oxford, UK.

Friedman, M and Savage, $\amalg$ 1952, 'The Expected-Utility Hypothesis and the Measurability of Utility', Journal of Political Economy, vol 60, no. 6, pp. 463-74

Friedrich, K and Brzezinski, Z 1965, Totalitarian Dictatorship and Autocracy, Harvard University Press, Cambridge, MA, USA.

Frey, L and Frey, M 1999, The History of Diplomatic Immunity, Ohio State University Press, Columbus, USA.

Fryer Jr, RG 2007, 'Belief Flipping in a Dynamic Model of Statistical Discrimination', Journal of Public Economics, vol. 91, no. 5-6, pp. 1151-66.

Fryer Jr, RG and Levitt, S 2004, 'The Causes and Consequences of Distinctively Black Names', The Quarterly Journal of Economics, vol. 119, no. 3, pp. 767-805.

Fryer Jr, RG and Torelli, P 2010, 'An Empirical Analysis of 'Acting White", Journal of Public Economics, vol. 94, no. 5-6, pp. 380-96.

Funk, P 2010, 'Social Incentives and Voter Turnout: Evidence from the Swiss Mail Ballot System', Journal of the European Economic Association, vol. 8, no. 5, pp. 1077-103.

Galanter, M 1981, 'Justice in Many Rooms: Courts, Private Ordering, and Indigenous Law', The Journal of Legal Pluralism and Unofficial Law, vol. 13, no. 19, pp. 1-47. 
Gambetta, D 1993, The Sicilian Mafia: The Business of Private Protection, Harvard University Press, Cambridge, MA, USA.

---- 2006, 'Trust's Odd Ways', in J Elster, O Gjelsvik, A Hylland \& K Moene (eds), Understanding Choice, Explaining Behaviour: Essays in Honour of Ole-Jørgen Skog, Oslo Academic Press, Oslo, Norway, pp. 81-100.

---- 2011, Codes of the Underworld: How Criminals Communicate, Princeton University Press, Princeton, NJ, USA.

Gans, JS and Sheperd, GB 1994, 'How Are the Mighty Fallen: Rejected Classic Articles by Leading Economists', Journal of Economic Perspectives, vol. 8, no. 1, pp. 165-79.

Gardiner-Garden, J 2003, Defining Aboriginality in Australia, Department of the Parliamentary Library, Canberra, Australia.

Garner, BA 2009, Black's Law Dictionary, 9 ed, Claitors Pub Division, Baton Rouge, USA.

Garnsey, P and Rathbone, D 1985, 'The Background to the Grain Law of Gaius Gracchus', The Journal of Roman Studies, vol. 75, pp. 20-5.

Gayle, GL and Golan, L 2012, 'Estimating a Dynamic Adverse-Selection Model: Labour-Force Experience and the Changing Gender Earnings Gap 1968-1997', The Review of Economic Studies, vol. 79, no. 1, pp. 227-67.

Gely, R 2007, 'The Law and Economics of Identity', Duke J. Gender L. \& Pol'y, vol. 14, no. 1, pp. 229-42.

Genesove, D 1993, 'Adverse Selection in the Wholesale Used Car Market', The Journal of Political Economy, vol. 101, no. 4, pp. 644-65.

Gerber, AS, Green, DP and Larimer, CW 2008, 'Social Pressure and Voter Turnout: Evidence from a Large-Scale Field Experiment', American Political Science Review, vol. 102, no. 1, pp. 33-48.

Gerber, AS, Huber, GA, Doherty, D and Dowling, CM 2016, 'Why People Vote: Estimating the Social Returns to Voting', British Journal of Political Science, vol. 46, no. 2, pp. 24164.

Gerstner, E 1985, 'Do Higher Prices Signal Higher Quality?', Journal of Marketing Research, vol. 22, no. 2, pp. 209-15.

Gersuny, C 1974, 'Occupations, Occupational Surnames and the Development of Society', The Journal of Popular Culture, vol. 8, no. 1, pp. 99-106.

Geselle, A 2001, 'Domenica Saba Takes to the Road: Origins and Development of a Modern Passport System in Lombardy-Veneto', in J Caplan \& J Torpey (eds), Documenting Individual Identity, Princeton University Press, Princeton, NJ, USA, pp. 199-217. 
Gibbons, R and Katz, L 1991, 'Layoffs and Lemons', Journal of Labor Economics, vol. 9, no. 4, pp. 351-80.

Gibbons, R and Waldman, M 1999, 'Race and Gender in the Labor Market', in O Ashenfelter \& D Card (eds), Handbook of Labor economics. Volume 3, Part C, North Holland, Amsterdam, Holland, pp. 3143-259.

Giddens, A 1991, Modernity and Self-identity: Self and Society in the Late Modern Age, Stanford University Press, Palo Alto, CA, USA.

Gil, R and Hartmann, WR 2011, 'Airing Your Dirty Laundry: Vertical Integration, Reputational Capital, and Social Network', Journal of Law, Economics \& Organization, vol. 27, no. 2, pp. 219-44.

Gleason, P 1983, 'Identifying Identity: A Semantic History', Journal of American History, vol. 69 , no. 4, pp. 910-31.

Glover, J 2008, 'Identity, Violence and the Power of Illusion', In Arguments for a Better World: Essays in Honor of Amartya Sen, Volume 2: Society, Institutions, and Development, K Basu \& R Kanbur (eds), Oxford University Press, Oxford, UK, pp. 43651

Goette, L, Huffman, D and Meier, S 2006, 'The Impact of Group Membership on Cooperation and Norm Enforcement: Evidence Using Random Assignment to Real Social Groups', The American Economic Review, vol. 96, no. 2, pp. 212-16.

Goffman, E 1963, Stigma; Notes on the Management of Spoiled Identity, Prentice-Hall, Upper Saddle River, NJ, USA.

Grabo, A, Spisak, B and van Vugt, M 2017, 'Charisma as Signal: An Evolutionary Perspective on Charismatic Leadership', The Leadership Quarterly, vol. 28, no. 4, pp. 473-85.

Granovetter, M 1985, 'Economic Action and Social Structure: The Problem of Embeddedness', American Journal of Sociology, vol. 91, no. 3, pp. 481-510.

Gravel, M 2012, 'Of Palaces, Hunts, and Pork Roast: Deciphering the Last Chapters of the Capitulary of Quierzy (a. 877)', Florilegium, vol. 29, pp. 89-115.

Greenwald, BC 1986, 'Adverse Selection in the Labour Market', The Review of Economic Studies, vol. 53, no. 3, pp. 325-47.

Greer, D 1951, The Incidence of the Emigration During the French Revolution, Harvard University Press, Cambridge, MA, USA.

Greif, A 1989, 'Reputation and Coalitions in Medieval Trade: Evidence on the Maghribi Traders', The Journal of Economic History, vol. 49, no. 4, pp. 857-82. 
---- 1993, 'Contract Enforceability and Economic Institutions in Early Trade: The Maghribi Traders' Coalition', The American Economic Review, vol. 83, no. 3, pp. 525-48.

---- 1994, 'Cultural Beliefs and the Organization of Society: A Historical and Theoretical Reflection on Collectivist and Individualist Societies', Journal of Political Economy, vol. 102, no. 5, pp. 912-50.

---- 2000, 'The Fundamental Problem of Exchange: A Research Agenda in Historical Institutional Analysis', European Review of Economic History, vol. 4, no. 3, pp. 25184.

---- 2005, 'Commitment, Coercion, and Markets: The Nature and Dynamics of Institutions Supporting Exchange', in C Menard \& MM Shirley (eds), Handbook of new institutional economics, Springer, Berlin, Germany, pp. 727-86.

---- 2006, Institutions and the Path to the Modern Economy: Lessons from Medieval Trade, Cambridge University Press, Cambridge, UK.

---- 2012, 'The Maghribi Traders: A Reappraisal?', Economic History Review, vol. 65, no. 2, pp. 445-69.

Greif, A, Milgrom, P and Weingast, BR 1994, 'Coordination, Commitment, and Enforcement: The Case of the Merchant Guild', Journal of Political Economy, vol. 102, no. 4, pp. 745-76.

Groebner, V 2001, 'Describing the Person, Reading the Signs in Late Medieval and Renaissance Europe: Identity Papers, Vested Figures and the Limits of Identitification, 1400-1600', in J Caplan \& J Torpey (eds), Documenting Individual Identity, Princeton University Press, Princeton, NJ, USA, pp. 15-27

Groot, W and Oosterbeek, H 1994, 'Earnings Effects of Different Components of Human Capital vs. Screening', Review of Economics and Statistics, vol. 76, no. 2, pp. 317-21.

Grossman, S and Stiglitz, J 1980, 'On the Impossibility of Informationally Efficient Markets', The American Economic Review, vol. 70, no. 3, pp. 393-408.

Grossman, G and Shapiro, C 1984, 'Informative Advertising with Differentiated Products', The Review of Economic Studies, vol. 51, no. 1, pp. 63-81.

Guasch, JL and Weiss, A 1980, 'Wages as Sorting Mechanisms in Competitive Markets with Asymmetric Information: A Theory of Testing', The Review of Economic Studies, vol. 47, no. 4, pp. 653-64.

Gumusluoglu, L, Karakitapoğlu-Aygün, Z and Scandura, TA 2017, 'A Multilevel Examination of Benevolent Leadership and Innovative Behavior in R\&D Contexts: A Social Identity Approach', Journal of Leadership \& Organizational Studies, vol. 24, no. 4, pp. 479-93. 
Günther, S 2016, 'Taxation in the Greco-Roman World: The Roman Principate', Oxford Handbooks Online.

<https://www.oxfordhandbooks.com/view/10.1093/oxfordhb/9780199935390.001. 0001/oxfordhb-9780199935390-e-38?rskey=RVJJ5o\&result=1>

Gupta, R and Somani, AK 2005, 'Game Theory as a Tool to Strategize as well as Predict Nodes' Behavior in Peer-To-Peer Networks', 11th International Conference on Parallel and Distributed Systems (ICPADS'05), Fukuoka, 2005, pp. 244-49.

Guryan, J and Charles, KK 2013, 'Taste-Based or Statistical Discrimination: The Economics of Discrimination Returns to its Roots', The Economic Journal, vol. 123, no. 572, pp. F417-32.

Gutmann, A 2009, Identity in Democracy, Princeton University Press, Princeton, NJ, USA.

Hall, C and Hartman, L 2010, 'Moral Hazard Among the Sick and Unemployed: Evidence from a Swedish Social Insurance Insurance Reform', Empirical Economics, vol. 39, no. 1, pp. 27-50.

Hametz, ME 2002, “To Have What Was Mine": Reclaiming Surnames in Trieste', Names, vol. 50 , no. 1, pp. 3-22.

Han, E 2010, 'Boundaries, Discrimination, and Interethnic Conflict in Xinjiang, China', International Journal of Conflict and Violenc (IJCV), vol. 4, no. 2, pp. 244-56.

Han, S 2004, 'Discrimination in Lending: Theory and Evidence', The Journal of Real Estate Finance and Economics, vol. 29, no. 1, pp. 5-46.

Handel, B 2013, 'Adverse Selection and Inertia in Health Insurance Markets: When Nudging Hurts', The American Economic Review, vol. 103, no. 7, pp. 2643-82.

Harvey, S 2014, Domesday: Book of Judgement, Oxford University Press, Oxford, UK.

Harvey, S 1970, 'The Knight and the Knight's Fee in England' Past \& Present, vol. 49, pp. 343.

Haslam, SA 2004, Psychology in Organizations, SAGE, Thousand Oaks, CA, USA.

Haughton, J and Sun, W 2018, 'Discrimination Against Migrants in Urban Vietnam', International Advances in Economic Research, vol. 24, no. 3, pp. 211-32.

Hausman, DM 2005, 'Sympathy, Commitment, and Preference', Economics \& Philosophy, vol. 21, no. 1, pp. 33-50.

Hayek, FA 1945, 'The Use of Knowledge in Society', The American Economic Review, vol. 35, no. 4, pp. 519-30. 
---- 1948, 'The Meaning of Competition', in FA Hayek, Individualism and Economic Order, Routledge, London, UK, pp. 92-106.

---- 1973, Law, Legislation and Liberty: Vol. 1. Rules \& Order, University of Chicago Press, Chicago, USA.

---- 1976, The Denationalisation of Money: The Argument Refined, Institute of Economic Affairs, London, UK.

Haynes, J. 'Risk as an Economic Factor', Quarterly Journal of Economics, vol. 9, no. 4, pp. 40949.

Heffetz, O 2011, 'A Test of Conspicuous Consumption: Visibility and Income Elasticities', Review of Economics and Statistics, vol. 93, no. 4, pp. 1101-17.

Hellmann, T and Stiglitz, J 2000, 'Credit and Equity Rationing in Markets with Adverse Selection', European Economic Review, vol. 44, no. 2, pp. 281-304.

Hellmann, T, Murdock K and Stiglitz, J 2000, 'Liberalization, Moral Hazard in Banking, and Prudential Regulation: Are Capital Requirements Enough?', The American Economic Review, vol. 90, no. 1, pp. 147-65.

Hennart, JF and Reddy, SB 2000, 'Digestibility and Asymmetric Information in the Choice Between Acquisitions and Joint Ventures: Where's the Beef?', Strategic Management Journal, vol. 21, no. 2, pp. 191-3.

Hertzberg, A, Liberman, A and Paravisini, D 2018, 'Screening on Loan Terms: Evidence from Maturity Choice in Consumer Credit', The Review of Financial Studies, vol. 31, no. 9, pp. 3532-67.

Heywood, JS and Wei, X 2004, 'Education and Signaling: Evidence from a Highly Competitive Labor Market', Education Economics, vol. 12, no. 1, pp. 1-16.

Higgs, E 2003, The Information State in England: The Central Collection of Information on Citizens since 1500, Palgrave Macmillan, London, UK.

---- 2004, Life, Death and Statistics: Civil Registration, Censuses and the Work of the General Register Office, 1836-1952, University of Hertfordshire Press, Hatfield, UK.

Hill, RA, and Dunbar, RIM 2003, 'Social Network Size in Humans', Human Nature, vol. 14, no. 1, pp. 53-72.

Hin, S, Conde, DA and Lenart, A 2016, 'New Light on Roman Census Papyri Through SemiAutomated Record Linkage', Historical Methods: A Journal of Quantitative and Interdisciplinary History, vol. 49, no. 1, pp. 50-65.

Hindmoor, A, and Taylor, B 2015, Rational Choice, Macmillan Education, Basingstoke, UK. 
Hirschman, AO 1970, Exit, Voice, and Loyalty: Responses to Decline in Firms, Organizations, and States, Harvard University Press, Cambridge, MA, USA.

Hoch, SJ, and Ha, YW 1986, 'Consumer Learning: Advertising and the Ambiguity of Product Experience', Journal of Consumer Research, vol. 13, no. 2, pp. 221-33.

Hodson, H 2015, 'Inside China's Plan to Give Every Citizen a Character Score', New Scientist, 9 October 2015.

Hoffer, GE and Pratt, MD 1987, 'Used Vehicles, Lemons Markets, and Used Car Rules: Some Empirical Evidence', Journal of Consumer Policy, vol. 10, no. 4, pp. 409-14.

Hoffman, PT 2012, 'Why was it Europeans who Conquered the World?', The Journal of Economic History, vol. 72, no. 3, pp. 601-33.

Hogg, MA and Ridgeway, CL 2003, 'Social Identity: Sociological and Social Psychological Perspectives', Social Psychology Quarterly, vol. 66, no. 2, pp. 97-100.

Hogg, MA, Terry, DJ and White, KM 1995, 'A Tale of Two Theories: A Critical Comparison of Identity Theory with Social Identity Theory', Social Psychology Quarterly, vol. 58, no. 4, pp. 255-69.

Hölmstrom, B 1979, 'Moral Hazard and Observability', The Bell Journal of Economics, vol. 10, no. 1 , pp. 324-40.

---- 1982, 'Moral Hazard in Teams', The Bell Journal of Economics, vol. 13, no. 2, pp. 74-91.

Holt, JC 1972, 'Politics and Property in Early Medieval England', Past \& Present, vol. 57, pp. 3-52.

Horowitz, JK and Lichtenberg, E 1993, 'Insurance, Moral Hazard, and Chemical Use in Agriculture', American Journal of Agricultural Economics, vol. 75, no. 4, pp. 926-35.

Horstmann, I and MacDonald, G 1994, 'When is Advertising a Signal of Product Quality?', Journal of Economics and Management Strategy, vol. 3, no. 3, pp. 561-84.

Hsu, CY 2012, China: A New Cultural History, translated by TD Baker and M Duke, Columbia University Press, New York, USA.

Huang, Y 2001, 'Gender, Hukou, and the Occupational Attainment of Female Migrants in China (1985-1990)', Environment and Planning A, vol. 33, no. 2, pp. 257-79.

Hudson, J 2012, The Oxford History of the Laws of England Volume II: 871-1216, Oxford University Press, Oxford, UK.

Hudson, J 2000, 'Court Cases and Legal Arguments in England, c. 1066-1166', Transactions of the Royal Historical Society, vol. 10, pp. 91-115. 
Hughes, CJP 1959, How You Got Your Name, Phoenix House, London, UK.

Huntington, SP 1993, 'The Clash of Civilizations?', Foreign Affairs vol. 72, no. 3, pp. 22-49.

---- 1996, The Clash of Civilizations and the Remaking of World Order, Simon \& Schuster, New York, NY, USA.

Hupkau, C and Maniquet, F 2018, 'Identity, Non-Take-Up and Welfare Conditionality', Journal of Economic Behavior \& Organization, vol. 147, pp. 13-27.

Huscroft, R 2005, Ruling England, 1042-1217, Pearson/Longman, London, UK.

lannaccone, L 1992, 'Sacrifice and Stigma: Reducing Free-riding in Cults, Communes, and Other Collectives', The Journal of Political Economy, vol. 100, no. 2, pp. 271-91.

---- 1998, 'Introduction to the Economics of Religion', Journal of Economic Literature, vol. 36, no. 3, pp. 1465-95.

Ihlanfeldt, KR and Scafidi, B 2002, 'Black Self-Segregation as a Cause of Housing Segregation: Evidence from the Multi-City Study of Urban Inequality', Journal of Urban Economics, vol. 51 , no. 2 , pp. $366-90$.

Jackson, CK and Schneider, HS 2011, 'Do Social Connections Reduce Moral Hazard? Evidence from the New York City Taxi Industry', American Economic Journal: Applied Economics, vol. 3, no. 3, pp. 244-67.

Jackson, MO, Rodriguez-Barraquer, T and Tan, X 2012, 'Social Capital and Social Quilts: Network Patterns of Favor Exchange', The American Economic Review, vol. 102, no. 5, pp. 1857-97.

Jackson, O 2018, 'PSD2 Gives Banks Chance to Evolve', International Financial Law Review, 26 January 2018.

Jaikumar, S, Singh, R and Sarin, A 2018, "I Show Off, So I Am Well Off': Subjective Economic Well-Being and Conspicuous Consumption in an Emerging Economy', Journal of Business Research, vol. 86, pp. 386-393.

Jansen, MM and Delahaij, R 2019, 'Leadership Acceptance Through the Lens of Social Identity Theory: A Case Study of Military Leadership in Afghanistan', Armed Forces \& Society, 2May 2019.

Janssen, M and Roy, S 2010, 'Signaling Quality Through Prices in an Oligopoly', Games and Economic Behavior, vol. 68, no. 1, pp. 192-207.

Jappelli, T and Pagano M 2000, 'Information Sharing in Credit Markets: The European Experience', Centre for Studies in Economics and Finance: Working Paper, no. 35, pp. 1-51. 
---- 2002, 'Information Sharing, Lending and Defaults: Cross-country Evidence', Journal of Banking \& Finance, vol. 26, no. 10, pp. 2017-45.

Jaramillo, JJ and Srikant, R 2010, 'A Game Theory Based Reputation Mechanism to Incentivize Cooperation in Wireless ad hoc Networks', Ad Hoc Networks, vol. 8, no. 4, pp. 416-29.

Jensen, M and Meckling, W 1976, 'Theory of the Firm: Managerial Behaviour, Agency Costs, and Ownership Structure', Journal of Financial Economics, vol. 3, no. 4, pp. 305-60.

Jeon, S 1996, 'Moral Hazard and Reputational Concerns in Teams: Implications for Organizational Choice', International Journal of Industrial Organization, vol. 14, no. 3, pp. 297-315.

Jisheng, Y 2012, Tombstone: The Great Chinese Famine, 1958-1962, translated by S Mosher \& J Guo, Farrar, Straus and Giroux, New York, NY, USA.

Johansson, P and Palme, M 2005, 'Moral Hazard and Sickness Insurance', Journal of Public Economics, vol. 89, no. 9, pp. 1879-90.

John, K and Williams, J 1985, 'Dividends, Dilution, and Taxes: A Signalling Equilibrium', The Journal of Finance, vol. 40, no. 4, pp. 1053-70.

Johnson Jr, JH, Bienenstock, EJ and Stoloff, JA 1995, 'An Empirical Test of the Cultural Capital Hypothesis', The Review of Black Political Economy, vol. 23, no. 4, pp. 7-27.

Johnson, JP and Waldman, M 2010, 'Leasing, Lemons, and Moral Hazard', The Journal of Law and Economics, vol. 53, no. 2, pp. 307-28.

Jolivet, G, Jullien, B and Postel-Vinay, F 2016, 'Reputation and Prices on the e-Market: Evidence from a Major French Platform', International Journal of Industrial Organization, vol. 45, pp. 59-75.

Jones, MJ 2018, 'Domesday Book: An Early Fiscal, Accounting Narrative?', The British Accounting Review, vol. 50, no. 3, pp. 275-90.

Jourard, SM 1966, 'Some Psychological Aspects of Privacy', Law \& Contemp. Probs, vol. 31, pp. 307-18.

Jowell, R and Prescott-Clarke, P 1970, 'Racial Discrimination and White-Collar Workers in Britain', Race, vol. 11, no. 4, pp. 397-417.

Kaas, L and Manger, C 2012, 'Ethnic Discrimination in Germany's Labour Market: A Field Experiment', German Economic Review, vol. 13, no. 1, pp. 1-20.

Kachwamba, M and Sæb $\varnothing, \varnothing$ 2011, 'E-Government in Marketing a Country: A Strategy for Reducing Transaction Cost of Doing Business in Tanzania', International Journal of Marketing Studies, vol. 3, no. 4, pp. 2-16. 
Kadens, E 2004, 'Order within Law, Variety within Custom: The Character of the Medieval Merchant Law', Chi. J. Int'll, vol. 5, no. 1, pp. 39-65.

Kahn, LM 1991, 'Customer Discrimination and Affirmative Action', Economic Inquiry, vol. 29, no. 3, pp. 555-71.

Kaltman, B 2014, Under the Heel of the Dragon: Islam, Racism, Crime, and the Uighur in China, Ohio University Press, Athens, USA.

Kandori, M 1992, 'Social Norms and Community Enforcement', Review of Economics Studies, vol. 59, no. 1 , pp. 63-80.

Kapor, A, Neilson, C and Zimmerman, SD 2018, 'Heterogeneous Beliefs and School Choice Mechanisms', American Economic Review, vol. 110, no. 5, pp. 1274-1315.

Karis, T 2013, 'Unofficial Hanoians: Migration, Native Place and Urban Citizenship in Vietnam', The Asia Pacific Journal of Anthropology, vol. 14, no. 3, pp. 256-73.

Kaus, W 2013, 'Conspicuous Consumption and "Race": Evidence from South Africa', Journal of Development Economics, vol. 100, no. 1, pp. 63-73.

Keech, WR, Munger, MC and Simon, C 2012, 'Market Failure and Government Failure', Paper submitted for presentation to Public Choice World Congress, Miami, USA.

Keener, CS 2015, Acts: An Exegetical Commentary : Volume 4: 24:1-28:31, Baker Publishing Group, Grand Rapids, USA.

Kemp, T 2006, 'Of Transactions and Transaction Costs: Uncertainty, Policy, and the Process of Law in the Thought of Commons and Williamson', Journal of Economic Issues, vol. 40 , no. 1 , pp. 45-58.

Kershaw, I 2008, Hitler, the Germans, and the Final Solution, Yale University Press, New Haven, USA.

Kihlstrom, RE and Riordan, MH 1984, 'Advertising as a Signal', Journal of Political Economy, vol. 92, no. 3, pp. 472-85.

Killgrove, K 2010, 'Migration and Mobility in Imperial Rome', Doctoral Thesis, Department of Anthropology, University of North Carolina at Chapel Hill, USA.

Kim, JC 1985, 'The Market for "Lemons" Reconsidered: A Model of the Used Car Market with Asymmetric Information', The American Economic Review, vol. 75, no. 4, pp. 836-43.

King, AT and Mieszkowski, P 1973, 'Racial Discrimination, Segregation, and the Price of Housing', Journal of Political Economy, vol. 81, no. 3. pp. 590-606. 
Kinnan, C and Townsend, R 2012, 'Kinship and Financial Networks, Formal Financial Access, and Risk Reduction', The American Economic Review, vol. 102, no. 3, pp. 289-93.

Kippen, R 2002, 'An Indispensable Duty of Government: Civil Registration in NineteenthCentury Tasmania', Tasmanian Historical Studies, vol. 8, no. 1, pp. 42-58.

Kirman, A and Teschl, M 2006, 'Searching for Identity in the Capability Space', Journal of Economic Methodology, vol. 13, no. 3, pp. 299-325.

Klandermans, PG 2014, 'Identity Politics and Politicized Identities: Identity Processes and the Dynamics of Protest', Political Psychology, vol. 35, no. 1, pp. 1-22.

Klein, B 1980, 'Transaction Cost Determinants of 'Unfair' Contractual Arrangements', The American Economic Review, vol. 70, no. 2, pp. 356-62.

Klein, B, Crawford, RG and Alchian, AA 1978, 'Vertical Integration, Appropriable Rents, and the Competitive Contracting Process', The Journal of Law and Economics, vol. 21, no. 2, pp. 297-326.

Klein, B and Leffler, KB 1981, 'The Role of Market Forces in Assuring Contractual Performance', Journal of Political Economy, vol. 89, no. 4, pp. 615-41.

Klein, B and Saft, LF 1985, 'The Law and Economics of Franchise Tying Contracts', The Journal of Law and Economics, vol. 28, no. 2, pp. 345-61.

Klein, DB 1992, 'Promise Keeping in the Great Society: A Model of Credit Information Sharing', Economics \& Politics, vol. 4, no. 2, pp. 117-36.

---- 1997a, 'Knowledge, Reputation, and Trust, by Voluntary Means', in Reputation: Studies in the Voluntary Elicitation of Good Conduct, DB Klein (ed), The University of Michigan Press, Ann Arbor, USA, pp. 1-14.

---- (ed), 1997b, Reputation: Studies in the Voluntary Elicitation of Good Conduct. The University of Michigan Press, Ann Arbor, USA.

---- 1997c, 'Trust for Hire: Voluntary remedies for quality and safety', in Reputation: Studies in the Voluntary Elicitation of Good Conduct, DB Klein (ed), The University of Michigan Press, Ann Arbor, USA, pp. 97-133.

Knowles, J, Persico, N and Todd, P 2001, 'Racial Bias in Motor Vehicle Searches: Theory and Evidence', Journal of Political Economy, vol. 109, no. 1, pp. 203-29.

Kobie, N 2019, 'The Complicated Truth about China's Social Credit System', Wired, 7 June 2019.

Kopecky, K and VanHoose, D 2006, 'Capital Regulation, Heterogeneous Monitoring Costs, and Aggregate Loan Quality', Journal of Banking and Finance, vol. 30, no. 8, pp. 2235-55. 
Kosfeld, M and Neckermann, S 2011, 'Getting More Work for Nothing? Symbolic Awards and Worker Performance', American Economic Journal: Microeconomics, vol. 3, no. 3, pp. 86-99.

Kotowitz, Y and Mathewson, F 1979, 'Advertising, Consumer Information, and Product Quality', The Bell Journal of Economics, vol. 10, no. 2, pp. 566-88.

Krashinsky, H 2002, 'Evidence on Adverse Selection and Establishment Size in the Labor Market', Industrial \& Labor Relations Review, vol. 56, no. 1, pp. 84-96.

Balakrishnan, S and Koza, MP 1993, 'Information Asymmetry, Adverse Selection and JointVentures: Theory and Evidence', Journal of Economic Behavior \& Organization, vol. 20, no. 1, pp. 99-117.

Kreps, DM and Wilson, R 1982, 'Reputation and Imperfect Information', Journal of Economic Theory, vol. 27, no. 2, pp. 253-79.

Krueger, A and Meyer, B 2002, 'Labor Supply Effects of Social Insurance', in A Auerbach \& M Feldstein (eds), Handbook of Public Economics Vol 4. North-Holland, Amsterdam, Holland, pp. 2327-92.

Kübler, D, Müller, W and Normann, HT 2008, 'Job-Market Signaling and Screening: An Experimental Comparison', Games and Economic Behaviour, vol. 64, no. 1, pp. 21936.

Kuiper, K 2011, Ancient Rome: From Romulus and Remus to the Visigoth Invasion, Britannica Educational Publishing, New York, NY, USA.

Kulkarni, SP, and Heriot, KC 1999, 'Transaction Costs and Information Costs as Determinants of the Organizational Form: A Conceptual Synthesis', American Business Review, vol. 17 , no. 2, pp. 43-52.

Kumar, S, and Park, JC 2012, 'Partner Characteristics, Information Asymmetry, and the Signaling Effects of Joint Ventures', Managerial and Decision Economics, vol. 33, no. 2, pp. 127-45.

Laband, DN 1991, 'An Objective Measure of Search Versus Experience Goods', Economic Inquiry, vol. 29, no. 3, pp. 497-509.

Laffont, JL and Matoussi, MS 1995, 'Moral Hazard, Financial Constraints and Sharecropping in El Oulja', The Review of Economic Studies, vol. 62, no. 3, pp. 381-99.

Lafontaine, F 1992, 'Agency Theory and Franchising: Some Empirical Results', The RAND Journal of Economics, vol. 23, no. 2, pp. 263-83.

Lancaster, KJ 1966, 'A New Approach to Consumer Theory', Journal of Political Economy, vol. 74, no. 1, pp. 132-57. 
---- 1971, Consumer Demand: A New Approach, Columbia University Press, New York, USA.

Landa, JT 1981, 'A Theory of the Ethnically Homogeneous Middleman Group: An Institutional Alternative to Contract Law', The Journal of Legal Studies, vol. 10, no. 2, pp. 349-62.

---- 1994, Trust, Ethnicity, and Identity: Beyond the New Institutional Economics of Ethnic Trading Networks, Contract Law, and Gift-Exchange, University of Michigan Press, Michigan, USA.

---- 2016a, 'Cognitive and Classificatory Foundations of Trust and Informal Institutions: A New and Expanded Theory of Ethnic Trading Networks', in JT Landa (ed), Economic Success of Chinese Merchants in Southeast Asia, Springer, Berlin, Germany, pp. 17389.

---- 2016b, 'The Role of Culture and Institutions in Promoting Middleman-Entrepreneurship in Less Developed Economies', in JT Landa (ed), Economic Success of Chinese Merchants in Southeast Asia, Springer, Berlin, Germany, pp. 191-213.

Landa, JT and Salaff, JW 2016, 'The Socio-Economic Functions of Kinship and Ethnic Ties in the Establishment and Growth of the Tan Kah Kee Family Firm in Singapore: A Transaction Costs Approach', in JT Landa (ed), Economic Success of Chinese Merchants in Southeast Asia, Springer, Berlin, Germany, pp. 249-276.

Landon, S and Smith, CE 1997, 'The Use of Quality and Reputation Indicators by Consumers: The Case of Bordeaux Wine', Journal of Consumer Policy, vol. 20, no. 3, pp. 289-323.

Lane, FC 1958, 'Economic Consequences of Organized Violence', The Journal of Economic History, vol. 18, no. 4, pp. 401-17.

Lang, K and Lehmann, JYK 2012, 'Racial Discrimination in the Labor Market: Theory and Empirics', Journal of Economic Literature, vol. 50, no. 4, pp. 959-1006.

Lardy, NR 1983, Agriculture in China's Modern Economic Development, Cambridge University Press, Cambridge, UK.

Lavan, M 2016, 'The Spread of Roman Citizenship, 14-212 ce: Quantification in the Face of High Uncertainty', Past \& Present, vol. 230, no. 1, pp. 3-46.

Law, M and Kim, S 2005, 'Specialization and Regulation: The Rise of Professionals and the Emergence of Occupational Licensing Regulation', The Journal of Economic History, vol. 65 , no. 3 , pp. $723-56$.

Lee, CH and Warren, EH 1976, 'Rationing by Seller's Preference and Racial Price Discrimination', Economic Inquiry, vol. 14, no. 1, pp. 36-44. 
Lee, Z, Im, I and Lee, SJ 2006, 'The Effect of Buyer Feedback Scores on Internet Auction Prices', Journal of Organizational Computing and Electronic Commerce, vol. 16, no. 1, pp. 51-64.

Leeson, PT 2007, 'Better Off Stateless: Somalia Before and After Government Collapse', Journal of Comparative Economics, vol. 35, no. 4, pp. 689-710.

---- 2014, 'Pirates, Prisoners, and Preliterates: Anarchic Context and the Private Enforcement of Law', European Journal of Law and Economics, vol. 37, no. 3, pp. 365-79.

Lefebvre, G 2005, The French Revolution: From Its Origins to 1793, translated by EM Evanson, Routledge, London, UK.

Leiblein, MJ and Miller, DJ 2003, 'An Empirical Examination of Transaction-and Firm-Level Influences on the Vertical Boundaries of the Firm', Strategic Management Journal, vol. 24, no. 9, pp. 839-59.

Leigh, K and Li, D 2018, 'China's Radical Plan to Judge Each Citizen's Behavior', The Washington Post, 2 December 2018.

Lemcke, L 2016, 'Imperial Transportation and Communication from the Third to the Late Fourth Century: The Golden Age of the Cursus Publicus', Peeters Publishers, Leuven, Belgium.

Levin, J 2001, 'Information and the Market for Lemons', The RAND Journal of Economics, vol. 32, no. 4, pp. 657-66.

---- 2009, 'The Dynamics of Collective Reputation', The BE Journal of Theoretical Economics, vol. 9, no. 1, pp. 1935-704.

Levine, CB and Hughes, J 2005, 'Management Compensation and Earnings-Based Covenants as Signaling Devices in Credit Markets', Journal of Corporate Finance, vol. 11, no. 5, pp. 832-50.

Levine, DI 1991, 'Just-Cause Employment Policies in the Presence of Worker Adverse Selection', Journal of Labor Economics, vol. 9, no. 3, pp. 294-305.

Levitt, SD 2004, 'Testing Theories of Discrimination: Evidence from Weakest Link.', The Journal of Law and Economics, vol. 47, no. 2, pp. 431-52.

Levy, Nadav Spiegel, Y and Gilo, D 2018, 'Partial Vertical Integration, Ownership Structure, and Foreclosure', American Economic Journal: Microeconomics, vol. 10, no. 1, pp. 132-80.

Liang, F, Das, V, Kostyuk, N and Hussain, MM 2018, 'Constructing a Data-Driven Society: China's Social Credit System as a State Surveillance Infrastructure', Policy \& Internet, vol. 10 , no. 4 , pp. 415-53. 
Libecap, GD 1978, 'Economic Variables and the Development of the Law: The Case of Western Mineral Rights', The Journal of Economic History, vol. 38, no. 2, pp. 338-362.

Lijiang, Z 2003, 'The Hukou System of the People's Republic of China: A Critical Appraisal under International Standards of Internal Movement and Residence', Chinese Journal of International Law, vol. 2, no. 2, pp. 519-65.

Lin, JY, Cai, F and Li, Z 2003, The China Miracle: Development Strategy and Economic Reform, Chinese University Press, Hong Kong.

Lindsay, CM 1976, 'A Theory of Government Enterprise', Journal of Political Economy, vol. 84 , no. 5, pp. 1061-78.

Lindsay, H 2011, 'Adoption and Heirship in Greece and Rome', in B Rawson (ed), A Companion to Families in the Greek and Roman Worlds, Wiley-Blackwell, Hoboken, NJ, USA, pp. 346-60.

Ling, M 2017, 'Returning to No Home: Educational Remigration and Displacement in Rural China', Anthropological Quarterly, vol. 90, no. 3, pp. 715-42.

Lipponen, J, Wisse, B and Jetten, J 2017, 'The Different Paths to Post-Merger Identification for Employees from High and Low Status Pre-Merger Organizations', Journal of Organizational Behavior, vol. 38, no. 5, pp. 692-711.

List, JA 2004, 'The Nature and Extent of Discrimination in the Marketplace: Evidence from the Field', The Quarterly Journal of Economics, vol. 119, no. 1, pp. 49-89.

Litwack, JM 1991, 'Legality and Market Reform in Soviet-Type Economies', Journal of Economic Perspectives, vol. 5, no. 4, pp. 77-89.

Liu, Z 2005, 'Institution and Inequality: The Hukou System in China', Journal of Comparative Economics, vol. 33, no. 1, pp. 133-57.

Lloyd, M 2005, The Passport: The History of Man's Most Travelled Document, Sutton, Stroud, Gloucestershire, UK.

Loureiro, ML and McCluskey, JJ 2000, 'Assessing Consumer Response to Protected Geographical Identification Labeling', Agribusiness: An International Journal, vol. 16, no. 3, pp. 309-20.

Loury, GC 2002, The Anatomy of Racial Inequality, Harvard University Press, Cambridge, MA USA.

Luca, M 2016, 'Reviews, Reputation, and Revenue: The Case of Yelp.com', Harvard Business School NOM Unit Working Paper, (12-016).

Luca, M and Zervas, G 2016, 'Fake It Till You Make it: Reputation, Competition, and Yelp Review Fraud', Management Science, vol. 62, no. 12, pp. 3412-27. 
Lucassen, L 2001, 'A Many-Headed Monster: The Evolution of the Passport System in the Netherlands and Germany in the Long Nineteenth Century', in J Caplan \& J Torpey (eds), Documenting Individual Identity, Princeton University Press, Princeton, NJ, USA, pp. 235-55.

Lundberg, SJ and Startz, R 1983, 'Private Discrimination and Social Intervention in Competitive Labor Market', The American Economic Review, vol. 73, no. 3, pp. 34047.

Ma, Z and Zeng, D 2015, 'Population and Internal Migration in North Korea Since 2000', Eurasian Geography and Economics, vol. 56, no. 4, pp. 446-68.

MacDonald, TJ, Allen, DWE and Potts, J 2016, 'Blockchains and the Boundaries of SelfOrganized Economies: Predictions for the Future of Banking', in P Tasca, T Aste, L Pelizzon \& N Perony (eds), Banking Beyond Banks and Money, Springer, Berlin, Germany, pp. 279-96.

MacLeod, WB 2007, 'Reputations, Relationships, and Contract Enforcement', Journal of Economic Literature, vol. 45, no. 3, pp. 595-628.

Magri, S and Pico, R 2011, 'The Rise of Risk-Based Pricing of Mortgage Interest Rates in Italy', Journal of Banking \& Finance, vol. 35, no. 5, pp. 1277-90.

Mailath, GJ 1987, 'Incentive Compatability in Signaling Games with a Continuity of Types', Econometrica, vol. 55, no. 6, pp. 1349-65.

Mann, JC and Roxan, MM 1988, 'Discharge Certificates of the Roman Army', Britannia, vol. 19, pp. 341-47.

Manove, MA, Padilla, J and Pagano, M 'Collateral versus Project Screening: A Model of Lazy Banks', The RAND Journal of Economics, vol. 32, no. 4, pp. 726-44.

Marshall, A 2013, Principles of Economics, Springer, Berlin, Germany.

Martin, RE and Hill, RC 2000, 'Loan Performance and Race', Economic Inquiry, vol. 38, no. 1, pp. 136-50.

Massey, DS 1994, 'Getting Away With Murder: Segregation and Violent Crime in Urban America', U. Pa. L. Rev, vol. 143, no. 5, pp. 1203-32.

Masson, RT 1973, 'Costs of Search and Racial Price Discrimination', Economic Inquiry, vol. 11 , no. 2, pp. 167-86.

Mathias, P 2007, 'Economic Growth and Robinson Crusoe', European Review, vol. 15, no. 1, pp. 17-31.

Mattesini, F 1990, 'Screening in the Credit Market: The Role of Collateral', European Journal of Political Economy, vol. 6, no. 1, pp. 1-22. 
Matthews, CM 1966, English Surnames, Weidenfeld and Nicolson, London, UK.

---- 2007, How Surnames Began, Lutterworth Press, Cambridge, UK.

Matthews, M 1993, The Passport Society: Controlling Movement in Russia and the USSR, Westview Press, Boulder, CA, USA.

Matthews, SA and Mirman, LJ 1983, 'Equilibrium Limit Pricing: The Effects of Private Information and Stochastic Demand', Econometrica, vol. 51, no. 4, pp. 981-96.

Matutes, C and Vives, X 2000, 'Imperfect Competition, Risk Taking, and Regulation In Banking', European Economic Review, vol. 44, no. 1, pp. 1-34.

Maurer-Fazio, M 2012, 'Ethnic Discrimination in China's Internet Job Board Labor Market', IZA Journal of Migration, vol. 1, no. 1, pp. 1-49.

McAdam, J 2011, 'An Intellectual History of Freedom of Movement in International Law: The Right to Leave as a Personal Liberty', Melb. J. Int'l L, vol. 12, no. 1, pp. 1-30.

McAdams, RH 1995, 'Cooperation and Conflict: The Economics of Group Status Production and Race Discrimination', Harvard Law Review, vol. 108, no. 5, pp. 1003-84.

McBain, G 2011, 'Abolishing Obsolete Crown Prerogatives Relating to the Military', Nottingham Law Journal, vol. 20, pp. 14-37.

McCall, JJ 1972, 'The Simple Mathematics of Information, Job Search, and Prejudice', in AH Pascal (ed), Racial Discrimination in Economic Life, Lexington, Lanham, USA, pp. 20524.

McCloskey, D 1975, 'Economics of Enclosure: A Market Analysis', in WN Parker \& EL Jones (eds), European Peasants and their Markets: Essays in Agrarian Economic History, Princeton University Press, Princeton, NJ, USA, pp. 123-60

McCloskey, D and Klamer, A 1995, 'One Quarter of GDP is Persuasion', The American Economic Review, vol. 85, no. 2, pp. 191-95.

McDonald, CG and Slawson Jr, VC 2002, 'Reputation in an Internet Auction Market', Economic inquiry, vol. 40, no. 4, pp. 633-50.

McDonald, DJ and Thornton, DL 2008, 'A Primer on the Mortgage Market and Mortgage Finance', Federal Reserve Bank of St. Louis Review, vol. 90, no. 1, pp. 31-45.

McDowell, JC 2016, Identity Politics in George Lucas' Star Wars McFarland \& Company, Jefferson, NC, USA.

McGuire, JB, Schneeweis, T and Branch, B 1990, 'Perceptions of Firm Quality: A Cause or Result of Firm Performance', Journal of Management, vol. 16, no. 1, pp. 167-80. 
McGuire, MC and Olson, M 1996, 'The Economics of Autocracy and Majority Rule: The Invisible Hand and the Use of Force', Journal of Economic Literature, vol. 34, no. 1, pp. 72-96.

McKechnie, WS 1914, Magna Carta: A Commentary on the Great Charter of King John, Burt Franklin, New York, NY, USA.

McKinley, RA 1990, A History of British Surnames, Longman, London, UK.

McLean, I 2000, 'The Divided Legacy of Mancur Olson', British Journal of Political Science, vol. 30 , no. 4 , pp. 651-68.

McMillan, J and Woodruff, C 2000, 'Private Order Under Dysfunctional Public Order', Michigan Law Review, vol. 98, no. 8, pp. 2421-58.

McWhorter, JH 2000, Losing the Race: Self-Sabotage in Black America, Free Press, New York, NY, USA.

Mead, GH, Joas, H, Huebner, DR and Morris, CW 2015, Mind, Self, and Society: The Definitive Edition, University of Chicago Press, Chicago, IL, USA.

Meer, J 2011, 'Brother, Can You Spare a Dime? Peer Pressure in Charitable Solicitation', Journal of Public Economics, vol. 95, no. 7-8, pp. 926-41.

Megyesi, B and Mike, K 2016, 'Organising Collective Reputation: An Ostromian Perspective', International Journal of the Commons, vol. 10, no. 2, pp. 1082-99.

Meijerink, G 2011, 'New Institutional Economics: Douglass North and Masahiko Aoki', in S Vellema (ed), Transformation and Sustainability in Agriculture, Wageningen Academic Publishers, Wageningen, Holland, pp. 21-33.

Ménard, C and Shirley, MM 2014, 'The Future of New Institutional Economics: From Early Intuitions to a New Paradigm?', Journal of Institutional Economics, vol. 10, no. 4, pp. 541-65.

Merry, SE 1997, 'Rethinking Gossip and Scandal', in DB Klein (ed), Reputation: Studies in the Voluntary Elicitation of Good Conduct, University of Michigan Press, Ann Arbor, USA, pp. 47-74

Metzger, MR 1983, 'Cherries, Lemons, and the FTC: Minimum Quality Standards in the Retail Used Automobile Industry', Economic Inquiry, vol. 21, no. 1, pp. 129-39.

Meyer, B 1990, 'Unemployment Insurance and Inemployment Spells', Econometrica, vol. 58, no. 4, pp. 757-82.

Michiardi, P and Molva, R 2003, 'A Game Theoretical Approach to Evaluate Cooperation Enforcement Mechanisms in Mobile ad hoc Networks', WiOpt'03: Modeling and Optimization in Mobile, Ad Hoc and Wireless Networks, March 2003, pp. 1-4. 
Middleton, N 2005, 'Early Medieval Port Customs, Tolls and Controls on Foreign Trade', Early Medieval Europe, vol. 13, no. 4, pp. 313-58.

Milde, H and Riley, JG 1988, 'Signaling in Credit Markets', The Quarterly Journal of Economics, vol. 103, no. 1, pp. 101-29.

Milgrom, PR and Roberts, J 1992, Economics, Organization, and Management, Prentice-Hall, Upper Saddle River, NJ, USA.

Milgrom, PR and Oster, S 1987, 'Job Discrimination, Market Forces, and the Invisibility Hypothesis', The Quarterly Journal of Economics, vol. 102, no. 3, pp. 453-76.

Milgrom, PR, North, DC and Weingast, BR 1990, 'The Role of Institutions in the Revival of Trade: The Law Merchant, Private Judges, and the Champagne Fairs', Economics \& Politics, vol. 2, no. 1, pp. 1-23.

Milinski, M, Semmann, D and Krambeck, HJ 2002, 'Reputation Helps Solve the 'Tragedy of the Commons", Nature, vol. 415, no. 6870, pp. 424-26.

Miller, M and Rock, K 1985, 'Dividend Policy Under Asymmetric Information', The Journal of Finance, vol. 40, no. 4, pp. 1031-51.

Mimra, W, Rasch, A and Waibel, C 2016, 'Price Competition and Reputation in Credence Goods Markets: Experimental Evidence', Games and Economic Behavior, vol. 100, pp. 337-52.

Mirman, L 2020, 'Perfect Information', in Vernengo, M, Caldentey, EP and Rosser Jr, BJ (eds), The New Palgrave Dictionary of Economics, Springer, Berlin, Germany.

Mitchell, MD and Boettke PJ 2017, Applied Mainline Economics, Mercatus Center, Arlington, VA, USA.

Mitchell, PT 2006, 'US Military Primacy and the New Operating System', The Adelphi Papers, vol. 46, no. 385, pp. 11-26.

Mlicki, PP 1996, 'Hostage Posting as a Mechanism for Co-Operation in the Prisoner's Dilemma Game', in Liebrand, WBG \& Messick, DM (eds), Frontiers in Social Dilemmas Research, Springer, Berlin, Germany, pp. 165-83.

Moatti, C 2006, 'Translation, Migration, and Communication in the Roman Empire: Three Aspects of Movement in History', Classical Antiquity, vol. 25, no. 1, pp. 109-40.

Moe, TM 2005, 'Power and Political Institutions', Perspectives on Politics, vol. 3, no. 2, pp. 215-33.

Moffitt, R 1985, 'Unemployment Insurance and the Distribution of Unemployment Spells', Journal of Econometrics, vol. 28, no. 1, pp. 85-101. 
Monroe, AE (ed) 2011, Early Economic Thought: Selections from Economic Literature Prior to Adam Smith, Literary Licensing, Whitefish, MT, USA.

Montgomery, JD 1999, 'Adverse Selection and Employment Cycles', Journal of Labor Economics, vol. 17, no. 2, pp. 281-97.

Moro, A 2003, 'The Effect of Statistical Discrimination on Black-White Wage Inequality: Estimating a Model with Multiple Equilibria', International Economic Review, vol. 44, no. 2, pp. 467-500.

Moro, A and Norman, P 2004, 'A General Equilibrium Model of Statistical Discrimination', Journal of Economic Theory, vol. 114, no. 1, pp. 1-30.

Moya, JC 1998, Cousins and Strangers: Spanish Immigrants in Buenos Aires, 1850-1930, University of California Press, Berkeley, CA, USA.

Mueller, U 2016, 'Lost in Representation? Feminist identity Economics and Women's Agency in India's Local Governments', Feminist Economics, vol. 22, no. 1, pp. 158-82.

Mulligan, RF 2005, 'The Common Law Character of English Charters: Spontaneous Order in the Constitutions of Clarendon (1164)', Constitutional Political Economy, vol. 16, no. 3, pp. 285-311.

Murphy, L 2011, 'The Global Financial Crisis and the Australian and New Zealand Housing Markets', Journal of Housing and the Built Environment, vol. 26, no. 3, pp. 335-51.

Murtazashvili, I and Murtazashvili, J 2016, 'When Does the Emergence of a Stationary Bandit Lead to Property Insecurity?', Rationality and Society, vol. 28, no. 3, pp. 335-60.

Myerson, RB 2008, 'The Autocrat's Credibility Problem and Foundations of the Constitutional State', The American Political Science Review, vol. 102, no. 1, pp. 12539.

Nakamoto, S 2008, 'Bitcoin: A Peer-to-Peer Electronic Cash System', $<$ https://bitcoin.org/bitcoin.pdf>

Nakayachi, K and Watabe, M 2005, 'Restoring Trustworthiness after Adverse Events: The Signaling Effects of Voluntary "Hostage Posting" on Trust', Organizational Behavior and Human Decision Processes, vol. 97, no. 1, pp. 1-17.

Narayanan, A. Bonneau, J, Felten, E, Miller, A and Goldfeder, S 2016, Bitcoin and Cryptocurrency Technologies: A Comprehensive Introduction, Princeton University Press, Princeton, NJ, USA.

Naseer, S and Heine, K 2017, 'Bureaucratic Identity and the Shape of Public Policy: A Game Theoretic Analysis', Annual Conference 2017 (Vienna): Alternative Structures for Money and Banking, pp. 1-46. 
Naughton, B 2007, The Chinese Economy: Transitions and Growth, MIT Press, Cambridge, MA, USA.

Nelson, JL 2014, Charles the Bald, Routledge, Abingdon, UK.

Nelson, P 1970, 'Information and Consumer Behaviour', Journal of Political Economy, vol. 78, no. 2, pp. 311-29.

---- 1974, 'Advertising as information', Journal of Political Economy, vol. 82, no. 4., pp. 72954.

Neral, J and Ochs, J 1992, 'The Sequential Equilibrium Theory of Reputation Building: A Further Test', Econometrica, vol. 60, no. 5, pp. 1151-69.

Netzer, N and Scheuer, F 2010, 'Competitive Screening in Insurance Markets with Endogenous Wealth Heterogeneity', Economic Theory, vol. 44, no. 2, pp. 187-211.

von Neumann, J and Morgenstern, 0 1947, Theory of Games and Economic Behavior, Princeton University Press, Princeton, NJ, USA.

Neumark, D, Bank, RJ and Van Nort, KD 1996, 'Sex Discrimination in Restaurant Hiring: An Audit Study', The Quarterly Journal of Economics, vol. 111, no. 3, pp. 915-41.

Newhouse, JP 1996, 'Reimbursing Health Plans and Health Providers: Efficiency in Production Versus Selection', Journal of Economic Literature, vol. 34, no. 3, pp. 123663.

Nicolainsen, WFH 1980, 'Tension and Extension: Thoughts on Scottish Surnames and Medieval Popular Culture', The Journal of Popular Culture, vol. 14, no. 1, pp. 119-30.

Nicolet, C 1980, The World of the Citizen in Republican Rome, translated by PS Falla, University of California Press, Berkeley, CA, USA.

Nicks, SJ 1987., 'Speak No Evil: Known Defects in the FTC's Used Car Rule', Journal of Consumer Policy, vol. 10, no. 1, pp. 69-87.

Nielsen, JP 2010, Sons and Descendants: A Social History of Kin Groups and Family Names in the Early Neo-Babylonian Period, 747-626 B.C, Brill, Leiden, Holland.

Nier, E and Baumann, U 2006, 'Market Discipline, Disclosure and Moral Hazard in Banking', Journal of Financial Intermediation, vol. 15, no. 3, pp. 332-61.

Niinimäki, JP 2009, 'Does Collateral Fuel Moral Hazard in Banking?', Journal of Banking and Finance, vol. 33, no. 3, pp. 514-21.

North, DC 1971, 'Institutional Change and Economic Growth', The Journal of Economic History, vol. 31, no. 1, pp. 118-25. 
---- 1981, Structure and Change in Economic History, Norton, New York, USA.

---- 1990, Institutions, Institutional Change and Economic Performance, Cambridge University Press, Cambridge, USA.

---- 1993, 'Institutions and Credible Commitment', Journal of Institutional and Theoretical Economics (JITE)/Zeitschrift für die gesamte Staatswissenschaft, vol. 149, no. 1, pp. 11-23.

---- 1994, 'Transaction Costs Through Time', Economics Working Paper Archive at WUSTL, pp. 1-9.

---- 2005, Understanding the Process of Economic Change, Princeton University Press, Princeton, NJ, USA.

North, DC and Thomas, RP 1971, 'The Rise and Fall of the Manorial System: A Theoretical Model', The Journal of Economic History, vol. 31, no. 4, pp. 777-803.

North, DC, Wallis, JJ and Weingast, BR 2006, 'A Conceptual Framework for Interpreting Recorded Human History, National Bureau of Economic Research Working Paper, no. 12795, pp. 1-80.

---- 2009, Violence and Social Orders: A Conceptual Framework for Interpreting Recorded Human History, Cambridge University Press, Cambridge, UK.

Nowak, MA and Sigmund, K 2005, 'Evolution of Indirect Reciprocity', Nature, vol. 437, no. 7063, pp. 1291-98.

Noy, D 2000, Foreigners at Rome: Citizens and Strangers, Classical Press of Wales, Swansea, UK.

Nygaard, A and Myrtveit, I 2000, 'Moral Hazard, Competition and Contract Design: Empirical Evidence from Managerial, Franchised and Entrepreneurial Businesses in Norway', Applied Economics, vol. 32, no. 3, pp. 349-56.

O’Brien, R 2016, 'Privacy and Security: The New European Data Protection and it's Data Breach Notification Requirements', Business Information Review, vol. 33, no. 2, pp. 81-4.

Offer, A 2007, 'The Markup for Lemons: Quality and Uncertainty in American and British Used-Car Markets c. 1953-73', Oxford Economic Papers, vol. 59, no. 5, pp. i31-i48.

Ogbu, J 2003, Black American Students in An Affluent Suburb: A Study of Academic Disengagement, Taylor \& Francis, Milton Park, UK.

Ogbu, JU 1999, 'Beyond Language: Ebonics, Proper English, and Identity in a Black-American Speech Community', American Educational Research Journal, vol. 36, no. 2, pp. 14784. 
Okuno-Fujiwara, M and Postlewaite, A 1995, 'Social Norms and Random Matching Games', Games and Economic Behavior, vol. 9, no. 1, pp. 79-109.

Olson, M 1965, The Logic of Collective Action. Public Goods and the Theory of Groups, Cambridge, MA, USA.

----1982, The Rise and Decline of Nations: Economic Growth, Stagflation, and Social Rigidities, Yale University Press, New Haven, CT, USA.

---- 1993, 'Dictatorship, Democracy, and Development', American Political Science Review, vol. 87 , no. 3 , pp. 567-76.

---- 1995, 'Why the Transition from Communism is so Difficult', Eastern Economic Journal, vol. 21 , no. 4, pp. 437-61.

Origgi, G 2017, Reputation: What It Is and Why It Matters, Princeton University Press, Princeton, NJ, USA.

Orjuela, C 2014, 'Corruption and Identity Politics in Divided Societies', Third World Quarterly, vol. 35, no. 5, pp. 753-69.

Ostrom, E 1986, 'An Agenda for the Study of Institutions', Public Choice, vol. 48, no. 1, pp. 325.

---- 1996, 'Crossing the Great Divide: Coproduction, Synergy, and Development', World Development, vol. 24, no. 6, pp. 1073-87.

Padilla, AJ and Pagano, M 2000, 'Sharing Default Information as a Borrower Discipline Device', European Economic Review, vol. 44, no. 10, pp. 1951-80.

Pagano, U 1995, 'Can Economics Explain Nationalism?', in A Breton, G Galeotti, P Salmon \& R Wintrobe (eds), Nationalism and Rationality, Cambridge University Press, Cambridge, UK, pp. 173-203.

Panagópoulos, AC 1978, Captives and Hostages in the Peloponnesian War, Grigoris Publications, Athens, Greece.

Panzone, L 2012, 'Alcohol Tax, Price-Quality Proxy and Discounting: A Reason Why Alcohol Taxes May Rebound', Journal of Agricultural Economics, vol. 63, no. 3, pp. 715-36.

Parasuraman, A, Berry, LL and Zeithaml, VA 1991, 'Understanding Customer Expectations of Service', Sloan Management Review, vol. 32, no. 3, pp. 39-48.

Parekh, B 2009, 'Logic of Identity', Politics, Philosophy \& Economics, vol. 8, no. 3, pp. 267-84.

Park, RE 1924, 'The Concept of Social Distance: As Applied to the Study of Racial Relations', Journal of Applied Sociology, vol. 8, pp. 339-44. 
Parker, R 1954, 'The Right to Go Abroad: To Have and to Hold a Passport', Virginia Law Review, vol. 40, no. 7, pp. 853-76.

Parks, GB 1954, The English Traveler to Italy, Stanford University Press, Palo Alto, USA.

Parks, RB, Baker, PC, Kiser, L, Oakerson, R, Ostrom, E, Ostrom, V, Percy, SL, Vandivort, MB, Whitaker, GP and Wilson, R 1981, 'Consumers as Coproducers of Public Services: Some Economic and Institutional Considerations', Policy Studies Journal, vol. 9, no. 7, pp. 1001-11.

Parliament of Great Britain 1829, Reports from the Lords Committees. Touching the Dignity of a Peer of the Realm. With Appendixes, London, UK.

Pascal, AH 1970, 'The Analysis of Residential Segregation', in JP Crecine (ed), Financing the Metropolis, Sage Publications, Beverley Hills, CA.

Pavlou, PA and Dimoka, A 2006, 'The Nature and Role of Feedback Text Comments in Online Marketplaces: Implications for Trust Building, Price Premiums, and Seller Differentiation', Information Systems Research, vol. 17, no. 4, pp. 392-414.

Pauly, MV 1968, 'The Economics of Moral Hazard: Comment', The American Economic Review, vol. 58 , no. 3 , pp. 531-37.

---- 1974, 'Overinsurance and Public Provision of Insurance: The Roles of Moral Hazard and Adverse Selection', The Quarterly Journal of Economics, vol. 88, no. 1, pp. 44-62.

Pearce, JA 2013, 'Using Social Identity Theory to Predict Managers' Emphases on Ethical and Legal Values in Judging Business Issues', Journal of Business Ethics, vol. 112, no. 3, pp. 497-514.

Persico, N 2009, 'Racial Profiling? Detecting Bias Using Statistical Evidence', Annual Review of Economics, vol. 1, pp. 229-54.

Petersen, H 1962, 'The Numeral Praenomina of the Romans', Transactions and Proceedings of the American Philological Association, vol. 93, pp. 347-54.

Peterson, RL 1981, 'An Investigation of Sex Discrimination in Commercial Banks' Direct Consumer Lending', The Bell Journal of Economics, vol. 12, no. 2, pp. 547-61.

Pettit, P 2005, 'Construing Sen on Commitment', Economics \& Philosophy, vol. 21, no. 1, pp. 15-32.

Phelps, ES 1972a, Inflation Policy and Unemployment Theory: The Cost-Benefit Approach to Monetary Planning, Macmillan, Basingstoke, UK.

---- 1972b, 'The Statistical Theory of Racism and Sexism', The American Economic Review, vol. 62 , no. 4 , pp. 659-61. 
Pilcher, J 2016, 'Names, Bodies and Identities', Sociology, vol. 50, no. 4, pp. 764-79.

---- 2017, 'Names and "Doing Gender": How Forenames and Surnames Contribute to Gender Identities, Difference, and Inequalities', Sex Roles, vol. 77, no. 11-12, pp. 812-22.

Pintens, W and Will, MR 1995, 'Names', in MA Glendon (ed), International Encyclopedia of Comparative Law, Instalment 30. Vol. IV: Persons and Family, Brill, Leiden, Holland.

Pissarides, C 2000, Equilibrium Unemployment Theory, Basil Blackwell, Oxford, UK.

Planché, JR 1874, The Conqueror and His Companions, Tinsley Brothers, London, UK.

Platteau, JP 1994, 'Behind the Market Stage where Real Societies Exist-Part I: The Role of Public and Private Order Institutions', The Journal of Development Studies, vol. 30, no. 3, pp. 533-77.

Polanyi, M 1948, 'Planning and Spontaneous Order', The Manchester School of Economic and Social Studies, vol. 16, no. 3, pp. 237-68.

Polishchuk, L and Syunyaev, G 2011, 'Taming the (Not So) Stationary Bandit: Turnover of Ruling Elites and Protection of Property Rights', Center for Institutional Studies Working Paper Series, WP10/2011/04, pp. 1-40.

Polski, MM 2001, 'Measuring Transaction Costs and Institutional Change in the US Commercial Banking Industry', Institute for Development Strategies Discussion Paper, Indiana University, pp. 1-41.

Ponzi L, Fombrun, CJ and Gardberg, NA 2011, 'RepTrak ${ }^{\mathrm{TM}}$ Pulse: Conceptualizing and Validating a Short-Form Measure of Corporate Reputation', Corporate Reputation Review, vol. 14, no. 1, pp. 15-35.

Posey, LL and Yavas, A 2007, 'Screening Equilibria in Experimental Markets', The Geneva Risk and Insurance Review, vol. 32, no. 2, pp. 147-67.

Posner, EA 1996, 'The Regulation of Groups: The Influence of Legal and Nonlegal Sanctions on Collective Action', The University of Chicago Law Review, vol. 63, no. 1, pp. 13397.

Posner, RA 1979, 'Privacy, Secrecy, and Reputation', Buffalo Law Review, vol. 28, no. 1, pp. 1-55.

---- 1980, 'A Theory of Primitive Society, with Special Reference to Law', The Journal of Law and Economics, vol. 23, no. 1, pp. 1-53.

---- 1981, 'The Economics of Privacy', The American Economic Review, vol. 71, no. 2, pp. 4059. 
Pothecary, S 1999, 'Strabo the Geographer: His name and its Meaning', Mnemosyne, vol. 52, no. 6, pp. 691-704.

Potter, SH and Potter, JM 1990, China's Peasants: The Anthropology of a Revolution, Cambridge University Press, Cambridge, UK.

Potts, J 2009, 'Open Occupations-Why Work Should be Free', Economic Affairs, vol. 29, no. 1, pp. 71-6.

Prescott, E and Townsend, R 1984, 'Pareto Optima and Competitive Equilibria with Adverse Selection and Moral Hazard', Econometrica, vol. 52, no. 1, pp. 21-45.

Prestwich, JO 1954, 'War and Finance in the Anglo-Norman State', Transactions of the Royal Historical Society, vol. 4, pp. 19-43.

Public Record Office, [1429-36] 1907, 'Calendar of the Patent Rolls, 1429-36', London, UK.

Puelz, R and Snow, A 1994, 'Evidence on Adverse Selection: Equilibrium Signaling and CrossSubsidization in the Insurance Market', Journal of Political Economy, vol. 102, no. 2, pp. 236-57.

Qi, M 2013, 'Mortgage Credit Risk', in D Rösch \& Scheule (eds), Credit Securitizations and Derivatives: Challenges for the Global Markets, Wiley, Hoboken, NJ, USA, pp. 33-52.

Qizilbash, M 2009, 'Identity, Community, and Justice: Locating Amartya Sen's Work on Identity', Politics, Philosophy \& Economics, vol. 8, no. 3, pp. 251-66.

---- 2014, 'Identity, Reason and Choice', Economics \& Philosophy, vol. 30, no. 1, pp. 11-33.

Rainwater, L 1970, Behind Ghetto Walls, Penguin, London, UK.

Rampton, M 1993, 'The Peasant's Revolt of 1381 and the Written Word', Comitatus: $A$ Journal of Medieval and Renaissance Studies, vol. 24, no. 1, pp. 45-60.

Ramsay, AM 1925, 'The Speed of the Roman Imperial Post', The Journal of Roman Studies, vol. 15 , no. 1 , pp. 60-74.

Ramsay, K 2004, 'Politics at the Water's Edge: Crisis Bargaining and Electoral Competition', Journal of Conflict Resolution, vol. 48, no. 4, pp. 459-86.

Rao, A 2005, 'The Quality of Price as a Quality Cue', Journal of Marketing Research, vol. 42, no. 4 , pp. 401-5.

Rasmusen, E 1987, 'Moral Hazard in Risk-Averse Teams', The RAND Journal of Economics, vol. 18 , no. 3 , pp. 428-35.

---- 2006, Games and Information: An Introduction to Game Theory, Wiley-Blackwell, Hoboken, NJ, USA. 
Rasmussen, RK 2000, 'Resolving Transnational Insolvencies Through Private Ordering', Michigan Law Review, vol. 98, no. 7, pp. 2252-75.

Rathbone, D 1991, Economic Rationalism and Rural Society in Third-Century AD Egypt, Cambridge University Press, Cambridge, UK.

---- 1993, 'Egypt, Augustus and Roman Taxation', Cahiers du Centre Gustave Glotz, vol. 4, pp. 81-112.

Raub, W and Keren, G 1993, 'Hostages as a Commitment Device: A Game-Theoretic Model and an Empirical Test of Some Scenarios', Journal of Economic Behavior \& Organization, vol. 21, no. 1, pp. 43-67.

Rayo, L 2007, 'Relational Incentives and Moral Hazard in Teams', Review of Economic Studies, vol. 74, no. 3, pp. 937-63.

Reaney, PH 1978, The Origins of English Surnames, Routledge and Kegan Paul, Abingdon, UK.

Reaney, PH and Wilson, RM 2006, A Dictionary of English Surnames, Taylor \& Francis, Milton Park, UK.

Redmonds, G, King, T and Hey, D 2011, Surnames, DNA, and Family History, Oxford University Press, Oxford, UK.

Refaei, MT, Srivastava, V, DaSilva, L and Eltoweissy M 2005, 'A Reputation-Based Mechanism for Isolating Selfish Nodes in ad hoc Networks', MOBIQUITOUS '05 The Second Annual International Conference on Mobile and Ubiquitous Systems: Networking and Services, pp. 3-11.

Rennick, RM 1970, 'The Nazi Name Decrees of the Nineteen Thirties', Names, vol. 18, no. 2, pp. 65-88.

Resnick, P, Zeckhauser, R, Swanson, J and Lockwood, K 2006, 'The Value of Reputation on eBay: A Controlled Experiment', Experimental Economics, vol. 9, no. 2, pp. 79-101.

Richter, R 2005, 'The New Institutional Economics: Its Start, its Meaning, its Prospects', European Business Organization Law Review', vol. 6, no. 2, pp. 161-200.

Riefler, P, Diamantopoulos, A and Siguaw, JA 2012, 'Cosmopolitan Consumers as a Target Group for Segmentation', Journal of International Business Studies, vol. 43, no. 3, pp. 285-305.

Riker, WH 1996, The Strategy of Rhetoric: Campaigning for the American Constitution, Yale University Press, New Haven, USA.

Riker, WH and Sened, I 1991, 'A Political Theory of the Origin of Property Rights: Airport Slots', American Journal of Political Science, vol. 35, no. 4, pp. 951-69. 
Riley, JG 2001, 'Silver Signals: Twenty-Five Years of Screening and Signaling', Journal of Economic Literature, vol. 39, no. 2, pp. 432-78.

Rindova, VP, Williamson, IO and Petkova, AP 2010, 'Reputation as an Intangible Asset: Reflections on Theory and Methods in Two Empirical Studies of Business School Reputations', Journal of Management, vol. 36, no. 3, pp. 610-9.

Riordan, MH 1986, 'Monopolistic Competition with Experience Goods', The Quarterly Journal of Economics, vol. 101, no. 2, pp. 265-79.

Robbktson, HM 1933, 'Robinson Crusoe Economics', The South Africa Journal of Economics, vol. 1, no. 1, pp. 24-35.

Roberts, PW and Dowling, GR 2002, 'Corporate Reputation and Sustained Superior Financial Performance', Strategic Management Journal, vol. 23, no. 12, pp. 1077-93.

Robertson, C 2010, The Passport in America: The History of a Document, Oxford University Press, Oxford, UK.

Robinson, CL 2013, 'What Makes the Names of Middle-earth So Fitting? Elements of Style in the Namecraft of JRR Tolkien', Names, vol. 61, no. 2, pp. 65-74.

Rocheteau, G 2001, 'Equilibrium Unemployment and Wage Formation with Matching Frictions and Worker Moral Hazard', Labour Economics, vol. 8, no. 1, pp. 75-102.

---- 2002, 'Working Time Regulation in a Search Economy with Worker Moral Hazard', Journal of Public Economics, vol. 84, no. 3, pp. 387-425.

Rodriguez, J 2007, Captives and Their Saviors in the Medieval Crown of Aragon, Catholic University of America Press. Washington DC, USA.

Roffe, D 2000, Domesday: The Inquest and the Book, Oxford University Press, Oxford, UK.

Rogers, CJ 1993, 'The Military Revolutions of the Hundred Years' War', The Journal of Military History, vol. 57, no. 2, pp. 241-78.

---- 1994, 'Edward III and the Dialectics of Strategy, 1327-1360 (The Alexander Prize Essay)', Transactions of the Royal Historical Society, vol. 4, pp. 83-102.

---- 1998, 'The Efficacy of the English Longbow: A Reply to Kelly DeVries', War in History, vol. 5, no. 2, pp. 233-42.

Rogerson, WP 1983, 'Reputation and Product Quality', The Bell Journal of Economics, vol. 14, no. 2, pp. 508-16.

Rokkan, Al, Heide, JB and Wathne, KH 2003, 'Specific Investments in Marketing Relationships: Expropriation and Bonding Effects', Journal of Marketing Research, vol. 40, no. 2, pp. 210-24. 
Rooks, G, Tazelaar, F and Snijders, C 2010, 'Gossip and Reputation in Business Networks', European Sociological Review, vol. 27, no. 1, pp. 90-106.

Rose-Ackerman, S 2004, 'Corruption', in CK Rowley \& F Schneider (eds), The Encyclopedia of Public Choice, Volume I, Springer, Berlin, Germany, pp. 67-77.

Rosenberg, N 1960, 'Some Institutional Aspects of the Wealth of Nations', Journal of Political Economy, vol. 68, no. 6, pp. 557-70.

Ross, SA 1977, 'The Determination of Financial Structure: The Incentive-Signalling Approach', The Bell Journal of Economics, vol. 8, no. 1, pp. 23-40.

Ross, SL 2000, 'Mortgage Lending, Sample Selection and Default', Real Estate Economics, vol. 28 , no. 4 , pp. 581-621.

Rosser, JB 2003, 'A Nobel Prize for Asymmetric Information: The Economic Contributions of George Akerlof, Michael Spence and Joseph Stiglitz', Review of Political Economy, vol. 15, no. 1, pp. 3-21.

Rothschild, M and Stiglitz, J 1976, 'Equilibrium in Competitive Insurance Markets: An Essay on the Economics of Imperfect Information', Quarterly Journal of Economics, vol. 90, no. 4, pp. 629-49.

Rowley, CK and Wu, B 2014, Britannia 1066-1884: From Medieval Absolutism to the Birth of Freedom Under Constitutional Monarchy, Limited Suffrage, and the Rule of Law, Springer, Berlin, Germany.

Rubinstein, A and Yaari, ME 1983, 'Repeated Insurance Contracts and Moral Hazard', Journal of Economic Theory, vol. 30, no. 1, pp. 74-97.

Sabatelli, RM and Cecil-Pigo, EF 1985, 'Relational Interdependence and Commitment in Marriage', Journal of Marriage and the Family, vol. 47, no. 4, pp. 931-7.

Saloner, G 1985, 'Old Boy Networks as Screening Mechanisms', Journal of Labor Economics, vol. 3, no. 3, pp. 255-67.

Salop, J and Salop, S 1976, 'Self-Selection and Turnover in the Labor Market', The Quarterly Journal of Economics, vol. 90, no. 4, pp. 619-27.

Salter, MB 2003, Rights of Passage: The Passport in International Relations, Lynne Rienner Publishers, Boulder, USA.

Salway, B 1994, 'What's in a Name? A Survey of Roman Onomastic Practice from c. 700 BC to AD 700', The Journal of Roman Studies, vol. 8, pp. 124-45.

Samuelson, P 1947, Foundations of Economic Analysis, Harvard University Press, Cambridge, MA, USA. 
Satsiou, A and Tassiulas, L 2010, 'Reputation-Based Resource Allocation in P2P Systems of Rational Users', IEEE Transactions on Parallel and Distributed Systems, vol. 21, no. 4, pp. 466-79.

Saviano, R 2019, Gomorrah: Italy's Other Mafia, Pan Macmillan, New York, NY, USA.

Scanzoni, J 1979, 'Social Exchange and Behavioral Interdependence', in RL Burgess \& TL Huaston (eds), Social Exchange in Developing Relationships, Academic Press, New York, USA, pp. 61-98.

Scassa, T 1996, 'National Identity, Ethnic Surnames and the State', Canadian Journal of Law \& Society/La Revue Canadienne Droit et Société, vol. 11, no. 2, pp. 167-91.

Schacht, J 1982, An Introduction to Islamic Law, Clarendon Press, Oxford, UK.

Schama, S 1990, Citizens: A Chronicle of The French Revolution, Vintage Books, New York, USA.

Schamel, G and Anderson, K 2003, 'Wine Quality and Varietal, Regional and Winery Reputations: Hedonic Prices for Australia and New Zealand', Economic Record, vol. 79, no. 246, pp. 357-69.

Schane, SA 1987, 'The Corporation is a Person: The Language of a Legal Fiction', Tulane Law Review, vol. 61, no. 3, pp. 563-609.

Scheidel, W 2002, 'A Model of Demographic and Economic Change in Roman Egypt After the Antonine Plague', Journal of Roman Archaeology, vol. 15, pp. 97-114.

---- 2004, 'Human Mobility in Roman Italy, I: The Free Population', The Journal of Roman Studies, vol. 94, pp. 1-26.

Schelling, TC 1956, 'An Essay on Bargaining', The American Economic Review, vol. 46, no. 3, pp. 281-306.

---- 1960, The Strategy of Conflict, Harvard University Press, Cambridge, MA, USA.

---- 2006, Strategies of Commitment and Other Essays, Harvard University Press. Cambridge, MA, USA.

Schneider, HS 2010, 'Moral Hazard in Leasing Contracts: Evidence from the New York City Taxi Industry', The Journal of Law and Economics, vol. 53, no. 4, pp. 783-805.

---- 2012, 'Agency Problems and Reputation in Expert Services: Evidence from Auto Repair', The Journal of Industrial Economics, vol. 60, no. 3, pp. 406-33.

Schultz, TW 1963, The Economic Value of Education, Columbia University Press, New York, NY, USA. 
---- 1978, ,Migration: An Economist's View', in WH McNeill \& RS Adams (eds), Human Migration: Patterns and Policies, American Academy of Arts and Sciences, Boston, USA, pp. 377-86.

Scitovszky, T 1944, 'Some Consequences of the Habit of Judging Quality by Price', The Review of Economic Studies, vol. 12, no. 2, pp. 100-5.

Scott, JS 1998, Seeing Like a State: How Certain Schemes to Improve the Human Condition Have Failed, Yale University Press, New Haven, CT, USA.

---- 2008, Weapons of the Weak: Everyday Forms of Peasant Resistance, Yale University Press, New Haven, CT, USA.

Scott, JA, Tehranian, J and Mathias, J 2002, 'The Production of Legal Identities Proper to States: The Case of the Permanent Family Surname', Comparative Studies in Society and History, vol. 44, no. 1, pp. 4-44.

Searle, JR 2005, 'What is an Institution?', Journal of Institutional Economics, vol. 1, no. 1, pp. 1-22.

Sellers-Rubio, R, Mas-Ruiz, F and Sancho-Esper, F 2018, 'Firm Reputation, Advertising Investment, and Price Premium: The Role of Collective Brand Membership in HighQuality Wines', Agribusiness, vol. 34, no. 2, pp. 351-62.

Selod, H and Zenou, Y 2013, 'Does City Structure Affect The Labor Market Outcomes of Black Workers?', Journal of Urban Economics, vol. 74, pp. 113-132.

Sen, A 1977, 'Rational Fools: A Critique of the Behavioral Foundations of Economic Theory', Philosophy \& Public Affairs, vol. 6, no. 4, pp. 317-44.

---- 1984, Resources, Values, and Development, Harvard University Press, Cambridge, MA, USA.

---- 1985, 'Goals, Commitment, and Identity', Journal of Law, Economics \& Organization, vol. 1, no. 2, pp. 341-55.

---- 1997, Choice, Welfare, and Measurement, Harvard University Press, Cambridge, MA, USA.

---- 1999, Reason Before Identity: The Romanes Lecture for 1998, Oxford University Press, Oxford, UK.

---- 2002, Rationality and Freedom, Harvard University Press, Cambridge, MA, USA.

---- 2005, 'Why Exactly is Commitment Important for Rationality?', Economics \& Philosophy, vol. 21 , no. 1 , pp. 5-14.

---- 2006, Identity and Violence: The Illusion of Destiny, Allen Lane, London, UK. 
---- 2008, 'Violence, Identity and Poverty', Journal of Peace Research, vol. 45, no. 1, pp. 5-15.

Sened, I 1997, The Political Institution of Private Property, Cambridge University Press, Cambridge, UK.

Sexton, SE and Sexton, AL 2014, 'Conspicuous Conservation: The Prius Halo and Willingness to Pay for Environmental Bona Fides', Journal of Environmental Economics and Management, vol. 67, no. 3, pp. 303-17.

Shamir, B, Zakay, E, Brainin, E and Popper, M 2000, 'Leadership and Social Identification in Military Units: Direct and Indirect Relationships', Journal of Applied Social Psychology, vol. 30, no. 3, pp. 612-40.

Shapiro, C 1983a, 'Optimal Pricing of Experience Goods', The Bell Journal of Economics, vol. 14, no. 2, pp. 497-507.

---- 1983b, 'Premiums for High Quality Products as Returns to Reputations', The Quarterly Journal of Economics, vol. 98, no. 4, pp. 659-79.

Shapiro, C and Stiglitz, JE 1984, 'Equilibrium Unemployment as a Worker Discipline Device', The American Economic Review, vol. 74, no. 3, pp. 433-44.

Shavell, S 1979, 'On Moral Hazard and Insurance', The Quarterly Journal of Economics, vol. 93, no. 4, pp. 541-62.

Shayo, M 2009, 'A Model of Social Identity with an Application to Political Economy: Nation, Class, and Redistribution', American Political Science Review, vol. 103, no. 2, pp. 14774.

ShearmurJ and Klein, DB 1997, 'Good Conduct in the Great Society: Adam Smith and the Role of Reputation', in DB Klein, (ed), Reputation: Studies in the Voluntary Elicitation of Good Conduct, University of Michigan Press, Ann Arbor, USA, pp. 29-45.

Shepsle, KA 1991, 'Discretion, Institutions, and the Problem of Government Commitment', in P Bourdrieu \& J Coleman (eds), Social Theory for a Changing Society, Western Press, Boulder, USA, pp. 245-263.

Sherwin-White, AN 1973, The Roman Citizenship, Clarendon Press, Oxford, USA.

Sibley, NW, 1906, 'The Passport System', Journal of the Society of Comparative Legislation, vol. 7, no. 1, pp. 26-33.

Silver, N 2012, The Signal and the Noise, Penguin, London, UK.

Silverman, Dan 2004, 'Street Crime and Street Culture', International Economic Review, vol. 45, no. 3, pp. 761-86.

Simon, HA 1957, Models of Man, Wiley, New York, NY, USA. 
---- 1961, Administrative Behavior, 2nd ed, Macmillan, New York, NY, USA.

Simpson, GE and Yinger, JM 1985, Racial and Cultural Minorities: An Analysis of Prejudice and Discrimination, Springer, Berlin, Germany.

Skeel, C 1901, Travel in the First Century After Christ: With Special Reference to Asia Minor, Cambridge University Press, Cambridge, UK.

Smith, A 1776a, The Wealth of Nations, Books I-III, Penguin Books, London, UK.

---- 1776b, The Wealth of Nations, Books IV-V, Penguin Books, London, UK.

Smith, CW and Wakeman, IM 1985, 'Determinants of Corporate Leasing Policy', The Journal of Finance, vol. 40, no. 3, pp. 895-908.

Smith, DJ 2014, 'Heterogeneity and Exchange: Safe-Conducts in Medieval Spain', The Review of Austrian Economics, vol. 27, no. 2, pp. 183-97.

Smith, J 1987, 'Trade Credit and Informational Asymmetry', The Journal of Finance, vol. 42, no. 4, pp. 863-72.

Smith, V 1996, 'Crop Insurance, Moral Hazard, and Agricultural Chemical Use', American Journal of Agricultural Economics, vol. 78, no. 2, pp. 428-38.

Sokol, DK 2013, “"First Do No Harm” Revisited', British Medical Journal, vol. 347, no. 7921, pp. 23-4.

Solinger, DJ 1999, Contesting Citizenship in Urban China: Peasant Migrants, the State, and the Logic of the Market, University of California Press, Berkeley, CA, USA.

Solove, DJ 2007, The Future of Reputation: Gossip, Rumor, and Privacy on the Internet,. Yale University Press, New Haven, CT, USA.

Song, J 2012, 'Futures Market: Contractual Arrangement to Restrain Moral Hazard in Teams', Economic Theory, vol. 51, no. 1, pp. 163-89.

Sosis, R 2005, 'Does Religion Promote Trust?: The Role of Signaling, Reputation, and Punishment', Interdisciplinary Journal of Research on Religion, vol. 1, pp. 1-30.

Speidel, MA 1992, 'Roman Army Pay Scales', The Journal of Roman Studies, vol. 82, pp. 87106.

Speidel, MP 1976, 'Citizen Cohorts in the Roman Imperial Army. New Data on the Cohorts Apula, Campana, and III Campestris', Transactions of the American Philological Association (1974-2014), vol. 106, pp. 339-48.

Speiler EA 1994, 'Perpetuating Risk? Workers' Compensation and the Persistence of Occupational Injuries', Houston Law Review, vol. 31, no. 1, pp. 119-264. 
Spence, M 1973, 'Job Market Signaling', The Quarterly Journal of Economics, vol. 87, no. 3, pp. 355-74.

---- 1974, Market Signaling, Harvard University Press, Cambridge, USA.

---- 1978, 'Job Market Signaling', in P Diamond \& M Rothschild (eds), Uncertainty in Economics, Elsevier, Amsterdam, Holland, pp. 355-374.

---- 2002, 'Signaling in Retrospect and the Informational Structure of Markets', The American Economic Review, vol. 92, no. 3, pp. 434-59.

Spence, M \& Zeckhauser, R 1971, 'Insurance, Information, and Individual Action', The American Economic Review, vol. 61, no. 2, pp. 380-7.

Spenkuch, JL 2012, 'Moral Hazard and Selection Among the Poor: Evidence From a Randomised Experiment', Journal of Health Economics, vol. 31, no. 1, pp. 72-85.

Spigelman, JJ 2004, Becket \& Henry: The Becket Lectures, St Thomas More Society, Sydney, Australia.

Stanley, J 2015, 'China's Nightmarish Citizen Scores Are a Warning For Americans', Free Future, 5 October 2015.

Stantcheva, S 2014, 'Optimal Income Taxation with Adverse Selection in the Labour Market', The Review of Economic Studies, vol. 81, no. 3, pp. 1296-329.

Steinfeld, RJ 2001, Coercion, Contract, and Free Labor in the Nineteenth Century, Cambridge University Press, Cambridge, UK.

Stern, RE and O'Brien, KJ 2012, 'Politics at the Boundary: Mixed Signals and the Chinese State', Modern China, vol. 38, no. 2, pp. 174-98.

Stigler, GJ 1961, 'The Economics of Information', The Journal of Political Economy, vol. 69, no. 3, pp. 213-25.

Stigler, GJ and Becker, GS 1977, 'De Gustibus non est Disputandum', The American Economic Review, vol. 67, no. 2, pp. 76-90.

Stiglitz, JE 1975, 'The Theory of "Screening," Education, and the Distribution of Income', The American Economic Review, vol. 65, no. 3, pp. 283-300.

---- 1987, 'The Causes and Consequences of The Dependence of Quality on Price', Journal of Economic Literature, vol. 25, no. 1, pp. 1-48.

---- 2000, 'The Contributions of the Economics of Information to Twentieth Century Economics', The Quarterly Journal of Economics, vol. 115, no. 4, pp. 1441-78. 
---- 2002, 'Transparency in Government', in R Islam (ed), The Right to Tell: The Role of Mass Media in Economic Development, World Bank, Washington DC, USA, pp. 27-44.

Stiglitz, JE and Weiss, A 1981, 'Credit Rationing in Markets with Imperfect Information', The American Economic Review, vol. 71, no. 3, pp. 393-410.

---- Weiss. 1990, 'Sorting Out the Differences between Signaling and Screening Models', NBER Technical Working Paper, no. 93, pp. 1-41.

Stone, DA 1999, 'Beyond Moral Hazard: Insurance as Moral Opportunity', Connecticut Insurance Law Journal, vol. 6, no. 1, pp. 11-46.

Strausz, R 2017, 'A Theory of Crowdfunding: A Mechanism Design Approach with Demand Uncertainty and Moral Hazard', The American Economic Review, vol. 107, no. 6, pp. 1430-76.

Stringham, EP 2002, 'The Emergence of the London Stock Exchange as a Self-Policing Club', Journal of Private Enterprise, vol. 17, no. 2, pp. 1-19.

---- 2015, Private Governance: Creating Order in Economic and Social Life, Oxford University Press, Oxford, UK.

Strischek, D 2000, 'The Quotable Five C's', Journal of Lending and Credit Risk Management, vol. 82, no. 7, pp. 47-9.

Stryker, R and Stryker, S 2017, 'Does Mead's Framework Remain Sound?', in JE Stets \& RT Serpe (eds), New Directions in Identity Theory and Research, Oxford University Press, Oxford, UK, pp. 31-58.

Stryker, S and Burke, PJ 2000' 'The Past, Present, and Future of an Identity Theory', Social Psychology Quarterly, vol. 63, no. 4, pp. 284-297.

Sue, CA and Telles, EE 2007, 'Assimilation and Gender in Naming', American Journal of Sociology, vol. 112, no. 5, pp. 1383-415.

Suh, EM 2002, 'Culture, Identity Consistency, and Subjective Well-Being', Journal of Personality and Social Psychology, vol. 83, no. 6, pp. 1378-91.

Sultan, A 2010, 'Lemons and Certified Pre-Owned Cars in the Used Car Market', Applied Economics Letters, vol. 17, no. 1, pp. 45-50.

Svolik, MW 2012, The Politics of Authoritarian Rule, Cambridge University Press, Cambridge, UK.

Swan, M 2015. Blockchain: Blueprint for a New Economy, O'Reilly Media, Newton, MT, USA.

Swedberg, R 2001, 'Sociology and Game Theory: Contemporary and Historical Perspectives', Theory and Society, vol. 30, no. 3, pp. 301-35. 
Syme, R 2009, 'Imperator Caesar: A Study in Nomenclature', in J Edmondson (ed), Augustus,. Edinburgh University Press, Edinburgh, UK, pp. 40-59.

---- [1939] 2002, The Roman Revolution, Oxford University Press, Oxford, UK.

Szarota, T 2004, 'The Reaction of Occupied Europe to the Stigmatization of the Jews with the Star of David', Acta Poloniae Historica, vol. 90, pp. 97-111.

Szreter, S 2007, 'The Right of Registration: Development, Identity Registration, and Social Security-A Historical Perspective', World Development, vol. 35, no. 1, pp. 67-86.

---- 2013, 'The Parish Registers in Early Modern English History: Registration from Above and Below', in J Brown, I About \& G Lonergan (eds), Identification and Registration Practices in Transnational Perspective, Palgrave Macmillan, London, UK, pp. 113-31.

Tadmor, N 2017, 'The Settlement of the Poor and the Rise of the Form in England, c. 16621780 ', Past \& Present, vol. 236, no. 1, pp. 43-97.

Tajfel, H 1978a, 'The Achievement of Group Differentiation', in H Tajfel (ed), Differentiation Between Social Groups: Studies in the Social Psychology of Intergroup Relations, Academic Press, London, UK, pp. 77-98.

---- 1978b, 'Interindividual Behaviour and Intergroup Behaviour', in H Tajfel (ed), Differentiation Between Social Groups: Studies in the Social Psychology of Intergroup Relations, Academic Press, London, UK, pp. 27-60.

Tajfel, H, Billig, MG, Bundy, RP and Flament, C 1971, 'Social Categorization and Intergroup Behaviour', European Journal of Social Psychology, vol. 1, no. 2, pp. 149-78.

Tajfel, $\mathrm{H}$ and Turner, JC 1986, 'The Social Identity Theory of Intergroup Behavior', in S Worchel and W Austin (eds), The Social Psychology of Intergroup Behavior, NelsonHall, Chicago, USA, pp. 7-24.

Tan, PKW 2006, 'Towards a Standardization Of Personal Names: The Case of the Ethnic Chinese in Singapore', Names, vol. 54, no. 4, pp. 291-319.

Taylor, C 2000, 'The Old Boy Network and the Young-Gun Effect', International Economic Review, vol. 41, no. 4, pp. 871-91.

Tellis, G and Wernerfelt, B 1987, 'Competitive Price and Quality under Asymmetric Information', Marketing Science, vol. 6, no. 3, pp. 240-53.

Telser, LG 1980, 'A Theory of Self-Enforcing Agreements', Journal of Business, vol. 53, no. 2, pp. 27-44.

Telser, LG and Higinbotham, HN 1977, 'Organized Futures Markets: Costs and Benefits', Journal of Political Economy, vol. 85, no. 5, pp. 969-1000. 
Temin, P 2013, The Roman Market Economy, Princeton University Press, Princeton, USA.

Terry, DJ and Callan, VJ 1998, 'In-Group Bias in Response to an Organizational Merger', Group Gynamics: Theory, Research, and Practice, vol. 2, no. 2, pp. 67-81.

Teschl, M and Derobert, L 2008, 'Does Identity Matter? On the Relevance of Identity and Interaction for Capabilities', in F Comim, M Qizilbash \& S Alkire (eds), The Capability Approach: Concepts, Measures and Applications, Cambridge University Press, Cambridge, UK, pp. 125-56.

The Economist 2019. 'Keeping Tabs', March 302019.

Thomas, HM 1988, 'Vassals, Heiresses, Crusaders and Thugs: The Knightly Class of Angevin Yorkshire, 1154-1216', Doctoral Thesis, Yale University, New Haven, USA.

Thomson Reuters 2016, 'Thomson Reuters 2016 Know Your Customer Surveys Reveal Escalating Costs and Complexity', 9 May 2016.

---- 2017, 'Thomson Reuters 2017 Global KYC Surveys Attest to Even Greater Compliance Pain Points', 26 October 2017.

Tirole, J 1996, 'A Theory of Collective Reputations (With Applications to the Persistence of Corruption and to Firm Quality)', The Review of Economic Studies, vol. 63, no. 1, pp. $1-22$.

Tollison, RD 2004, 'Rent Seeking', in CK Rowley \& F Schneider (eds), The Encyclopedia of Public Choice, Volume II, Springer, Berlin, Germany, pp. 498-499.

Tolman, EC 1948, 'Cognitive Maps in Rats and Men', Psychological Review, vol. 55, no. 4, pp. 189-208.

Tombs, R 2015, The English and Their History, Knopf Doubleday Publishing Group, New York, NY, USA.

Torpey, J 1997, 'Revolutions and Freedom of Movement: An Analysis of Passport Controls in the French, Russian, and Chinese Revolutions', Theory and Society, vol. 26, no. 6, pp. 837-68.

---- 1998, 'Coming and Going: On the State Monopolization of the Legitimate "Means of Movement"', Sociological Theory, vol. 16, no. 3, pp. 239-59.

---- 2000, The Invention of the Passport: Surveillance, Citizenship and the State, Cambridge University Press, Cambridge, UK.

Trakman, LE 1983, The Law Merchant: The Evolution of Commercial Law, FB Rothman, Littleton, NJ, USA. 
Trestian, R, Ormond, Olga and Muntean, GM 2011, 'Reputation-Based Network Selection Mechanism Using Game Theory', Physical Communication, vol. 4, no. 3, pp. 156-71.

Trivers, RL 1971, 'The Evolution of Reciprocal Altruism', The Quarterly Review of Biology, vol. 46 , no. 1 , pp. 35-57.

Tröster, M 2009, 'Roman Hegemony and Non-State Violence: A Fresh Look at Pompey's Campaign against the Pirates', Greece \& Rome, vol. 56, no. 1, pp. 14-33.

Tsui, HC 2012, 'Advertising, Quality, and Willingness-to-Pay: Experimental Examination of Signaling Theory', Journal of Economic Psychology, vol. 33, no. 6, pp. 1193-203.

Tullock, G 1985, 'Adam Smith and the Prisoners' Dilemma', The Quarterly Journal of Economics, vol. 100, pp. 1073-81.

Turack, D 1970, 'Early English Restrictions to Travel', in CH Alexandrowicz (ed), Grotian Society Papers 1968: Studies in the History of the Law of Nations, Springer, Berlin, Germany, pp. 136-165.

Türköz, M 2007, 'Surname Narratives and the State-Society Boundary: Memories of Turkey's Family Name Law of 1934', Middle Eastern Studies, vol.43, no. 6, pp. 893908.

Turner, JC 1975, 'Social Comparison and Social Identity: Some Prospects for Intergroup Behaviour', European Journal of Social Psychology, vol. 5, no. 1, pp. 1-34.

Turner, JC, Brown, RJ and Tajfel, H 1979, 'Social Comparison and Group Interest in Ingroup Favouritism', European Journal of Social Psychology, vol. 9, no. 2, pp. 187-204.

Twenge, JM 1997, “"Mrs. His Name”: Women's Preferences for Married Names', Psychology of Women Quarterly, vol. 21, no. 3, pp. 417-29.

Tyler, J, Murnane, R and Willett, J 2000, 'Estimating the Labor Market Signaling Value of the GED', The Quarterly Journal of Economics, vol. 115, no. 2, pp. 431-68.

Tyler, T and Blader, S 2000, Cooperation in Groups: Procedural Justice, Social Identity, and Behavioral Engagement, Psychology Press, New York, NY, USA.

Van der Lans, IA, Van Ittersum, K, De Cicco, A and Loseby, M 2001, 'The Role of the Region of Origin and EU Certificates of Origin in Consumer Evaluation of Food Products', European Review of Agricultural Economics, vol. 28, no. 4, pp. 451-77.

Van Knippenberg, D 2000, 'Work Motivation and Performance: A Social Identity Perspective', Applied Psychology, vol. 49, no. 3, pp. 357-71.

Van Knippenberg, D, Van Knippenberg, B, Monden, L and de Lima, F 2002, 'Organizational Identification After a Merger: A Social Identity Perspective', British Journal of Social Psychology, vol. 41, no. 2, pp. 233-52. 
van Tilburg, C 2007, Traffic and Congestion in the Roman Empire, Taylor \& Francis, Milton Park, UK

Varese, F 2001, The Russian Mafia: Private Protection in a New Market Economy, Oxford University Press, Oxford, UK.

Veblen, T 1899, The Theory of the Leisure Class, New American Library, New York, NY, USA.

Verlegh, PWJ 2007, 'Home Country Bias in Product Evaluation: The Complementary Roles of Economic and Socio-Psychological Motives', Journal of International Business Studies, vol. 38, no. 3, pp. 361-73.

Vincent, N 2011, A Brief History of Britain 1066 - 1485, Little, Brown Book Group, Boston, MT, USA.

---- 2012, Magna Carta: A Very Short Introduction, Oxford University Press, Oxford, UK.

Vorick, D 2016, 'Ensuring Bitcoin Fungibility in 2017 (And Beyond)', coindesk, 28 December 2016 <https://www.coindesk.com/ensuring-bitcoin-fungibility-in-2017-and-beyond>

Waddington, K 2016, 'Rethinking Gossip and Scandal in Healthcare Organizations', Journal of Health Organization and Management, vol. 30, no. 6, pp. 810-17.

Waldman, M 1984, 'Job Assignments, Signalling, and Efficiency', The RAND Journal of Economics, vol. 15, no. 2, pp. 255-67.

Wallis, JJ and North, DC 1986, 'Measuring the Transaction Sector in the American Economy, 1870-1970', in SL Engerman \& RE Gallman(eds), Long-Term Factors in American Economic Growth, University of Chicago Press, Chicago, USA, pp. 95-162.

Walras, L 2013, Elements of Pure Economics, Routledge, Abingdon, UK.

Wang, FL 2004, 'Reformed Migration Control and New Targeted People: China's Hukou System in the 2000s', The China Quarterly, vol. 177, pp. 115-32.

---- 2005, Organizing Through Division and Exclusion: China's Hukou System, Stanford University Press, Palo Alto, CA, USA.

Wang, J 2017, 'Debt Covenant Design and Creditor Control Rights: Evidence from the Tightest Covenant', Journal of Corporate Finance, vol. 44, pp. 331-52.

Wang, Y and Minzner, C 2015, 'The Rise of the Chinese Security State', The China Quarterly, vol. 222, pp. 339-59.

Wansbrough, J 1971, 'The Safe-Conduct in Muslim Chancery Practice', Bulletin of the School of Oriental and African Studies, vol. 34, no. 1, pp. 20-35. 
Wark, C and Galliher, JF 2007, 'Emory Bogardus and the Origins of the Social Distance Scale', The American Sociologist, vol. 38, no. 4, pp. 383-95.

Watson M 2011, 'Competing Models of Socially Constructed Economic Man: Differentiating Defoe's Crusoe from the Robinson of Neoclassical Economic', New Political Economy, vol. 16, no. 5, pp. 609-626.

Webster, G 1998, The Roman Imperial Army of the First and Second Centuries A.D, University of Oklahoma Press, Norman, USA.

Weesie, J and Raub, W 1996, 'Private Ordering: A Comparative Institutional Analysis of Hostage Games', Journal of Mathematical Sociology, vol. 21, no. 3, pp. 201-40.

Wegge, J, Van Dick, R, Fisher, GK, Wecking, C and Moltzen, K 2006, 'Work Motivation, Organisational Identification, and Well-Being in Call Centre Work', Work \& Stress, vol. 20 , no. 1 , pp. $60-83$.

Weiss, A 1995, 'Human Capital vs. Signalling Explanations of Wages', Journal of Economic Perspectives, vol. 9, no. 4, pp. 133-54.

Wernerfelt, B 1988, 'Umbrella Branding as a Signal of New Product Quality: An Example of Signalling by Posting a Bond', The RAND Journal of Economics, vol. 19, no. 3, pp. 45866.

Wetzels, M, De Ruyter, K and Van Birgelen, M 1998, 'Marketing Service Relationships: The Role of Commitment', Journal of Business \& Industrial Marketing, vol. 13, no. 4/5, pp. 406-423.

Whyte, WF 2012, Street Corner Society: The Social Structure of an Italian Slum, University of Chicago Press, Chicago, IL, USA.

Wildhagen, T 2011, 'Testing the 'Acting White' Hypothesis: A Popular Explanation Runs out of Empirical Steam', The Journal of Negro Education, vol. 80, no. 4, pp. 445-63.

Williams, DW 1974, 'British Passports and the Right to Travel', International \& Comparative Law Quarterly, vol. 23, no. 3, pp. 642-56.

Williamson, OE 1971 'The Vertical Integration of Production: Market Failure Considerations', The American Economic Review, vol. 61, no. 2, pp. 112-23.

---- 1975, Markets and Hierarchies, Analysis and Antitrust Implications: A Study in the Economics of Internal Organization, Free Press, New York, NY, USA.

---- 1979, 'Transaction-Cost Economics: The Governance of Contractual Relations', The Journal of Law and Economics, vol. 22, no. 2, pp. 233-61.

---- 1983, 'Credible Commitments: Using Hostages to Support Exchange', The American Economic Review, vol. 73, no. 4, pp. 519-40. 
---- 1984, 'Credible Commitments: Further Remarks', The American Economic Review, vol. 74, no. 3, pp. 488-90.

---- 1985, The Economic Institutions of Capitalism, Free Press, New York, NY, USA.

---- 1991, 'Comparative Economic Organization: The Analysis of Discrete Structural Alternatives', Administrative Science Quarterly, vol. 36, no. 2, pp. 269-296.

---- 1993, 'Calculativeness, Trust, and Economic Organization', The Journal of Law and Economics, vol. 36, no. 1, part 2, pp. 453-86.

---- 1994, 'The Institutions and Governance of Economic Development and Reform', The World Bank Economic Review, vol. 8, no. 1, pp. 171-97.

---- 1996, The Mechanisms of Governance, Oxford University Press, Oxford, UK.

---- 2002, 'The Theory of the Firm as Governance Structure: From Choice to Contract', Journal of Economic Perspectives, vol. 16, no. 3, pp. 171-95.

---- 2007, 'Transaction Cost Economics: An Introduction', Available at SSRN 1691869.

---- 2010, 'Transaction Cost Economics: The Natural Progression', Journal of Retailing, vol. 86, no. 3, pp. 215-26.

Williamson, OE and Ghani, T 2012, 'Transaction Cost Economics and its Uses in Marketing', Journal of the Academy of Marketing Science, vol. 40, no. 1, pp. 74-85.

Wilson, A 2005, 'German Dominatrices' Choices of Working Names as Reflections of SelfConstructed Social Identity', Sexuality and Culture, vol. 9, no. 2, pp. 31-41.

Wilson, C 1980, 'The Nature of Equilibrium in Markets with Adverse Selection', The Bell Journal of Economics, vol. 11, no. 1, pp. 108-30.

Wilson, S 2003, The Means of Naming: A Social History, Routledge, Abingdon, UK.

Wimmer, BS and Chezum, B 2003, 'An Empirical Examination of Quality Certification in a "Lemons Market"', Economic Inquiry, vol. 41, no. 2, pp. 279-91.

---- 2006, 'Adverse Selection, Seller Effort, and Selection Bias', Southern Economic Journal, vol. 73 , no. 1 , pp. 201-18.

Wimmer, BS and Garen, JE 1997, 'Moral Hazard, Asset Specificity, Implicit Bonding, and Compensation: The Case of Franchising', Economic Inquiry, vol. 35, no. 3, pp. 544-54.

Winfree, JA and McCluskey, JJ 2005, 'Collective Reputation and Quality', American Journal of Agricultural Economics, vol. 87, no. 1, pp. 206-13. 
Winter, RA 2000, 'Optimal Insurance Under Moral Hazard', in G Dionne (ed), Handbook of Insurance, Springer, Dordrecht, Germany, pp. 155-83.

Wintrobe, R 1990, 'The Tinpot and the Totalitarian: An Economic Theory of Dictatorship', American Political Science Review, vol. 84, no. 3, pp. 849-72.

---- 1998, The Political Economy of Dictatorship, Cambridge University Press, New York, USA.

---- 2009, 'Dictatorship: Analytical Approaches', in C Boix \& S Stokes (eds), The Oxford Handbook of Comparative Politics edited by. Oxford University Press, Oxford, UK.

Wolfson, MA 1985, 'Tax, Incentive, and Risk-Sharing Issues in the Allocation of Property Rights: The Generalized Lease-or-Buy Problem', The Journal of Business, vol. 58, no. 2, pp. 159-71.

Woloch, I 1986 'Napoleonic Conscription: State Power and Civil Society', Past \& Present, vol. 111 , pp. 101-129.

---- 1995, The New Regime: Transformations of the French Civic Order, 1789-1820s, WW Norton, New York, NY, USA.

Woolf, G 1998, Becoming Roman: The Origins of Provincial Civilization in Gaul, Cambridge University Press, Cambridge, UK.

Wu, S, Goodwin, BKK and Coble, K 2020, 'Moral Hazard and Subsidized Crop Insurance', Agricultural Economics, vol. 51, no. 1, pp. 131-42.

Yang, DT 2008, 'China's Agricultural Crisis and Famine of 1959-1961: A Survey and Comparison to Soviet Famines', Comparative Economic Studies, vol. 50, no. 1, pp. 129.

Yinger, J 1978, 'The Black-White Price Differential in Housing: Some Further Evidence', Land Economics, vol. 54, no. 2, pp. 187-206.

---- 1998, 'Evidence on Discrimination in Consumer Markets', Journal of Economic Perspectives, vol. 12, no. 2, pp. 23-40.

Zeckhauser, R 1970, 'Medical Insurance: A Case Study of the Tradeoff Between Risk

Spreading and the Appropriate Incentives', Journal of Economic Theory, vol. 2, no. 1, pp. 10-26.

Zeugner-Roth, KP, Žabkar, V and Diamantopoulos, A 2015, 'Consumer Ethnocentrism, National Identity, and Consumer Cosmopolitanism as Drivers of Consumer Behavior: A Social Identity Theory Perspective', Journal of International Marketing, vol. 23, no. 2, pp. 25-54. 
Zhang, $Y$ and Elsner, W 2017, 'A Social-Leverage Mechanism on the Silk Road: The Private Emergence of Institutions in Central Asia, from the 7th to the 9th Century', Journal of Institutional Economics, vol. 13, no. 2, pp. 379-400.

Zhou, R and Hwang, K 2007, 'Gossip-Based Reputation Aggregation for Unstructured Peerto-Peer Networks', IEEE International Parallel and Distributed Processing Symposium, Rome, pp. 1-10.

Zhu B, and Millward, C 1987, 'Personal Names in Chinese', Names, vol. 35, no. 1, pp. 8-21.

Zolberg, AR 1978, 'International Migration Policies in a Changing World System', in WH McNeill \& RS Adams (eds), Human Migration: Patterns and Policies, American Academy of Arts and Sciences, Boston, USA, pp. 241-286.

Zussman, A 2013, 'Ethnic Discrimination: Lessons from the Israeli Online Market for Used Cars', The Economic Journal, vol. 123, no. 572, pp. F433-68.

Zweifel, P 2020, 'Innovation in Long-Term Care Insurance: Joint Contracts for Mitigating Relational Moral Hazard', Insurance: Mathematics and Economics, vol. 93, pp. 116124. 